KCP-613-5804

Distribution Category UC-706

Approved for public release; distribution is unlimited.

\title{
UV CURABLE MATERIALS DEVELOPMENT
}

B. G. Parker

Published December 1996

Topical Report

B. G. Parker, Project Leader

Project Team:

D. N. Brown

M. H. Wilson

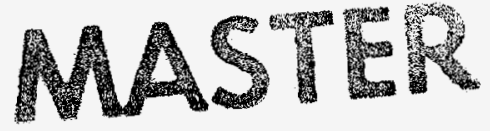


DISCLAMMER

Portions of this document may be illegible in electronic image products. Images are produced from the best available original document. 


\section{DISCLAIMER}

This report was prepared as an account of work sponsored by an agency of the United States Government. Neither the United States Government nor any agency thereof, nor any of their employees, make any warranty, express or implied, or assumes any legal liability or responsibility for the accuracy, completeness, or usefulness of any information, apparatus, product, or process disclosed, or represents that its use would not infringe privately owned rights. Reference herein to any specific commercial product, process, or service by trade name, trademark, manufacturer, or otherwise does not necessarily constitute or imply its endorsement, recommendation, or favoring by the United States Government or any agency thereof. The views and opinions of authors expressed herein do not necessarily state or reflect those of the United States Government or any agency thereof. 


\section{CONTENTS}

\section{Section}

ABSTRACT

SUMMARY

DISCUSSION

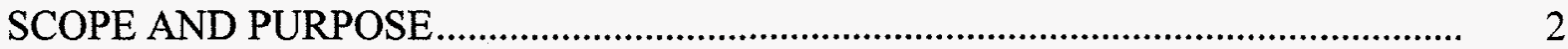

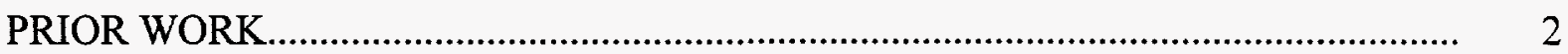

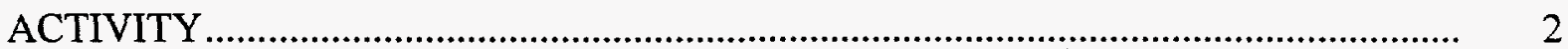

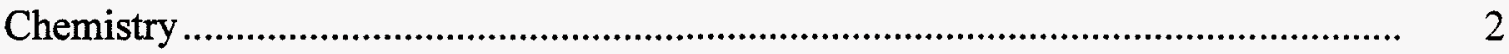

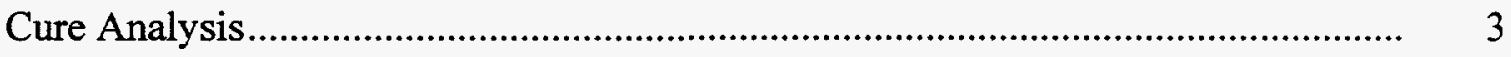

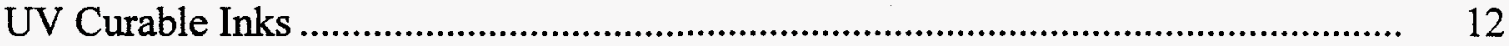

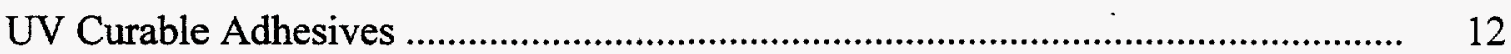

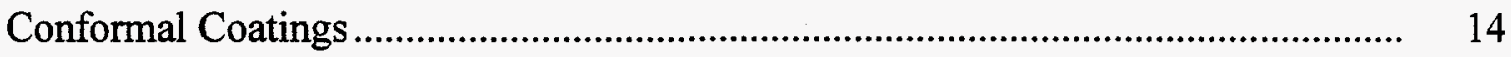

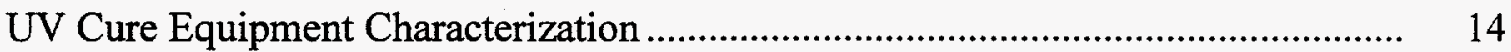

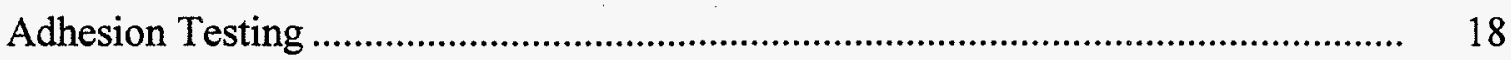

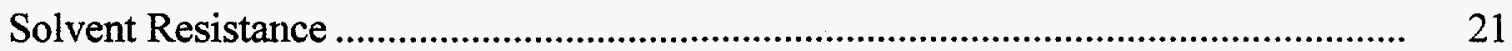

ACCOMPLISHMENTS ................................................................................... 23

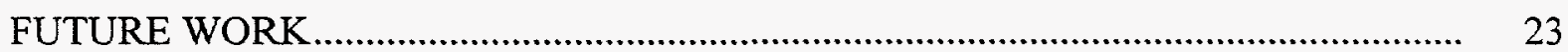

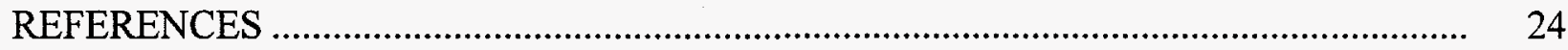

\section{APPENDICES}

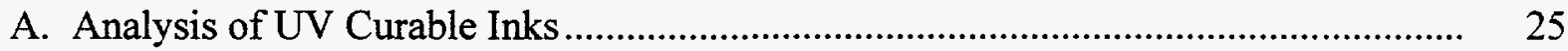

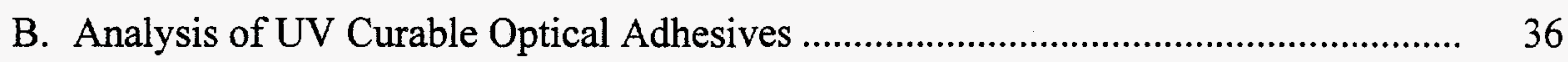


C. Analysis of HA84 UV Curäble Conformal Coating ..................................................... 46

D. Analysis of HA84F UV Curable Conformal Coating ................................................ 54

E. Characterization of UV Curing Equipment ……................................................... 62

F. Solvent Swell Testing ........................................................................................ 


\section{ILLUSTRATIONS}

Figure

Page

1 TA Instruments Differential Photo Calorimeter (DPC)

2 Schematic View of a Differential Photo Calorimeter

Differential Photo Calorimeter Accessories

Differential Scanning Calorimeter Versus Differential Photo Calorimeter.

Calibration Photometer.

Calibration of the DPC

Tecklite Handgun UV Source.

Tecklite ECLM 400 UV Source

EFOUS Ultracure 100 UV Light Source

Dymax UV Light Source With Shutter.

11 Fusion Systems UV Light Source.

16 Solvent Swell Testing Using a Thermal Mechanical Analyzer.

A-2 Cure Rate Versus Exposure Time for MS 5096986 White Ink

A-3 Kinetics Report for MS 5096986 White Ink... 
A-5 DSC Curve for MS 5096986 White Ink ............................................................. 28

A-6 DPC Curve for Markem 9040 White Ink ............................................................. 28

A-7 Cure Rate Versus Exposure Time for Markem 9040 White Ink............................ 29

A-8 Kinetics Report for Markem 9040 White Ink ....................................................... 29

A-9 Closeness of Fit Curve for Markem 9040 White Ink ............................................ 30

A-10 DSC Curve for Markem 9040 White Ink ........................................................... 30

A-11 DPC Curve for Markem 9060 White Ink ............................................................. 31

A-12 Cure Rate Versus Exposure Time for Markem 9060 White Ink........................... 31

A-13 Kinetics Report for Markem 9060 White Ink .................................................... 32

A-14 Closeness of Fit Curve for Markem 9060 White Ink............................................

A-15 DSC Curve for Markem 9060 White Ink ................................................................. 33

A-16 DPC Curve for Markem 9090 White Ink $\quad 33$

A-17 Cure Rate Versus Exposure Time for Markem 9090 White Ink............................. 34

A-18 Kinetics Report for Markem 9090 White Ink .................................................. 34

A-19 Closeness of Fit Curve for Markem 9090 White Ink ............................................. 35

A-20 DSC Curve for Markem 9090 White Ink ...................................................... 35

B-1 DPC Curve for $5 \mu \mathrm{L}$ Sample of Norland 60 Optical Adhesive ………................. 37

B-2 DPC Curve for $10 \mu \mathrm{L}$ Sample of Norland 60 Optical Adhesive ......................... 37

B-3 DPC Curve for $20 \mu \mathrm{L}$ Sample of Norland 60 Optical Adhesive ........................... 38

B-4 Closeness of Fit Curve for $5 \mu \mathrm{L}$ Sample of Norland 60 Optical Adhesive ........... 38

B-5 Closeness of Fit Curve for $10 \mu \mathrm{L}$ Sample of Norland 60 Optical Adhesive ......... 39

B-6 Closeness of Fit Curve for $20 \mu \mathrm{L}$ Sample of Norland 60 Optical Adhesive ......... 39

B-7 Kinetics Report for $5 \mu \mathrm{L}$ Sample of Norland 60 Optical Adhesive....................... 40 
B-8 Cure Rate Versus Exposure Time for $5 \mu \mathrm{L}$ Sample of Norland 60 Optical Adhesive.

B-9 DSC Curve for UV Cured $5 \mu \mathrm{L}$ Sample of Norland 60 Optical Adhesive............ 41

B-10 DPC Curve for $5 \mu \mathrm{L}$ Sample of Norland 61 Optical Adhesive .............................. 41

B-11 DPC Curve for $10 \mu \mathrm{L}$ Sample of Norland 61 Optical Adhesive ............................ 42

B-12 DPC Curve for $20 \mu \mathrm{L}$ Sample of Norland 61 Optical Adhesive ............................ 42

B-13 Closeness of Fit Curve for $5 \mu \mathrm{L}$ Sample of Norland 61 Optical Adhesive ........... 43

B-14 Closeness of Fit Curve for $10 \mu \mathrm{L}$ Sample of Norland 61 Optical Adhesive ......... 43

B-15 Closeness of Fit Curve for $20 \mu \mathrm{L}$ Sample of Norland 61 Optical Adhesive ......... 44

B-16 Kinetics Report for $5 \mu \mathrm{L}$ Sample of Norland 61 Optical Adhesive........................ 44

B-17 Cure Rate Versus Exposure Time for $5 \mu \mathrm{L}$ Sample of Norland 61

Optical Adhesive.

B-18 DSC Curve for UV Cured $5 \mu \mathrm{L}$ Sample of Norland 61 Optical Adhesive............ 45

C-1 DPC Curve for $5 \mu \mathrm{L}$ Sample of HA84 Conformal Coating ................................... 47

C-2 DSC Curve for UV Cured $5 \mu \mathrm{L}$ Sample of HA84 Conformal Coating ................. $\quad 47$

C-3 DPC Curve for $10 \mu \mathrm{L}$ Sample of HA84 Conformal Coating ............................... 48

C-4 DSC Curve for UV Cured $10 \mu \mathrm{L}$ Sample of HA84 Conformal Coating................ 48

C-5 DPC Curve for $20 \mu \mathrm{L}$ Sample of HA84 Conformal Coating ................................ 49

C-6 DSC Curve for UV Cured $20 \mu \mathrm{L}$ Sample of HA84 Conformal Coating ................ 49

C-7 DPC Curve for $40 \mu \mathrm{L}$ Sample of HA84 Conformal Coating ................................ $\quad 50$

C-8 DSC Curve for UV Cured $40 \mu \mathrm{L}$ Sample of HA84 Conformal Coating ............... 50

C-9 Closeness of Fit Curve for $5 \mu \mathrm{L}$ Sample of HA84 Conformal Coating ................ 51

C-10 Closeness of Fit Curve for $10 \mu \mathrm{L}$ Sample of HA84 Conformal Coating .............. 51 
C-11 Closeness of Fit Curve for $20 \mu \mathrm{L}$ Sample of HA84 Conformal Coating ............. 52

C-12 Closeness of Fit Curve for $40 \mu \mathrm{L}$ Sample of HA84 Conformal Coating ............. 52

C-13 Kinetics Report for $10 \mu \mathrm{L}$ Sample of HA84 Conformal Coating ....................... 53

C-14 Cure Rate Versus Exposure Time for $10 \mu \mathrm{L}$ Sample of HA84

Conformal Coating.

D-1 DPC Curve for $5 \mu \mathrm{L}$ Sample of HA84F Conformal Coating ….......................... 55

D-2 DSC Curve for UV Cured $5 \mu \mathrm{L}$ Sample of HA84F Conformal Coating.............. 55

D-3 DPC Curve for $10 \mu \mathrm{L}$ Sample of HA84F Conformal Coating ........................... 56

D-4 DSC Curve for UV Cured $10 \mu \mathrm{L}$ Sample of HA84F Conformal Coating............ 56

D-5 DPC Curve for $20 \mu \mathrm{L}$ Sample of HA84F Conformal Coating ........................ 57

D-6 DSC Curve for UV Cured $20 \mu \mathrm{L}$ Sample of HA84F Conformal Coating............ 57

D-7 DPC Curve for $40 \mu \mathrm{L}$ Sample of HA84F Conformal Coating ........................... 58

D-8 DSC Curve for UV Cured $40 \mu \mathrm{L}$ Sample of HA84F Conformal Coating............ $\quad 58$

D-9 Closeness of Fit Curve for $5 \mu \mathrm{L}$ Sample of HA84F Conformal Coating ............. 59

D-10 Closeness of Fit Curve for $10 \mu \mathrm{L}$ Sample of HA84F Conformal Coating ........... 59

D-11 Closeness of Fit Curve for $20 \mu \mathrm{L}$ Sample of HA84F Conformal Coating ........... $\quad 60$

D-12 Closeness of Fit Curve for $40 \mu \mathrm{L}$ Sample of HA84F Conformal Coating ........... $\quad 60$

D-13 Kinetics Report for $10 \mu \mathrm{L}$ Sample of HA84F Conformal Coating................... 61

D-14 Cure Rate Versus Exposure Time for $10 \mu \mathrm{L}$ Sample of HA84F Conformal Coating.

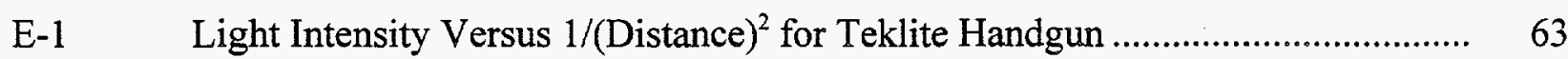

E-2 Spot Diameter Versus Distance From Tecklite Handgun ................................ 63

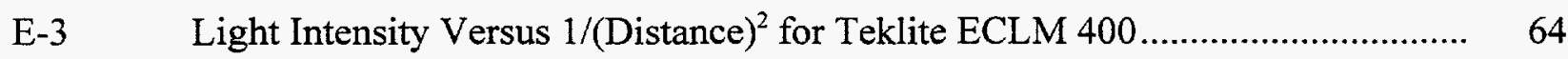

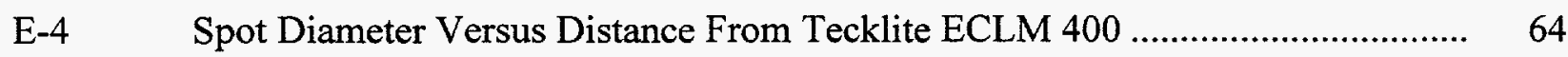


E-5 Light Intensity Versus $1 /$ (Distance) $^{2}$ for EFOUS Ultracure $100 \mathrm{UV}$ Light Source.

E-6 Spot Diameter Versus Distance From EFOUS Ultracure 100 UV Light Source.

E-7 Light Intensity Versus 1/(Distance) $)^{2}$ for Dymax UV Light Source........................ 66

E-8 Temperature Versus Distance From Dymax UV Light Source ……..................... 66

E-9 Light Intensity Versus Time for Dymax UV Light Source at 4 Inches ................. 67

E-10 Light Intensity Versus Time for Dymax UV Light Source at 5 Inches ................. 67

E-11 Light Intensity Versus Time for Dymax UV Light Source at 6 Inches ................. 68

E-12 Light Intensity Versus Time for Dymax UV Light Source at 9 Inches ................ 68

E-13 Light Intensity Versus 1/(Distance) ${ }^{2}$ for Fusion Systems UV Light Source ........ 69

F-1 Solvent Swell Test for Norland 60 in Toluene $(30 \mathrm{sec}$. UV Cure) ...................... 71

F-2 Solvent Swell Test for Norland 60 in Toluene (120 sec. UV Cure) ...................... 71

F-3 Solvent Swell Test for Norland 60 in Water (30 sec. UV Cure) ........................... 72

F-4 Solvent Swell Test for Norland 60 in IPA ( $30 \mathrm{sec}$. UV Cure).............................. 72

F-5 Solvent Swell Test for Norland 60 in Methylene Chloride ( $30 \mathrm{sec}$. UV Cure) .... 73

F-6 Solvent Swell Test for Norland 60 in d-Limonene (30 sec. UV Cure)................. 73

F-7 Solvent Swell Test for Norland 60 in d-Limonene (120 sec. UV Cure)................ 74

F-8 Solvent Swell Test for Norland 60 in Acetone $(120 \mathrm{sec}$. UV Cure) ........................ 74

F-9 Solvent Swell Test for Norland 60 in IPA (120 sec. UV Cure) ............................. 75

F-10 Solvent Swell Test for Norland 60 in Water (120 sec. UV Cure) ......................... 75 


\section{TABLES}

\section{Number}

1

2

3

Norland 60 and 61 Properties

Page

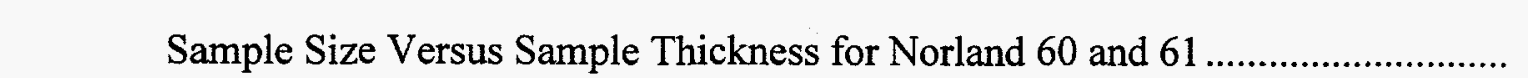

13

Torque Test Data for EC2216 Adhesive..

21 


\begin{abstract}
Adhesives, coatings, and inks were selected for evaluation based on the results of a literature search and possible production applications. $A$ differential photocalorimeter was used to measure the degree of cure and allow the prediction of optimum processing conditions. UV cure equipment was characterized, and the ability to size equipment to specific materials cure needs was established. Adhesion tests procedures were developed for the adhesives, and solvent resistance testing procedures were developed for the coatings and inks.
\end{abstract}

\title{
SUMMARY
}

The purpose of this project is to evaluate ultraviolet (UV) activated adhesives, inks, and coatings with respect to performance requirements of currently used materials.

Most coatings, inks, and some adhesives involve the release of flammable and/or hazardous materials into the air. UV light curable coatings, adhesives, and inks have much shorter processing times and generally do not liberate flammable solvents. Several of these materials are currently in use on or are being considered for use on production assemblies.

Adhesives, coatings, and inks were selected for this evaluation based on the results of a literature search and possible production applications. Two new testing capabilities, differential photocalorimeter (DPC) and torsion testing, were established during this project. A DPC was used to measure the degree of cure and allow the prediction of optimum processing conditions. UV cure equipment was characterized, and the ability to size equipment to specific materials cure needs was established. Adhesion tests procedures were developed for the adhesives, and solvent resistance testing procedures were developed for the coatings and inks. 


\section{DISCUSSION}

\section{SCOPE AND PURPOSE}

The purpose of this project is to evaluate ultraviolet (UV) activated adhesives, inks, and coatings with respect to performance requirements of currently used materials. In addition to evaluating the capabilities of those materials, the equipment needed to cure the various products will be evaluated and recommendations will be made.

The purchase of a differential photo calorimeter (DPC) would be required to support this project. Differential photocalorimetry provides a method for predicting optimum processing conditions for UV curable materials.

Several UV curable materials will be selected and evaluated for adhesion and solvent resistance. The results of these tests will be compared to the DPC test predictions. The use of UV curable materials have a potential for reducing process flowtime and the release of flammable solvent.

\section{PRIOR WORK}

A previous process development project established the benefits of UV curable materials. One UV curable epoxy, HA 84, was evaluated in that project.

\section{ACTIVITY}

Most coatings, inks, and some adhesives involve the release of flammable and/or hazardous materials into the fugitive air. UV light curable coatings, adhesives, and inks have much shorter processing times and generally do not liberate flammable solvents. Several of these materials are currently in use on or are being considered for use on production assemblies.

\section{Chemistry}

There are two basic types of UV curable polymeric systems: anionic and cationic. Both systems can be divided into three stages: initiation, propagation, and termination. In the anionic system, UV light is used to produce free radicals from a photoinitiator. The free radicals initiate a chain process in which monomers and oligomers are polymerized into a cross-linked film. The termination reaction involves the reaction of the propagating free radical with other free radicals or free radical scavengers, such as oxygen. 
In the cationic system UV light causes a photoinitator, such as a triarylsulfonium salt, to form a cation. The cation attacks monomers, such as cyclic ethers, epoxides, cyclicacetals, and some vinyl monomers, causing polymerization. The termination reaction step is usually caused by a reaction with an impurity.

All UV curable systems are composed of four basic components: photoinitiator, monomer, oligomer, and additive. The photoinitiator is the key component linking the UV light source to the polymerization reaction. Anionic photoinitiators generate reactive free radicals which are sensitive to oxygen. Oxygen free atmospheres can aid in the depth and degree of cure of this type of polymer. Oxygen rich atmospheres such as normal air can increase their shelf life. In the presence of air, cure of anionic UV systems proceeds from the bottom up to the surface where oxygen levels are higher. The maximum depth of cure can be measured by coating a steel block which has a tapered groove that is marked at various depth intervals. After curing, the coating is rubbed or washed with a solvent. The cured material only remains up to the depth of total cure. Cationic photoinitiators generate acids which act as a catalyst and are not sensitive to oxygen. In addition, the cationic polymer can undergo a post-thermal cure. The cationic UV systems typically have a much greater depth of cure.

Monomers are added to the polymer system for various reasons. The viscosity of the system can be lowered or adjusted by adding monomer. Addition of more low molecular weight monomer, however, can increase the volatility and odor. Since more chain reactions must take place in monomers to reach the same molecular weight of oligomers, monomer addition will slow the cure speed and can increase shelf life. Volume shrinkage is greatest with monomers. Reducing the amount of monomer can therefore reduce volume shrinkage and surface stresses. Finally, monomers are less costly than oligomers.

Oligomers will typically exhibit the opposite properties of what was discussed for the monomers. In addition, the backbone of the oligomer may be made up of a variety of polymer types and can control the final properties of the cured polymer. This backbone can be epoxy, urethane, polyester, or polyether, to name a few.

Additives can greatly control the final properties of the UV curable systems. They can vary to up to $50 \%$ of the system. Additives include pigments, surfactants, dispersants, and stabilizers. Care must be used in the selection of both additives in combination with photoinitiators. Pigments, used in ink or paint applications, block the UV light from reaching the photoinitator. Photoinitiators that absorb light which is closer to the visible spectrum permit further cure depth in pigmented systems. ${ }^{1}$

\section{Cure Analysis}

The selection of the proper cure frequency, intensity, and duration are essential in UV radiation curing. Under-curing will result in a product that does not have the desired physical properties. Excessive radiation may result in yellowing and embrittlement of the 
coating. Many different methods for evaluating the degree of cure of UV curable materials have been developed. Some of the methods are very simple and require a minimal amount of testing equipment.

\section{Cure Test Methods}

Finger-tip Test. This test is one of the easiest and most used tests. The surface of the coating is touched and then rubbed with the finger tip to check for any tackiness and then to determine how readily the surface can be marred. In a variation of this test, the thumb is pressed hard on the surface then twisted; this is referred to as the "thumb-twist" test.

Cotton Test. This is a surface test in which a cotton ball is used to check for tackiness. The cotton ball is placed on a coated surface. If the cotton ball falls from the surface when it is inverted, the surface is inspected closely to determine how many cotton fibers adhered to the surface.

Talcum Powder Test. Talcum powder is sprinkled onto the surface of the coating. The coated surface is inverted and shaken to remove any powder that has not adhered. The surface is then inspected for adhesion of the talc.

Hardness Tests. There are a wide variety of hardness tests have been used to investigate the curing of radiation-polymerizable systems. These tests measure the resistance of a material to indentation, scratching, abrasion, wear, cutting, or drilling.

Pencil hardness is a relatively simple and inexpensive test that only requires a collection of pencils with different hardness. The pencils are sharpened, then the lead is sanded to form a chisel point. The pencil is then used to scratch the coated surface. The test continues, increasing the hardness of the pencil, until the surface is scratched. The coating is then assigned a hardness value such as $\mathrm{H}, 2 \mathrm{H}, 3 \mathrm{H}$, etc., signifying the hardest grade which would not scratch the surface.

A variety of other hardness or abrasion tests such as microhardness, pendulum hardness, Sward hardness, Sutherland rub test, and Taber abrasion test may be used.

\section{The UV Cure Tester}

The UV Cure Tester measures and records in real time the "test force" required to move a stylus through or across a film of coating material while it is being UV irradiated. The stylus is a stainless steel sphere (1-3 mm diameter) mounted in one end of a rod-shaped holder. The stylus holder is mounted on a pivot, so that the horizontal test force creates a turning moment which is opposed by the action of a spring. The deflection of the stylus holder is measured by a Hall-effect sensor and magnetic arrangement. The change in the test force as the sample undergoes curing is recorded continuously by the integral chart recorder. This instrument is no longer commercially available. 


\section{Other Cure Test Methods}

Some additional test methods include Evaporative Rate Analysis (ERA), Resistivity, Dilatometry, and Permanganate Stain Test.

To follow the cure kinetics with more precision, an infrared or thermal analytical method must be used. The $\mathrm{C}=\mathrm{C}$ double bonds of the acrylate groups of an acrylate resin disappear during radiation curing, forming a cross-linked polymer. The percentage conversion of an acrylate resin may be expressed as a percentage of the total number of such bonds present initially in the original uncured material.

Infrared spectroscopy offers the most direct method of measuring the concentration of $\mathrm{C}=\mathrm{C}$ double bonds. The percentage conversion may be expressed as:

$$
\frac{(A o-A t)}{A o} \times 100 \%
$$

where At is the absorbance (peak height) after exposure time $t$ due to the $\mathrm{C}=\mathrm{C}$ double bond (at the stretching frequency or the twisting frequency) and Ao is the absorbance due to this bond at the same frequency for the original uncured film. The area under the peaks is sometimes used rather than the absorbance values in the above expression.

Alternatively, a calorimetric method can be used to measure the enthalpy (heat) given off as the $\mathrm{C}=\mathrm{C}$ disappear. The degree of cure is given by:

$$
\frac{H t}{H o} \times 100 \%
$$

where $\mathrm{Ht}$ is the heat of reaction after a given period of irradiation $(\mathrm{t})$ and $\mathrm{Ho}$ is the heat of reaction for complete conversion of the acrylate $\mathrm{C}=\mathrm{C}$ double bonds to $\mathrm{C}-\mathrm{C}$ single bonds in the polymer. The theoretical value of Ho is $86.1 \mathrm{~kJ}$ mol-1.

To determine the exact degree of cure of a UV curable material, IR spectroscopy, calorimetry, or another method that has been calibrated against one of these two techniques is required. With some radiation-curable materials, it may be impossible or unnecessary to achieve one hundred percent conversion. Some UV curing materials cross-link between multifunctional monomers and oligomers. Even when a significant amount of unsaturation remains, the amount of extractable monomer may be small. For these reasons, it is desirable to separate the terms "degree of cure" and "percentage conversion." The degree of cure may be considered to be the extent to which the properties of the coating approach those of the functionally cured state. 
Measurements of the degree of cure and the kinetics of curing may be classified into two main types: (a) real-time and (b) intermittent. In real-time, the measurement of some property of the coating is made continuously while curing takes place. In the intermittent type of measurement, the coating is given a certain radiation dose after which measurements are made. The measurements are repeated after each subsequent exposure. Real-time, or continuous, monitoring is possible with IR spectroscopy, IR radiometry, calorimetric methods, dilatometry, and with the UV Cure Tester. ${ }^{2}$

\section{Differential Photocalorimetry}

This type of commercial instrumentation uses dual sample differential scanning calorimetry (DSC) to measure the heat of reaction of one or two samples as they are exposed to radiation - usually that from a high pressure mercury vapor lamp, although other interchangeable lamps are available. An internal standard may be subjected to identical conditions of light intensity, wavelength, temperature, and atmosphere. A photofeedback system maintains the intensity of the lamp at constant over long periods.

The dual-sample facility allows the photo-curing behavior of two samples to be compared under identical irradiation conditions. Data analysis software provides a plot of percentage conversion versus time. The instrument also allows one to study the increase in the glass transition temperature of samples with an increasing UV dose. In addition, any post-thermal cure can be monitored by performing DSC analysis. A typical DPC is shown in Figure 1.

The UV light housing (upper) and high voltage power supply (on the right) set on top of a DSC. A interlock switch below the light source prevents the lamp from being turned on without the door being closed. A schematic view of the UV light generation and control is shown in Figure 2.

Once the UV light is generated, it is collected and reflected off an infrared absorbing mirror. By removing the infrared portion of the light source, thermal radiation is prevented from reaching the sample. A small amount of the light is allowed to pass through the mirror to a photofeedback sensor. The sensor provides feedback to the highvoltage generator which controls the light intensity of the lamp. Constant intensity thermal-free UV radiation passes on to the sample and reference sample on a typical DSC cell. 


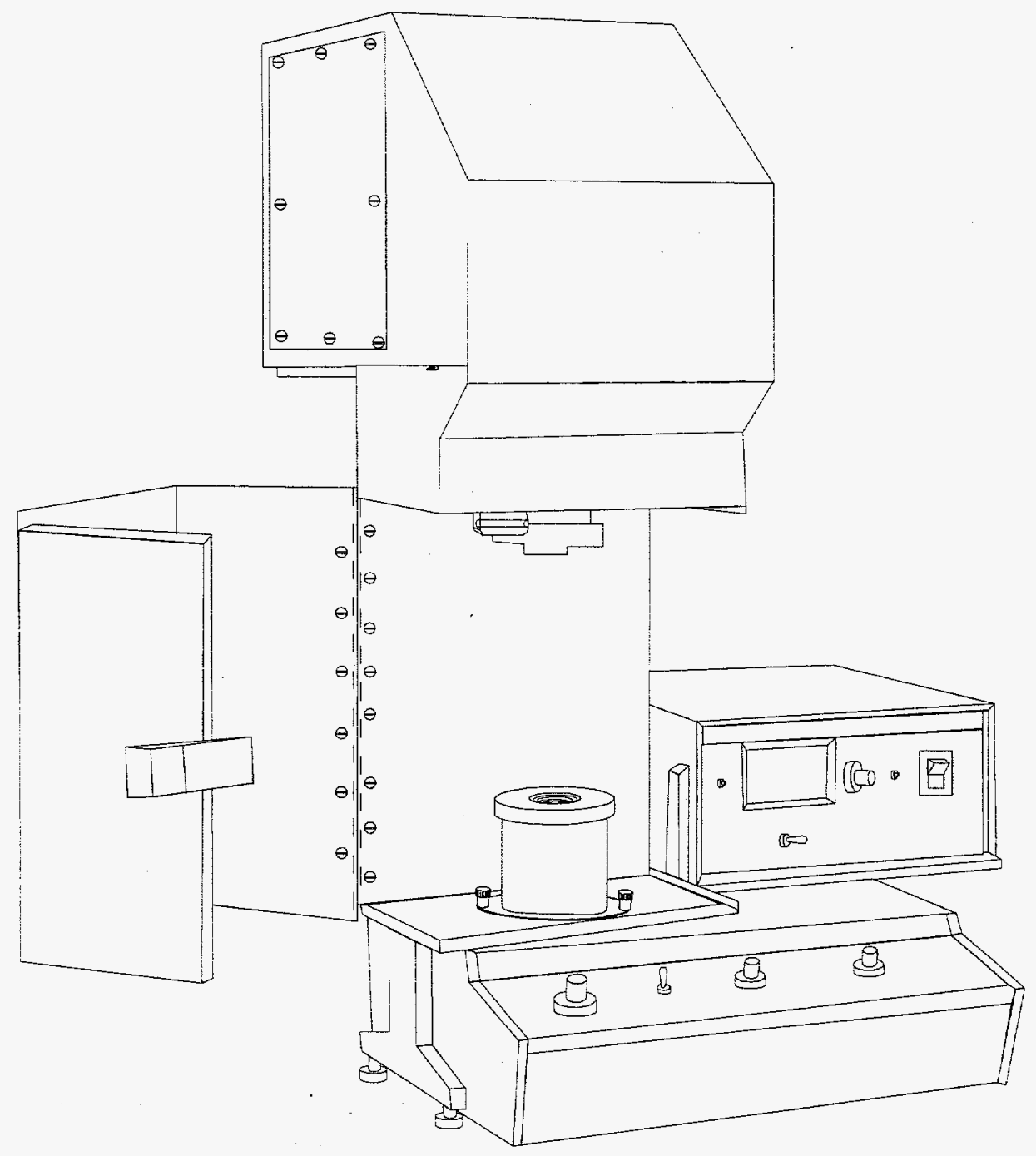

Figure 1. TA Instruments Differential Photo Calorimeter (DPC) 


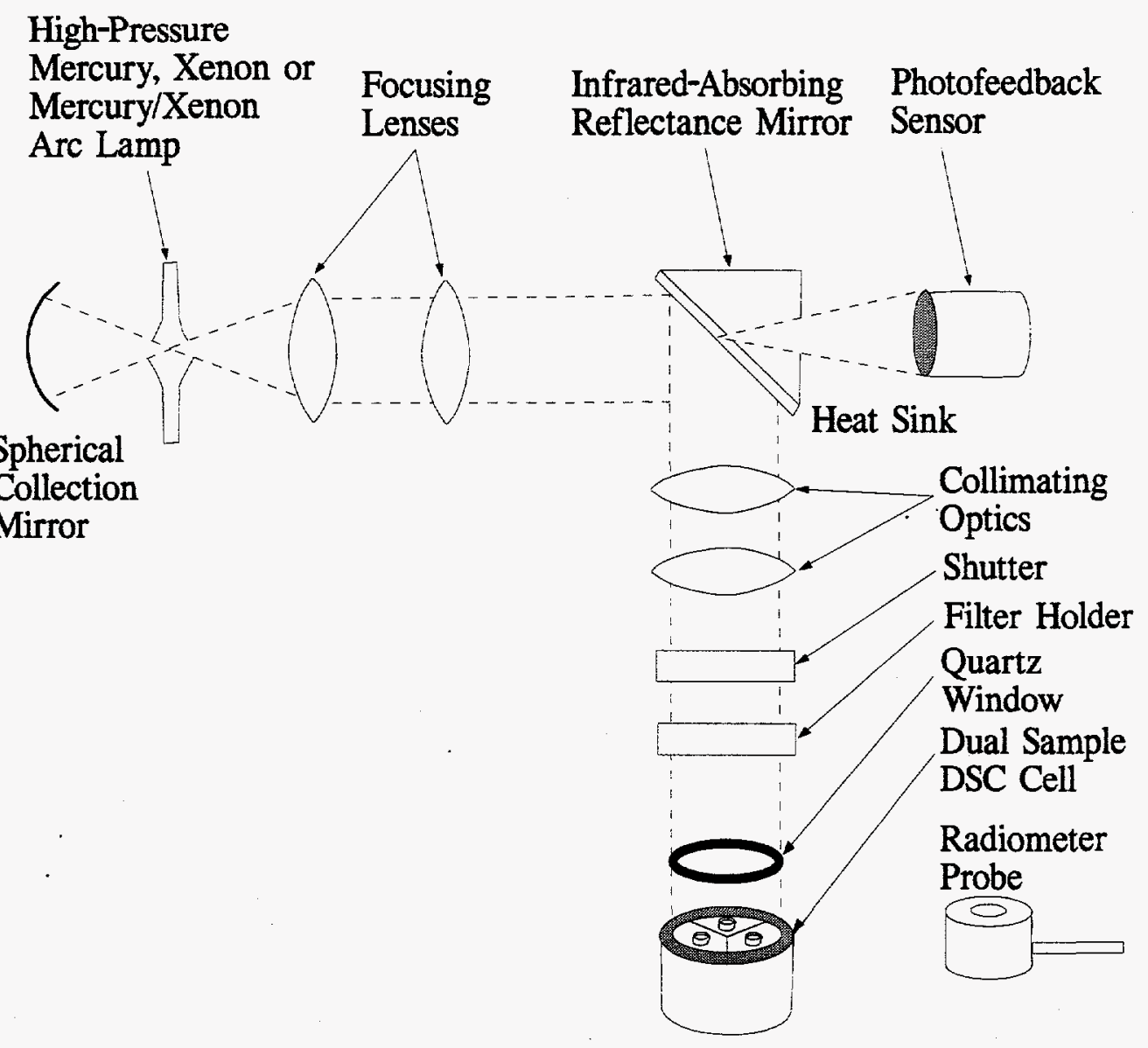

Figure 2. Schematic View of a Differential Photo Calorimeter

Because cure depth is very critical in DPC analysis, micropipettes are used to measure sample solutions into typical DSC pans. Reference samples contain the same volume of sample material that has already been cured. The typical silver lid that covers the samples in a DSC is replaced with one that has holes through the lid to allow light to pass through. An additional quartz window is added on top the silver lid to help exclude air (oxygen) from the samples.

Some of the accessories used in DPC analysis are shown in Figure 3. 


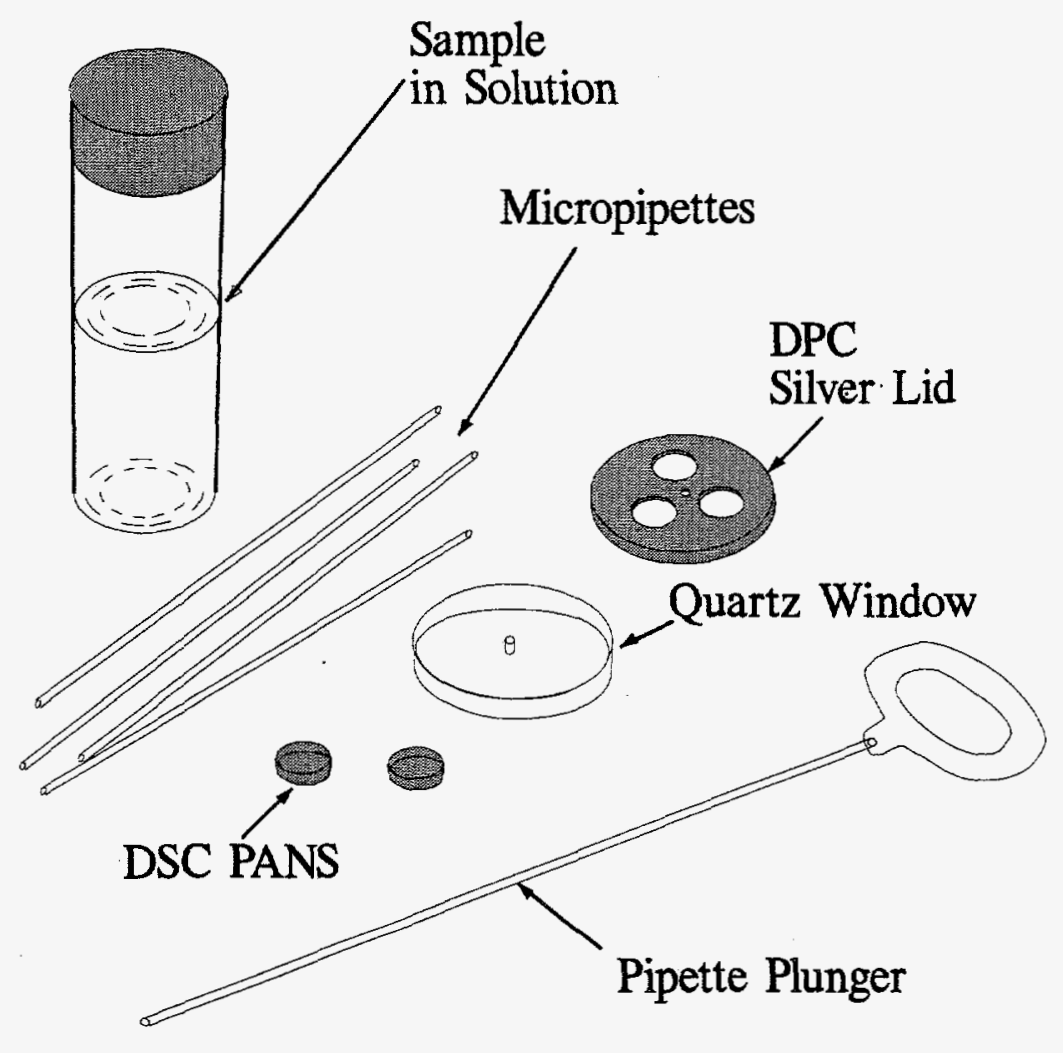

Figure 3. Differential Photo Calorimeter Accessories

A typical DSC cell base being converted to a DPC cell base is shown in Figure 4.

The glass bell jar of the DSC is replaced with an open top aluminum cylinder with a cell cover that has a quartz window to allow light to pass through to the samples.

An additional accessory, a radiometer/photometer, is shown in Figure 5. 

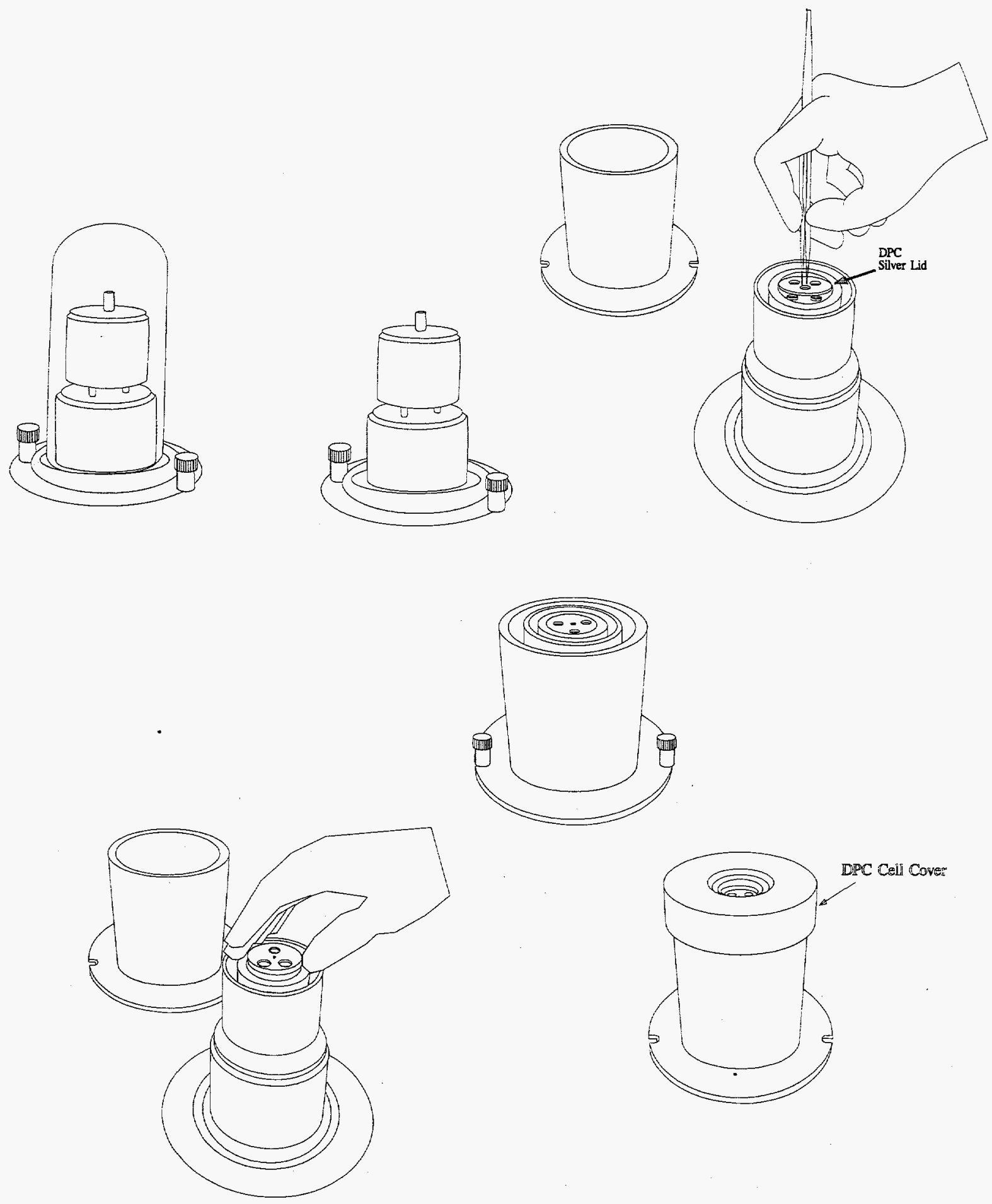

Figure 4. Differential Scanning Calorimeter Versus Differential Photo Calorimeter 


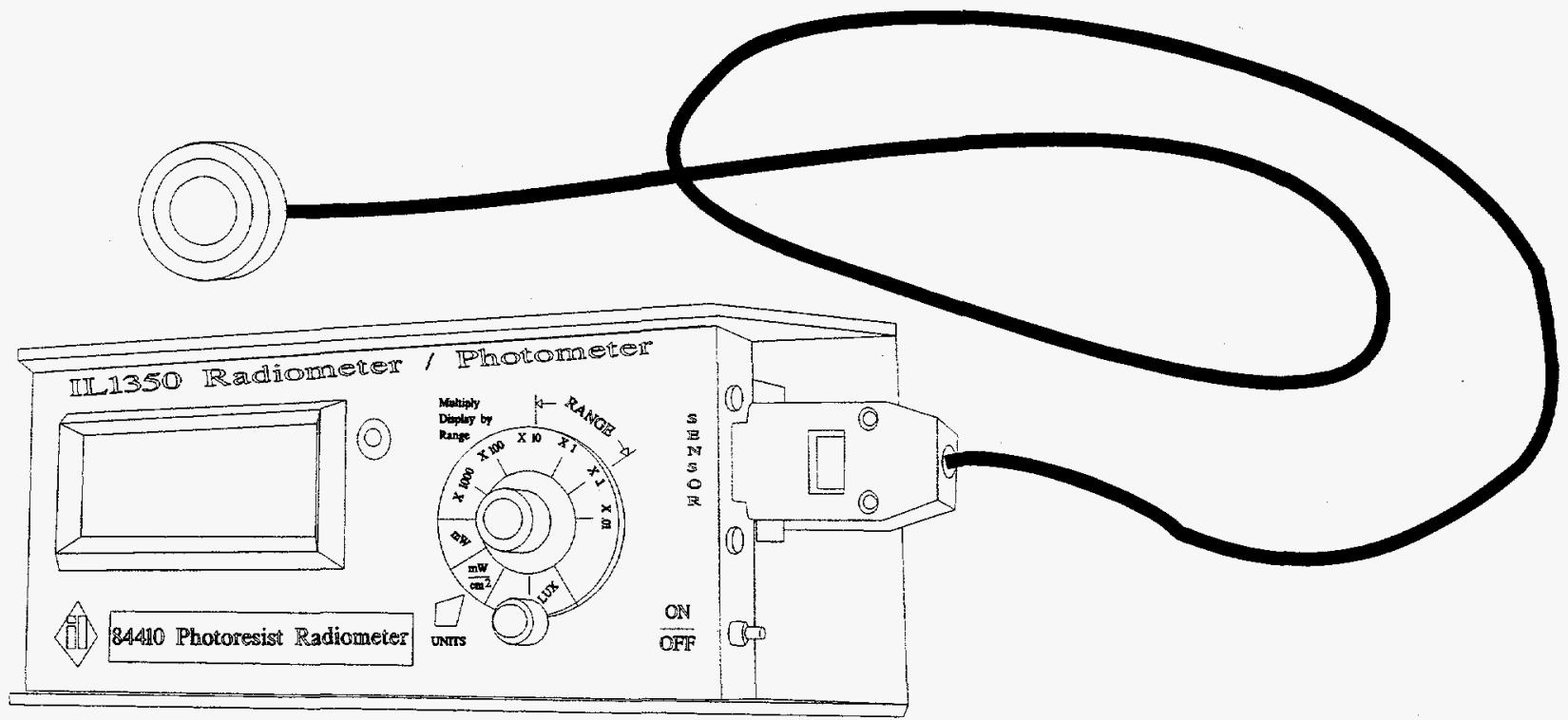

Figure 5. Calibration Photometer

The UV photometer is used for calibration of the DPC and can be used for calibration of the various UV light sources used in processing. The location of the photometer sensor during DPC calibration is shown in Figure 6.

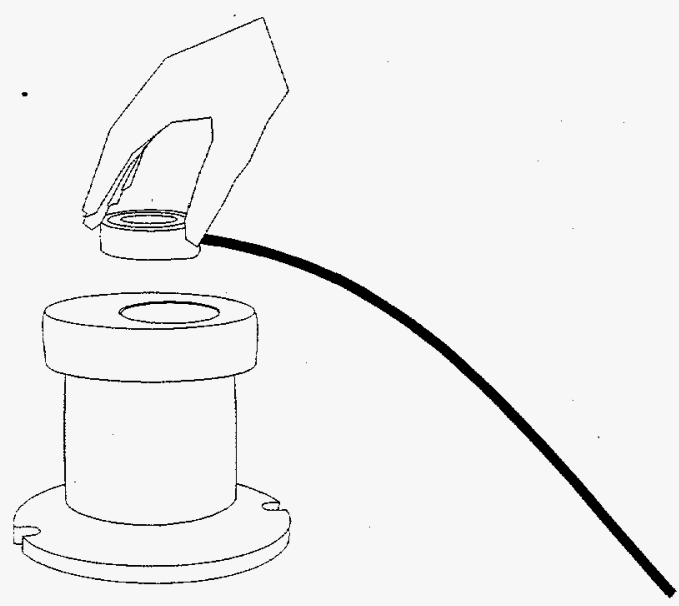

Figure 6. Calibration of the DPC

The light sensor is placed in the off-centered recessed area of the calibration cover. The cover can be rotated, which moves the sensor into position under the reference sample or the other sample locations. The DPC can be adjusted to yield the same light intensities at all three locations. 


\section{UV Curable Inks}

Several UV curable inks were selected for DPC analysis. MS 5096986 at one time was Dexter Hysol 70-700. When Dexter Hysol discontinued UV curable inks, MS 5096986 was changed to Markem 9060. Both the original Dexter Hysol and Markem 9060 as well as Markem 9040 and 9090 white inks were analyzed. The DPC curve for the original MS 5096986 is show in Figure A-1, Appendix A. The heat of cure was very low, $4.8 \mathrm{~J} / \mathrm{g}$. In Figure A-2 (Appendix A), the cure rate as a function of exposure time is shown. The kinetics information generated during the DPC analysis is shown in Figure A-3. In Figure A-4, the closeness of fit curve for MS 5096986 white ink is shown. The closer the data points fall on the calculated line, the more reliable the kinetic information. After UV curing, the same sample was analyzed thermally on the same equipment using DSC. As seen in Figure A-5, there is no residual thermal cure.

The same tests were repeated for Markem 9040 and are shown in Figures A-6 through A-10 (Appendix A). The heat of cure was much higher, $101.5 \mathrm{~J} / \mathrm{g}$, and the cure rate was slightly slower (Figure A-7). The Markem 9040 also showed no residual thermal cure (Figure A-10).

The tests were again repeated for Markem 9060 and are shown in Figures A-11 through A-15. The heat of cure of the 9060 was even higher than the $9040,151.8 \mathrm{~J} / \mathrm{g}$, and the cure rate was much faster, as shown in Figure A-12. Like the other inks, the Markem 9060 showed no residual thermal cure (Figure A-15).

Finally, the tests were repeated for Markem 9090 and are shown in Figures A-16 through A-20. The heat of cure of the 9090 was much lower than the other Markem inks, $14.2 \mathrm{~J} / \mathrm{g}$, and the cure rate was much slower (Figure A-17). Like the other inks, the Markem 9090 showed no residual thermal cure (Figure A-20).

\section{UV Curable Adhesives}

Two UV curable adhesives used for optical applications, Norland 60 and 61 , were chosen for analysis. Norland 60 is typically used as a mounting cement for lenses, for the assembly of prisms, or for mounting components between a sandwich of glass or methacrylate plastic. Norland 60 also has excellent electrical insulating properties and can be used as a protective covercoat.

Norland 61 is designed to bond glass surfaces as in fiber optic applications. It meets MIL-A-3920 for optical adhesives and has excellent adhesion to metal, fiberglass, and glass-filled plastics. Some of the properties of Norland 60 and 61 are shown in Table 1. 
Table 1. Norland 60 and 61 Properties

\begin{tabular}{|l|l|l|}
\hline Property & Norland 60 & Norland 61 \\
\hline Viscosity (CPS) & 300 & 300 \\
\hline Refractive Index & 1.56 & 1.56 \\
\hline Modulus (psi) & 135,000 & 150,000 \\
\hline Tensile Strength (psi) & 2,800 & 3,000 \\
\hline Elongation at Failure (\%) & 35 & 38 \\
\hline Shore D Hardness & 81 & 85 \\
\hline
\end{tabular}

Depth of cure is always a concern with UV curable materials. Because samples are dispensed with micropipettes and the diameter of the DSC pans used for DPC analysis is constant, a relationship between the sample size in $\mu \mathrm{L}$ and sample thickness in mils or $\mathrm{mm}$ can be established. For Norland 60 and 61, this relationship is shown in Table 2.

Table 2. Sample Size Versus Sample Thickness for Norland 60 and 61

\begin{tabular}{|l|l|l|}
\hline Sample Volume $(\mu \mathrm{L})$ & Thickness (mil) & Thickness $(\mathrm{mm})$ \\
\hline 0 & 0 & 0 \\
\hline 5 & 6.2 & 0.158 \\
\hline 10 & 12.4 & 0.316 \\
\hline 20 & 24.8 & 0.632 \\
\hline
\end{tabular}

\section{Norland 60}

Samples of Norland 60 were prepared at 5,10 , and $20 \mu \mathrm{L}$. The DPC analyses are shown in Figures B-1 through B-3 (Appendix B). As the sample size increases, a shoulder begins to form on the right-hand side of the curve. The reason for the shoulder formation is that shrinkage of the polymer during cure results in a greater depth of light penetration, and additional polymer can be cured. Therefore, the formation of a shoulder indicates maximum depth of cure has been exceeded. As seen in Figure B-2 and to an even greater extent in Figure B-3, depth of cure is limited to 6 mils or less.

In addition to the appearance of a shoulder, the closeness of fit to the predicted kinetics curve, as shown in Figures B-4 through B-6 (Appendix B), is another indication that maximum cure depth is being exceeded. The kinetics report and cure rate as a function of cure time for the $5 \mu \mathrm{L}$ sample are shown in Figures B-7 and B-8. DSC analysis was performed on the UV cured sample, and the results are shown in Figure B-9. Some additional thermal cure does occur after UV curing. 


\section{Norland 61}

Samples of Norland 61 were also prepared at 5,10 , and $20 \mu \mathrm{L}$. The DPC analyses are shown in Figures B-10 through B-12. Again, as the sample size increases, a shoulder begins to form on the right hand side of the curve. As seen in Figure B-11 and to even a greater extent in Figure B-12, depth of cure is also limited to 6 mils or less.

Again, in addition to the appearance of a shoulder, the closeness of fit to the predicted kinetics curve, as shown in Figures B-13 through B-15, is another indication that maximum cure depth is being exceeded. The kinetics report and cure rate as a function of cure time for the $5 \mu \mathrm{L}$ sample are shown in Figures B-16 and B-17. DSC analysis was performed on the UV cured sample, and the results are shown in Figure B-18. Again, some additional thermal cure does occur after UV curing.

\section{Conformal Coatings}

\section{HA84}

Two conformal coatings developed at Sandia National Laboratory, Albuquerque HA84 and a flexiblized version, HA84F - were selected for DPC and DSC analysis. The DPC and DSC curves for 5, 10, 20, and $40 \mu \mathrm{L}$ samples are shown in Figures C-1 through C-8 (Appendix C). By comparing the amount of heat given off during cure of the HA84, approximately one third is from UV curing and two thirds are from thermal curing. Cure depth is much greater for the HA84, somewhere between 25 and 50 mils. Again, the depth of cure can be observed in the closeness of fit curves: see Figures C-9 through C-12 (Appendix C). The kinetics report and cure rate as a function of time are shown in Figures $\mathrm{C}-13$ and $\mathrm{C}-14$.

\section{HA84F}

The DPC and DSC curves for 5, 10, 20, and $40 \mu \mathrm{L}$ samples of HA84F are shown in Figures D-1 through D-8 (Appendix D). Unlike the HA84, much more cure takes place during UV curing. Of the amount of heat given off during cure of the HA84F, approximately three fourths is from UV curing and one forth is from thermal curing. Again, the cure depth of HA84F is somewhere between 25 and 50 mils. Also again, the depth of cure can be observed in the closeness of fit curves: see Figures D-9 through D-12. The kinetics report and cure rate as a function of time are shown in Figures D-13 and D-14.

\section{UV Cure Equipment Characterization}

To properly cure UV curable materials, a specific dose (intensity $\mathrm{x}$ time) of radiation is desirable to yield repeatable results. In addition, UV light sources must be sized to the 
material being cured. As discussed before, the DPC can help predict the required dose, but the UV sources must be characterized to determine exposure times. The UV cure equipment evaluated is shown in Figures 7 through 11.

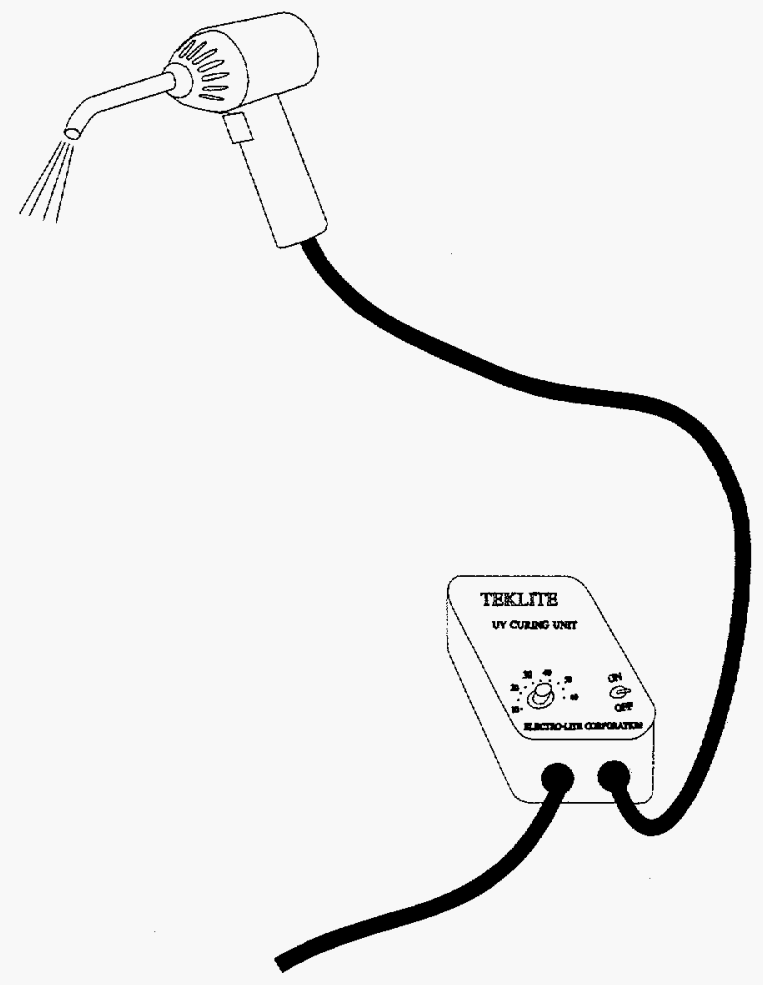

Figure 7. Tecklite Handgun UV Source

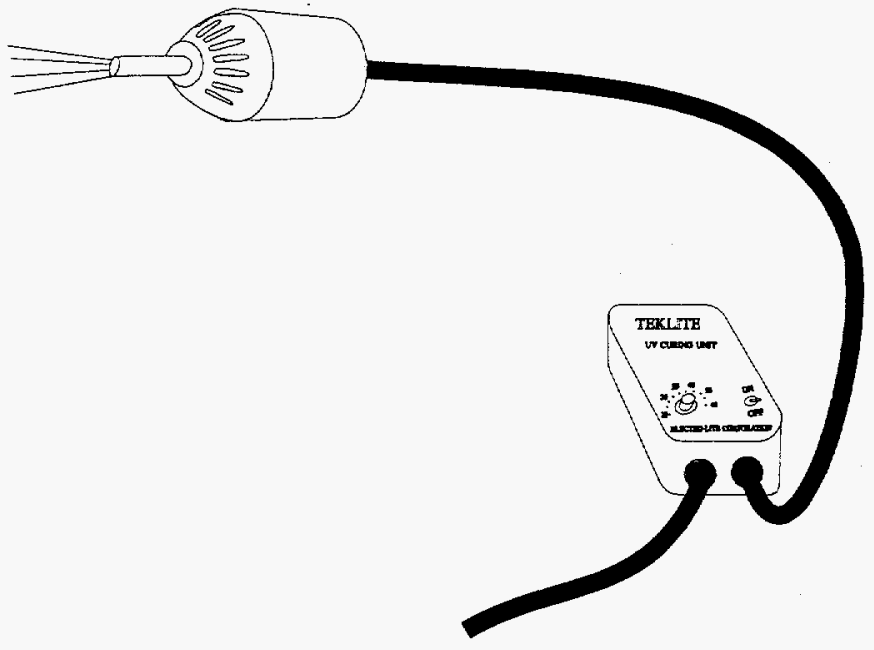

Figure 8. Tecklite ECLM 400 UV Source 


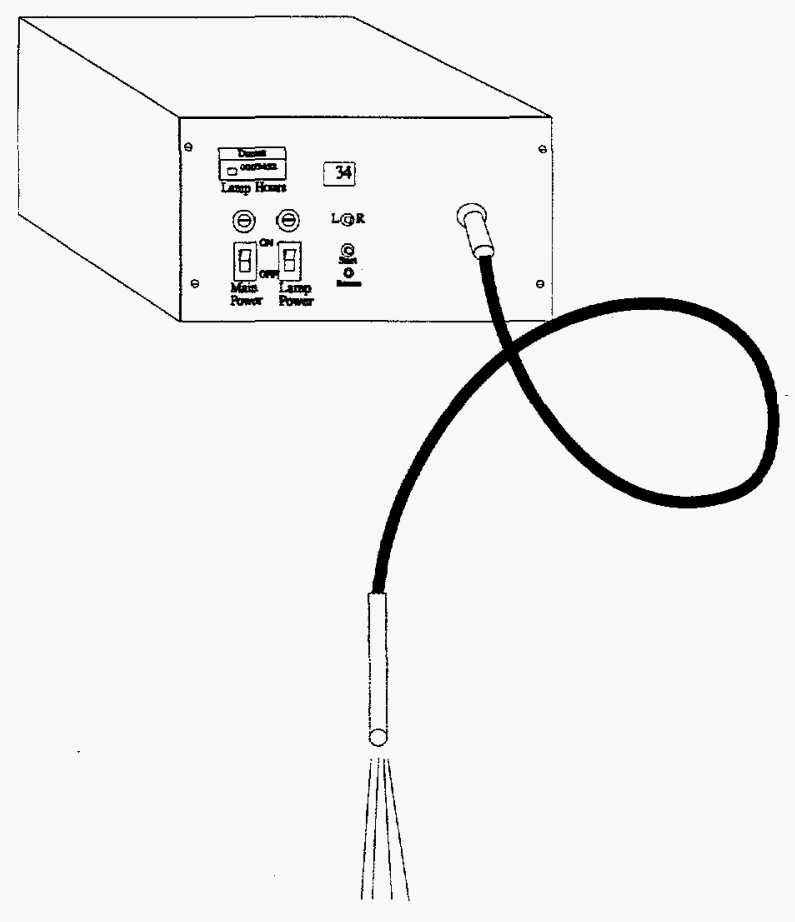

Figure 9. EFOUS Ultracure 100 UV Light Source

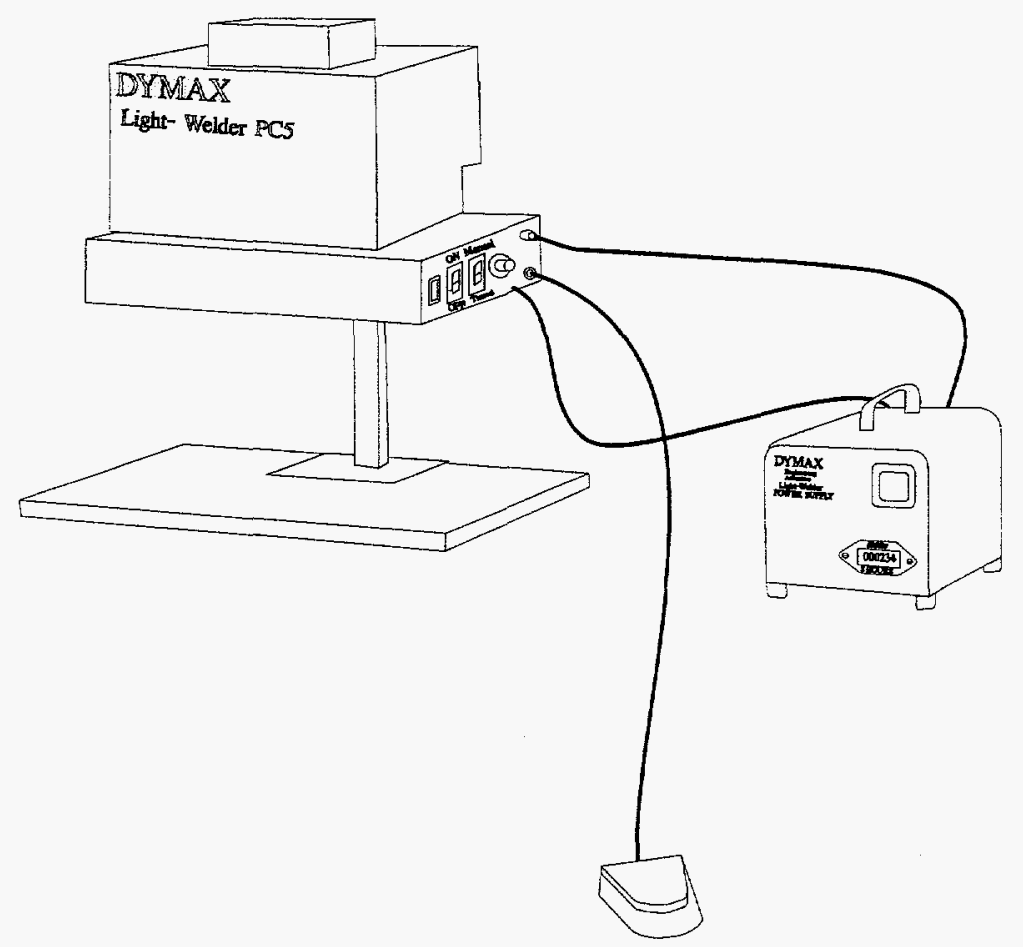

Figure 10. Dymax UV Light Source With Shutter 


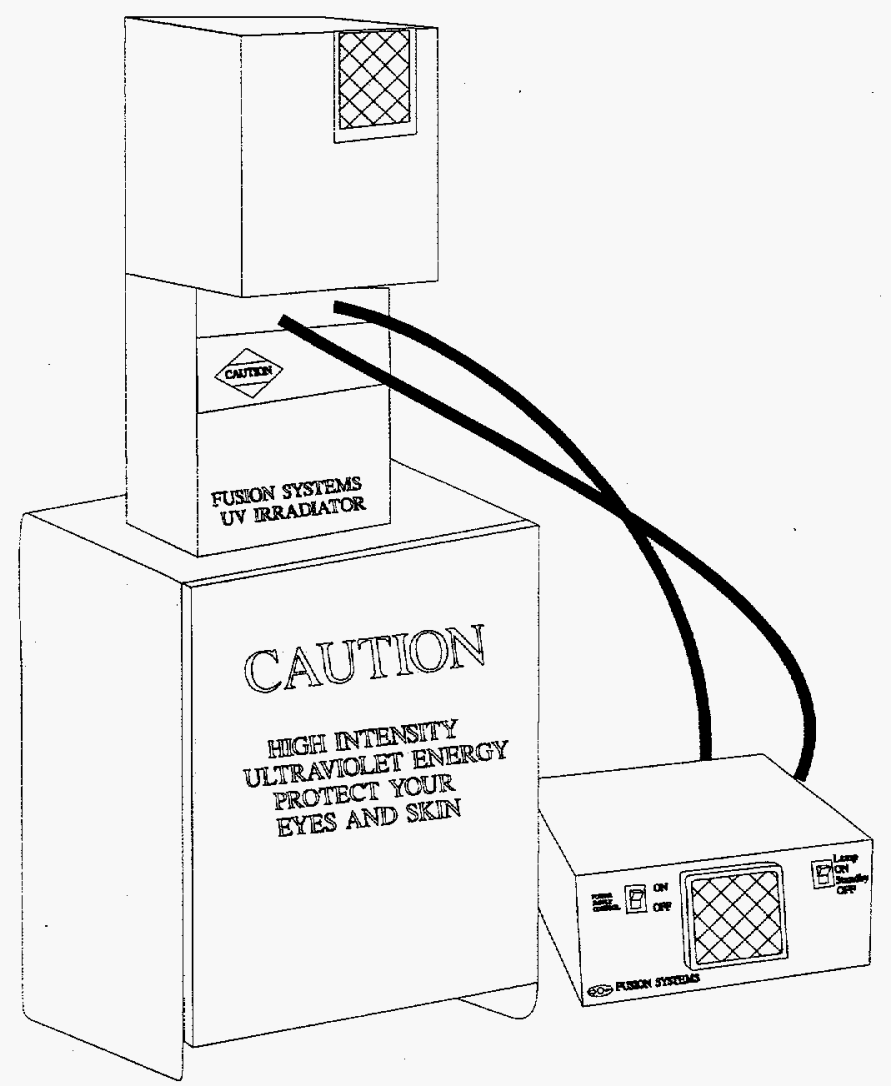

Figure 11. Fusion Systems UV Light Source

The first three light sources have small circular light beams which diverge as the light leaves the end of the source. The duration of the light pulse for the low-energy UV light gun shown in Figure 7 can be adjusted on the power supply box. When the trigger on the handgun is pulled, the light will come on for the adjusted time period. The slightly higher energy Tecklite ECLM 400 UV source also has a light duration adjustment on the power supply box but is made to be mounted on a fixture; the material to be cured is passed under the light beam. Like the other two light sources, the spot diameter for the EFOUS Ultracure $100 \mathrm{UV}$ light source increases with increasing distance from the fiber optic wand.

The next two UV light sources are designed to cure large areas at one time, and multiple units can be ganged together to cover even wider areas. Both units use reflectors to concentrate the light down to the product. The Dymax UV light source can be connected to a pneumatically controlled shutter assembly, as shown in Figure 10.

For personnel safety, the lamp, shutter assembly, and stand were placed inside an aluminum housing to prevent light from escaping. The housing has an electrical interlock switch to prevent the lamp from being energized when the door to the housing is open. The high-voltage power supply and pneumatic switch were located outside of the 
housing. The lamp used in this system loses intensity during its lifetime. Small amounts of metal are deposited on the interior surfaces of the lamp after each use. Although the light output was characterized for this system at the time of the project, it must be continually rechecked.

The largest light intensity system evaluated was the Fusion Systems UV light source, shown in Figure 11. The Fusion Systems light source generates UV light by microwave radiation and reaches stability in a much shorter time (about $1-2$ seconds). By using microwave radiation, light intensity is more stable during the life of the UV lamp. Like the Dymax system, the Fusion Systems source generates lots of thermal radiation. Again, for personnel safety, the lamp assembly was placed on top of an aluminum housing to prevent light from escaping. The housing has an electrical interlock switch to prevent the lamp from being energized when the door to the housing is open. The high voltage power supply and control circuitry are located outside of the housing.

Light intensity decreases with the square of the distance from the light source. The UV light diverges as it leaves the UV light pipe of the first three light sources and covers a larger area as the distance from the handgun increases. The relationship of the light to the equipment was characterized by measuring the light intensity and spot diameter at various distances, as shown in Figures E-1 through E-6, Appendix E.

Again, the light intensity varies as a function of the distance from the light source for the last two light sources. The Dymax UV light source requires a warmup time period until the light intensity is stable. Measurements were made after one minute to allow the source to stabilize. In addition to the variation in light intensity (and unlike the fiber optic light sources), thermal radiation is generated by the light source. This thermal radiation causes the temperature of the chamber and product being exposed to increase. A thermal couple was placed at various distances from the light source, and the temperature was measured after one minute of exposure. The results of the Dymax UV light sources characterization are shown in Figures E-7 through E-12 (Appendix E).

The light intensity for the Fusion Systems UV light source was also characterized and is shown in Figure E-13.

\section{Adhesion Testing}

The capability of performing ASTM D-3658 (Standard Test Method for Determining the Torque Strength of Ultraviolet Light-Cured Glass/Metal Adhesive Joints) was established. This test method provides reasonably accurate information with regard to the ability of UV curing adhesives to withstand torsional shearing forces. The test fixture is shown in Figure 12. 


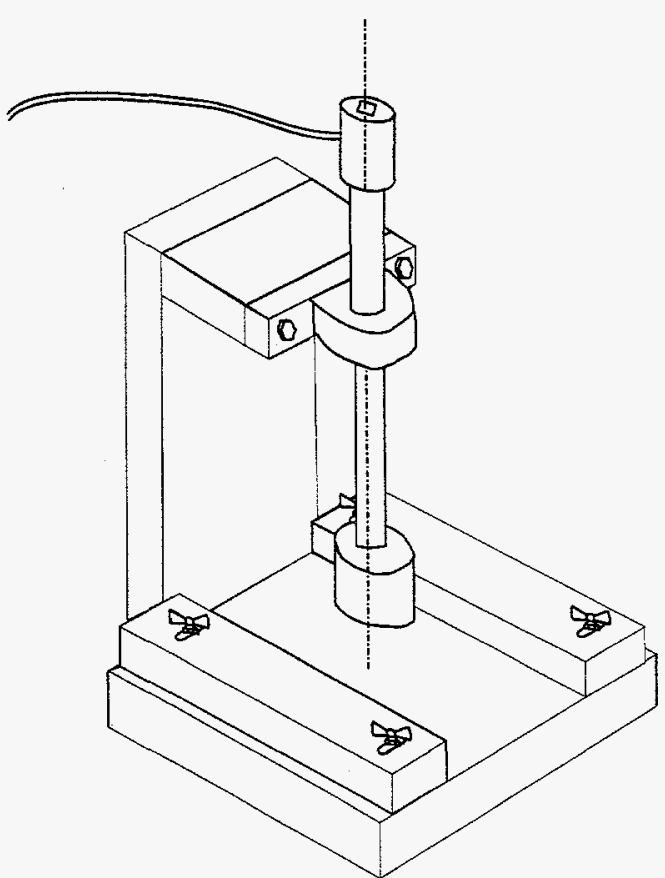

Figure 12. ASTM D-3658 Shear Torsion Test Fixture

This fixture is capable of transferring uniform and continuous torque to the bonded hexagonal block of the test sample. The test requires an accurate means of measuring load failure and is shown with a torque load cell at the top. Alternately, the test fixture may be attached to an Instron, as shown in Figure 13.

The ASTM D-3658 test sample shown in Figure 14 is composed of a 1 inch hex aluminum stock cut to $1 / 2$ inch thick and a 3 by 3 by $1 / 2$ inch glass plate. The UV curable adhesive is layered between the two, and UV radiation is passed through the glass.

During the timeframe the ASTM D-3658 testing capability was being established, there was a need for a ring torsion test capability to support the DOI program. Although this testing was for a non-UV curable adhesive, it is applicable to testing coatings and adhesives. An annular ring is machined into the aluminum to a depth representative of the bond thickness of a specific application. Fill and vent holes are drilled through the aluminum. For UV applications, the substrate material can be an optically transparent material or a substrate that is coated with a UV curable coating. In the case of a UV curable adhesive, an optically transparent substrate would be used. For a substrate such as a circuit board material, the UV coating would be cured and the conventional adhesive would be used. The modified test sample is shown in Figure 15. 


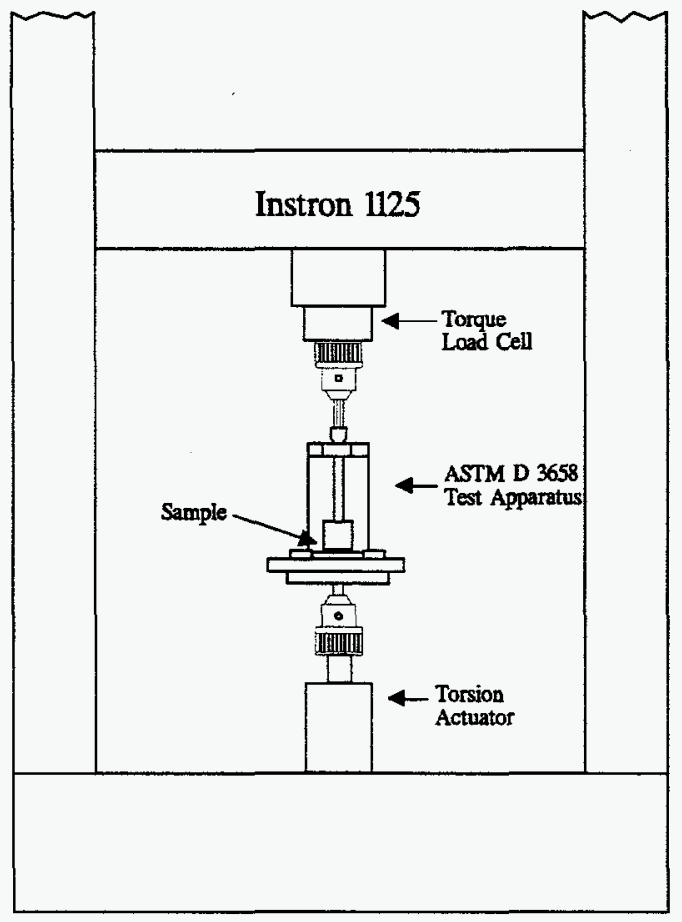

Figure 13. ASTM D-3658 Torsion Fixture Attached to an Instron

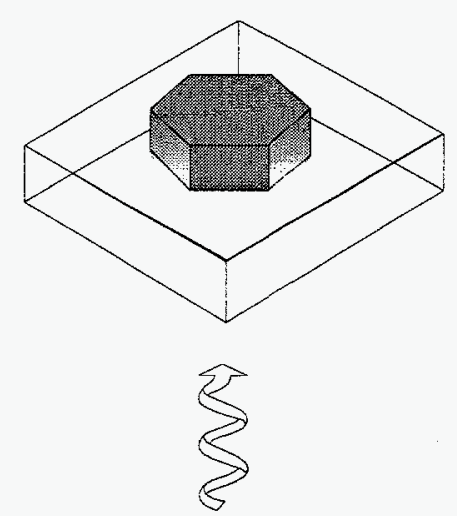

U.V. Light

Figure 14. ASTM D-3658 Test Sample 

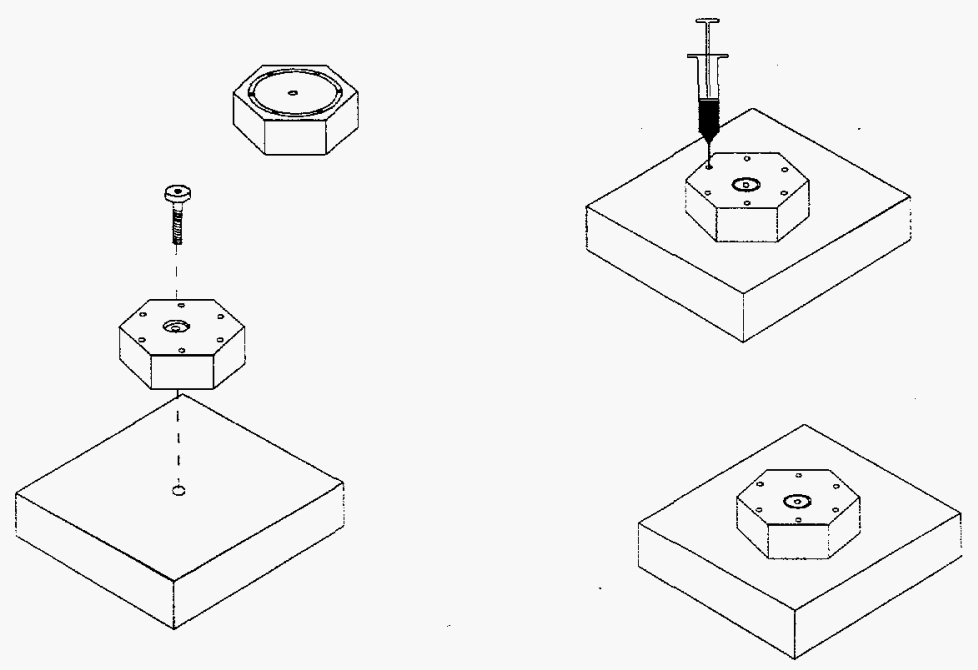

Figure 15. Modified ASTM D-3658 Test Samples

The use of an annular ring bonding area, a constant bondline, and torsional testing is thought to provide test data with less variation than conventional lap shear testing. The results of testing the adhesion between aluminum for a conventional adhesive are shown in Table 3.

Table 3. Torque Test Data for EC2216 Adhesive

\begin{tabular}{|c|c|c|}
\hline $\begin{array}{l}\text { Sample } \\
\text { Number }\end{array}$ & $\begin{array}{l}\text { Torque Strength } \\
(\text { in } 1 \text { bs })\end{array}$ & $\begin{array}{l}\text { Talure Node } \\
\text { (location) }\end{array}$ \\
\hline 1 & 265 & Both (both) \\
\hline 2 & 255 & Adhesive (hex side) \\
\hline 3 & 210 & Adhesive (hex side) \\
\hline$\overline{4}$ & 250 & Adhesive (hex side) \\
\hline 5 & 210 & Adhesive (hex side) \\
\hline Average (dev.) & $238(26)$ & --- \\
\hline
\end{tabular}

With typical lap shear testing, a deviation of 20 percent or more might be expected.

\section{$\underline{\text { Solvent Resistance }}$}

\section{Solvent Rub Test}

This is the determination of the number of double rubs (with a cloth soaked in a suitable solvent, such as methyl ethyl ketone [MEK], attached to a two-pound ball peen hammer) that can be performed on the coating before the substrate is exposed. A double rub is one forward and backward motion of the solvent-impregnated cloth attached to the hammer. The hammer provides a constant force loading on the solvent-soaked cloth. The surface is 
periodically inspected for loss of sheen or other wear. This test can be useful in comparisons between different curing conditions and materials.

\section{TMA Testing}

The thermal mechanical analyzer (TMA) was evaluated as a method for measuring solvent swell, as shown in Figure 16. During a conventional TMA test, a sample is heated by a furnace and the height of the sample is measured with a linear variable displacement transducer (LVDT). In this solvent swell test, the furnace is removed and replaced with a small beaker of solvent. The test is started at the time the solvent is raised to cover the sample. The height is measured as a function of time.

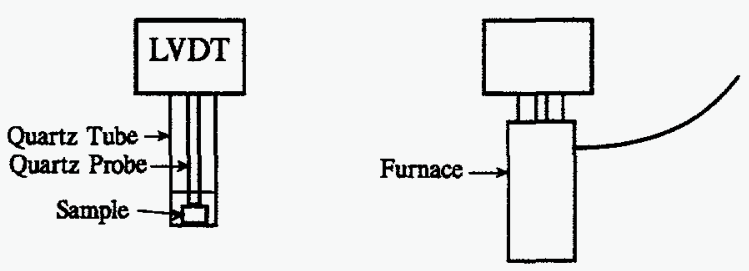

Normal

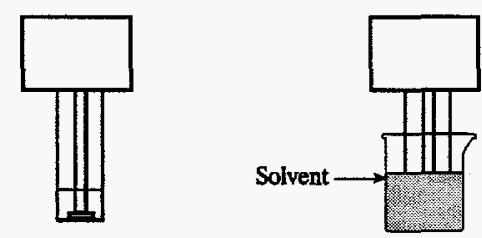

Solvent Swell Test

\section{Figure 16. Solvent Swell Testing Using a Thermal Mechanical Analyzer}

Norland 60 optical adhesive was chosen as a test material to evaluate this method. Samples were cured for 30 and 120 seconds in the DYMAX cure chamber. The 30 second cure represented an under-cured and less solvent-resistant material, and the 120 second cure represented a completely cured material. The test results for exposure to toluene are shown in Figures F-1 and F-2 (Appendix F). As shown, the sample cured for 120 seconds has much better resistance, with no increase in height.

The test results for exposure to water are shown in Figures F-3 and F-4 (Appendix F). As shown, the sample cured for 120 seconds appears to be losing height and the sample in methylene chloride, Figure F-5, appears to shrink and then expand. The reason for the anomalies was traced to the temperature variation in the solvent due to evaporation. This is also shown in Figure F-5, with curve on the right, which measured the temperature during the same timeframe. To overcome this problem, the surface area of exposed solvent was reduced, the beaker of solvent was inserted into a large mass metal container, 
and both the TMA and solvent were allowed to reach the same temperature before immersion. With these changes, temperature effects on the dimensional change were reduced. Figures F-6 and F-7 show the solvent swell testing of Norland 60 with d-limonene. Finally, the solvent swell tests in acetone, isopropyl alcohol, and water are shown in Figures F-8 through F-10.

\section{ACCOMPLISHMENTS}

Two new testing capabilities, DPC and torsion testing, were established during this project. A differential photocalorimeter was used to measure the degree of cure and allow the prediction of optimum processing conditions. The UV cure equipment at FM\&T was characterized, and the ability to size equipment to specific material cure needs was established. Adhesion test procedures were developed for the adhesives, and solvent resistance testing procedures were developed for the coatings and inks.

\section{FUTURE WORK}

The original guidance for this project was changed from a general overview of UV curable materials to more specific applications on conformal coatings. The remainder of this project will focus on characterizing conformal coatings such as HA84 and issuing material specifications for them. 


\section{REFERENCES}

${ }^{1}$ Radiation Curing of Polymeric Materials. Hoyle \& Kinstle, ACS Symposium Series 417, April 1989.

${ }^{2}$ A. K. Davies, Experimental Techniques to Monitor the Degree of Cure in RadiationCured Coatings, Department of Chemistry and Applied Chemistry, University of Salford, Salford M5 4WT, U. K. 


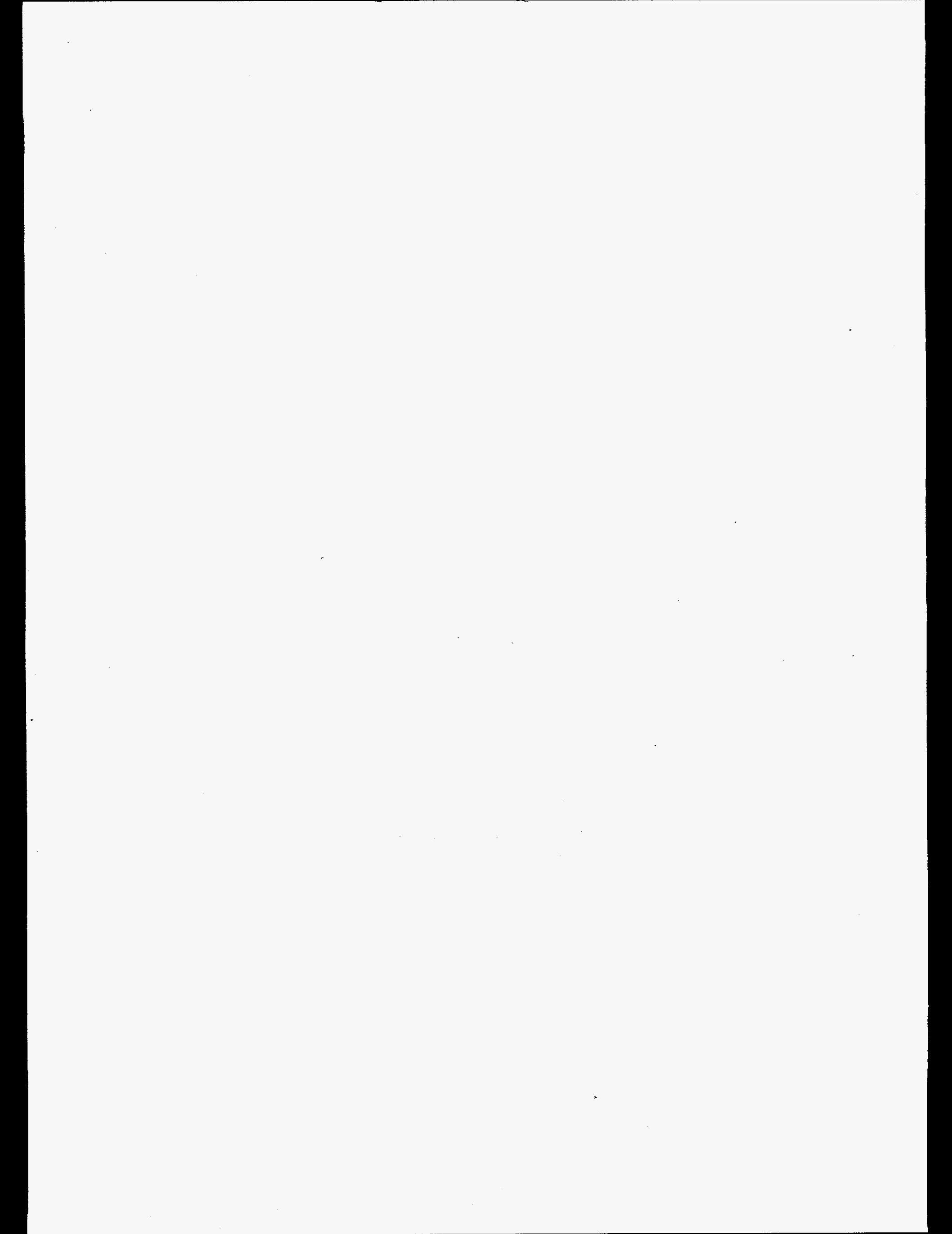




\section{APPENDIX A}

Analysis of UV Curable Inks 


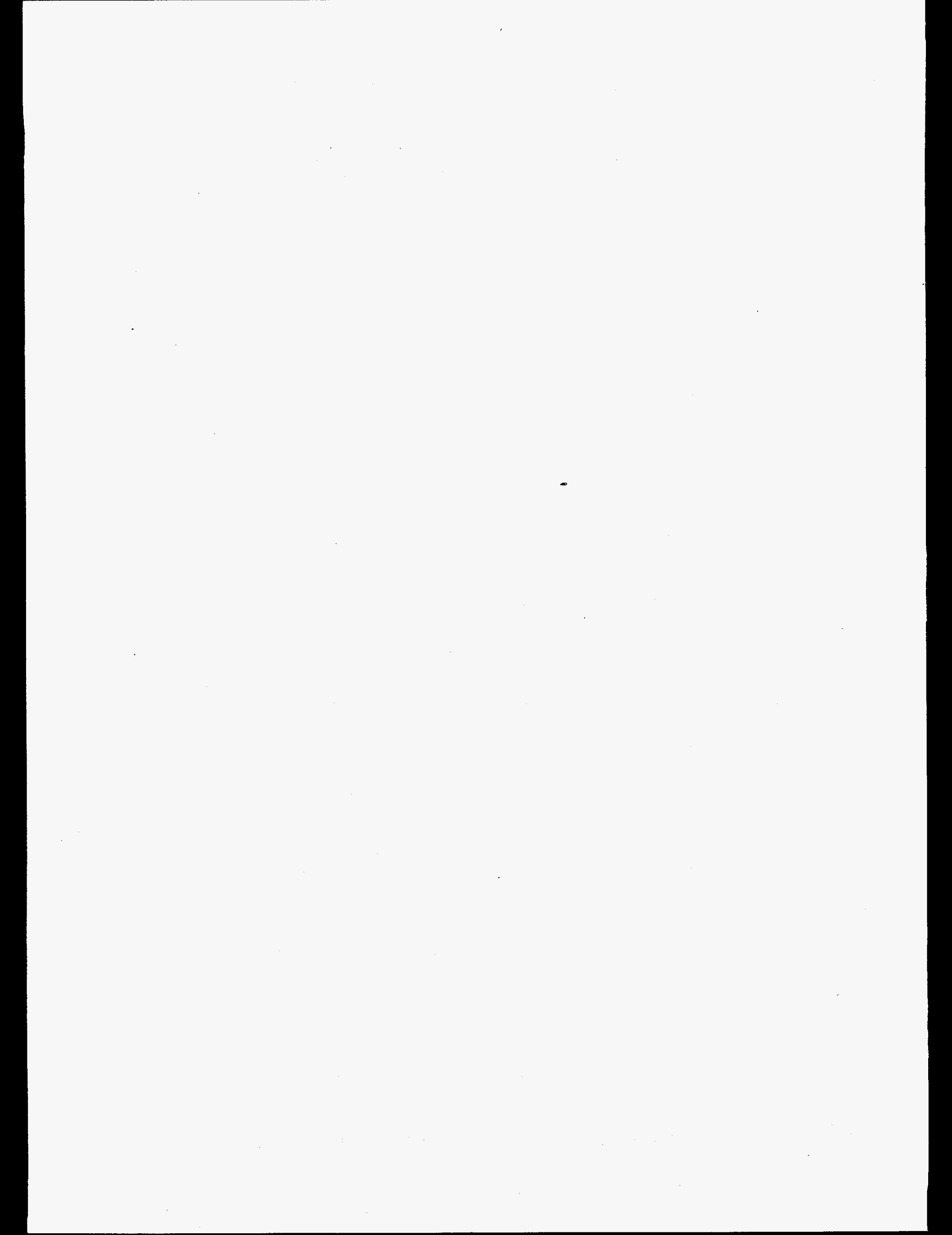




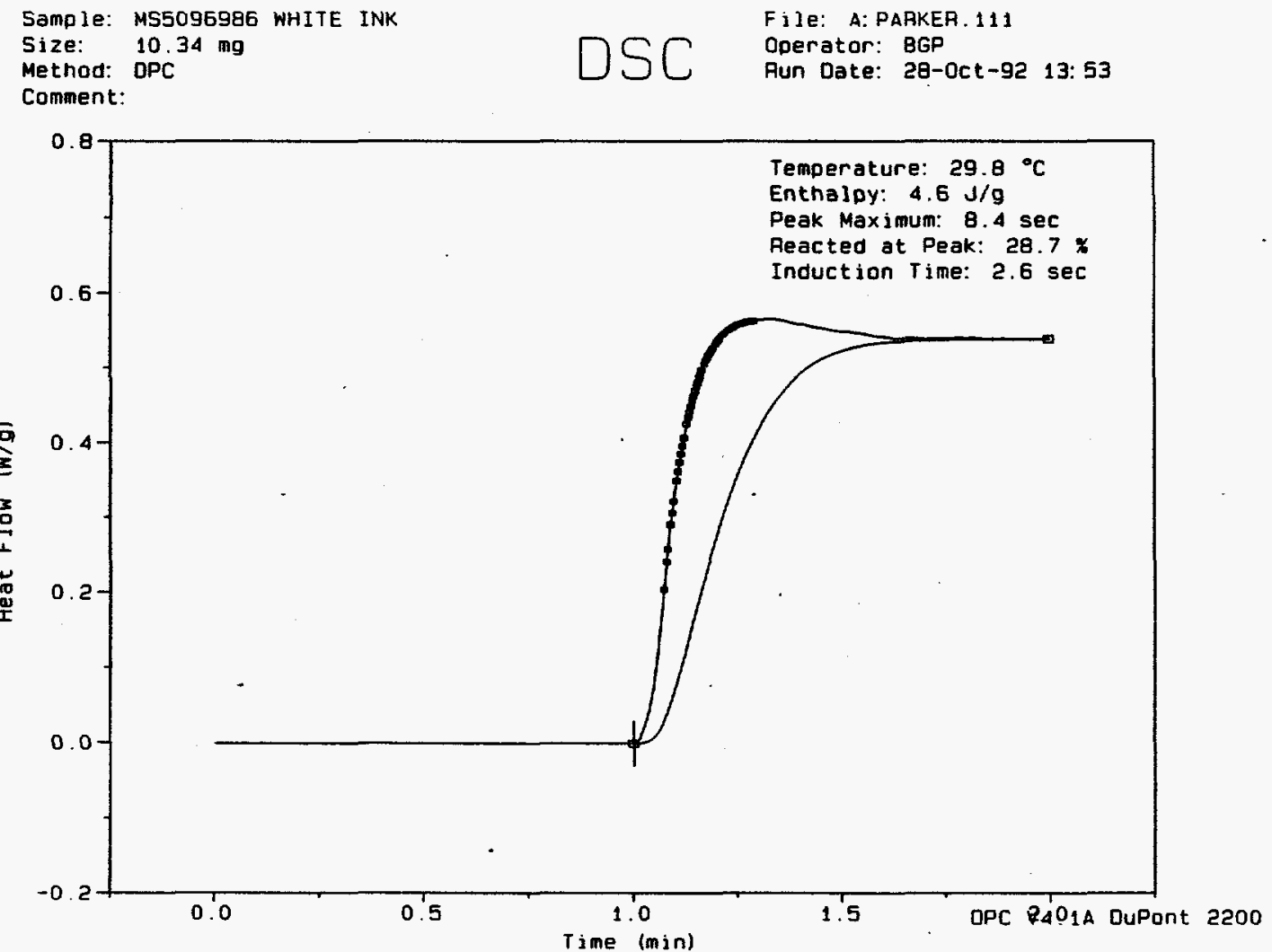

Figure A-1. DPC Curve for MS 5096986 White Ink

Sample: MS5096986 WHITE INK Size: $10.34 \mathrm{mg}$

File: A: PARKER. 111

Comanent:

Operator: BGP

Run Date: 28-0ct-92

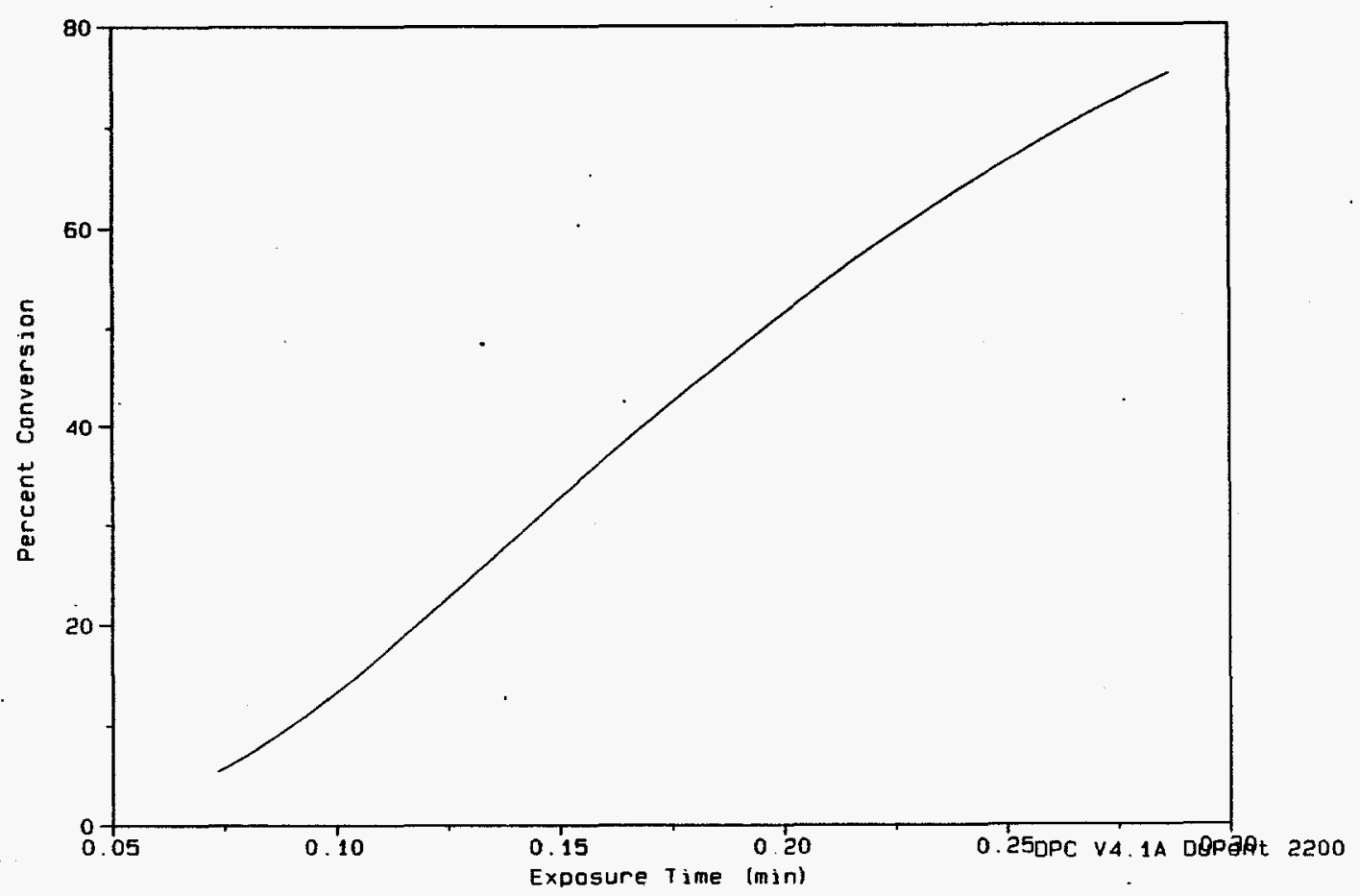

Figure A-2. Cure Rate Versus Exposure Time for MS 5096986 White Ink 
DIFFERENTIAL. PHOTO CALORIMETRY KINETICS REPOAT

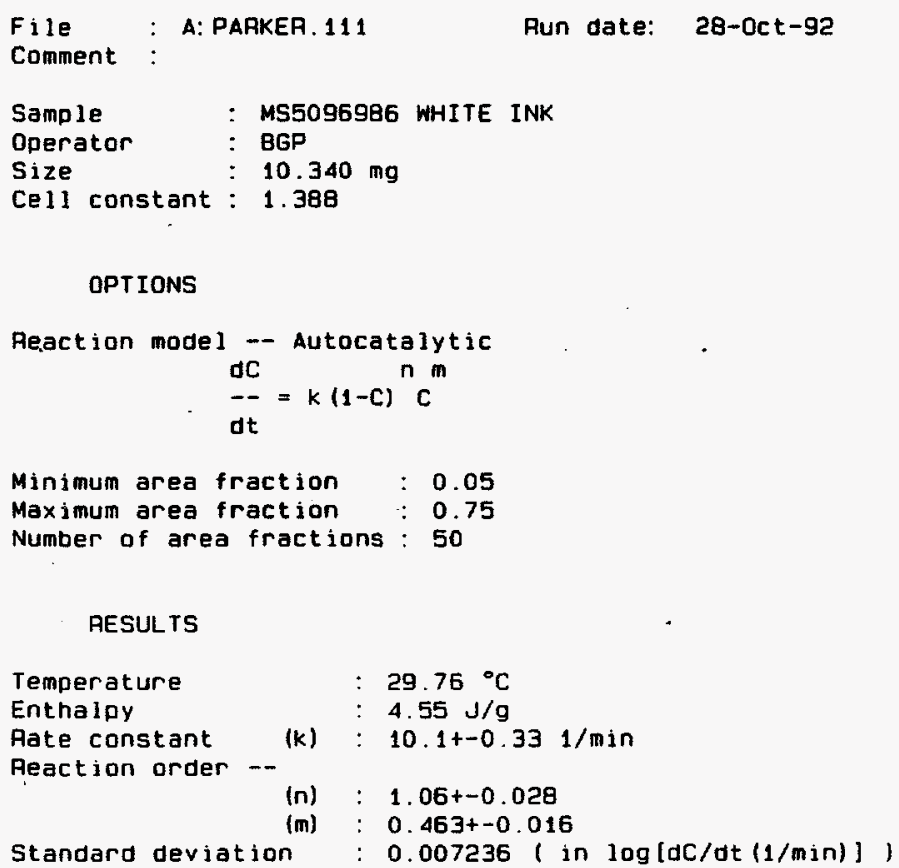

RESULTS

Temperature

$29.76^{\circ} \mathrm{C}$

Enthalpy $\quad: 4.55 \mathrm{~J} / \mathrm{g}$

Pate constant (k) : 10.1+-0.331/min

Peaction order -- (n) : $1.06+-0.028$

(m) $: 0.463+-0.016$

Standard deviation : 0.007236 ( in $\log [d C / d t(1 / m i n)]$ )

\section{Figure A-3. Kinetics Report for MS 5096986 White Ink}

Sample: MS5096986 WHITE INK

Size: $\quad 10.34 \mathrm{mg}$

Comment:
File: A: PARKER. 111

Operator: BGP

Pun Date: 28-0ct-92

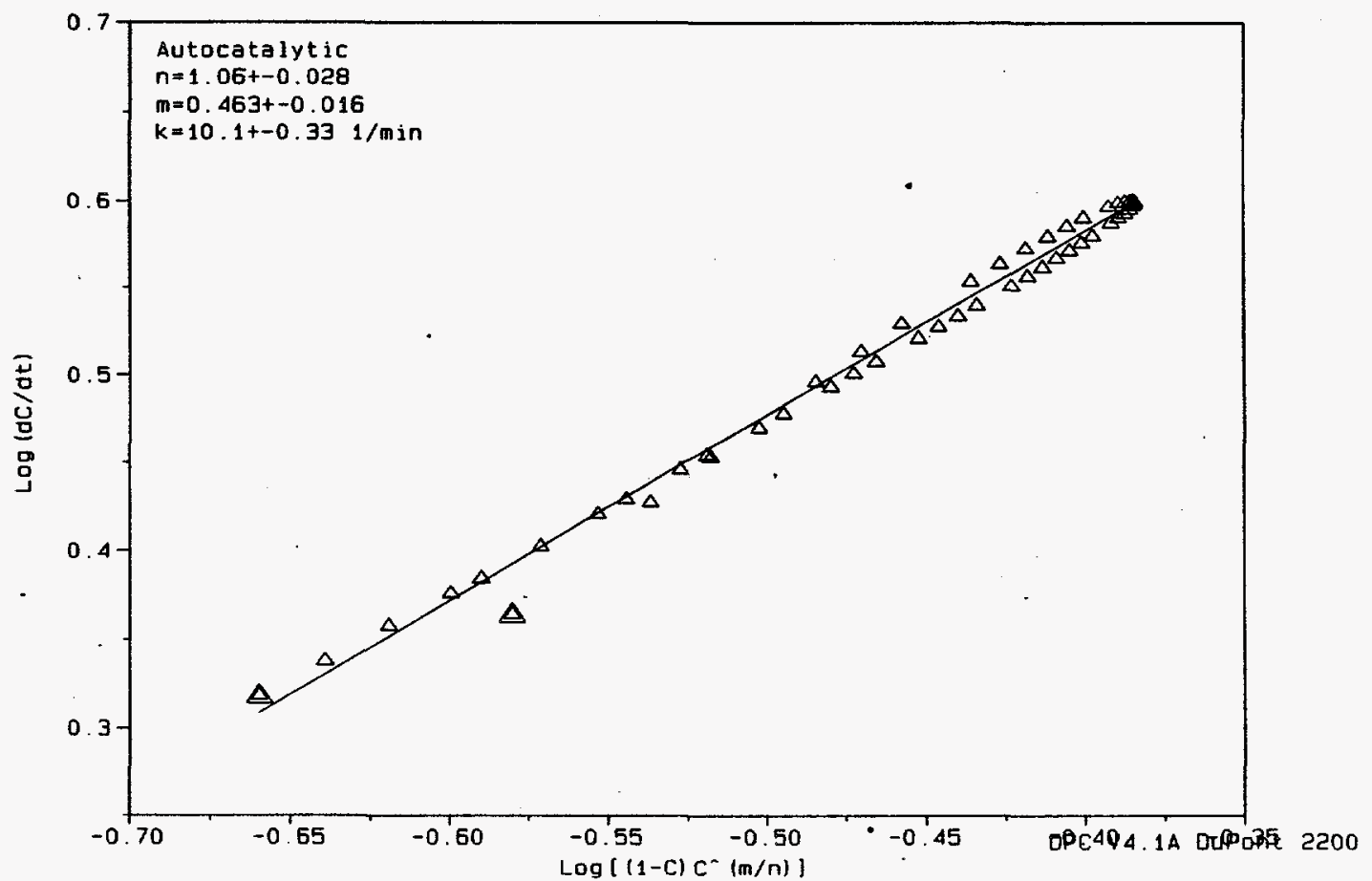

Figure A-4. Closeness of Fit Curve for MS 5096986 White Ink 
Sample: MS5096986 WHITE INK

Size: $10.3400 \mathrm{mg}$

Method: A.T. to $150 \bar{C}$ at $5 \mathrm{C} / \mathrm{min}$

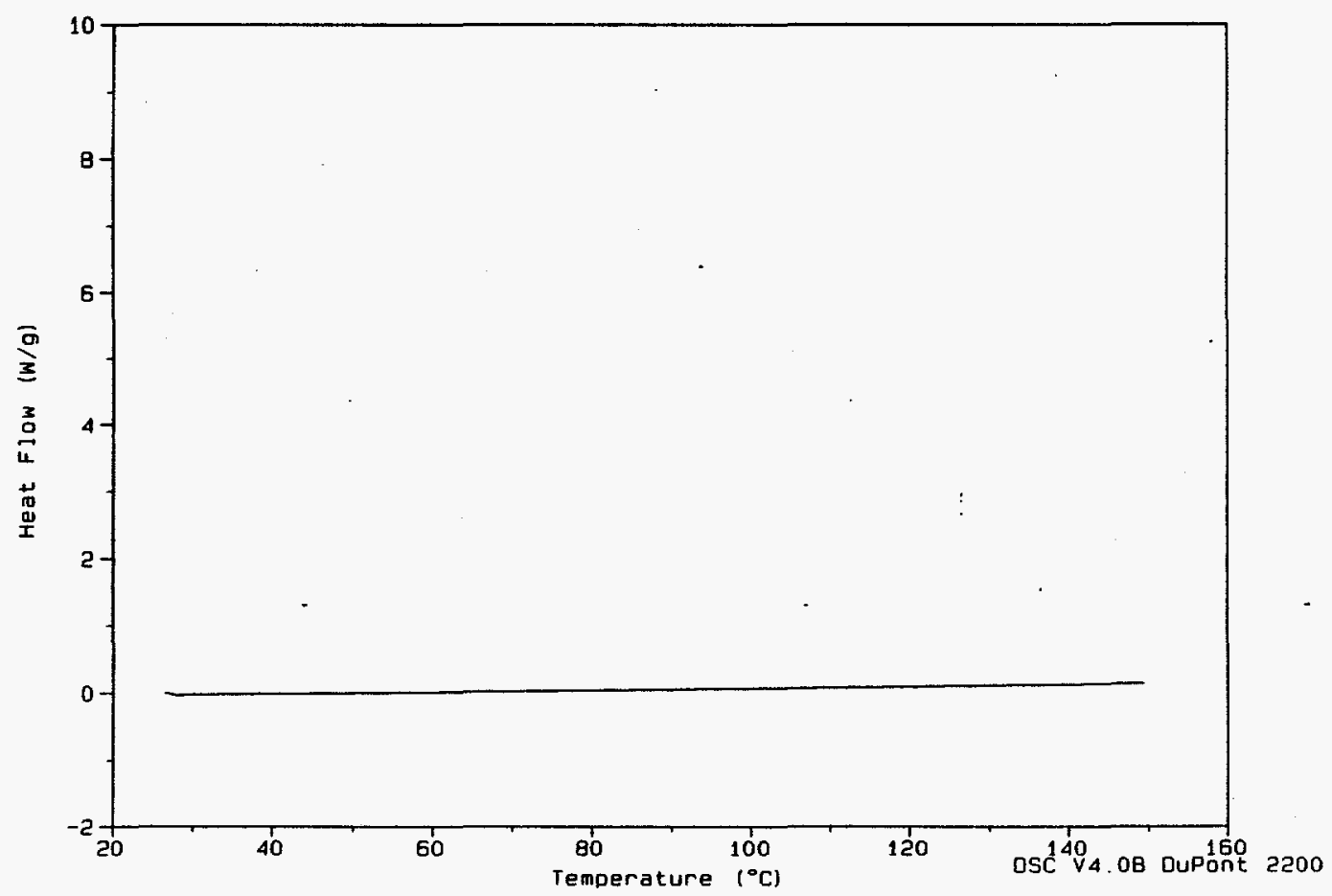

Figure A-5. DSC Curve for MS 5096986 White Ink

Sample: MARKEM 9040 WHITE INK Size: $\quad 1.41 \mathrm{mg}$

Method: OPC

Comment:

File: C: PAAKER. 202

Operator: B> PARKER

Run Date: 12-Nov-92 08: 23

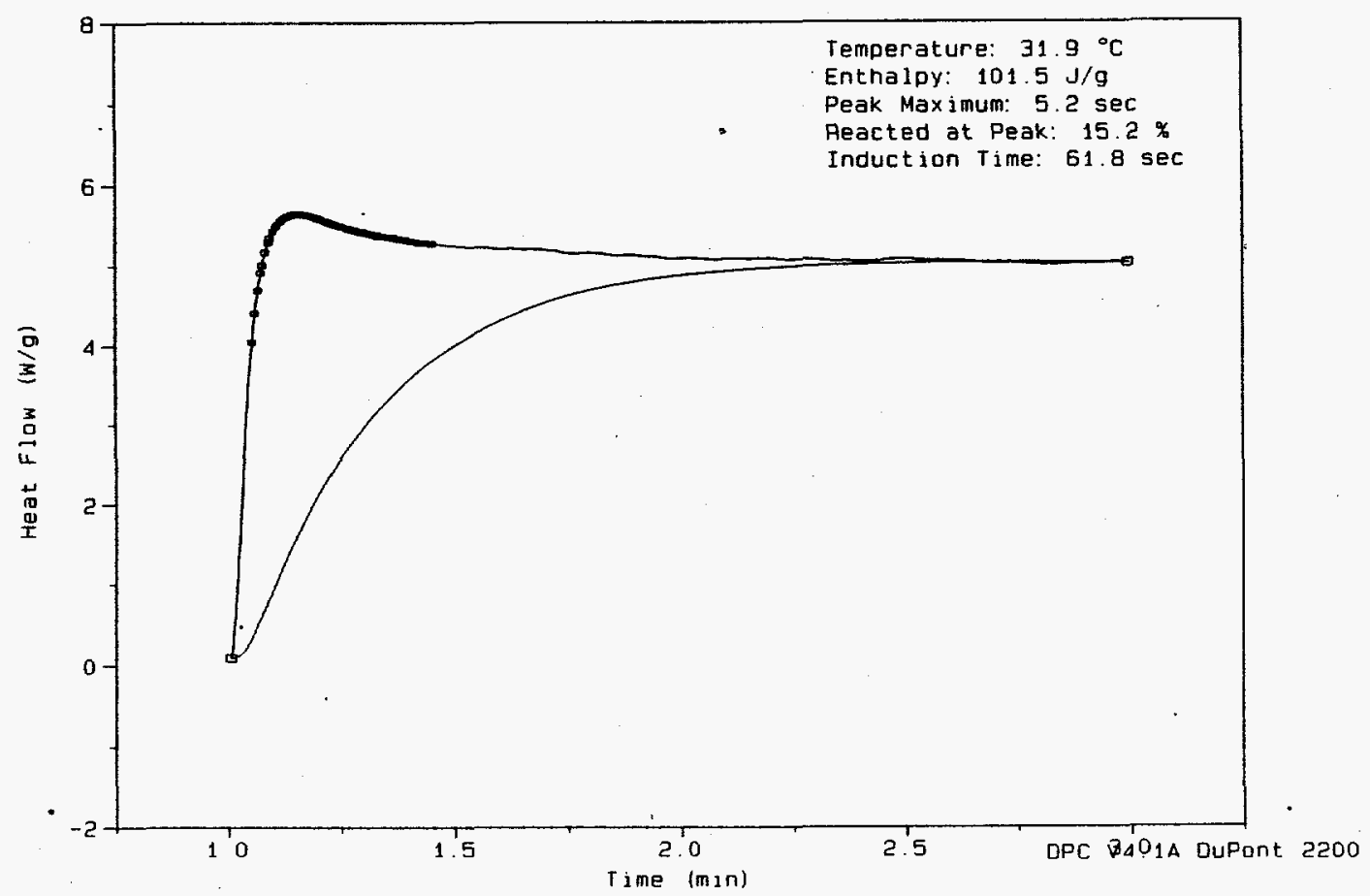

Figure A-6. DPC Curve for Markem 9040 White Ink 
Sample: MARKEM 9040 WHITE INK Size: $1.41 \mathrm{mg}$

Comment:
File: C: PARKER zOZ

Operator: B> PARKEA

Run Date: 12-Nov-92

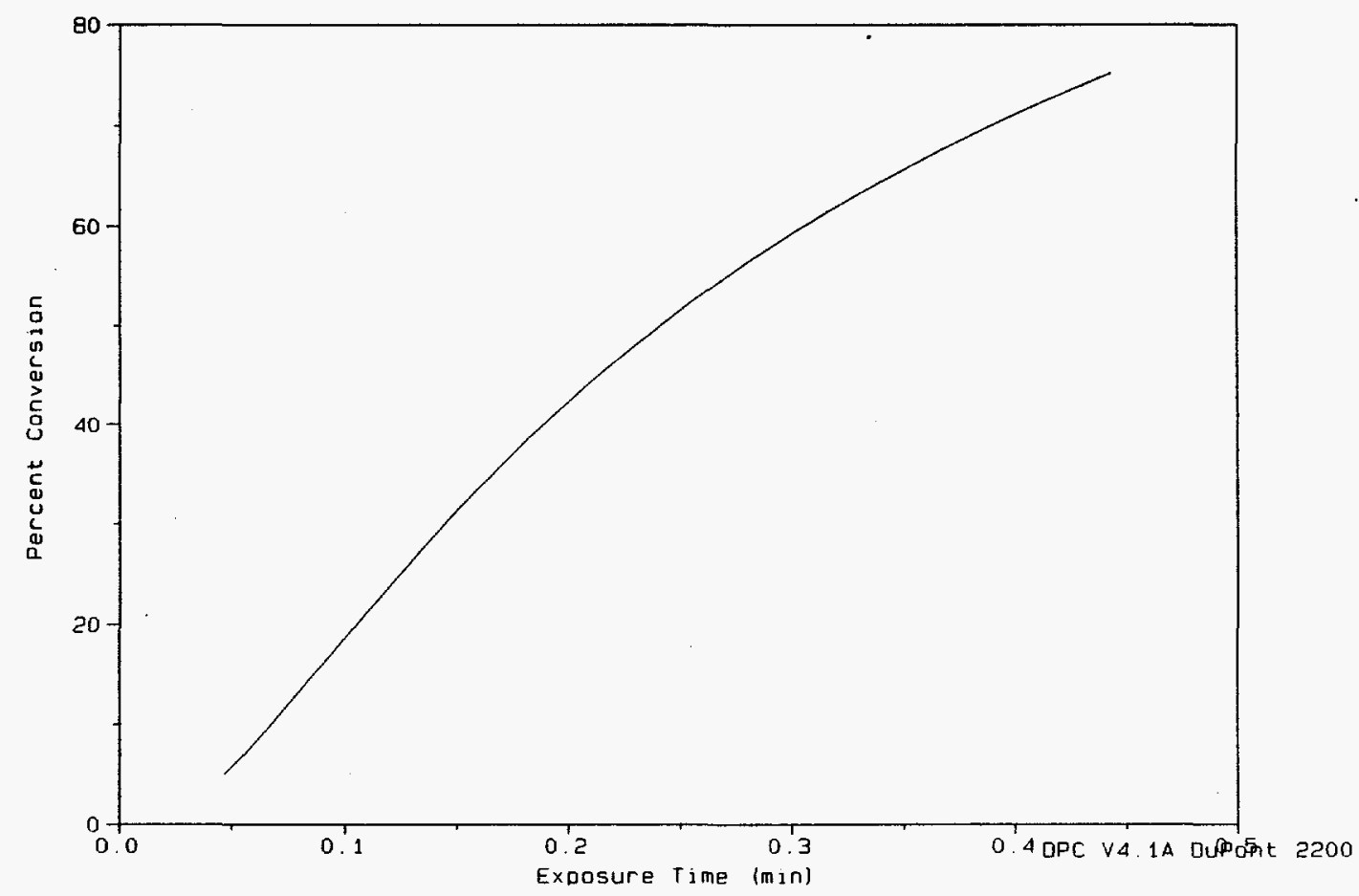

Figure A-7. Cure Rate Versus Exposure Time for Markem 9040 White Ink

DIFFERENTIAL PHOTO CALOAIMETRY KINETICS REPORT

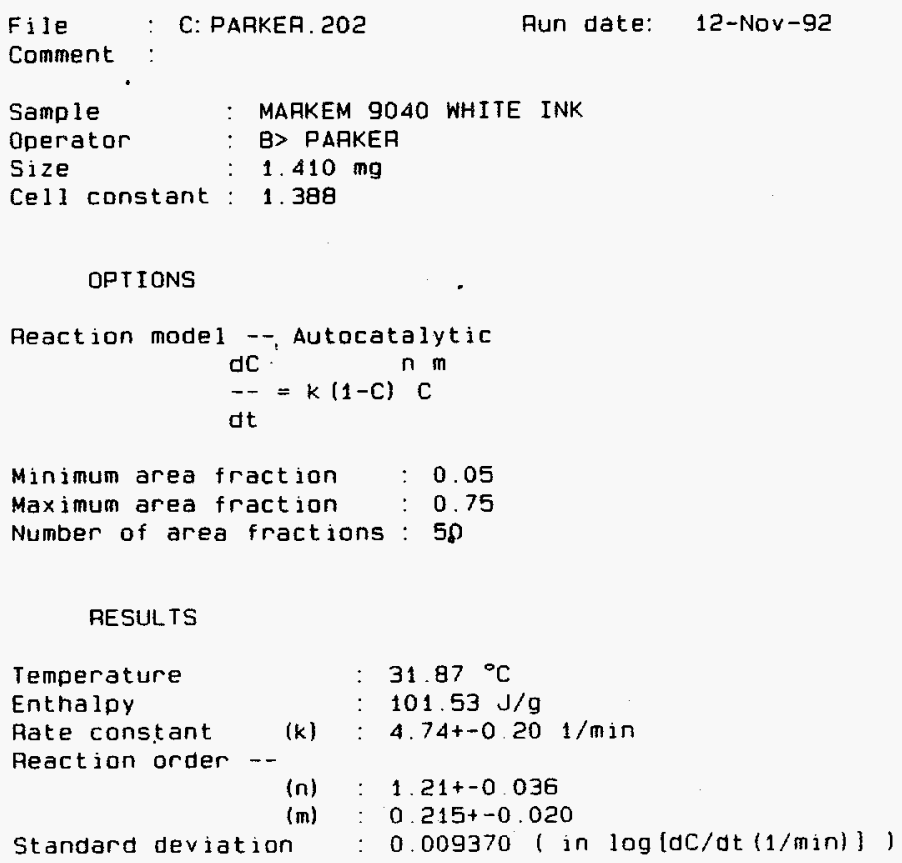

RESULTS

Temperature Enthalpy

Rate constant

Reaction order 
Sample: MARKEM 9040 WHITE INK

Size:

1. $41 \mathrm{mg}$

Comment

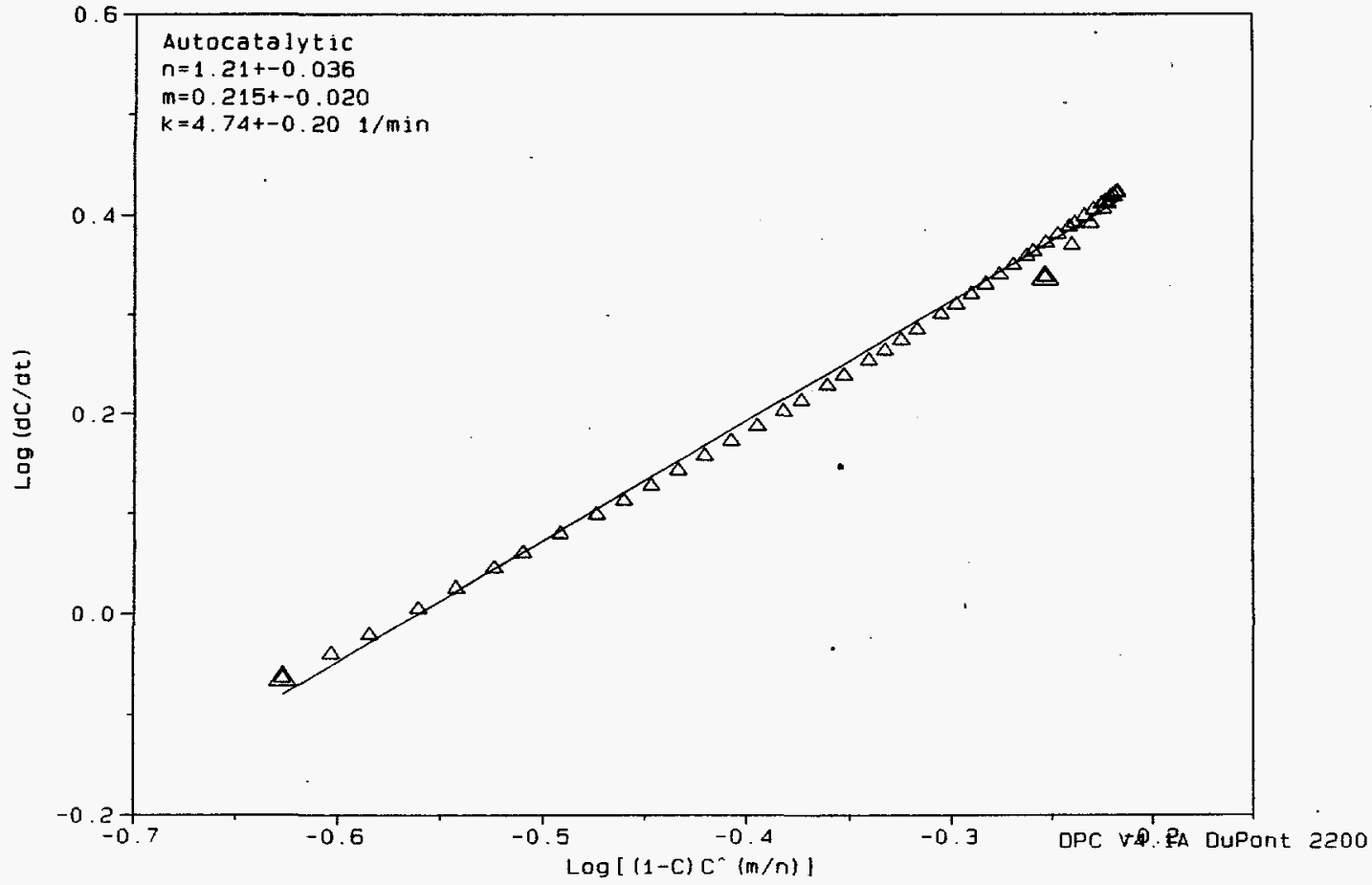

Figure A-9. Closeness of Fit Curve for Markem 9040 White Ink

Sample: MARKEM 9040 WHITE INK

Size: $1.3900 \mathrm{mg}$

Method: A.T to $150 \mathrm{C}$ at $5 \mathrm{C} / \mathrm{min}$.

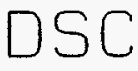

File: C: PARKEA. 205

Operator: B. PARKER

Run Date: 12-Nov-92 15: 03

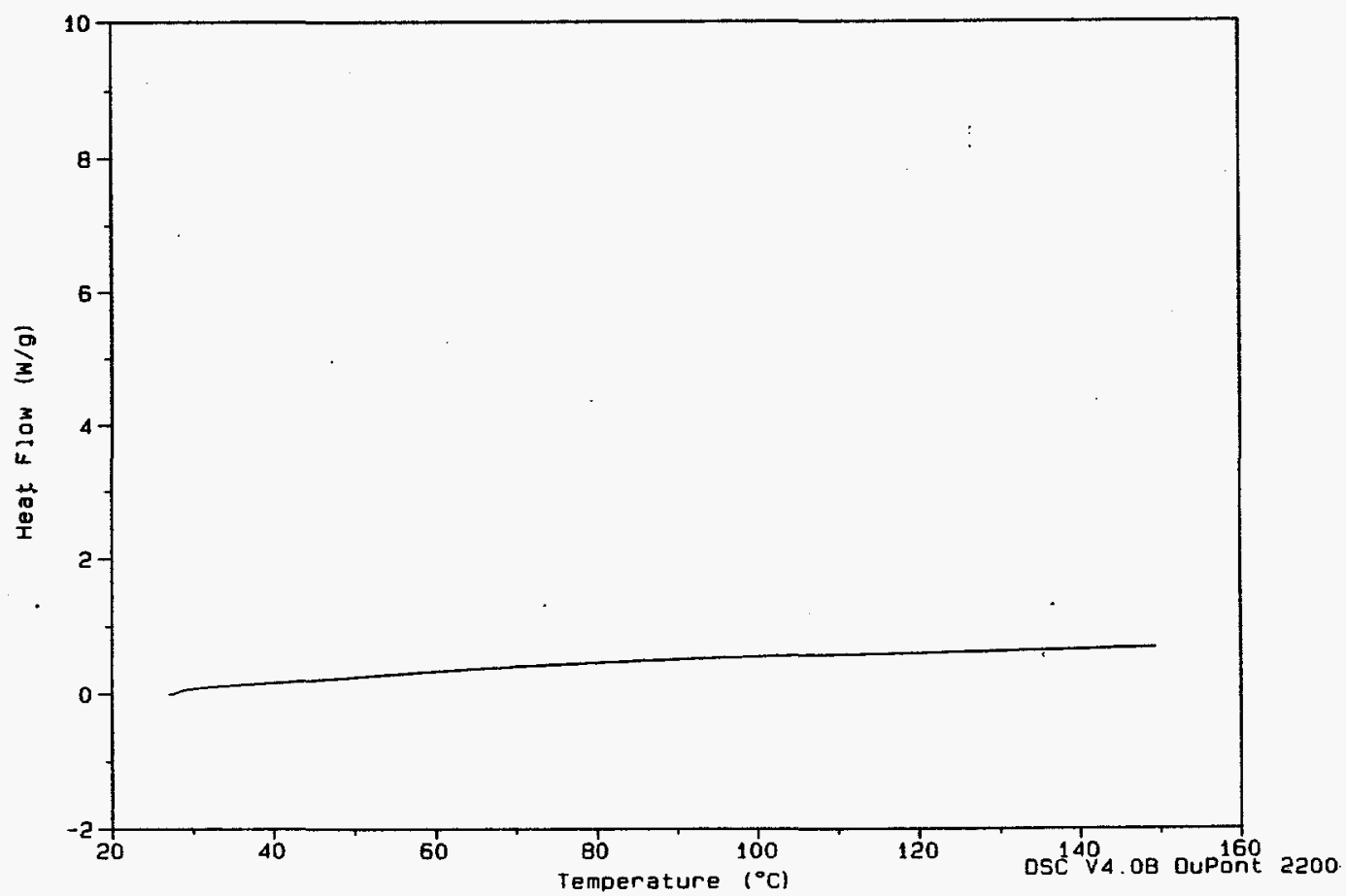

Figure A-10. DSC Curve for Markem 9040 White Ink 
Sample: MARKEM 9060 WHITE INK

Size:

$2.00 \mathrm{mg}$

Method: DPC

Comment:
File: A: PARKEA. 212

Operator: B PARKER

Aun Date: 13-Nov-92 11: 56

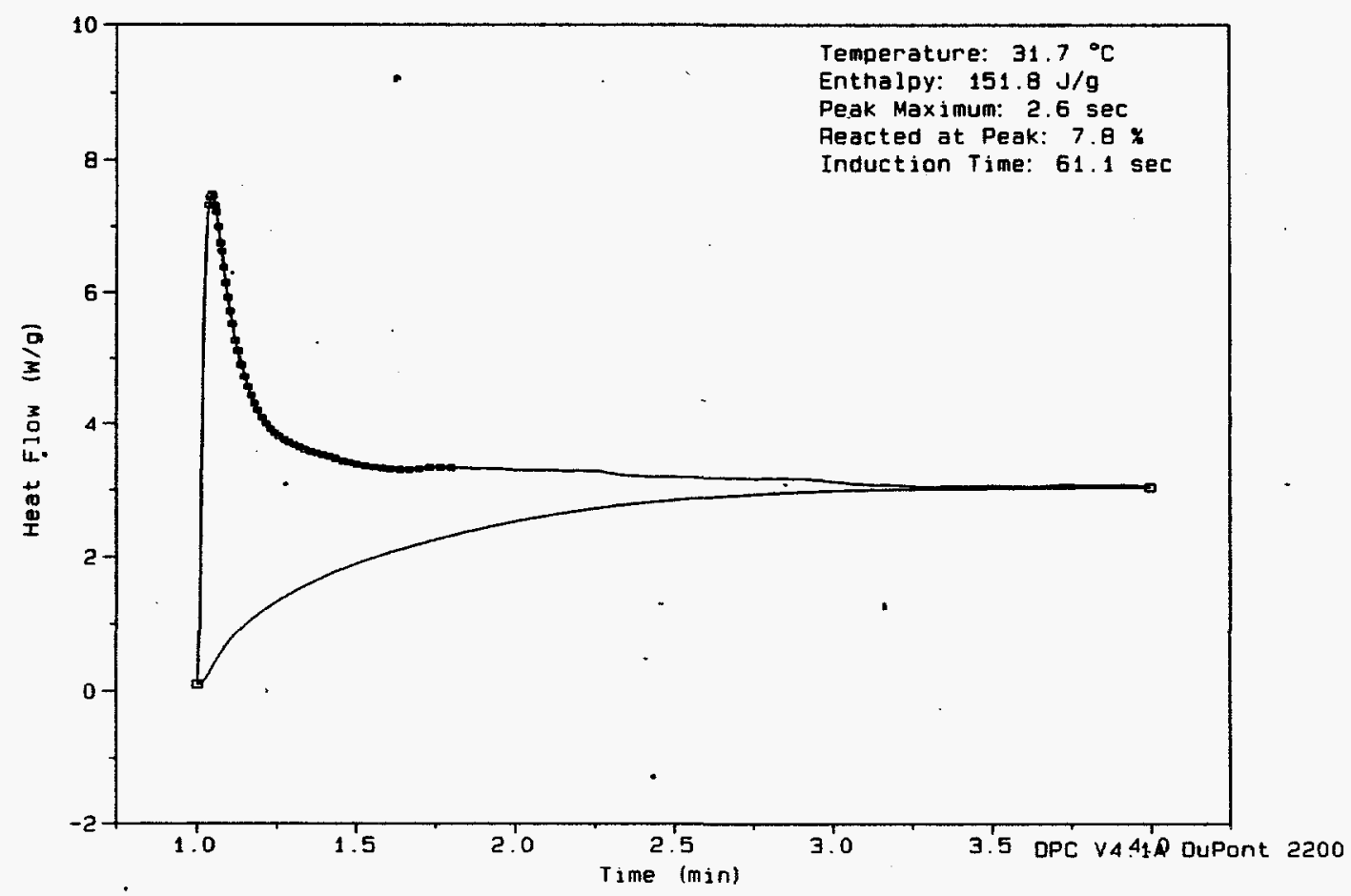

Figure A-11. DPC Curve for Markem 9060 White Ink

Sample: MARKEM 9060 WHITE INK Size: $\quad 2.00 \mathrm{mg}$

Comment
File: A: PARKER. 212

Operator: B. PARKEA

Run Date: 13-Nov-92

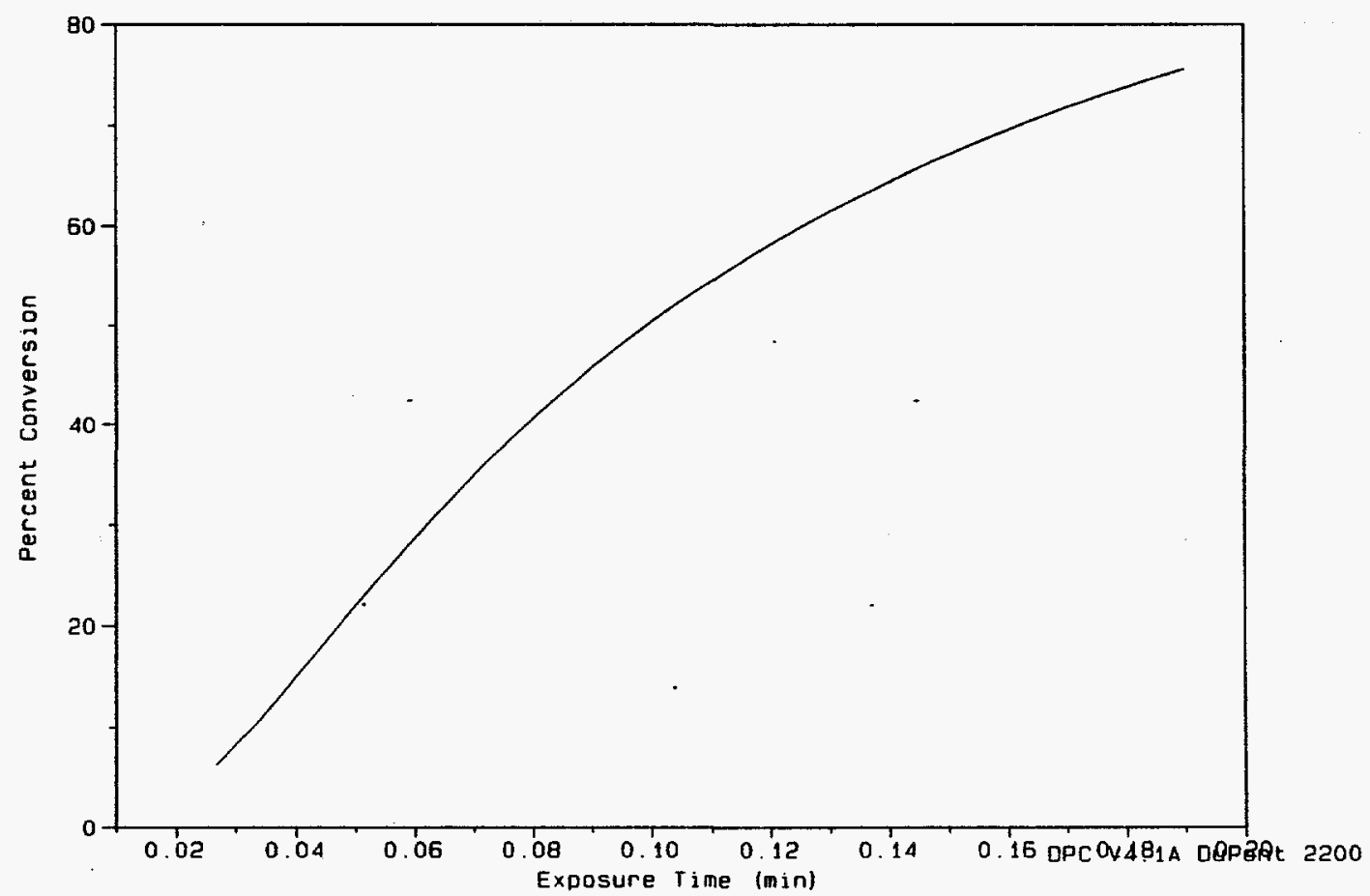

Figure A-12. Cure Rate Versus Exposure Time for Markem 9060 White Ink 
DIFFERENTIAL PHOTO CALORIMETAY KINETICS REPOAT

File

Comment

Sample

Operator

Size

MARKEM 9060 WHITE INK

B. PARKEA

2.000 $\mathrm{mg}$

Cell constant

1. 388

OPTIONS
Reaction model -- Autocatalytic

$$
\text { ac } n(1-c){ }^{n} \mathrm{~m}
$$$$
\text { at }
$$

$\begin{array}{ll}\text { Minimum area fraction }: & 0.06 \\ \text { Maximum area fraction } & 0.76 \\ \text { Number of area fractions : } & 50\end{array}$

RESULTS

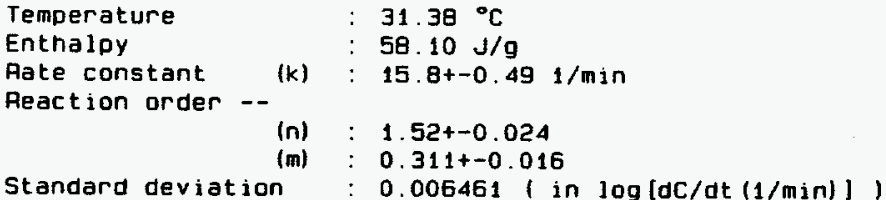

Figure A-13. Kinetics Report for Markem 9060 White Ink
Sample: MARKEM 9060 WHITE INK
File: A: PARKEA, 212
Size: $\quad 2.00 \mathrm{mg}$
Operator: B. PARKEA

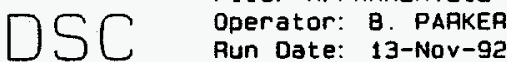

Comment:

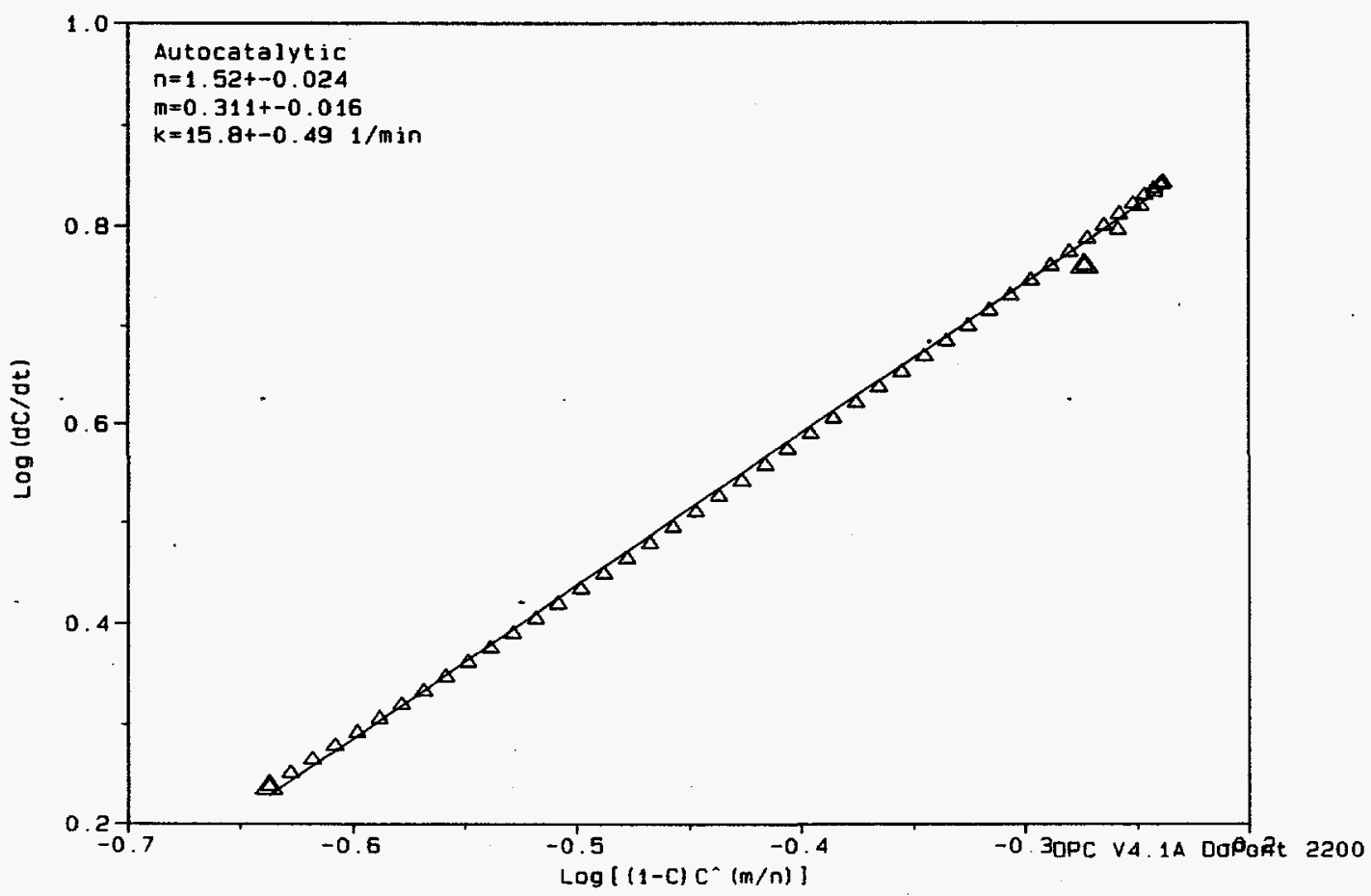

Figure A-14. Closeness of Fit Curve for Markem 9060 White Ink 


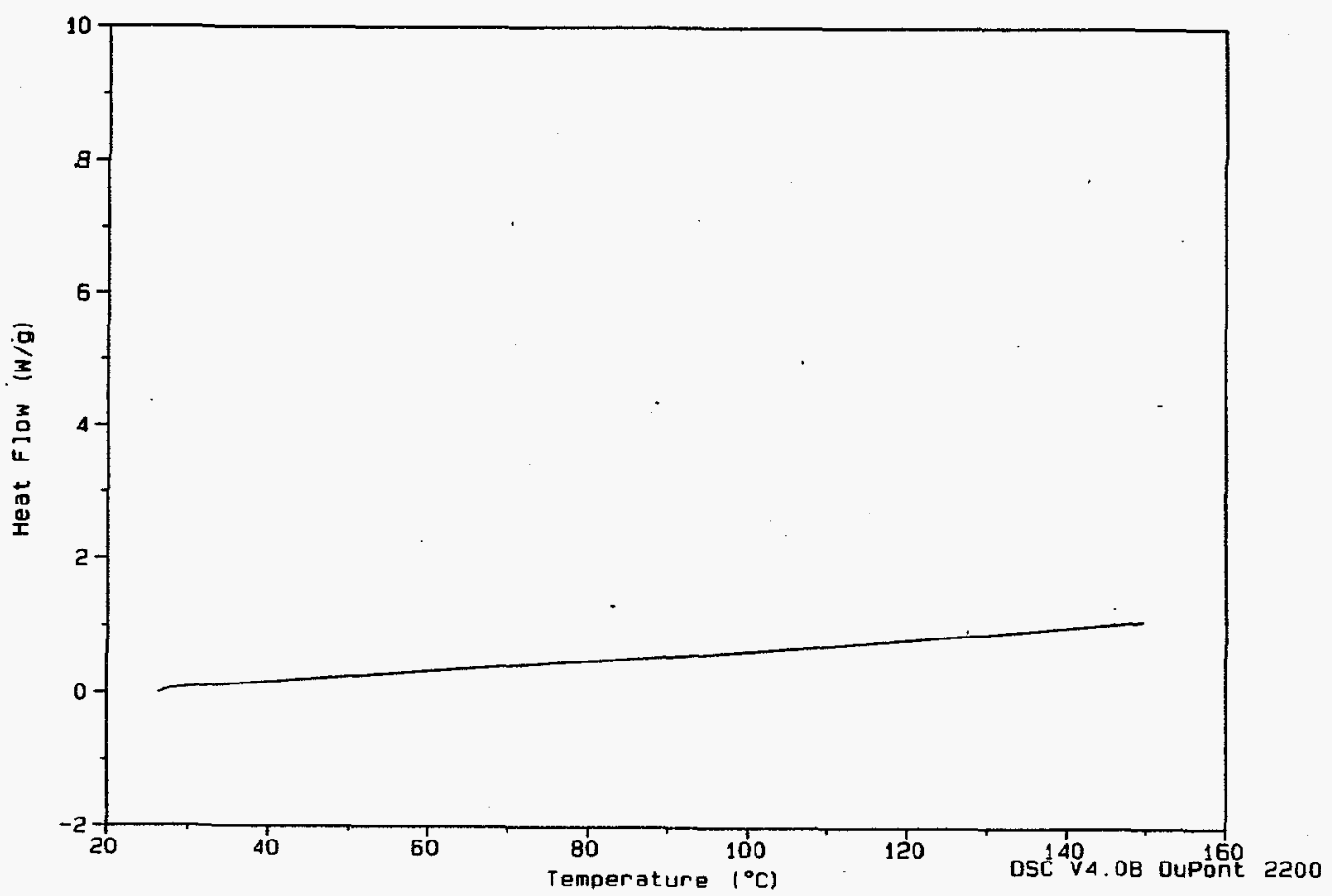

Figure A-15. DSC Curve for Markem 9060 White Ink

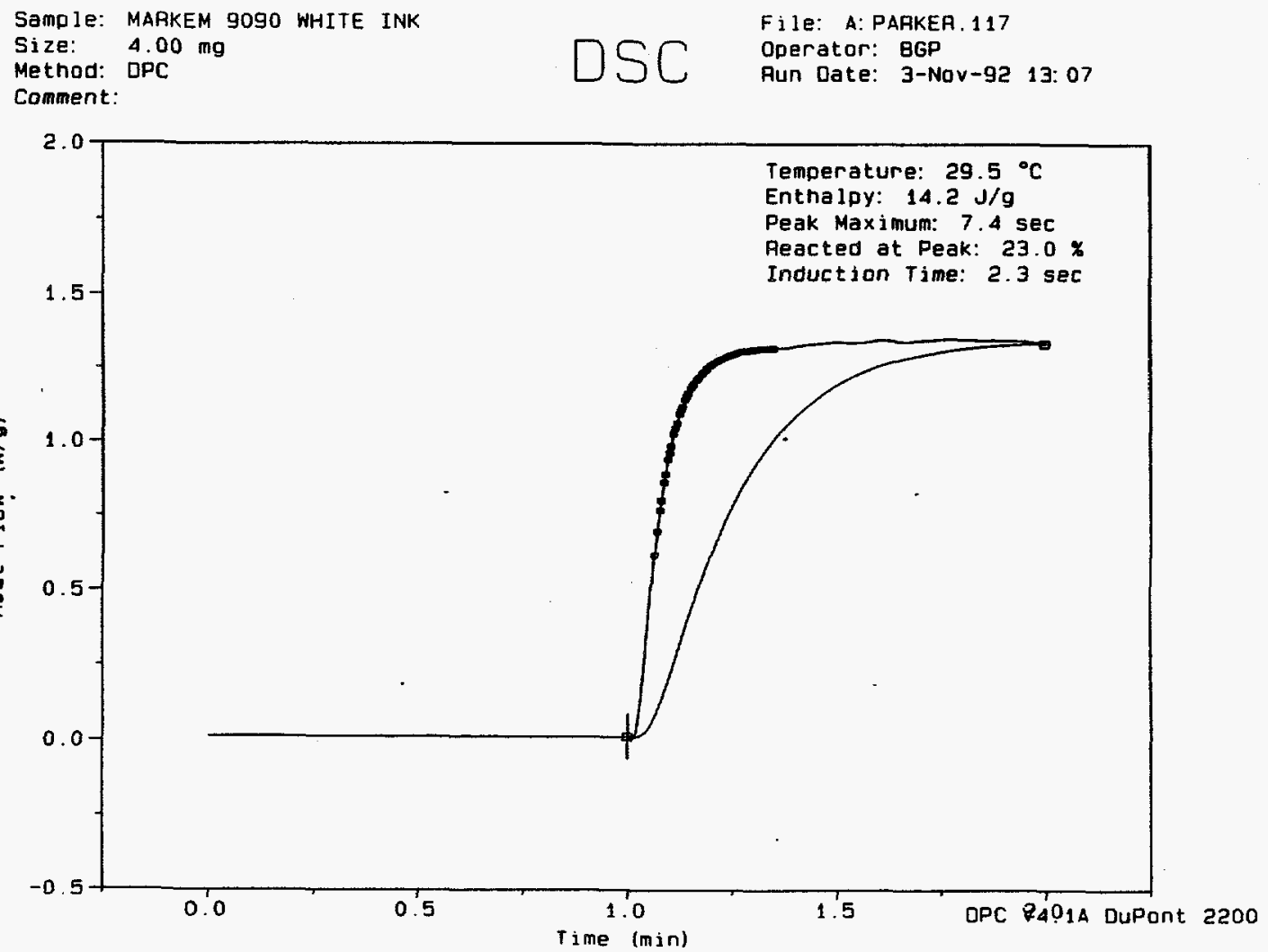

Figure A-16. DPC Curve for Markem 9090 White Ink 
Sample: MARKEM 9090 WHITE INK

Size: $\quad 4.00 \mathrm{mg}$

File: A: PARKER. 117

Comment:

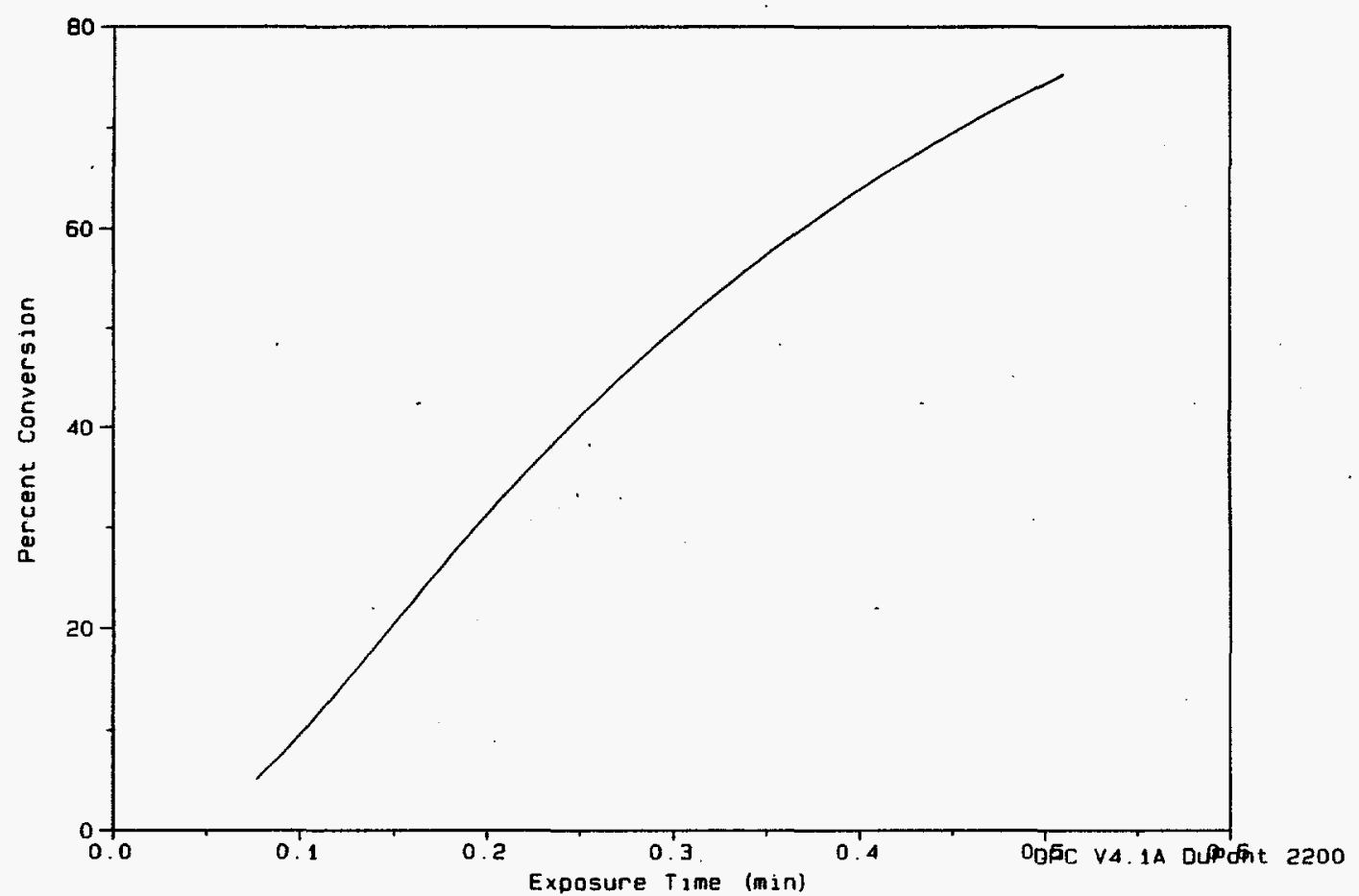

Figure A-17. Cure Rate Versus Exposure Time for Markem 9090 White Ink

DIFFERENTIAL PHOTO CALORIMETRY KINETICS REPORT

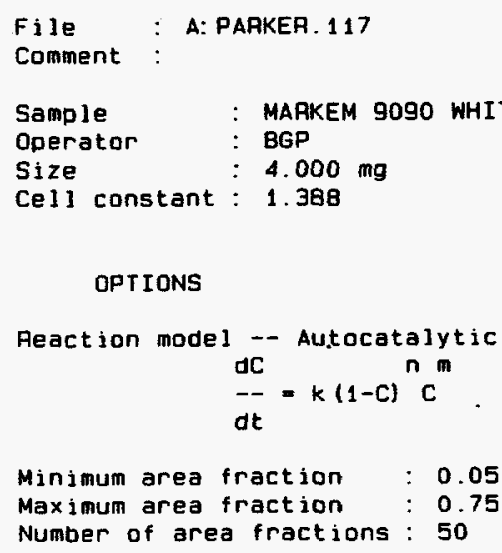

RESULTS

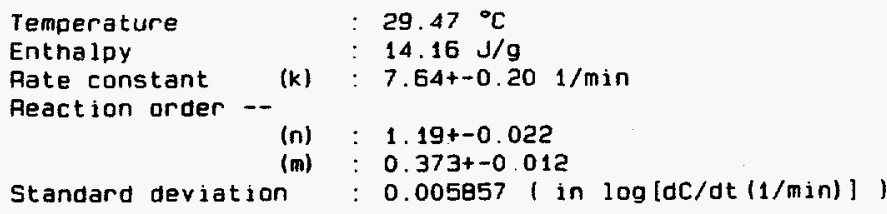

Figure A-18. Kinetics Report for Markem 9090 White Ink 
Sample: MARKEM 9090 WHITE INK Size: $4.00 \mathrm{mg}$

Comment:

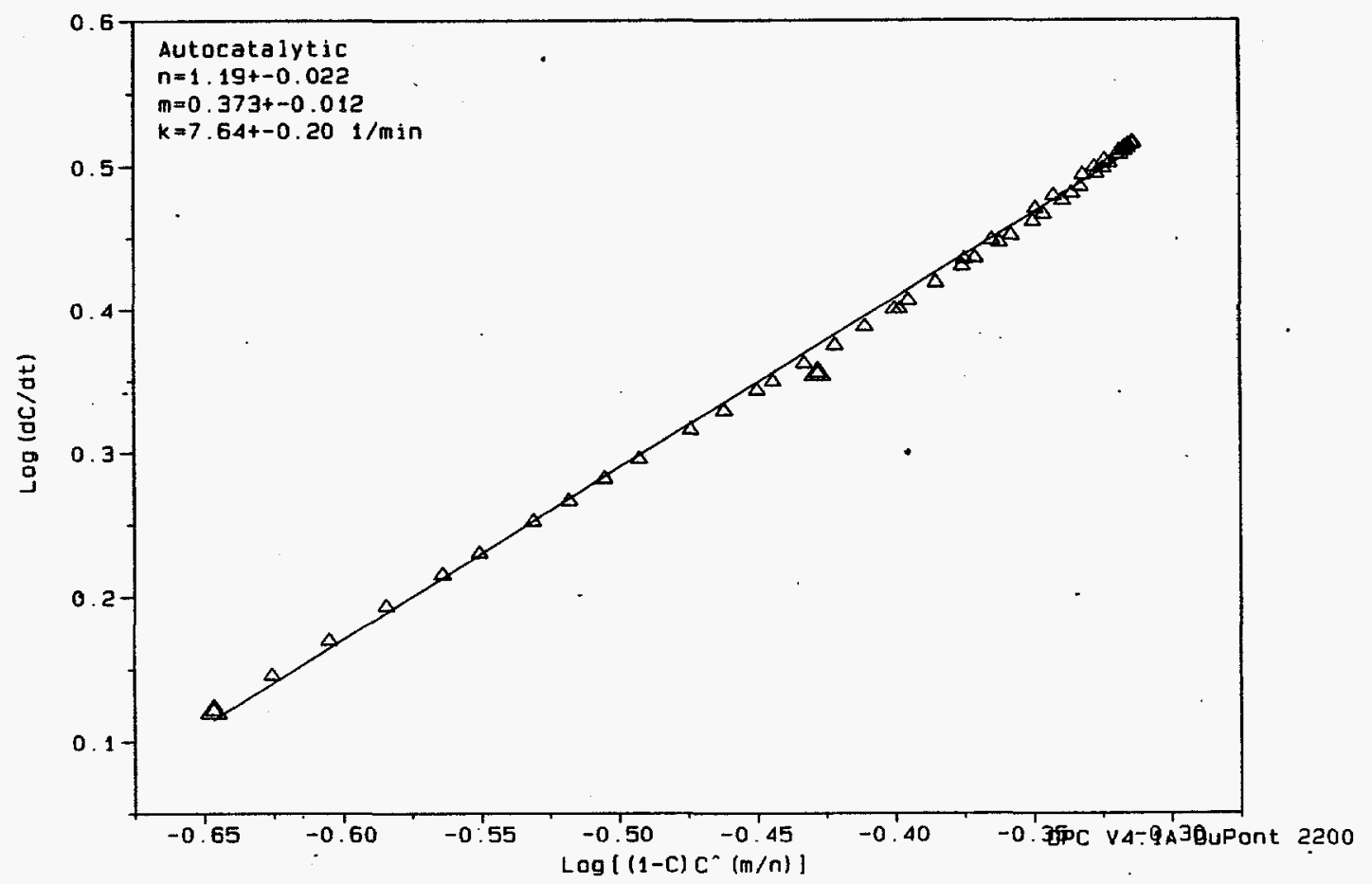

Figure A-19. Closeness of Fit Curve for Markem 9090 White Ink

Sample: MARKEM 9090 WHITE INK Size: $4.0000 \mathrm{mg}$

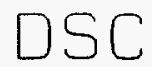

File: A: PAAKER. 119 Operator: BGP Method: A.T. to $150 \mathrm{C}$ at $5 \mathrm{C} / \mathrm{min}$

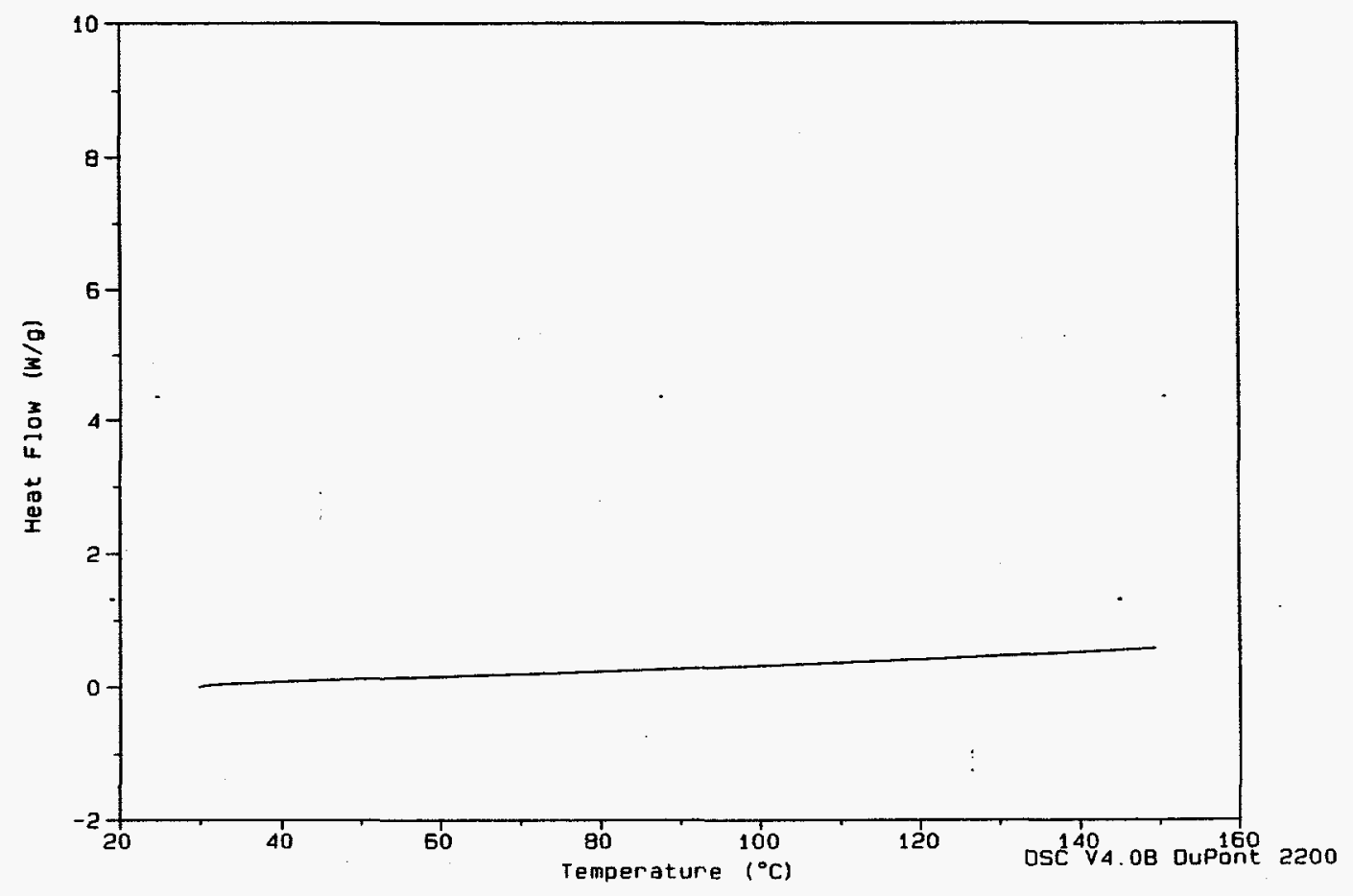

Figure A-20. DSC Curve for Markem 9090 White Ink 


\section{APPENDIX B}

\section{Analysis of UV Curable Optical Adhesives}


Sample: NOALAND OPTICAL AOHESIVE 60 Size: $\quad 7.15 \mathrm{mg}$

Method: DPC

Comment: $5 \mathrm{UL}$

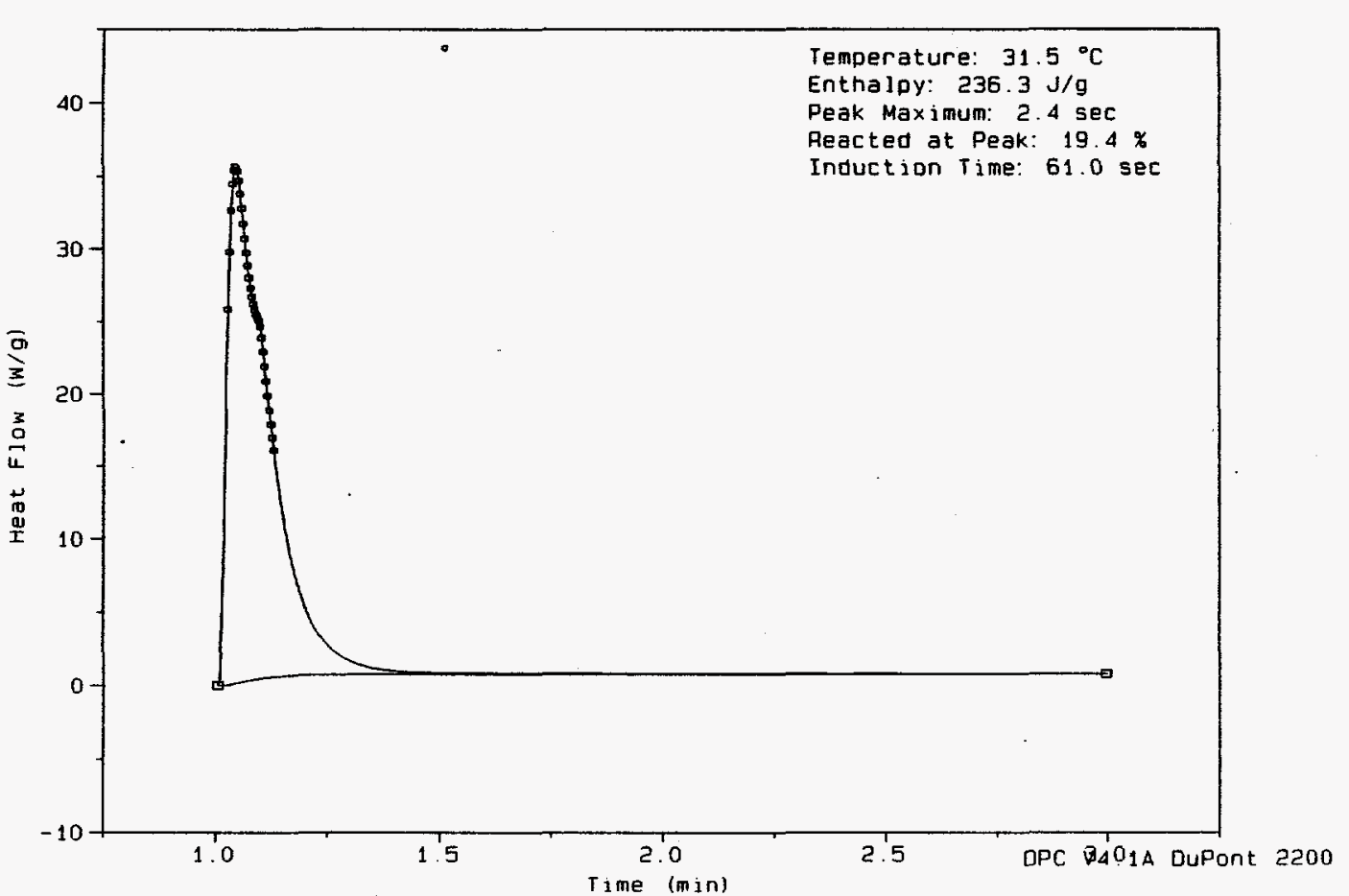

Figure B-1. DPC Curve for $5 \mu \mathrm{L}$ Sample of Norland 60 Optical Adhesive

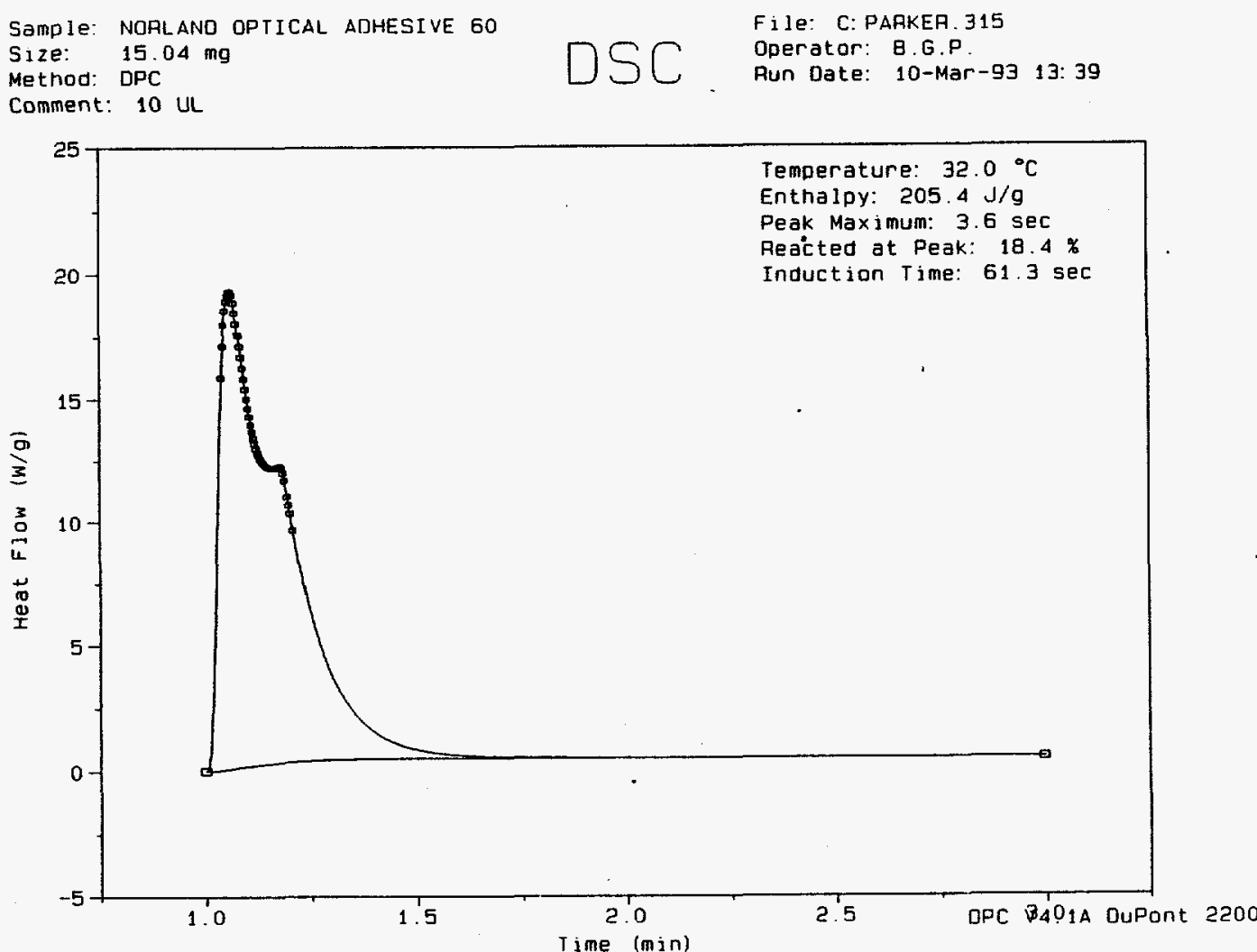

Figure B-2. DPC Curve for $10 \mu \mathrm{L}$ Sample of Norland 60 Optical Adhesive 
Sample: NORLAND OPIICAL ADHESIVE 60 Size: $23.47 \mathrm{mg}$

Method: $\mathrm{OPC}$

Comment:
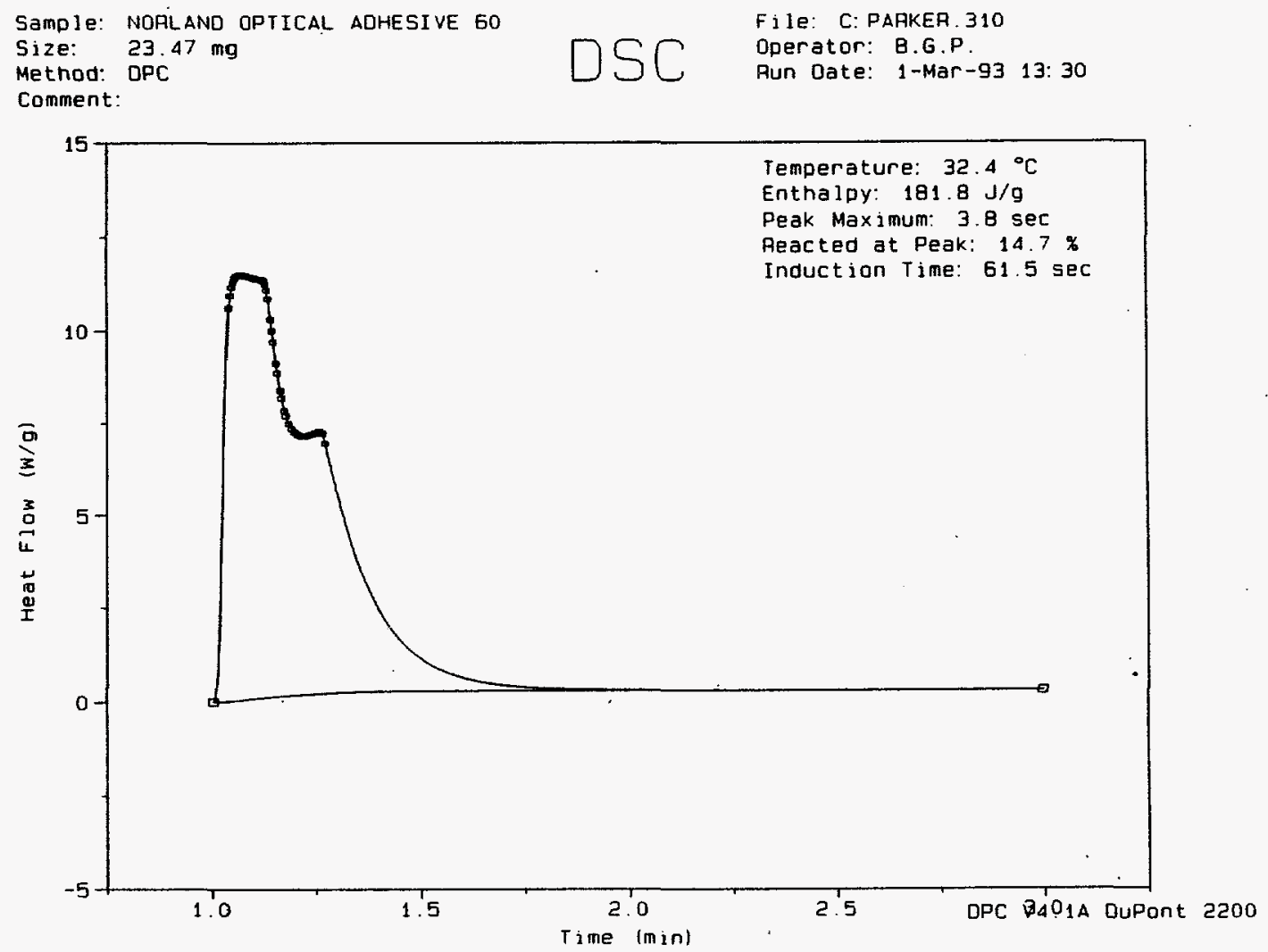

Figure B-3. DPC Curve for $20 \mu \mathrm{L}$ Sample of Norland 60 Optical Adhesive

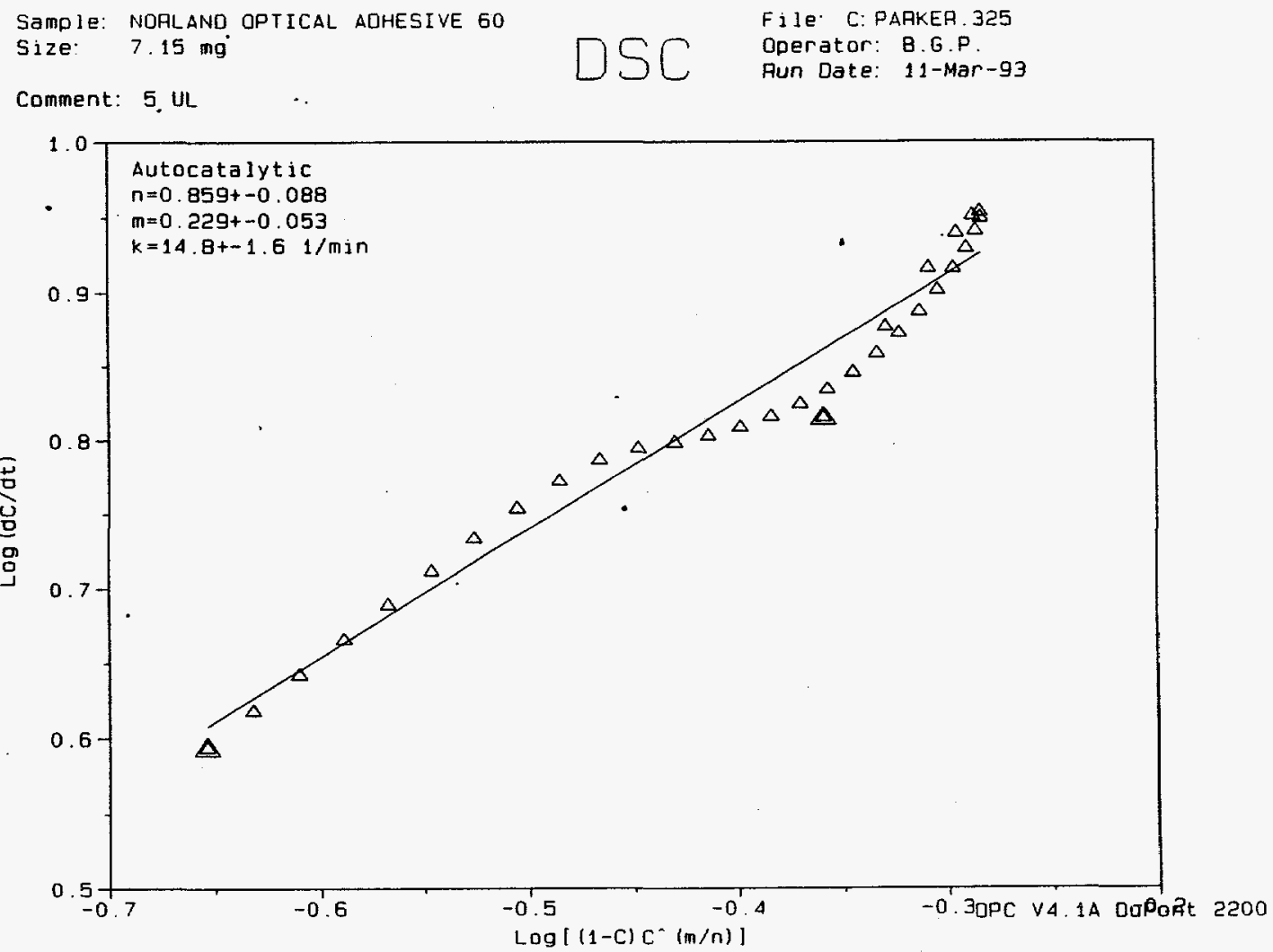

Figure B-4. Closeness of Fit Curve for $5 \mu \mathrm{L}$ Sample of Norland 60 Optical Adhesive 
Sample: NOALAND OPTICAL ADHESIVE 60

Size: $\quad 15.04 \mathrm{mg}$

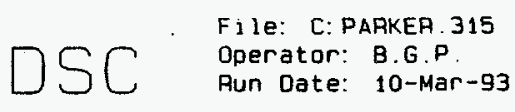

Comment: $10 \mathrm{UL}$

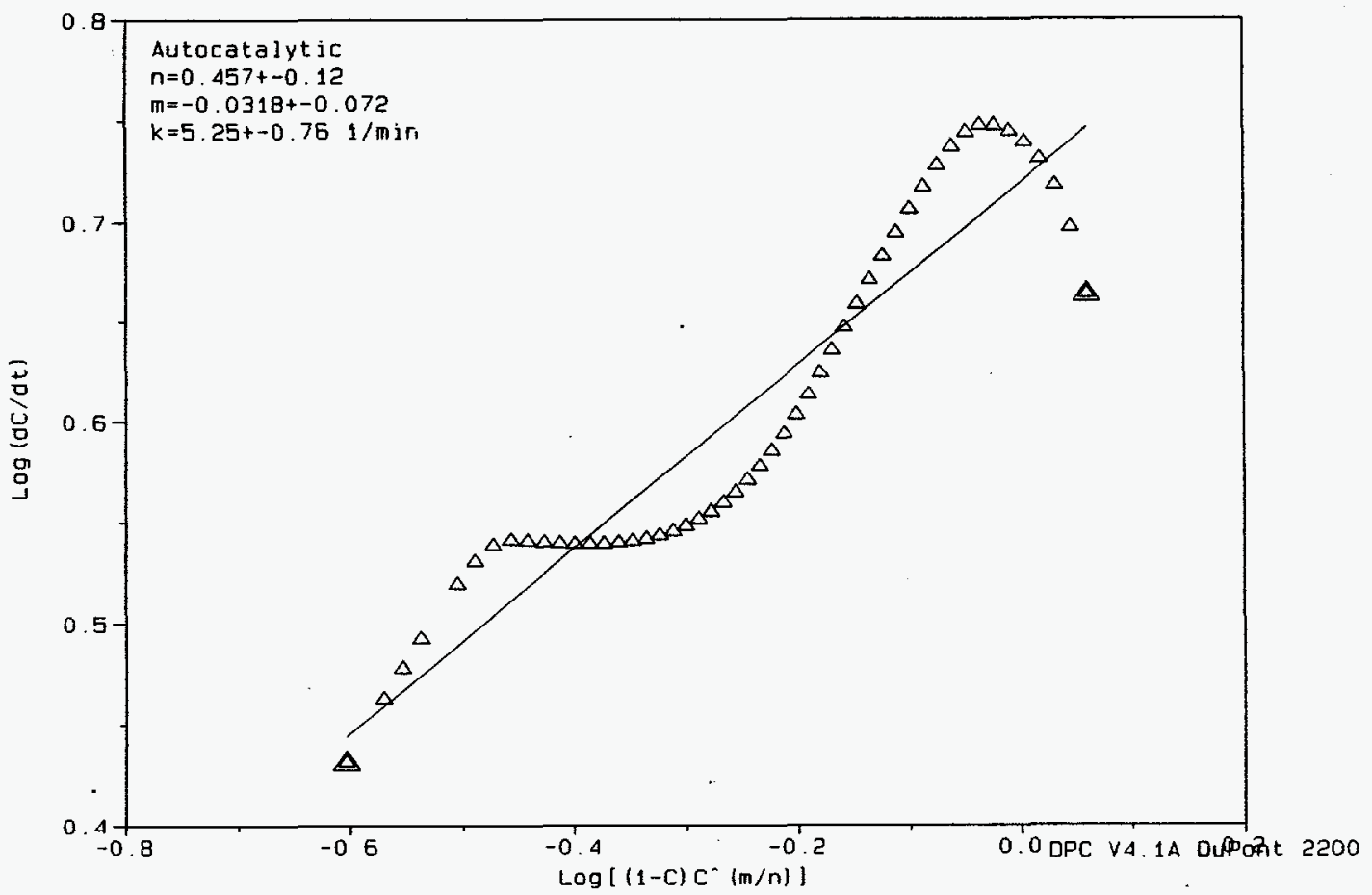

Figure B-5. Closeness of Fit Curve for $10 \mu \mathrm{L}$ Sample of Norland 60 Optical Adhesive

Sample: NORLAND OPTICAL ADHESIVE 60 Size: $23.47 \mathrm{mg}$

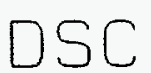

File: C: PARKER. 310

Operator: B.G.P.

Comment

Run Date: 1-Mar-93

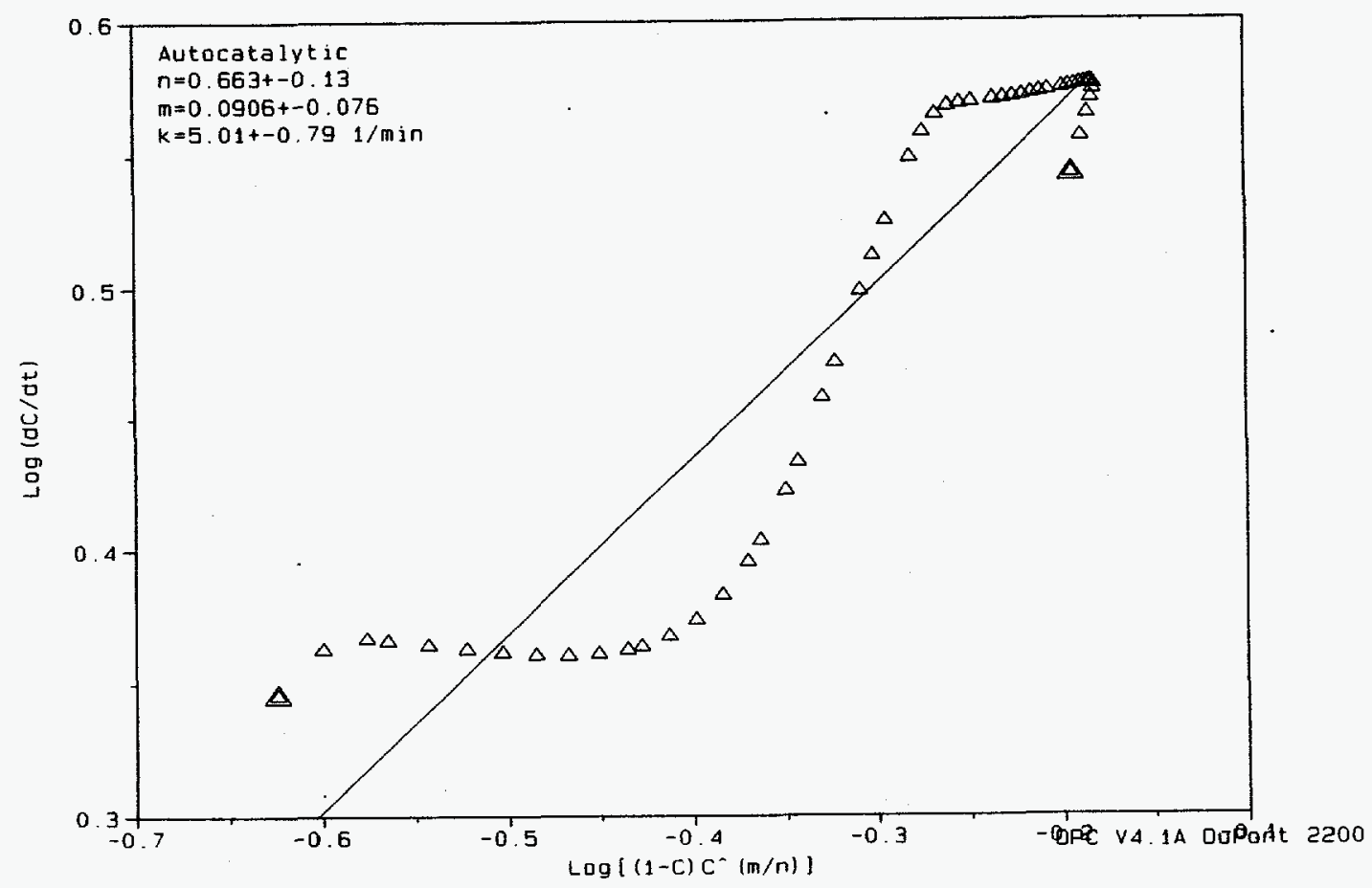

Figure B-6. Closeness of Fit Curve for $20 \mu \mathrm{L}$ Sample of Norland 60 Optical Adhesive 
DIFFERENTIAL PHOTO CALORIMETAY KINETICS REPOAT

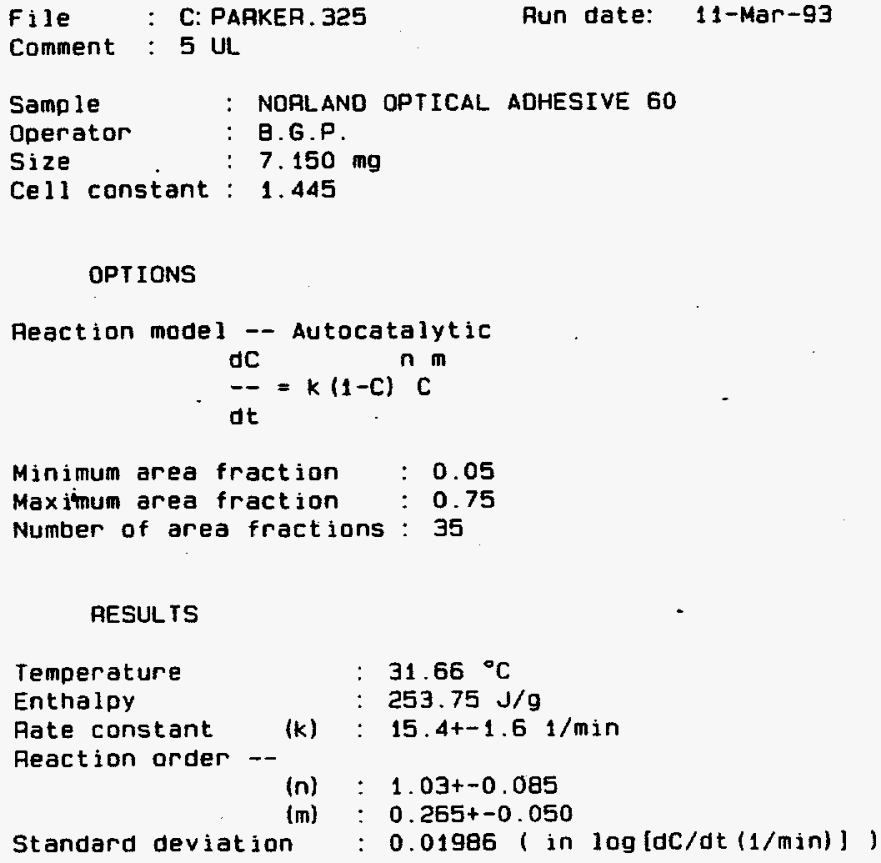

AESULTS

Temperature

Enthalpy

$31.66^{\circ} \mathrm{C}$

Rate constant

Peaction order

Figure B-7. Kinetics Report for $5 \mu \mathrm{L}$ Sample of Norland 60 Optical Adhesive

Sample: NOALAND OPTICAL ADHESIVE 60 Size: $\quad 7.15 \mathrm{mg}$

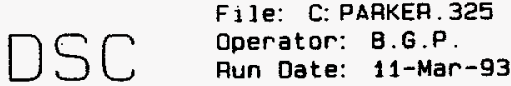

Comment: 5 UL

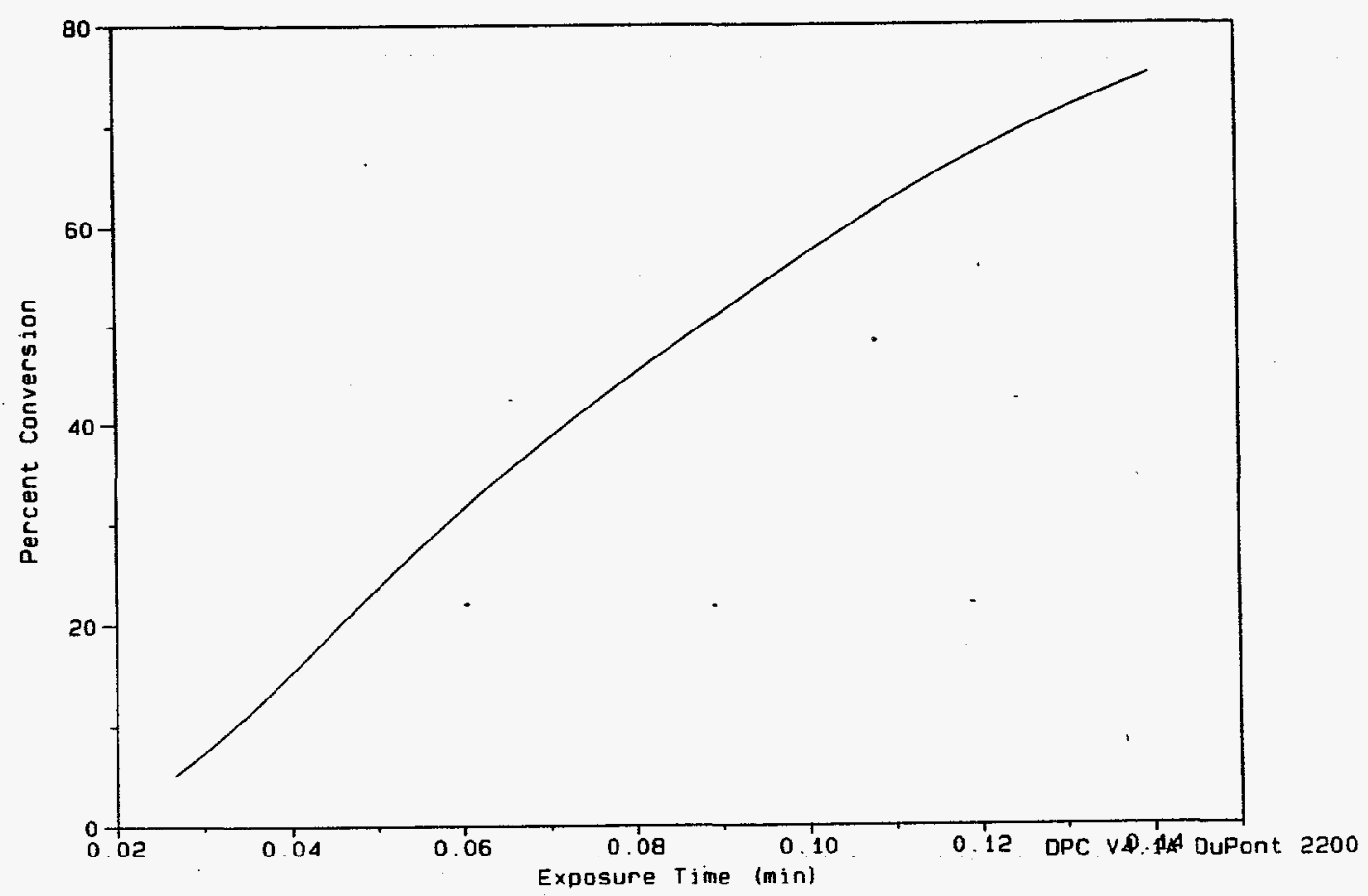

Figure B-8. Cure Rate Versus Exposure Time for $5 \mu \mathrm{L}$ Sample of Norland 60 Optical Adhesive 
Sample: NORLAND OPTICAL ADHESIVE 60 Size: $7.1500 \mathrm{mg}$

Method: R.T. to $300 \mathrm{C}$ at $10 \mathrm{C} / \mathrm{min}$

Comment: 5 UL $\square S C \quad \begin{aligned} & \text { File: C: PAAKER.327 } \\ & \text { Operator: B.G.P. }\end{aligned}$

Fun Date: 11-Mar-93 12: 52

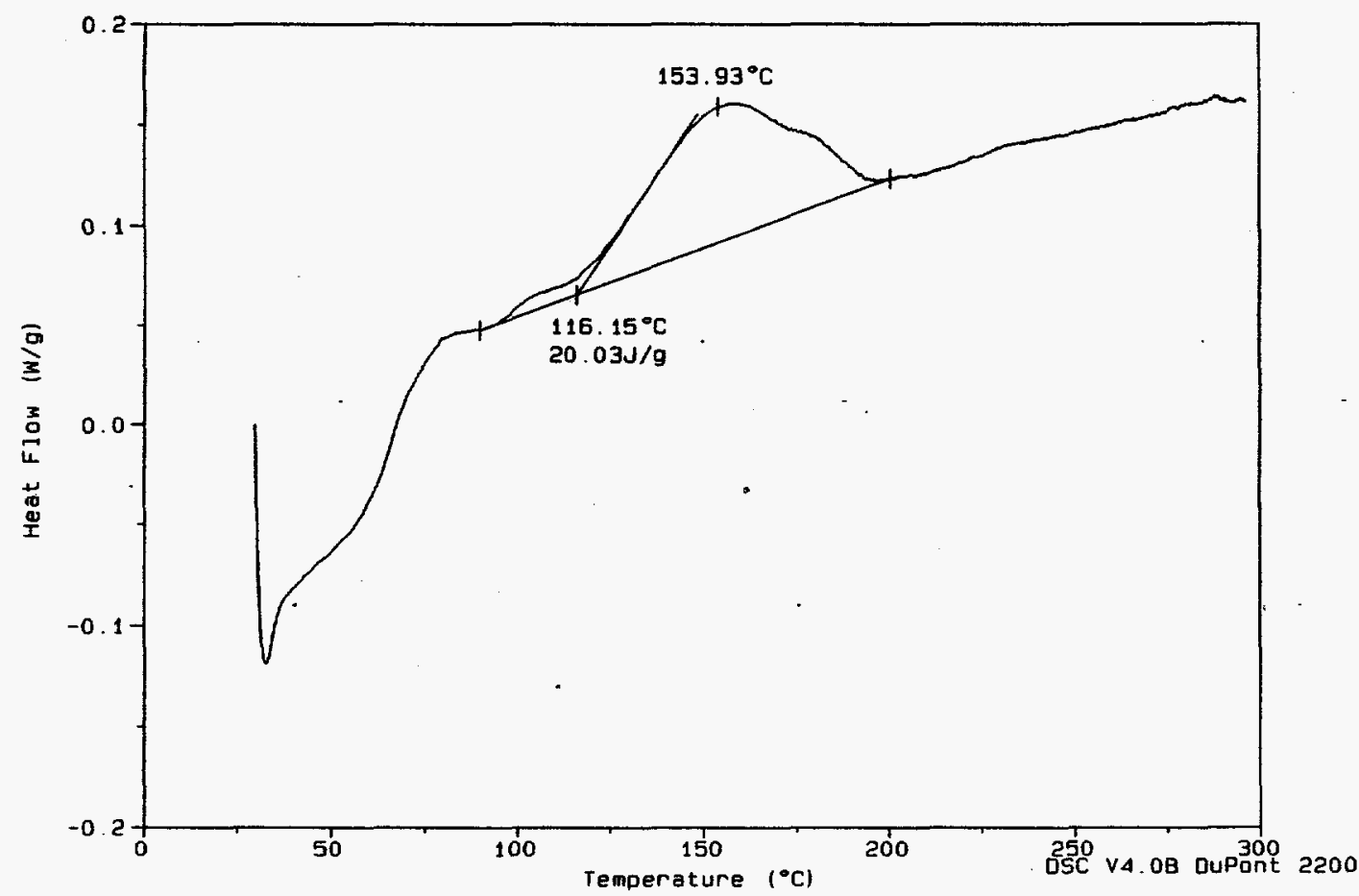

Figure B-9. DSC Curve for UV Cured $5 \mu \mathrm{L}$ Sample of Norland 60 Optical Adhesive

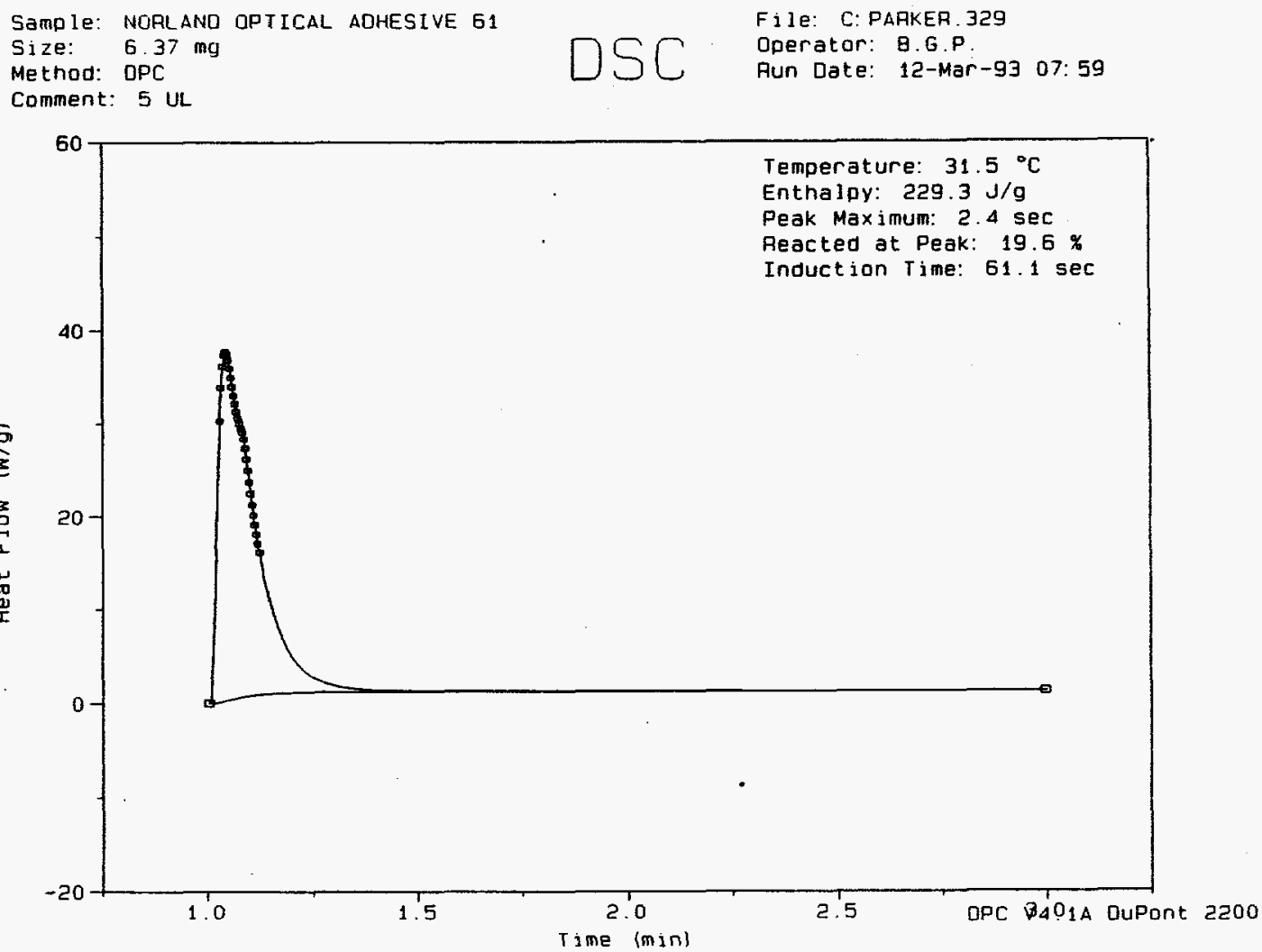

Figure B-10. DPC Curve for $5 \mu \mathrm{L}$ Sample of Norland 61 Optical Adhesive 
Sample: NURLANU OPTICAL ADHESIVE 61

Size: $12.34 \mathrm{mg}$

Method: $D P C$

Comment: $10 \mathrm{UL}$
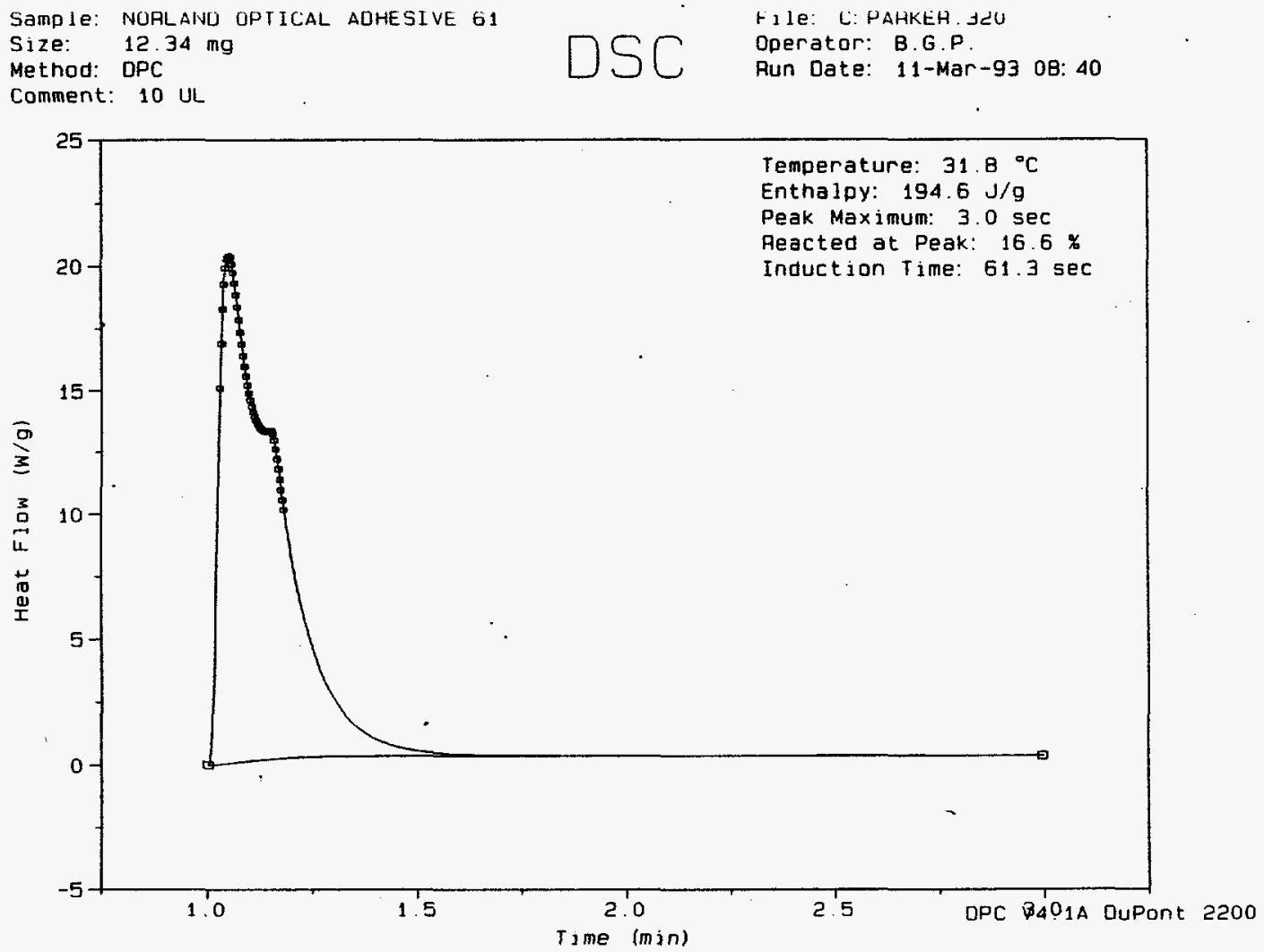

Figure B-11. DPC Curve for $10 \mu \mathrm{L}$ Sample of Norland 61 Optical Adhesive

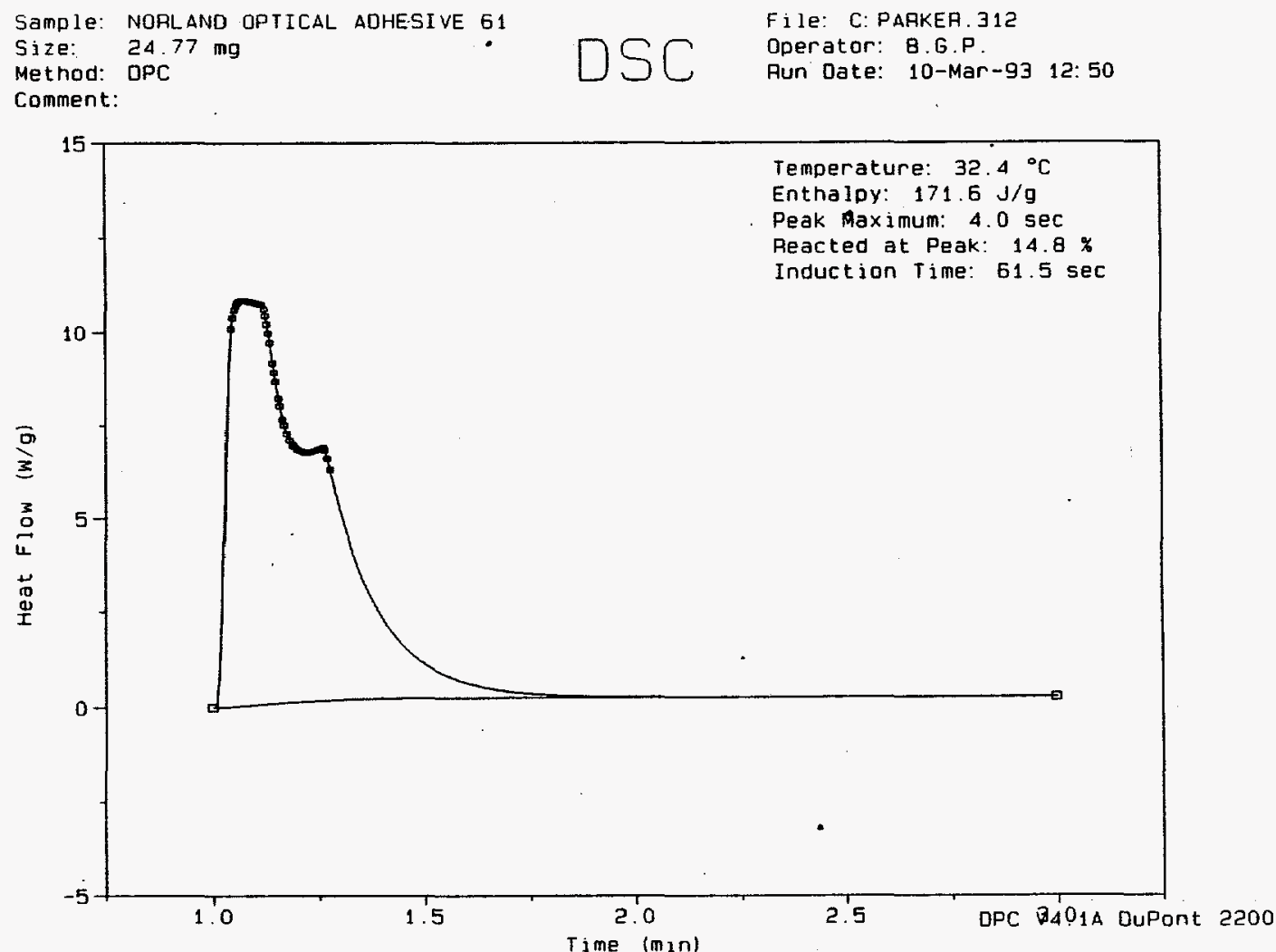

Figure B-12. DPC Curve for $20 \mu \mathrm{L}$ Sample of Norland 61 Optical Adhesive 
Sample: NORLAND OPIICAL ADHESIVE 61 Size: $\quad 6.37 \mathrm{mg}$

Comment: 5 UL
FIIE: L: HAHKEH. JLY

Operator: B.G.P.

Run Date: 12-Mar-93

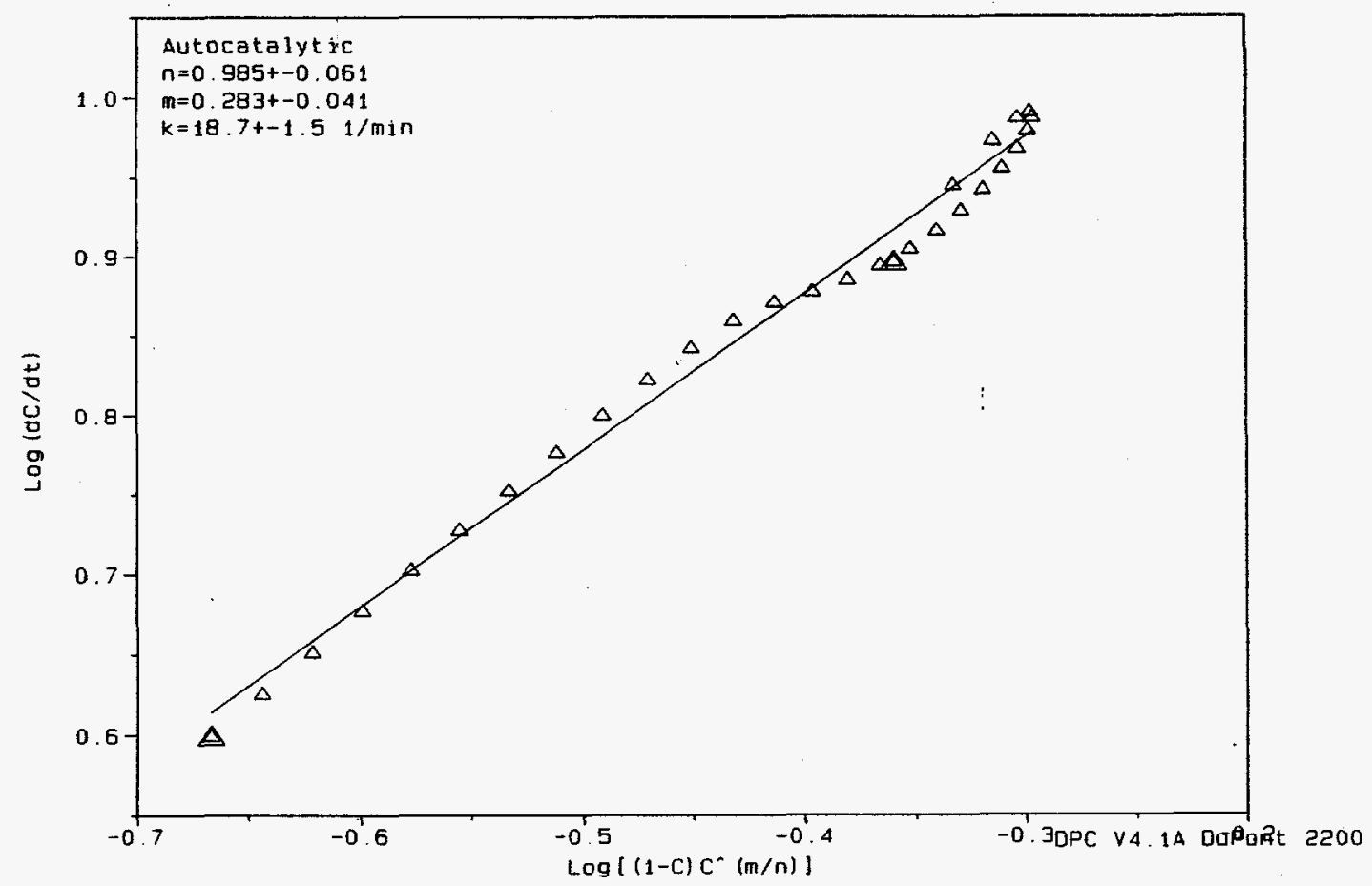

Figure B-13. Closeness of Fit Curve for $5 \mu \mathrm{L}$ Sample of Norland 61 Optical Adhesive

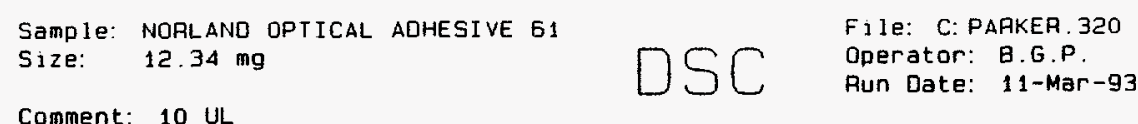

Comment: 10 UL

Run Date: 11-Mar-93

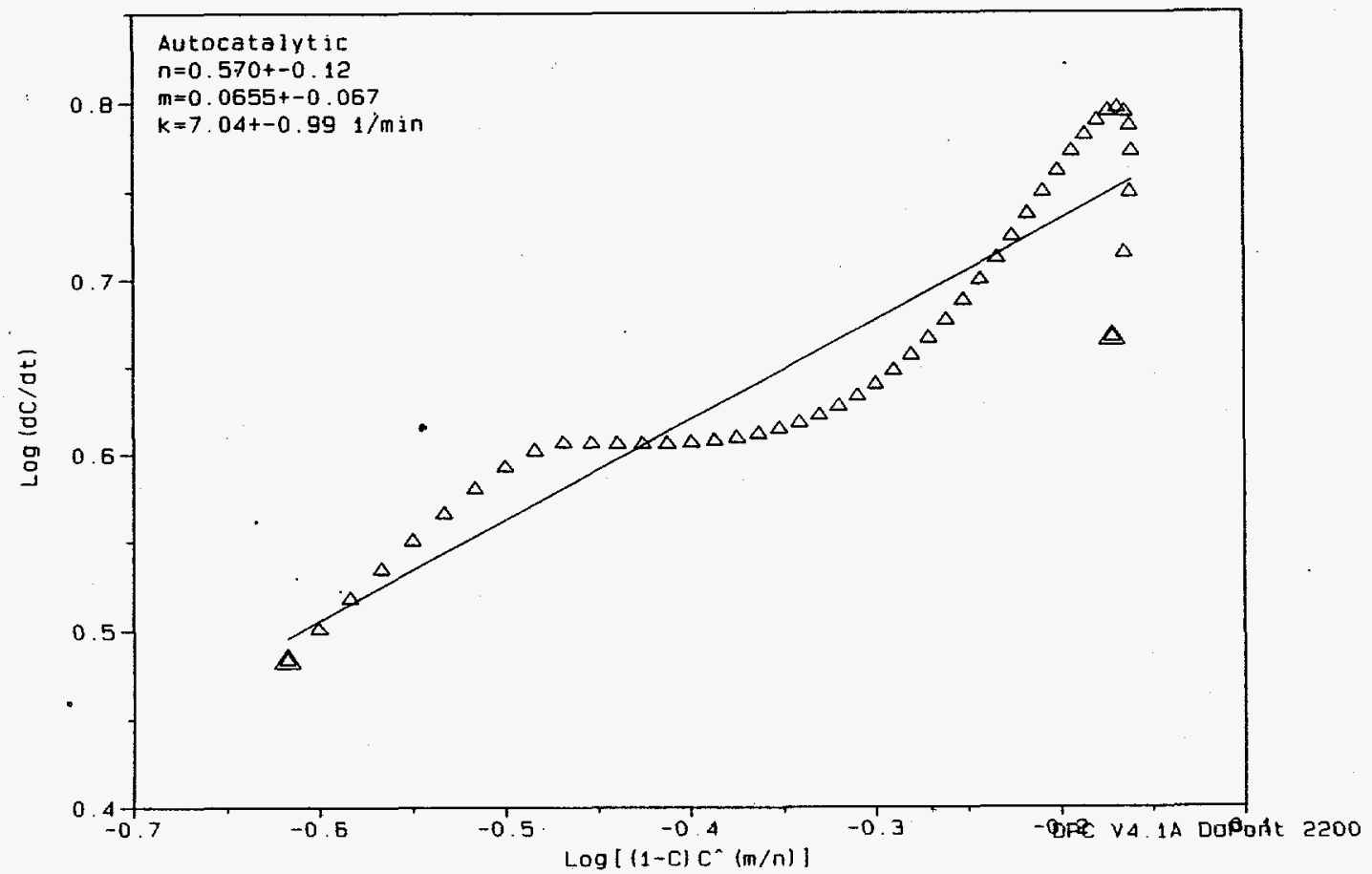

Figure B-14. Closeness of Fit Curve for $10 \mu \mathrm{L}$ Sample of Norland 61 Optical Adhesive 
Sample: NOHLAND OPTICAL ADHESIVE 61

Size: $\quad 2477 \mathrm{mg}$

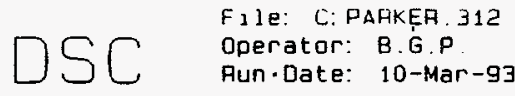

Comment:

Bun-Date: 10-Mar-93

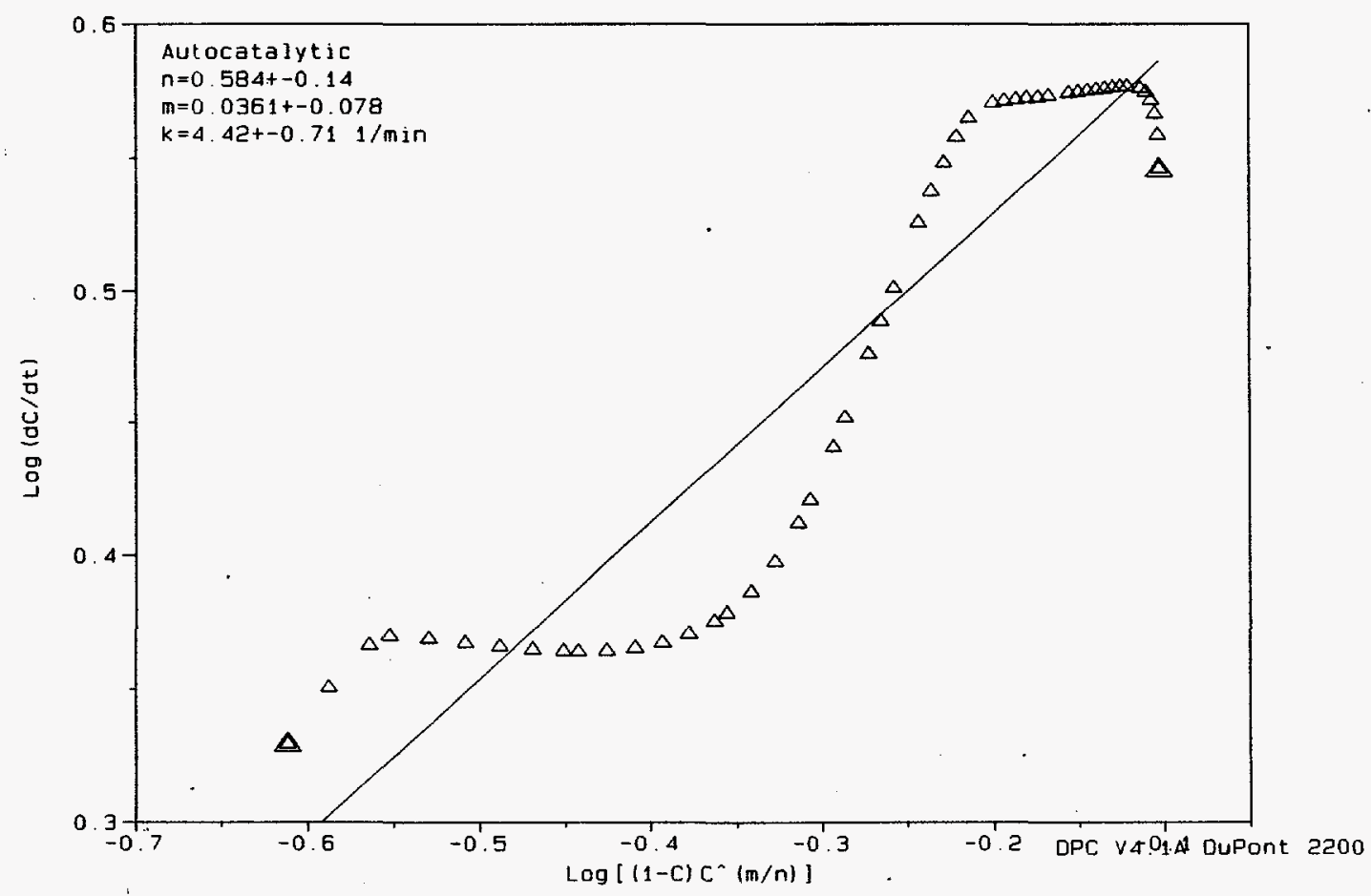

Figure B-15. Closeness of Fit Curve for $20 \mu \mathrm{L}$ Sample of Norland 61 Optical Adhesive

DIFFERENTIAL PHOTO CALORIMETAY KINETICS REPORT

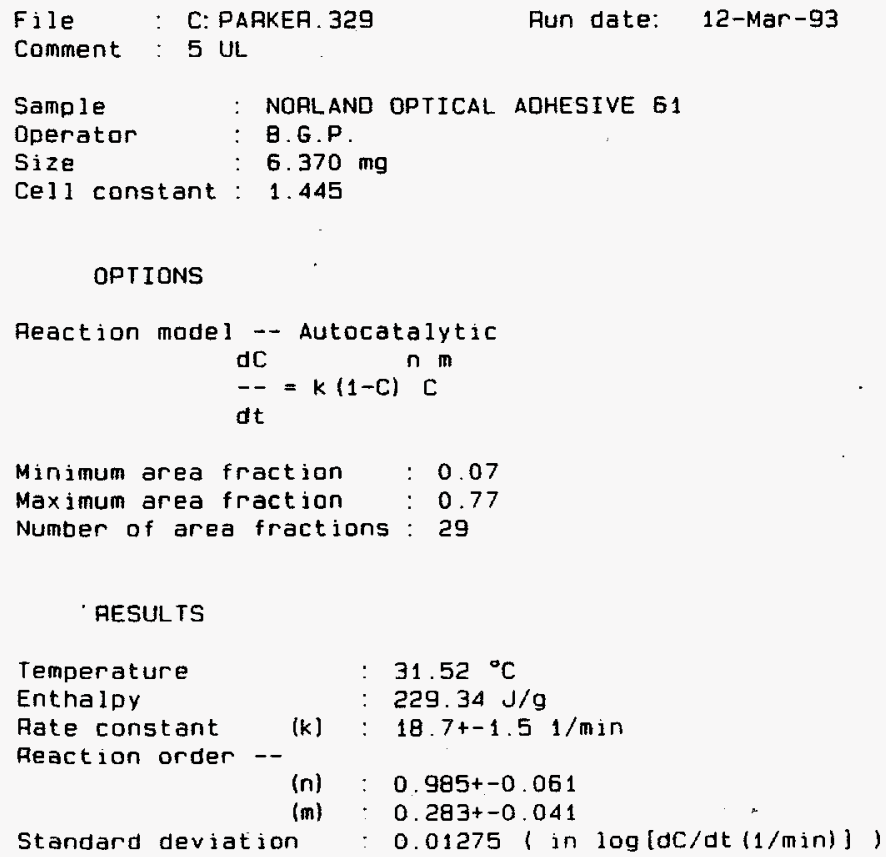

Figure B-16. Kinetics Report for $5 \mu \mathrm{L}$ Sample of Norland 61 Optical Adhesive 
Sample: NORLAND OPTICAL ADHESTVE 61 Size: $\quad 6.37 \mathrm{mg}$

Comment: 5 UL

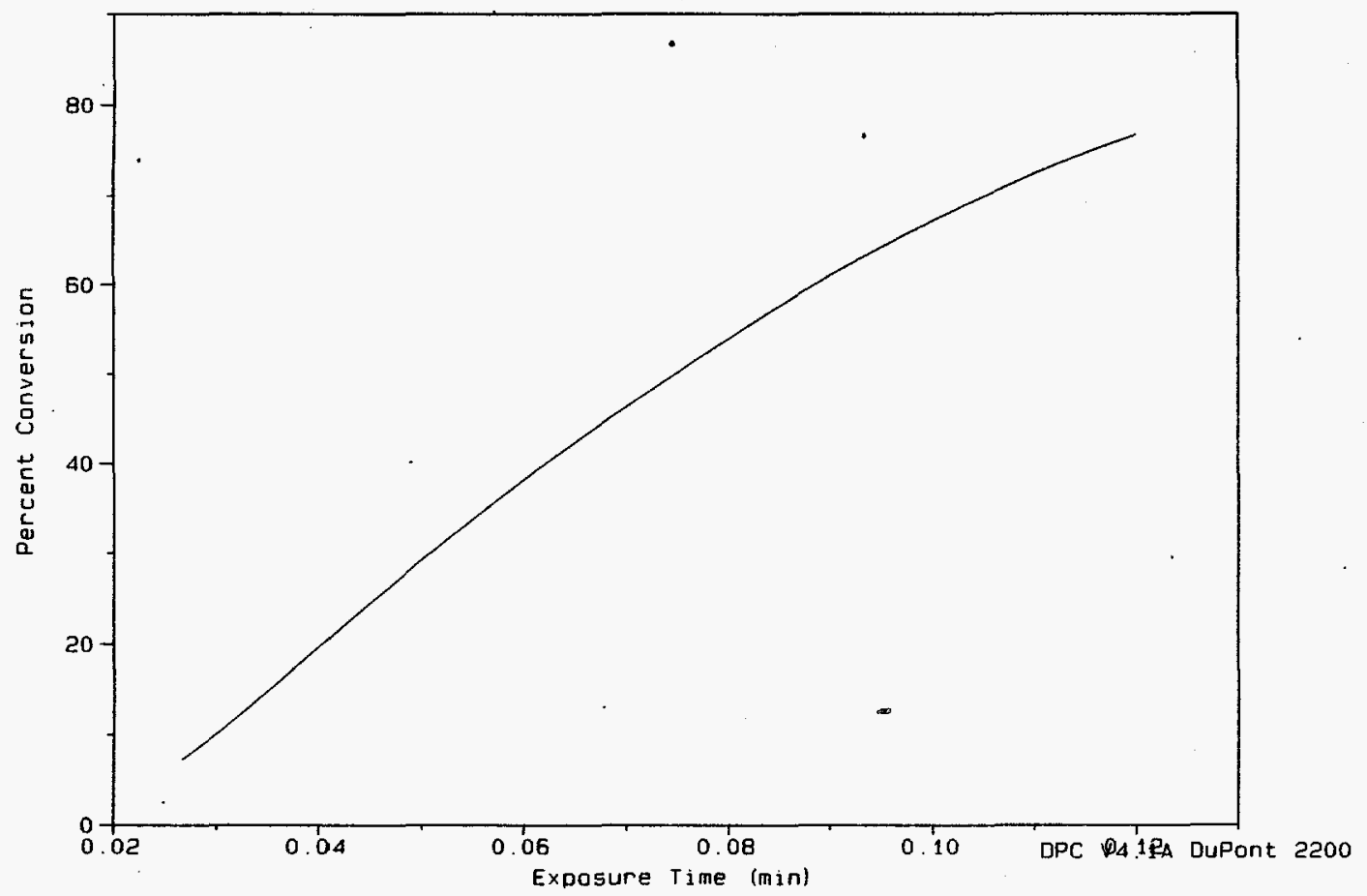

Figure B-17. Cure Rate Versus Exposure Time for $5 \mu \mathrm{L}$ Sample of Norland 61 Optical Adhesive

Sample: NOALANO OPIICAL ADHESIVE 61 Size: $\quad 6.3700 \mathrm{mg}$

Method: R.T. to $300 \mathrm{C}$ at $10 \mathrm{C} / \mathrm{min}$.

$\square \circlearrowleft\left[\begin{array}{l}\text { File: PAAKEA.331 } \\ \text { Dperator: B.G.P. }\end{array}\right.$

Comment: 5 UL CURED U.V.

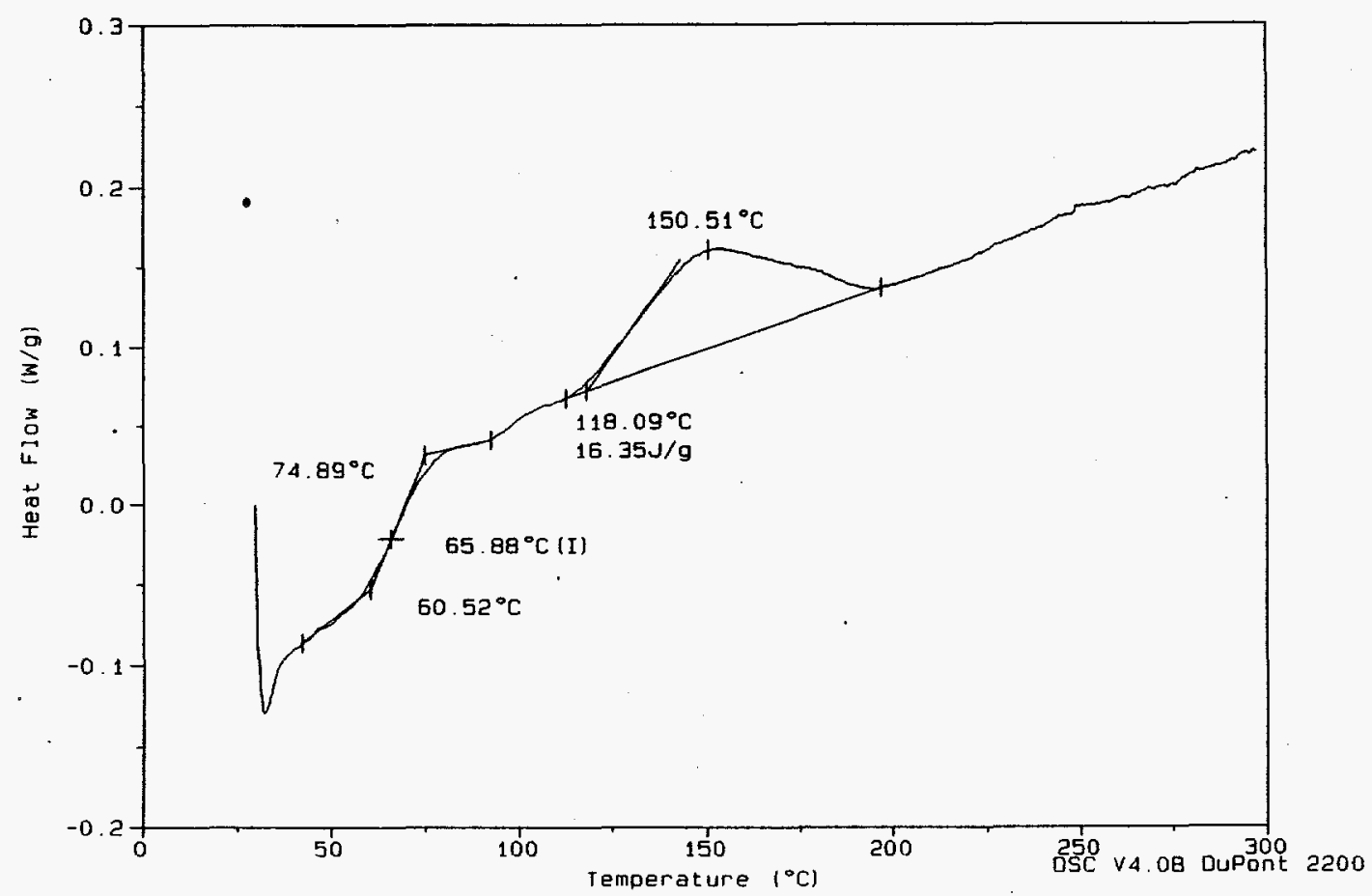

Figure B-18. DSC Curve for UV Cured $5 \mu \mathrm{L}$ Sample of Norland 61 Optical Adhesive 


\section{APPENDIX C}

\section{Analysis of HA84 UV Curable Conformal Coating}





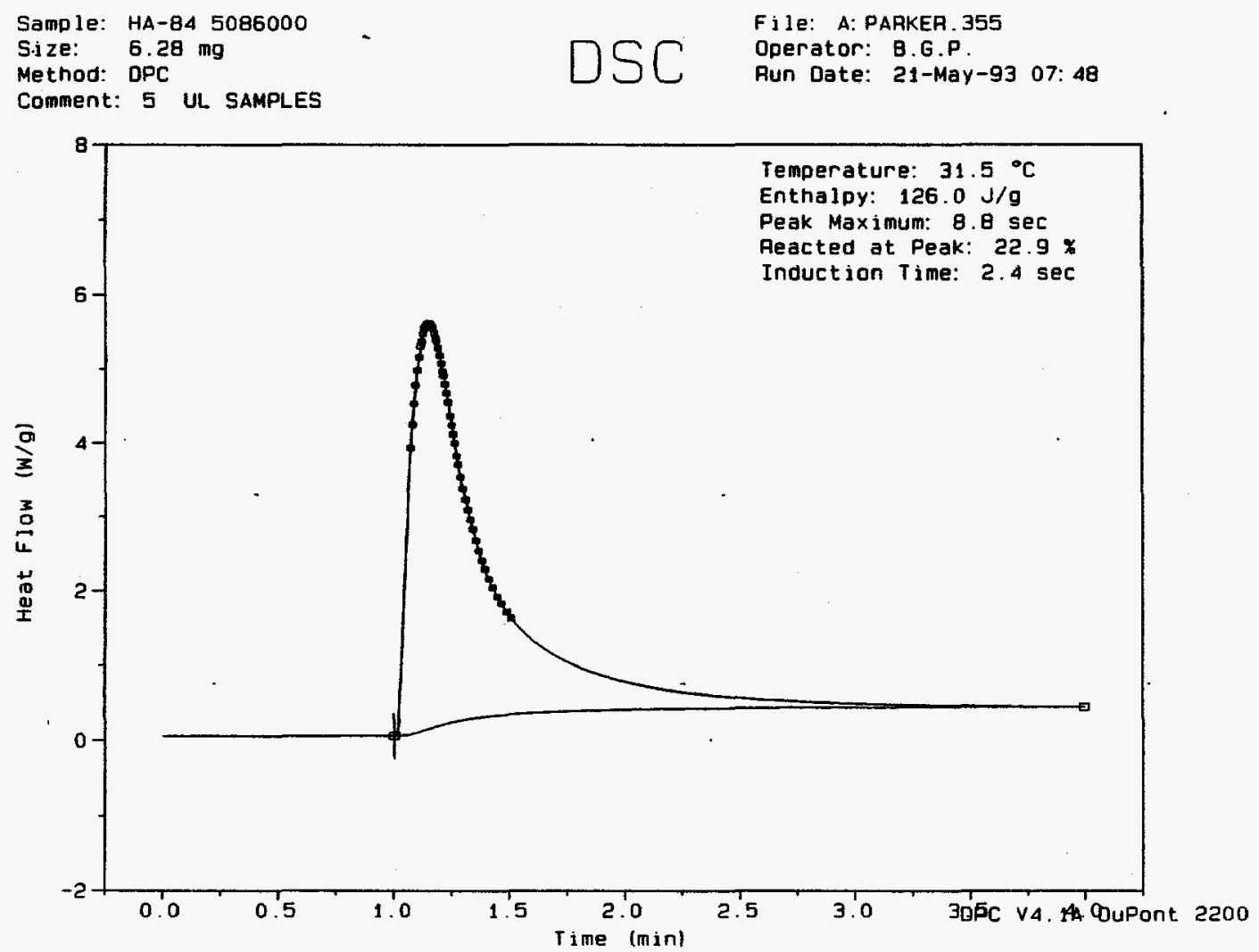

Figure C-1. DPC Curve for $5 \mu \mathrm{L}$ Sample of HA84 Conformal Coating
Sample: HA-84 5086000
Size: $6.2800 \mathrm{mg}$
$\square \circlearrowleft$
File: A: PAAKER. 357
Method: A.T. to $300 \mathrm{C}$ at $10 \mathrm{C} / \mathrm{min}$.
Operator: 8.G.P.
Method: A.T. to $300 C$ at
Comment: 5 UL SAMPLES.
Pun Date: 21-May-93 07: 57

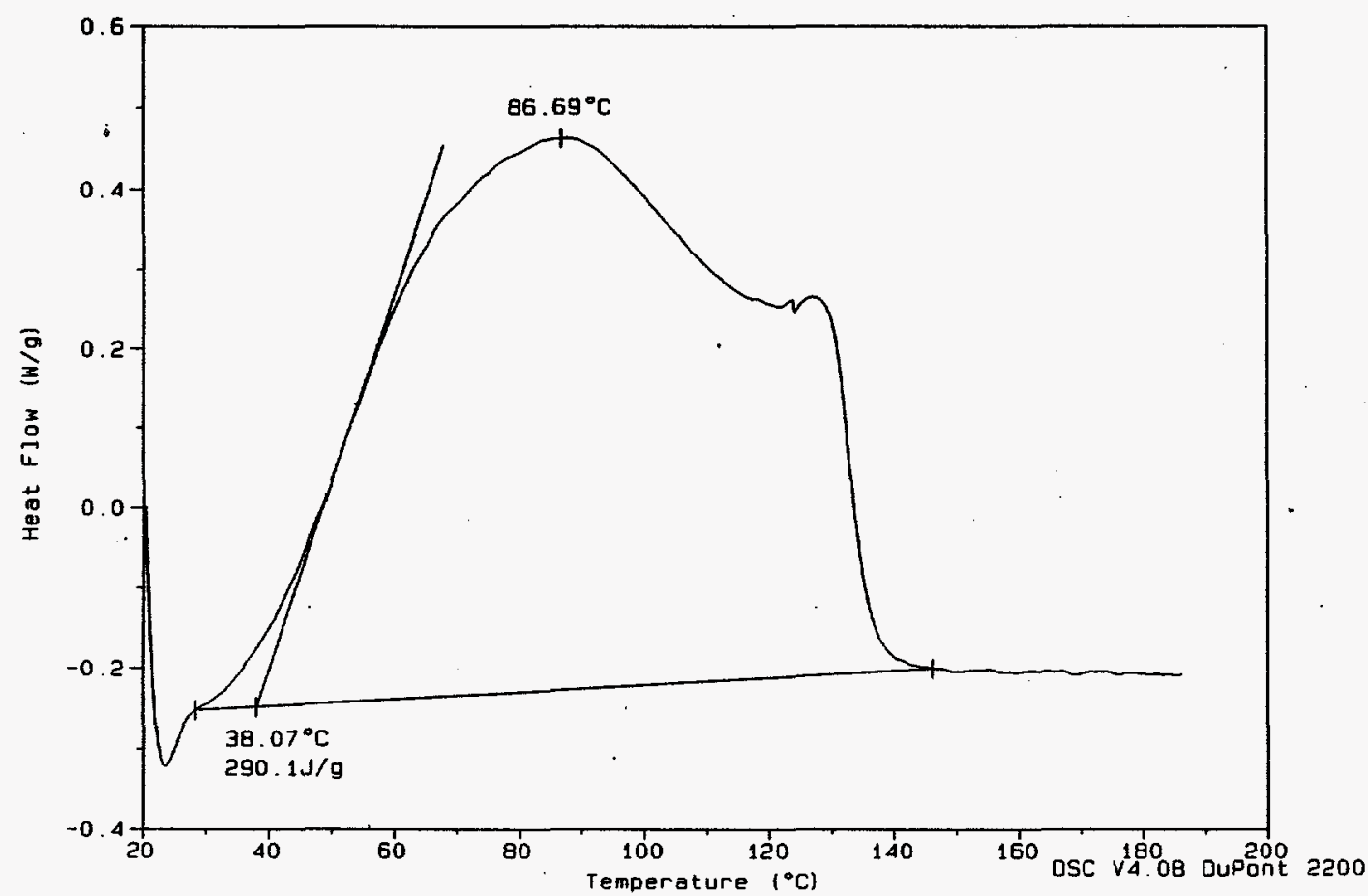

Figure C-2. DSC Curve for UV Cured $5 \mu \mathrm{L}$ Sample of HA84 Conformal Coating 


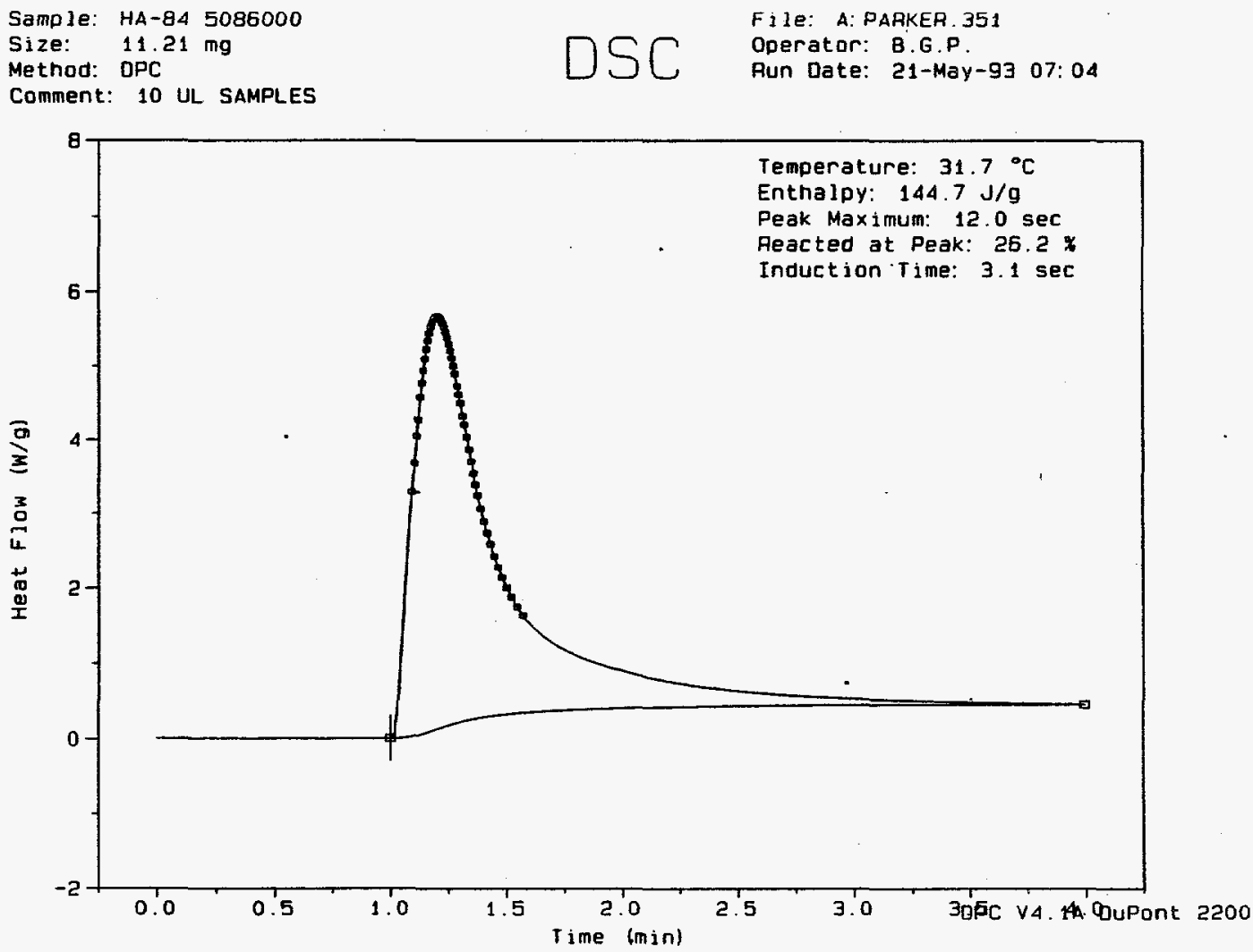

Figure C-3. DPC Curve for $10 \mu \mathrm{L}$ Sample of HA84 Conformal Coating

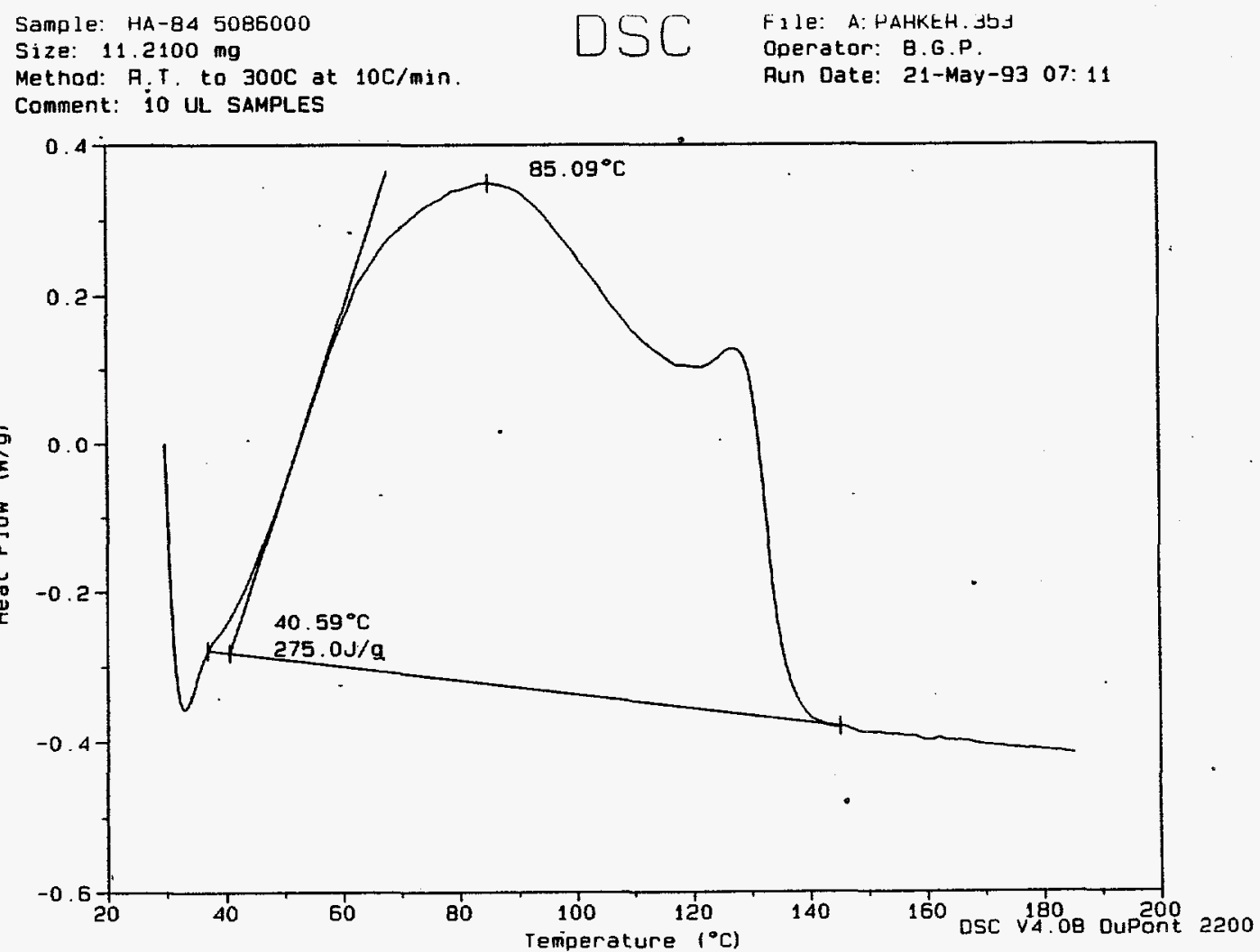

Figure C-4. DSC Curve for UV Cured $10 \mu \mathrm{L}$ Sample of HA84 Conformal Coating 
Sample: HA-84 5096000

Size: $21.97 \mathrm{mg}$

Method: DPC

Comment: 20 UL SAMPLES
File: A: PARKER. 360

Operator: B.G.P

Run Date: 21-May-93 08: 28

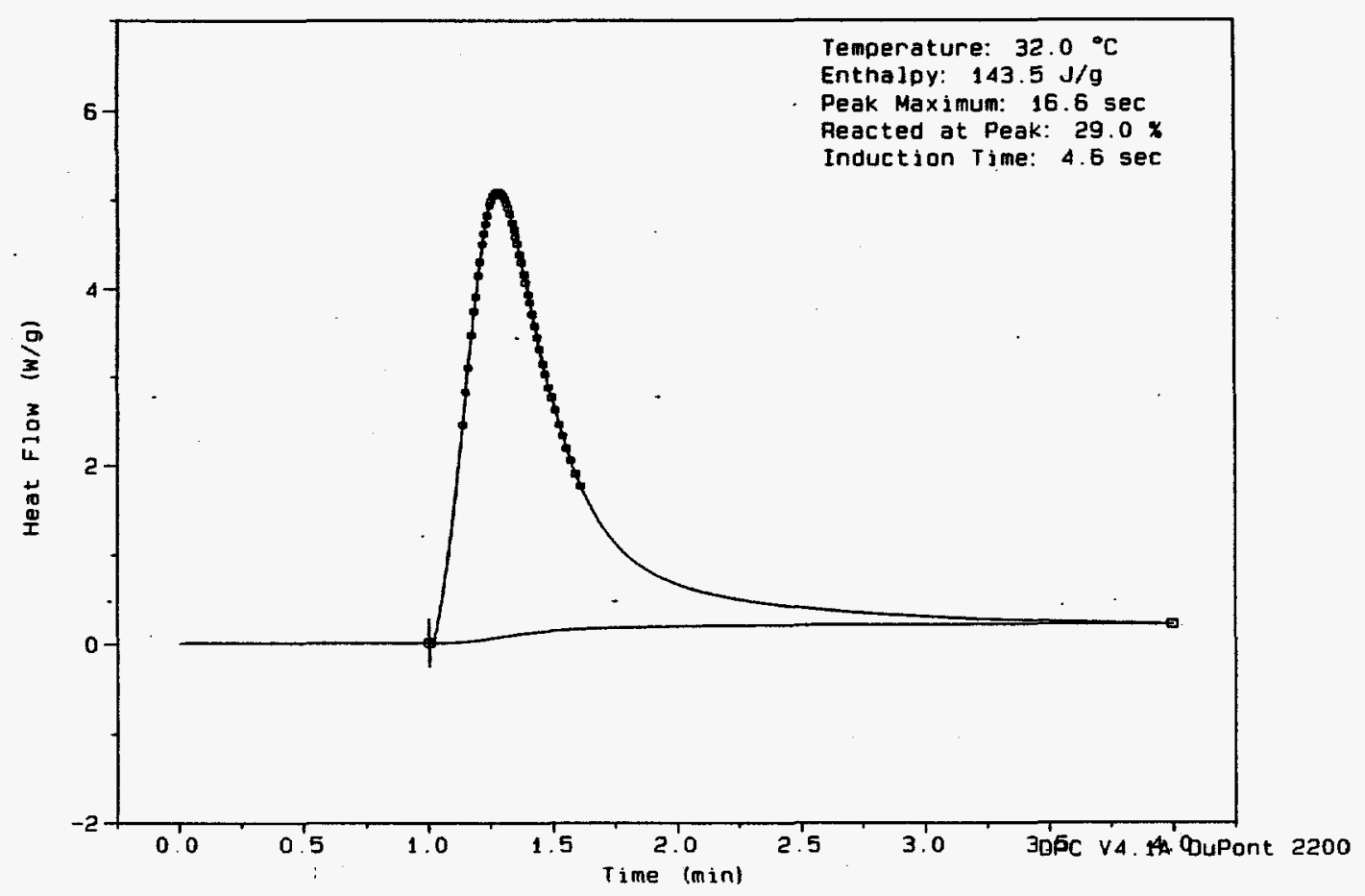

Figure C-5. DPC Curve for $20 \mu \mathrm{L}$ Sample of HA84 Conformal Coating

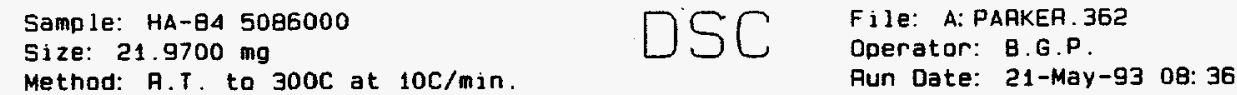

Method: A.T to $300 \mathrm{C}$ at $10 \mathrm{C} / \mathrm{min}$

Operator: B.G.P

Comment: 20 UL. SAMPLES

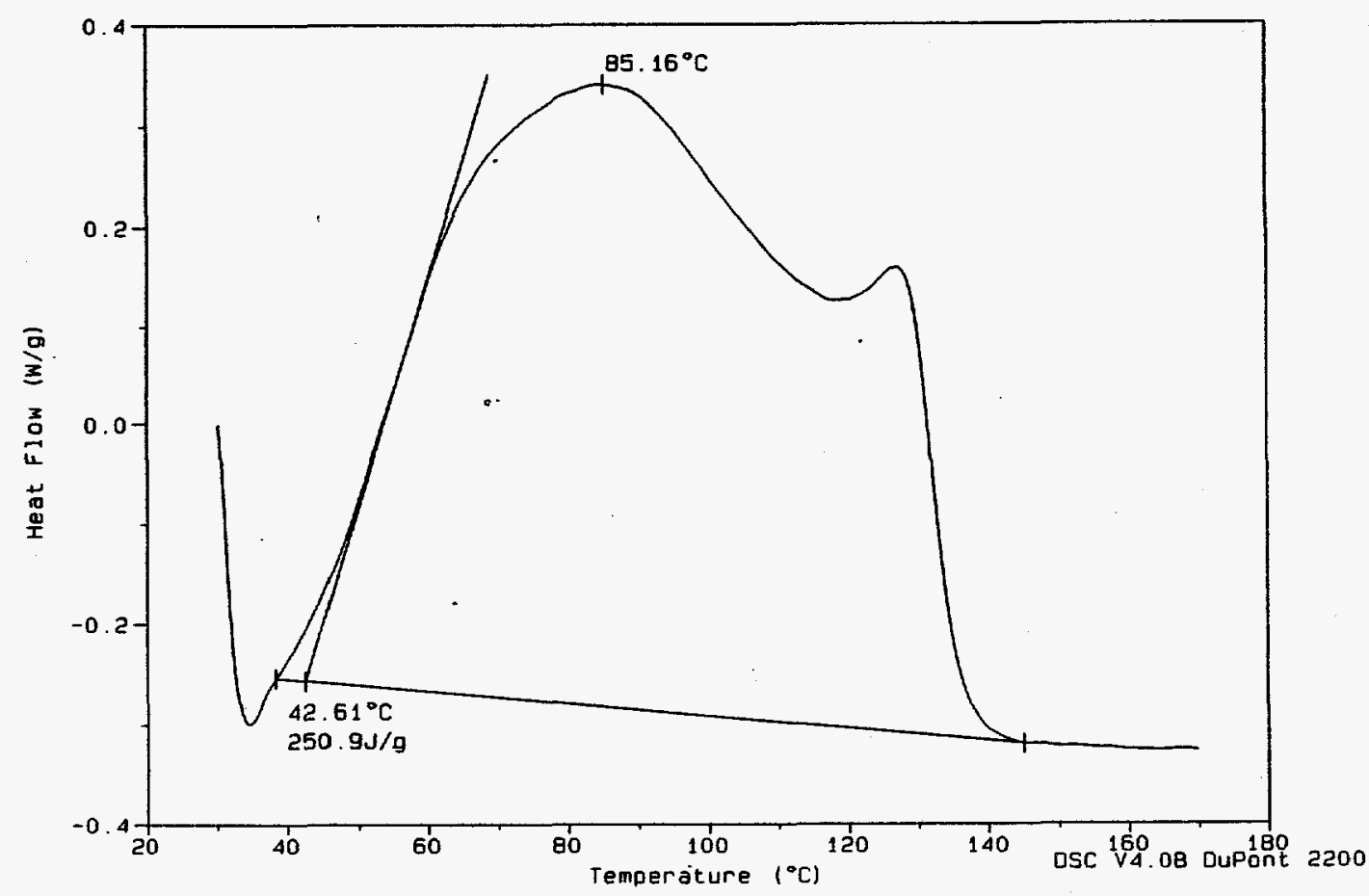

Figure C-6. DSC Curve for UV Cured $20 \mu \mathrm{L}$ Sample of HA84 Conformal Coating 
Sample: HA-84 5086000

Size: $\quad 44.29 \mathrm{mg}$

Method: DPC

Comment: 40 UL SAMPLES
File: A: PAAKEA. 364

Operator: B.G.P.

Fun Date: 21-May-93 09: 00

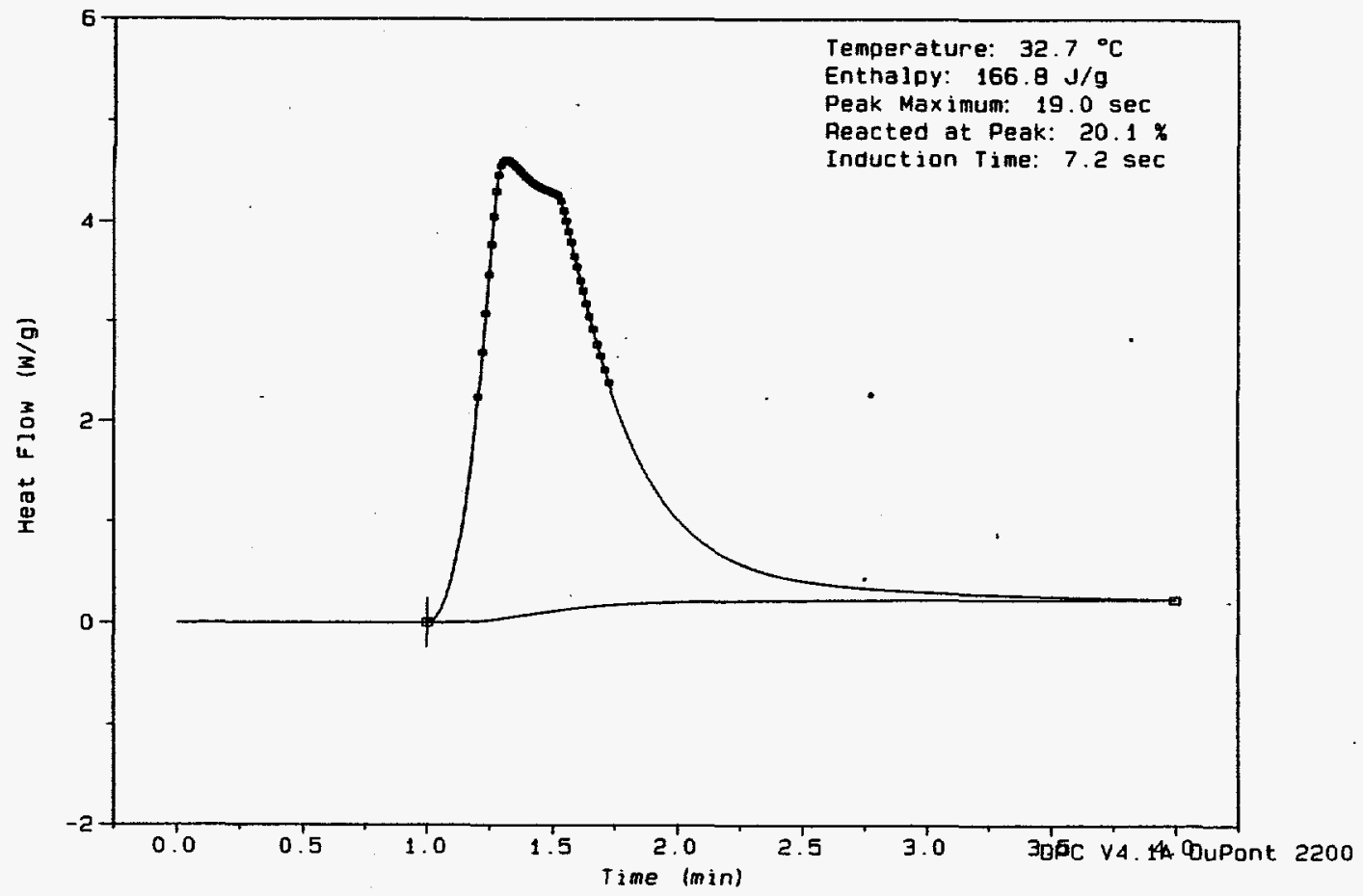

Figure C-7. DPC Curve for $40 \mu \mathrm{L}$ Sample of HA84 Conformal Coating

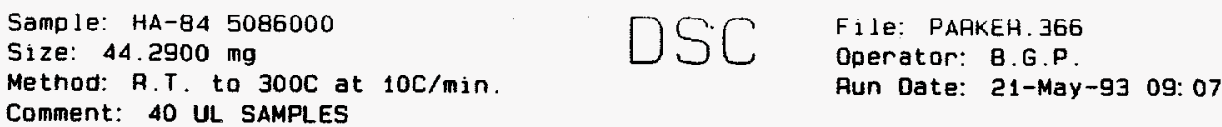

Comment: 40 UL SAMPLES

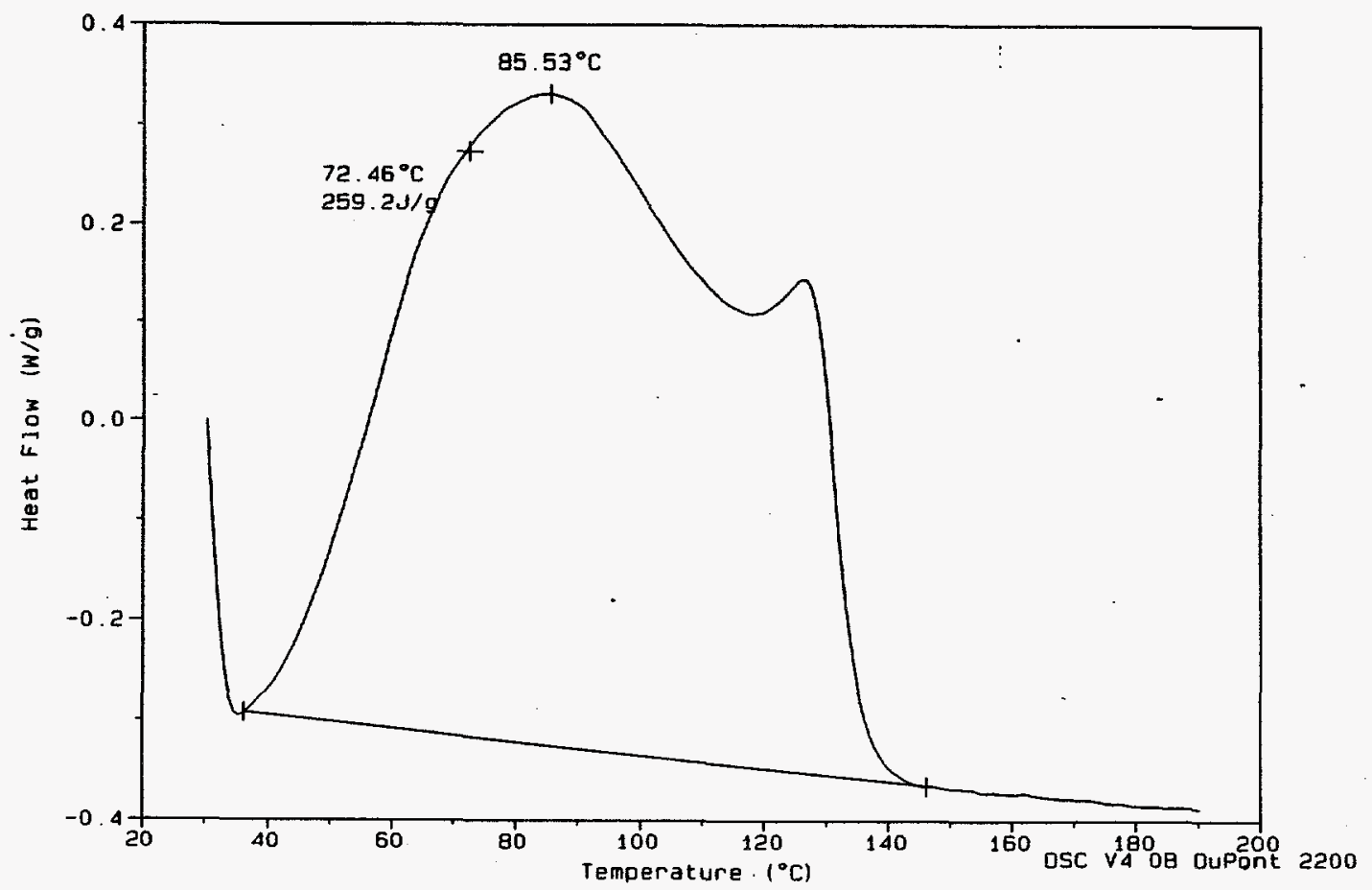

Figure C-8. DSC Curve for UV Cured $40 \mu \mathrm{L}$ Sample of HA84 Conformal Coating 
Sample: HA-B4 5086000

Size: $6.28 \mathrm{mg}$

Comment: 5 UL SAMPLES
Fi 1e: A: PARKER 355

Operator: B.G.P

Pun Date: 21-May-93

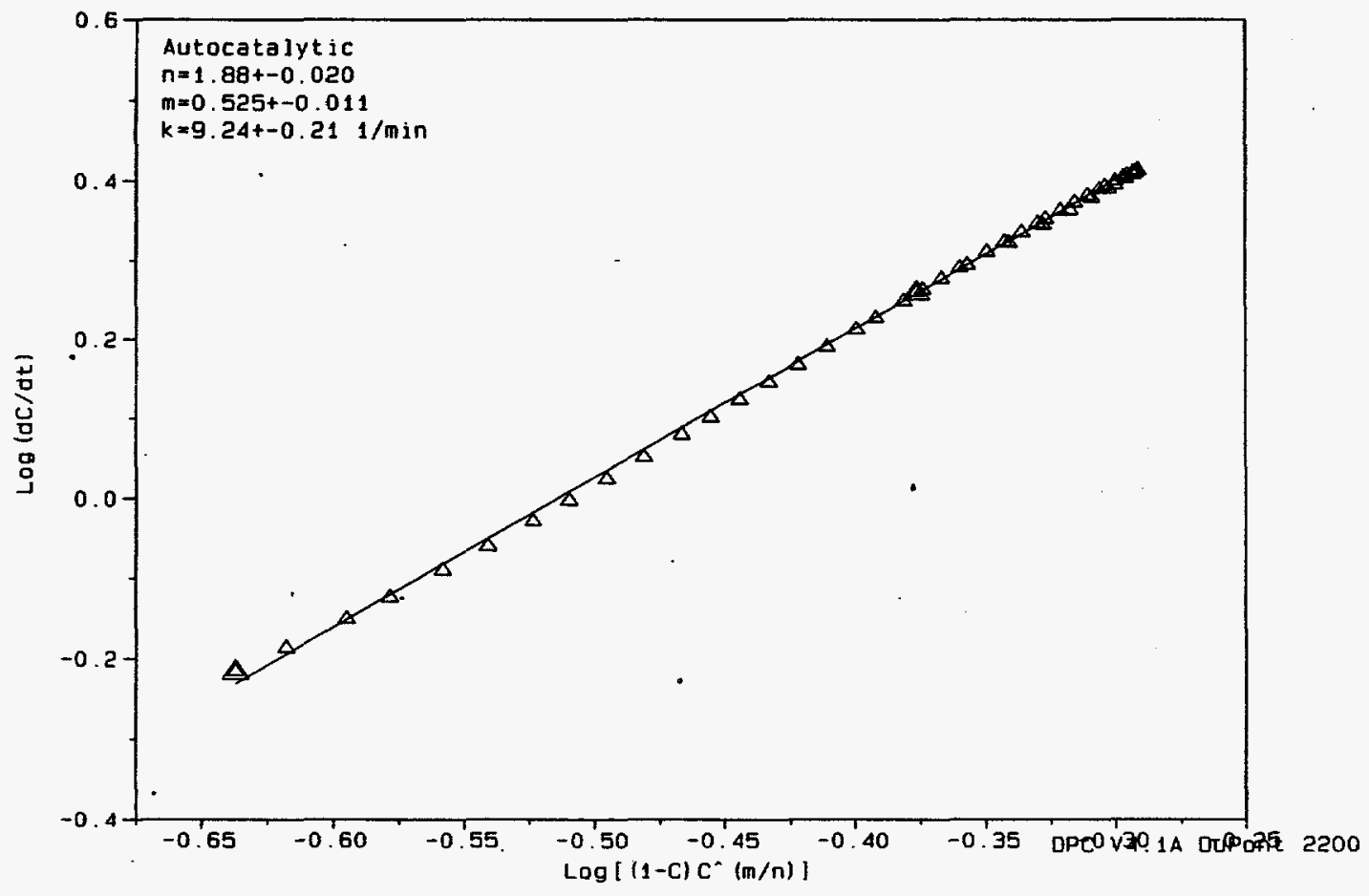

Figure C-9. Closeness of Fit Curve for $5 \mu \mathrm{L}$ Sample of HA84 Conformal Coating

Sample: HA-84 5086000

Size: $\quad 11.21 \mathrm{mg}$

File: A: PARKER. 351

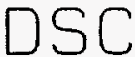

Comment: 10 UL SAMPLES

Run Date: 21-May-93

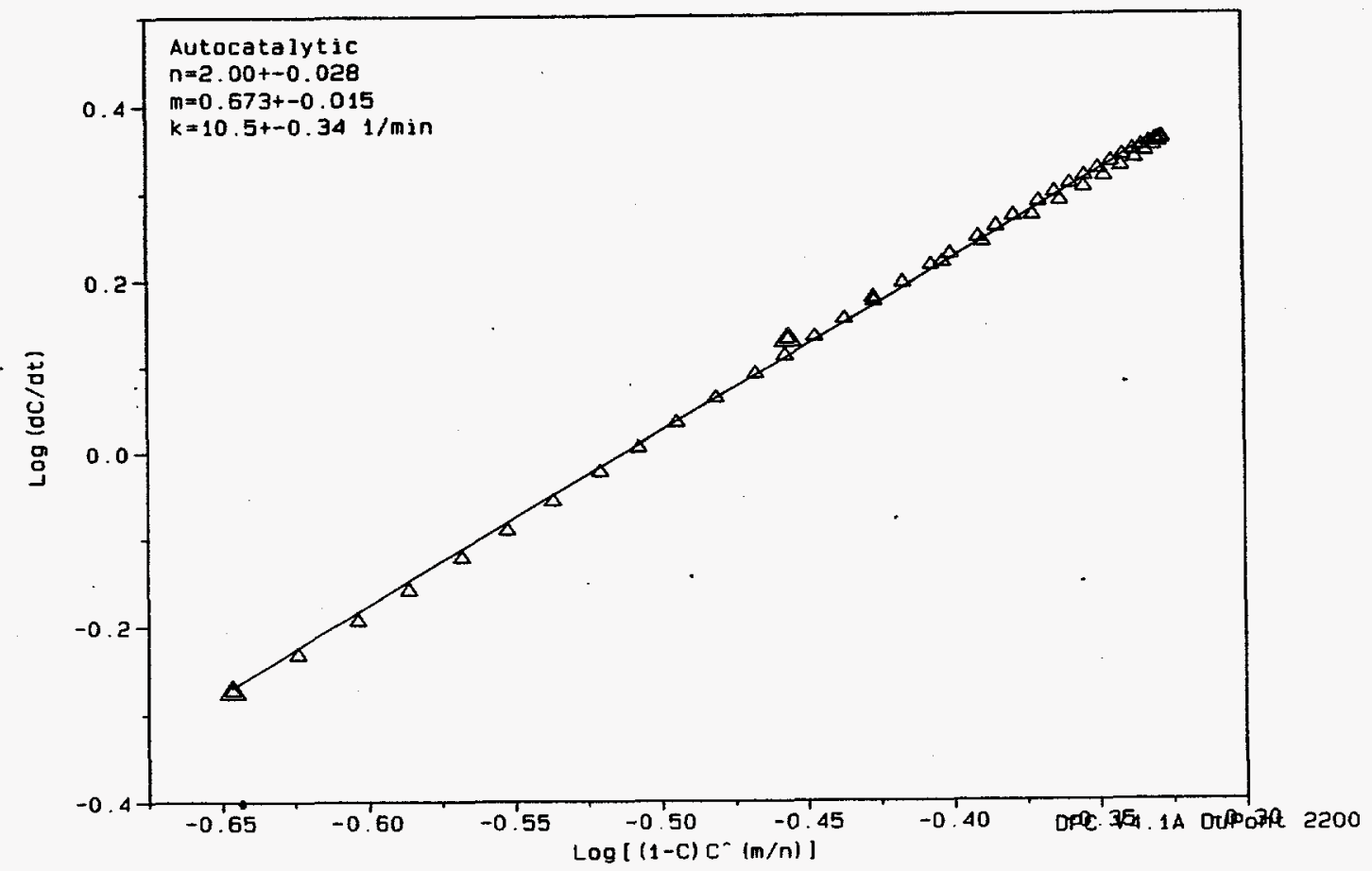

Figure C-10. Closeness of Fit Curve for $10 \mu \mathrm{L}$ Sample of HA84 Conformal Coating 
Sample: HA-84 5086000

Size: $21.97 \mathrm{mg}$

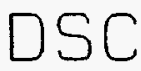

File: A: PAAKER. 360

Operator: B.G.P

Comment: 20 UL SAMPLES

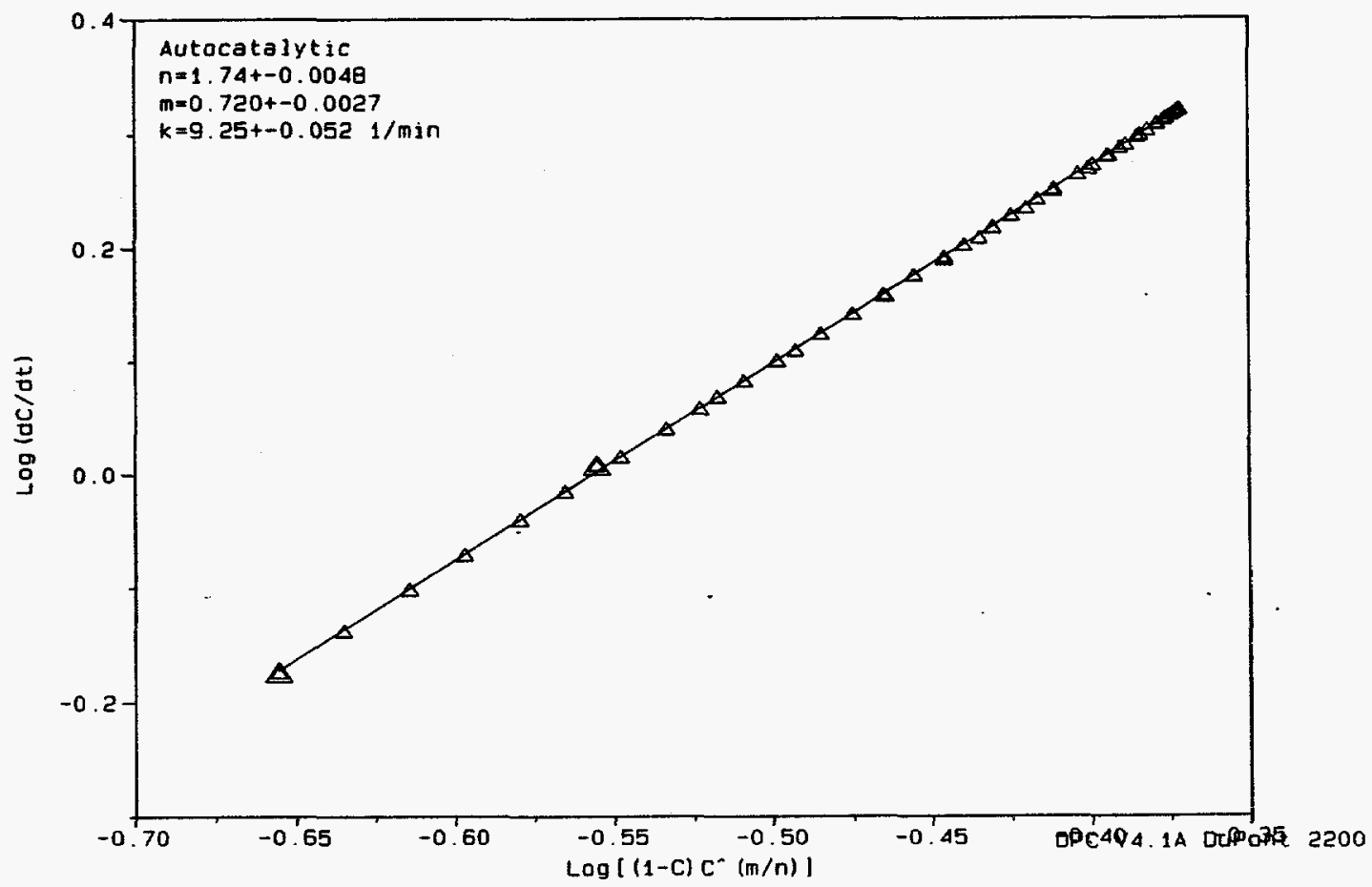

Figure C-11. Closeness of Fit Curve for $20 \mu \mathrm{L}$ Sample of HA84 Conformal Coating

Sample: HA-84 5086000

Size: $\quad 44.29 \mathrm{mg}$

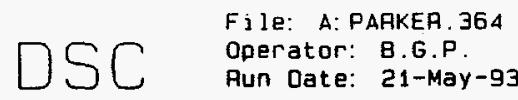

Comment: 40 UL SAMPLES

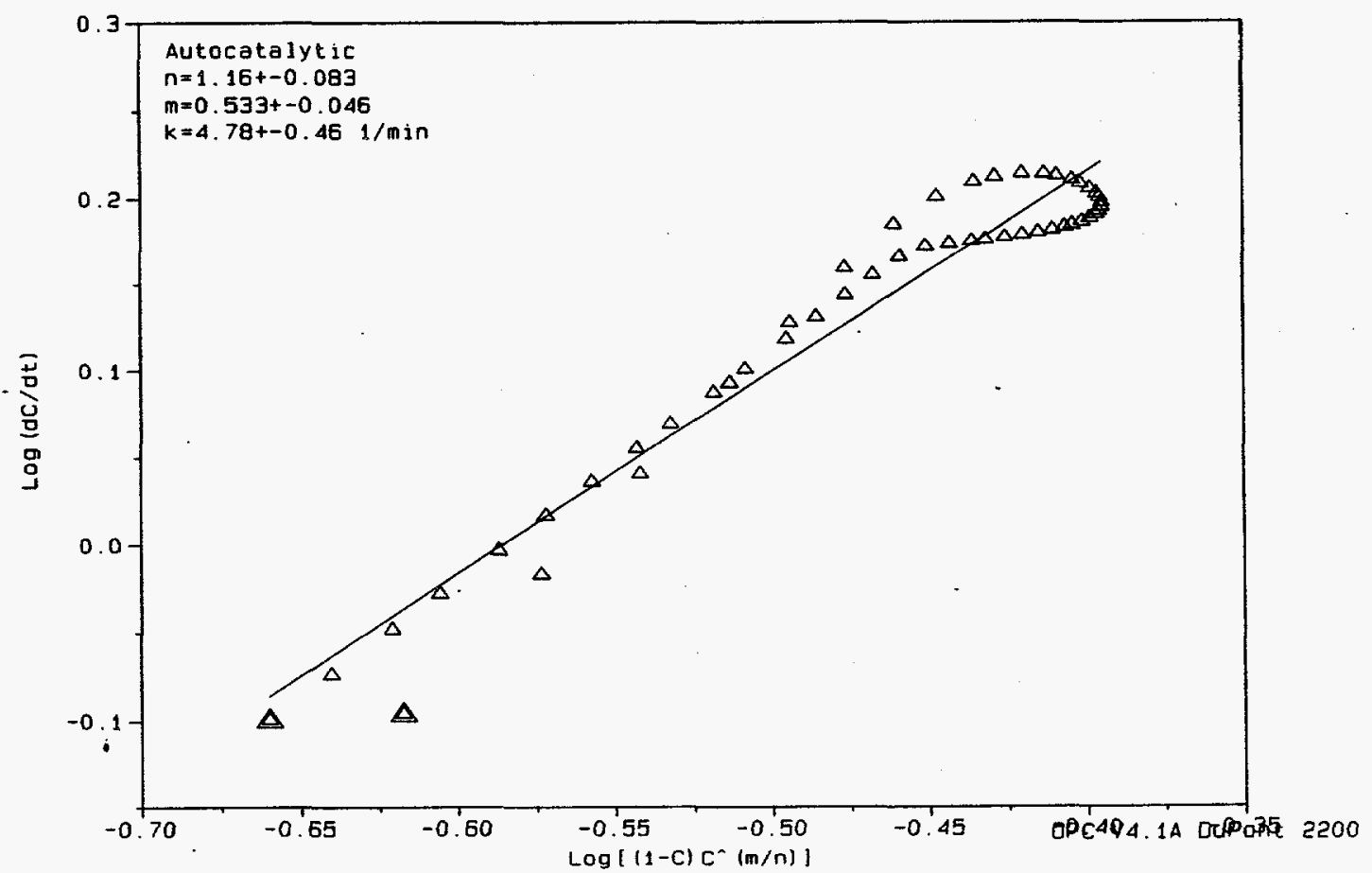

Figure C-12. Closeness of Fit Curve for $40 \mu \mathrm{L}$ Sample of HA84 Conformal Coating 
OIFFERENTIAL PHOTO CALOHIMETAY KINETICS REPORT

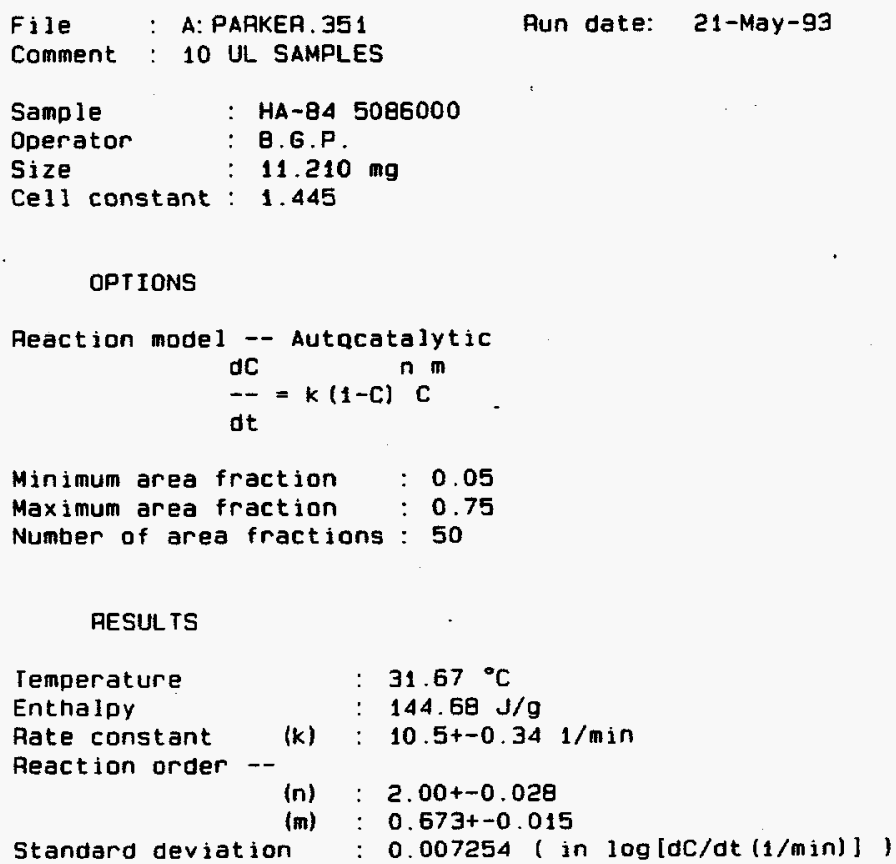

PESULTS

Figure C-13. Kinetics Report for $10 \mu \mathrm{L}$ Sample of HA84 Conformal Coating

Sample: HA-84 5006000

Size: $\quad 11.21 \mathrm{mg}$

Comment: 10 UL SAMPLES

File: A: PARKER. 351

$\square S C \quad \begin{aligned} & \text { Operator: B.G.P. } \\ & \text { Pun Date: } 21-\text { May-93 }\end{aligned}$

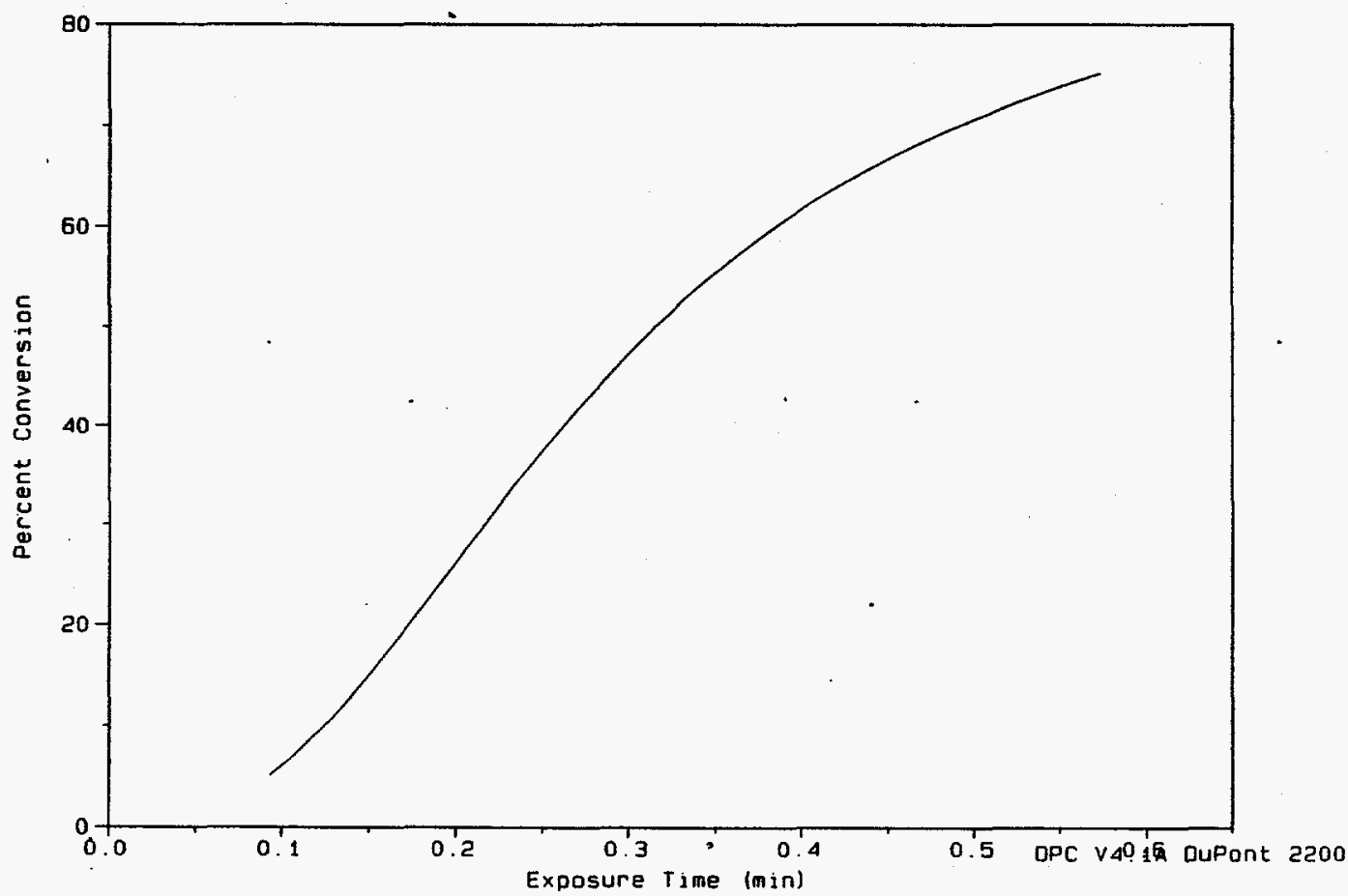

Figure C-14. Cure Rate Versus Exposure Time for $10 \mu \mathrm{L}$ Sample of HA84 Conformal Coating 


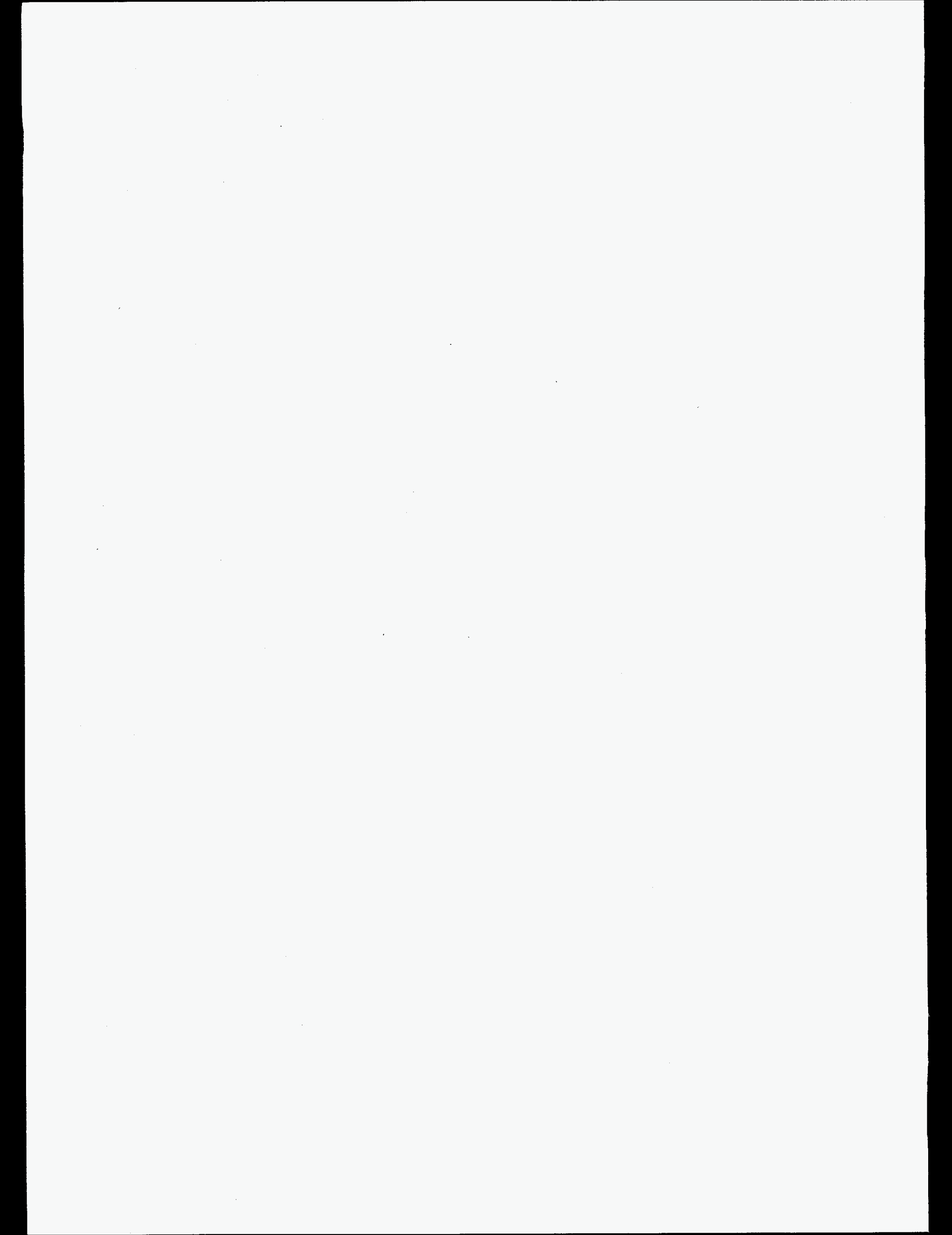




\section{APPENDIX D}

\section{Analysis of HA84F UV Curable Conformal Coating}



Sample: HA-84F 57005301

Size: $\quad 6.03 \mathrm{mg}$

Method: DPC

Comment: 5 UL SAMPLES

File: A: PARKER. 347

Operator: B.G.P.

Run Date: 20-May-93 12: 39

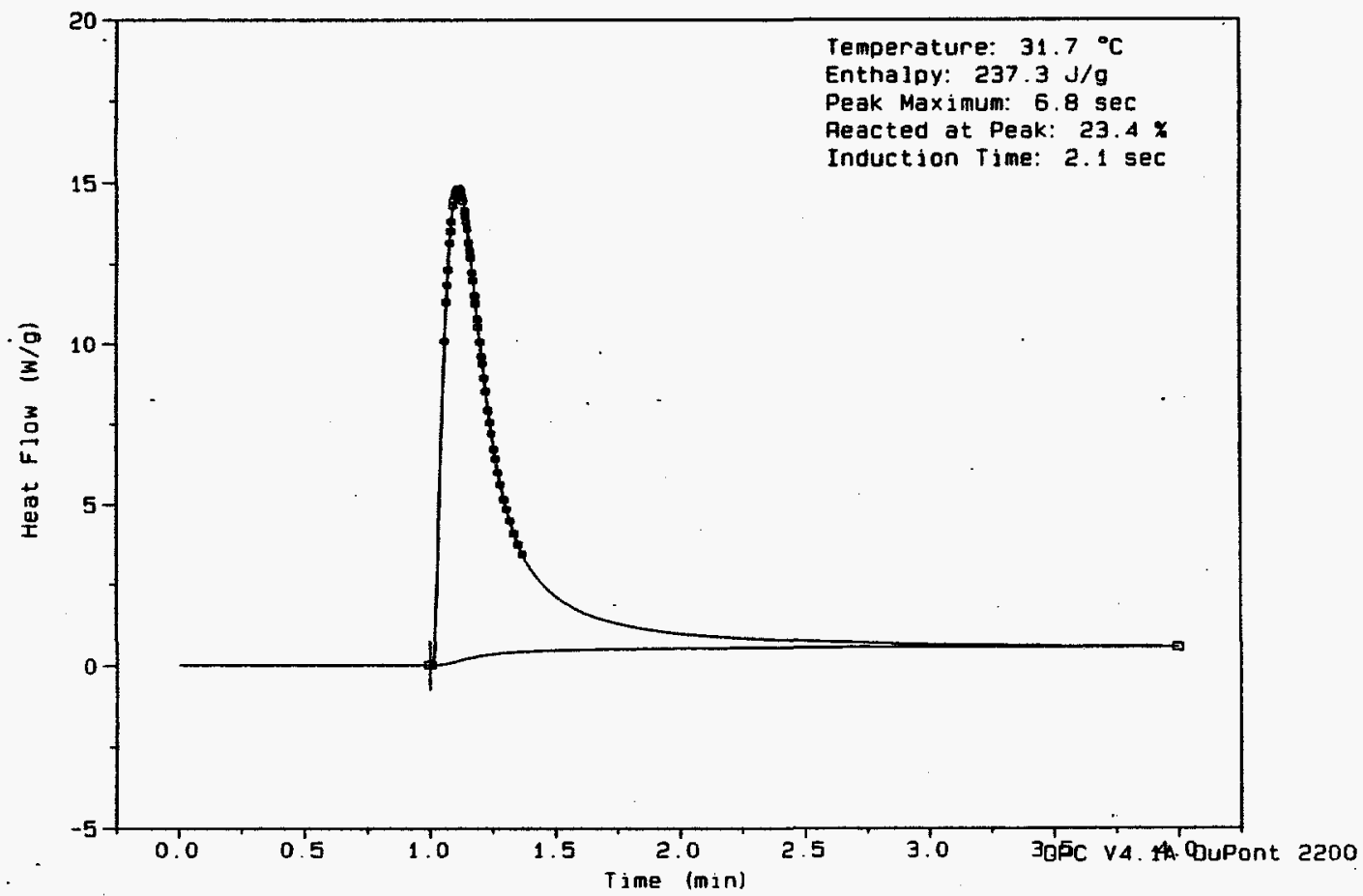

Figure D-1. DPC Curve for $5 \mu \mathrm{L}$ Sample of HA84F Conformal Coating

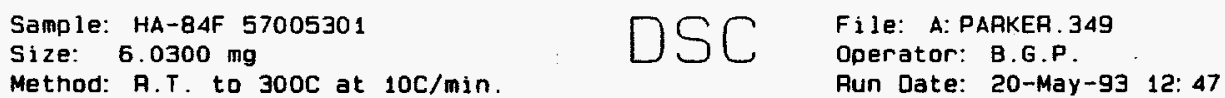

$300 \mathrm{C}$ at $10 \mathrm{C} / \mathrm{min}$.

Run Date: 20-May-93 12: 47

Comment: 5 UL SAMPLES

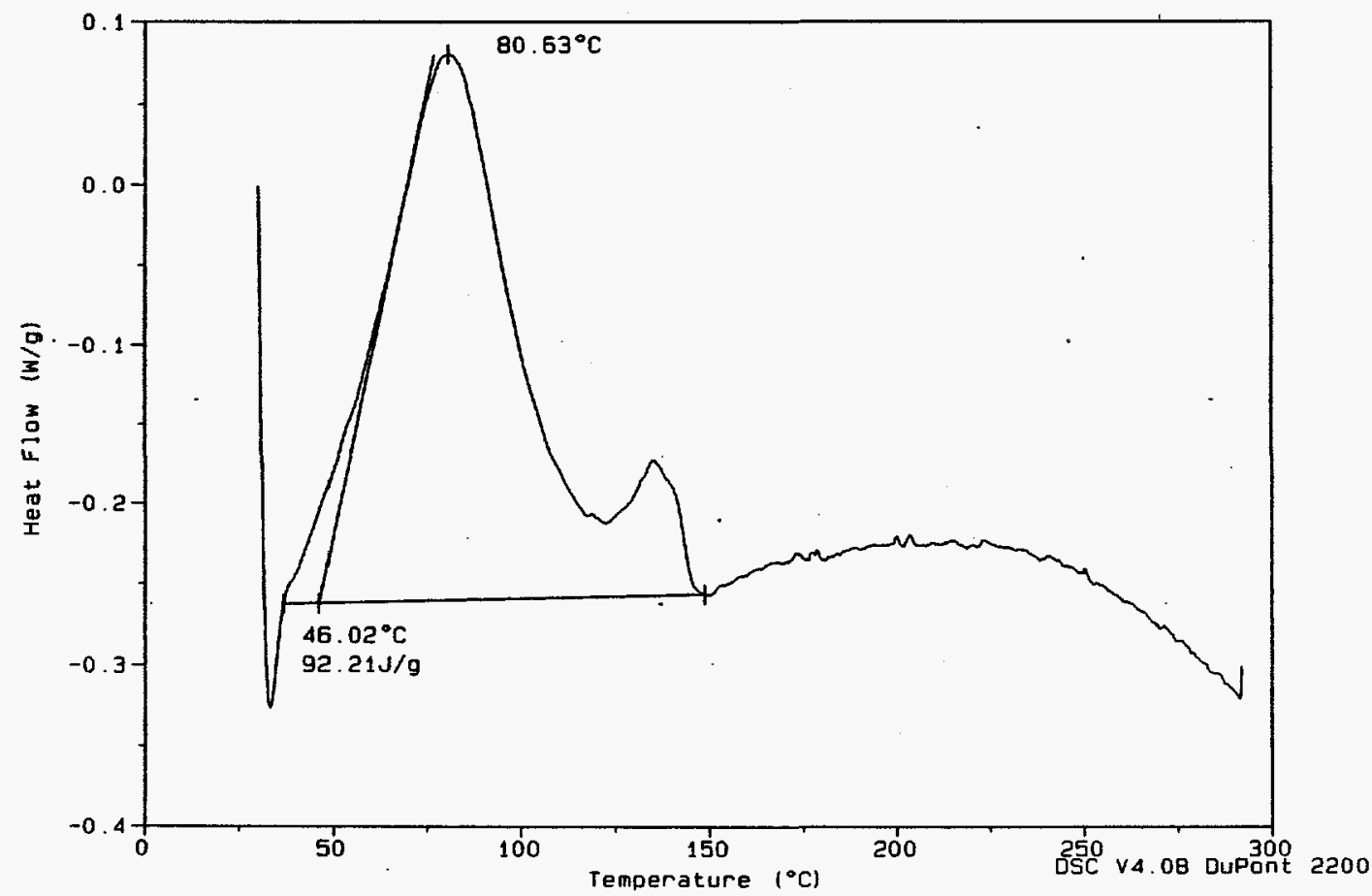

Figure D-2. DSC Curve for UV Cured $5 \mu \mathrm{L}$ Sample of HA84F Conformal Coating 
Sample: HA-84F 57005301

Size: $\quad 10.91 \mathrm{mg}$

Method: $D P C$

Comment: 10 UL SAMPLES
File: C: PARKER. 339

Operator: B.G.P.

Run Date: 20-May-93 08: 17

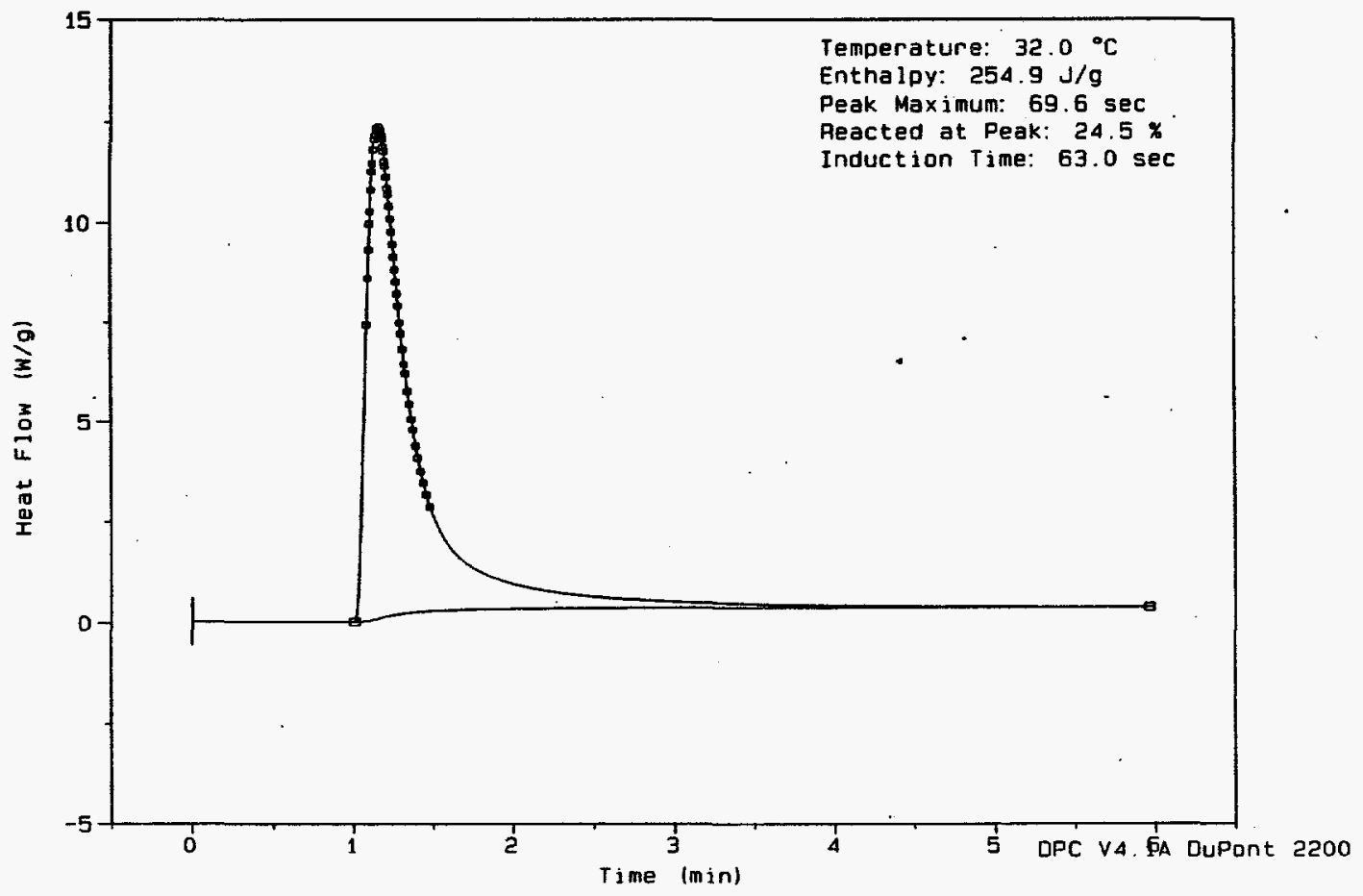

Figure D-3. DPC Curve for $10 \mu \mathrm{L}$ Sample of HA84F Conformal Coating

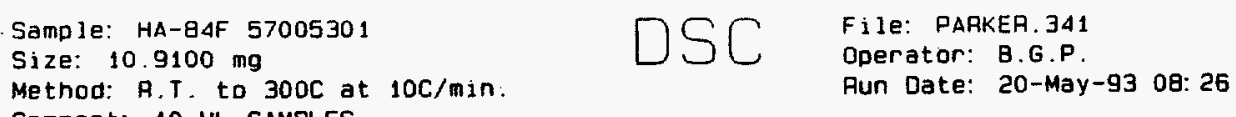

Method: A.T. to $300 \mathrm{C}$ at $10 \mathrm{C} / \mathrm{min}$

Aun Date: 20-May-93 08: 26

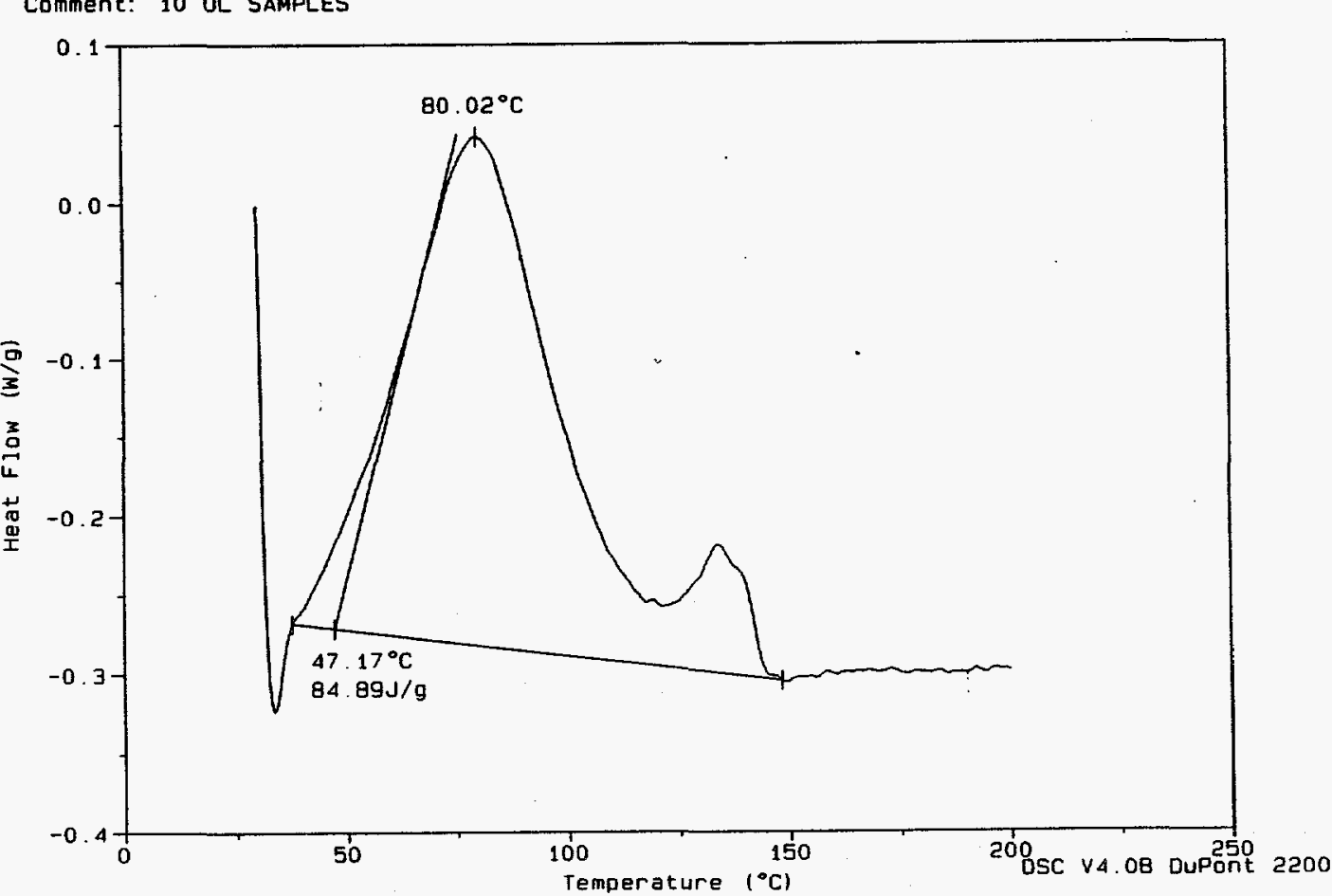

Figure D-4. DSC Curve for UV Cured $10 \mu \mathrm{L}$ Sample of HA84F Conformal Coating 
Sample: HA-84F 5700530104

Size: $\quad 22.46 \mathrm{mg}$

Me thod: DPC

Comment: 20 UL SAMPLES
Fi le: C: PARKER. 336

Operator: B.G.P

Run Date: 20-May-93 07: 16

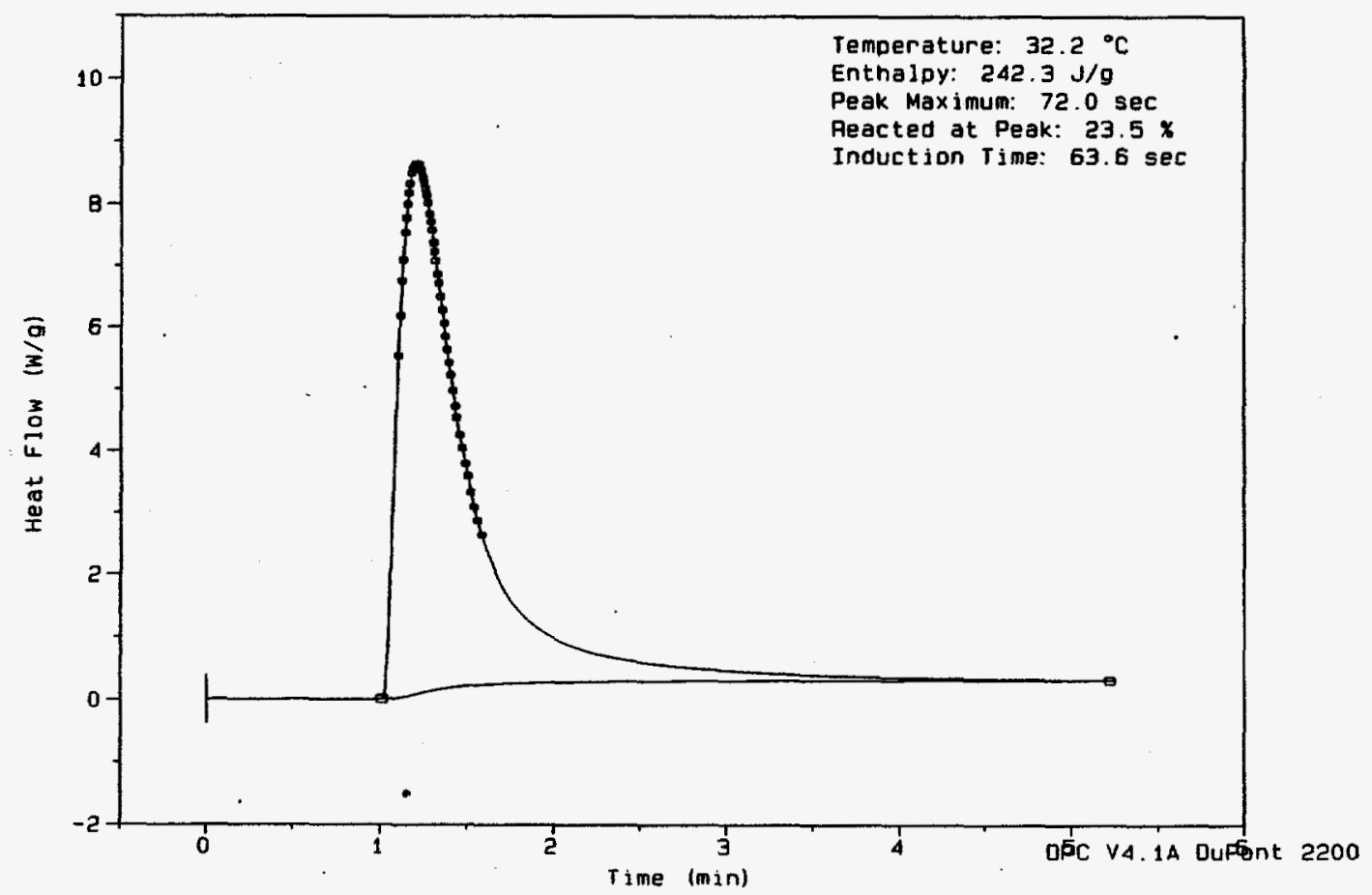

Figure D-5. DPC Curve for $20 \mu \mathrm{L}$ Sample of HA84F Conformal Coating

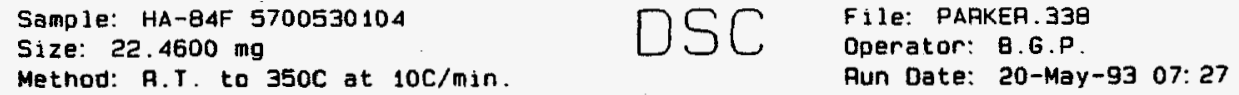

Method: $A$.

Run Date: 20-May-93 07: 27

Comment: 20 UL SAMPLES

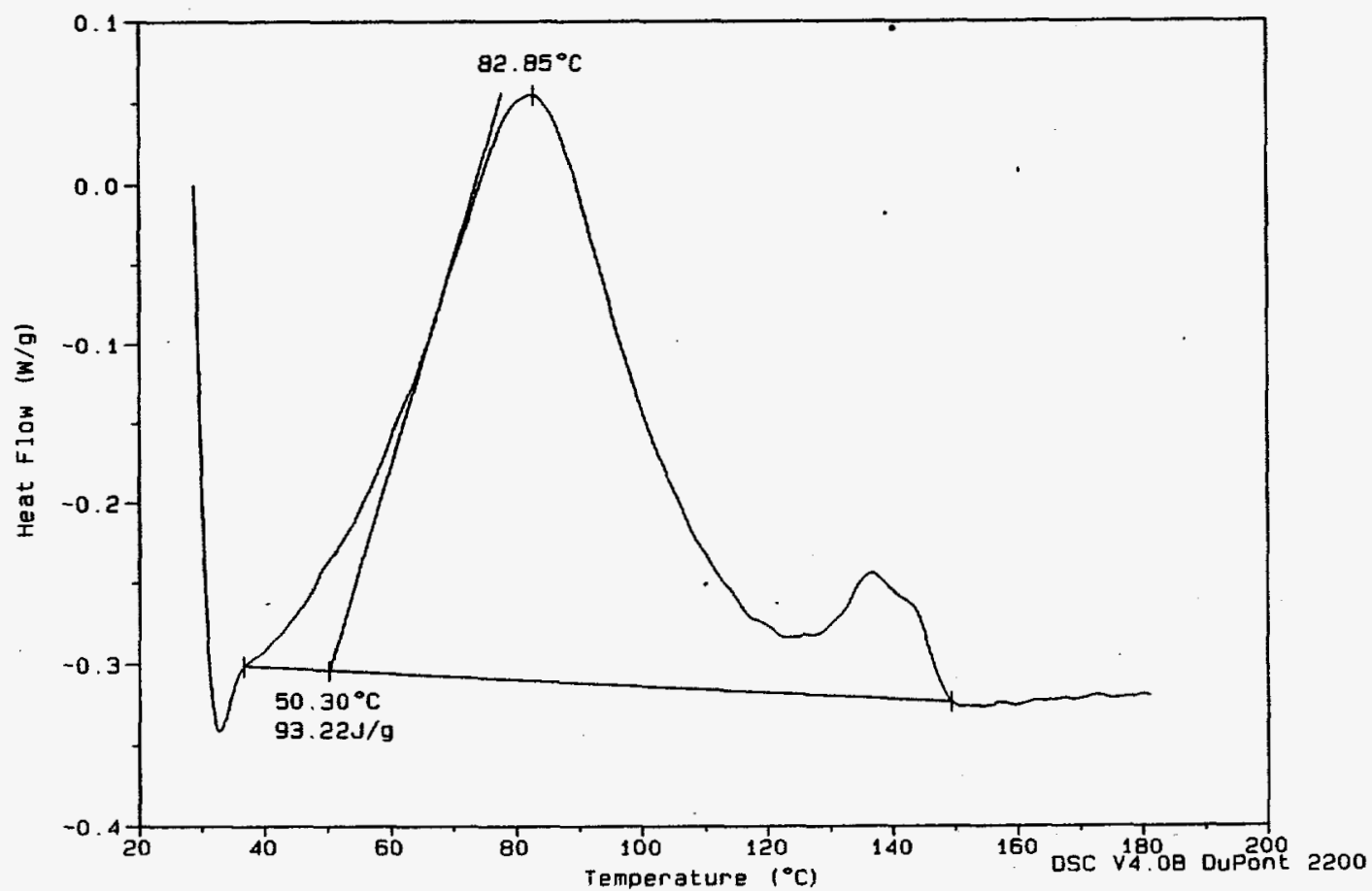

Figure D-6. DSC Curve for UV Cured $20 \mu \mathrm{L}$ Sample of HA84F Conformal Coating 
Sample: HA-84F 57005301

Size: $\quad 44.98 \mathrm{mg}$

Method: DPC

Comment: 40 UL SAMPLES

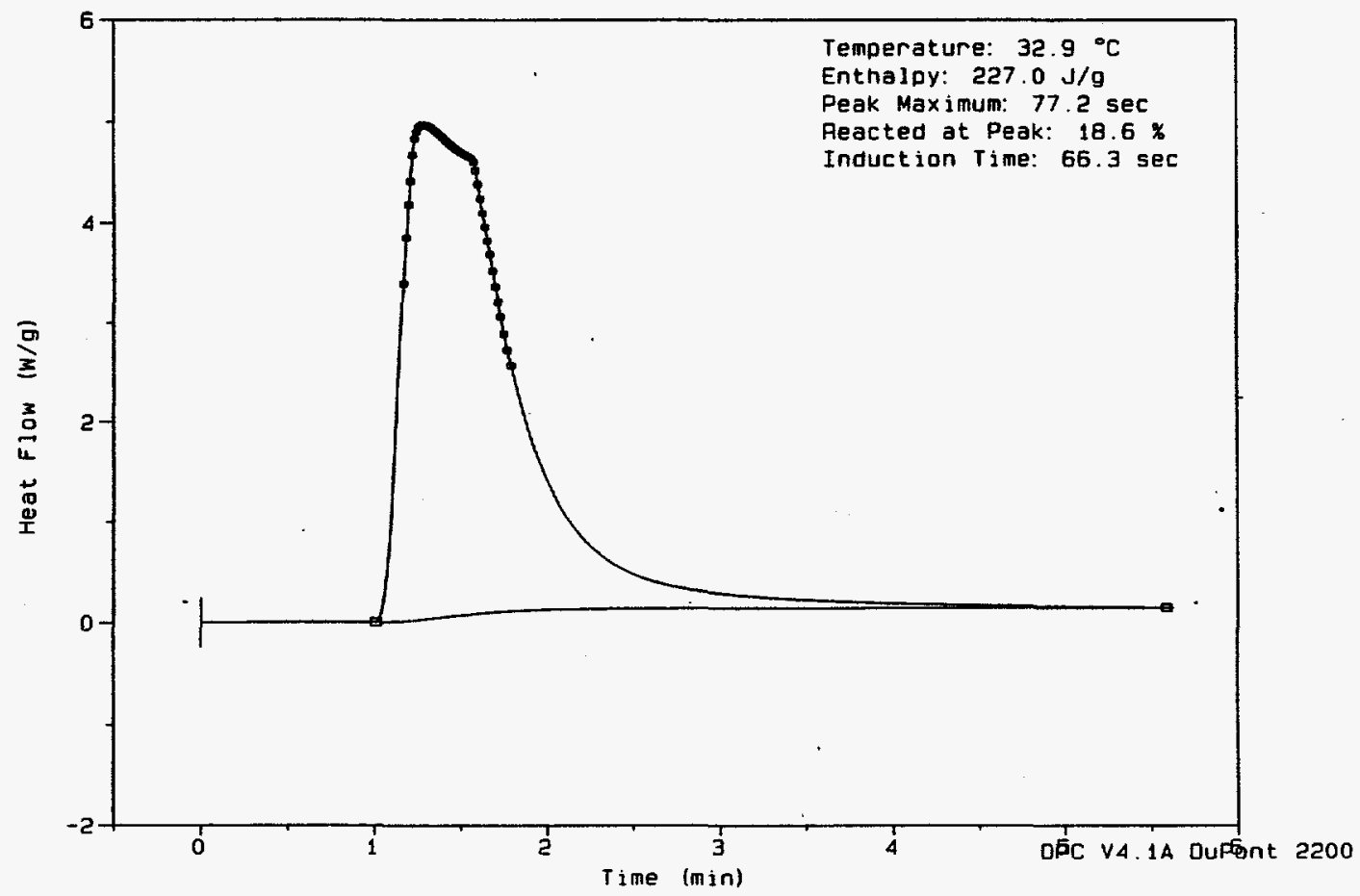

F i le: C: PARKEA 343

Operator: B.G.P

Run Date: 20-May-93 10: 16

Figure D-7. DPC Curve for $40 \mu \mathrm{L}$ Sample of HA84F Conformal Coating

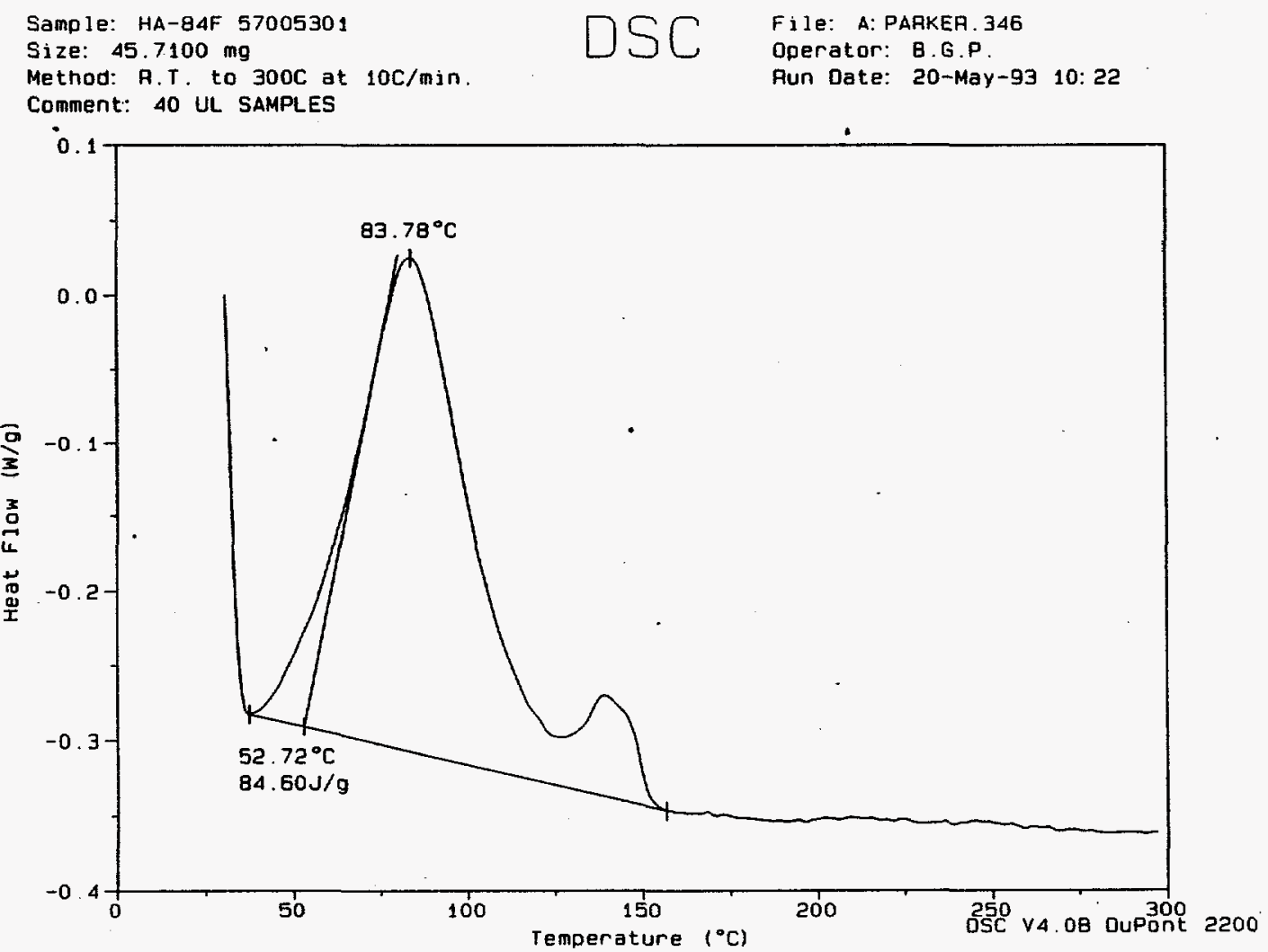

Figure D-8. DSC Curve for UV Cured $40 \mu \mathrm{L}$ Sample of HA84F Conformal Coating 
Sample: HA-84F 57005301

Size: : $6.03 \mathrm{mg}$

Comment:
File: A: PAFKER. 347

Operator: B. G.P.

Run Date: 20-May-93

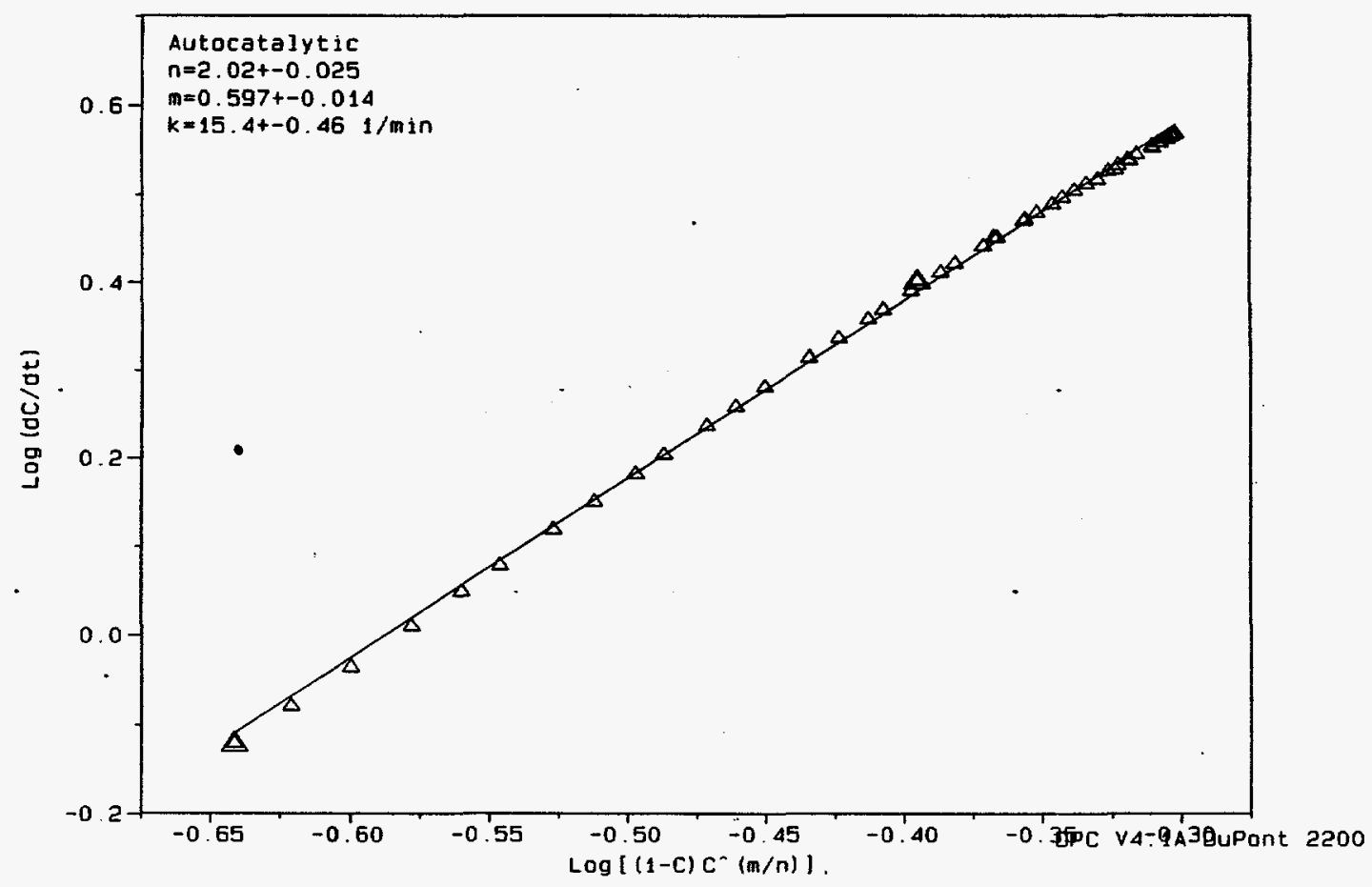

Figure D-9. Closeness of Fit Curve for $5 \mu \mathrm{L}$ Sample of HA84F Conformal Coating

Sample: HA-84F 57005301

Size: $\quad 10.91 \mathrm{mg}$

Comment: 10 UL SAMPLES
File: C: PARKER. 340

Operator: B.G.P.

Run Date: 20-May-93

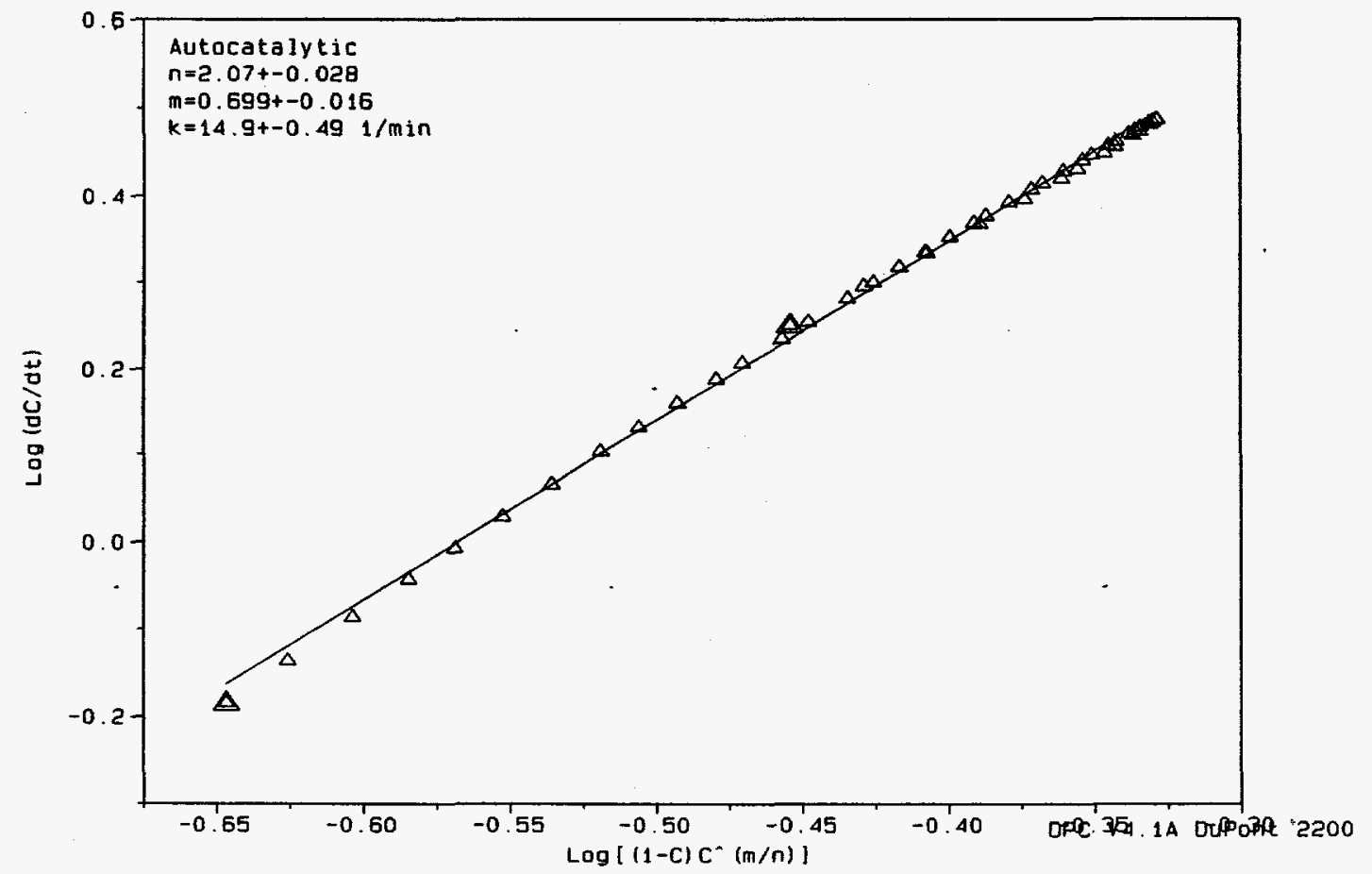

Figure D-10. Closeness of Fit Curve for $10 \mu \mathrm{L}$ Sample of HA84F Conformal Coating 
Sample: HA-84F 5700530104

Size: $22.46 \mathrm{mg}$

File: C: PARKEA. 336

Comment: 20 UL SAMPLES

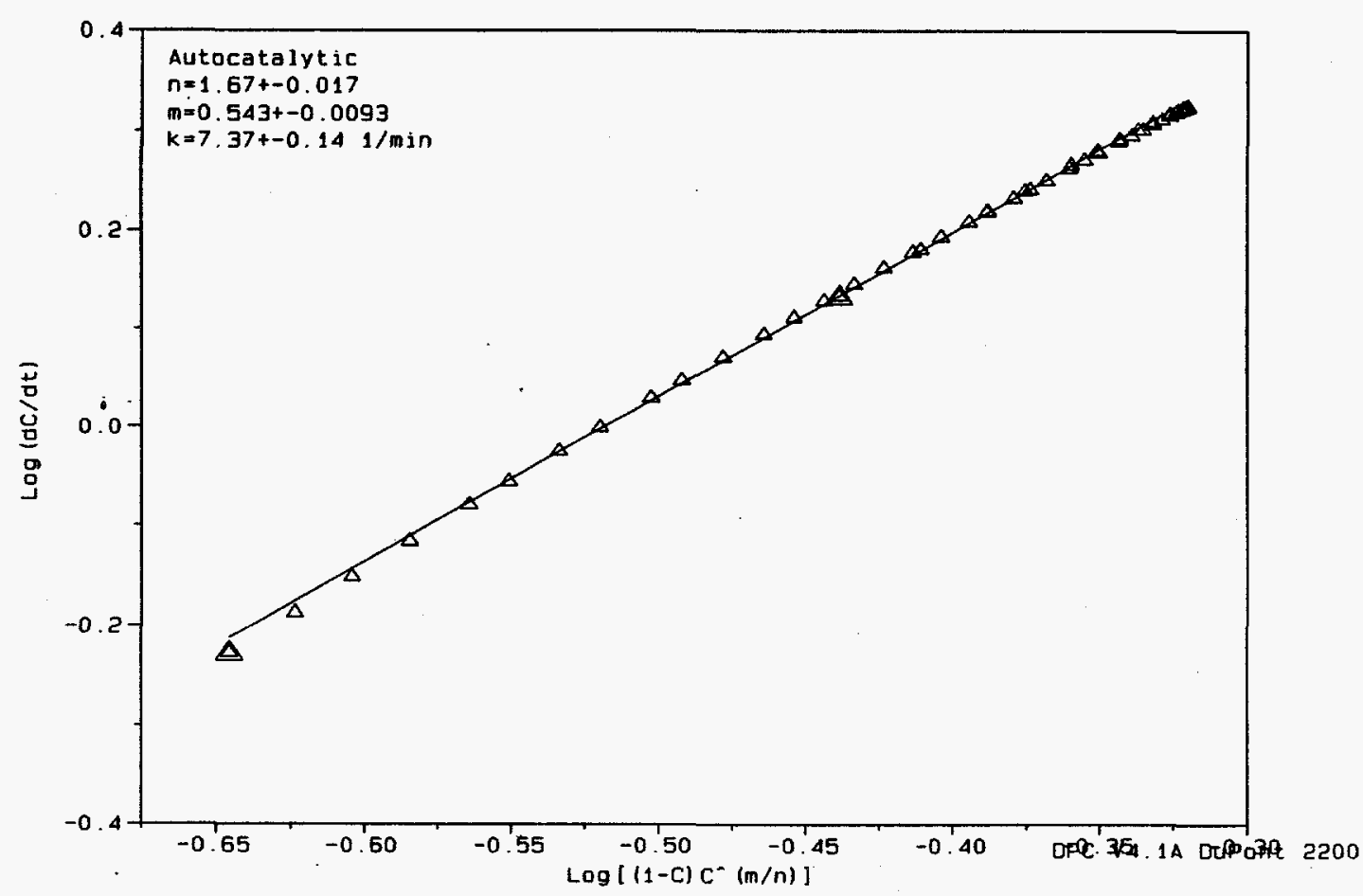

Figure D-11. Closeness of Fit Curve for $20 \mu \mathrm{L}$ Sample of HA84F Conformal Coating

Sample: HA-B4F 57005301

Size: $\quad 45.71 \mathrm{mg}$

Comment: 40 UL SAMPLES
File: C: PARKER. $\mathbf{3 4 4}$

Operator: B.G.P

Run Date: 20-May-93

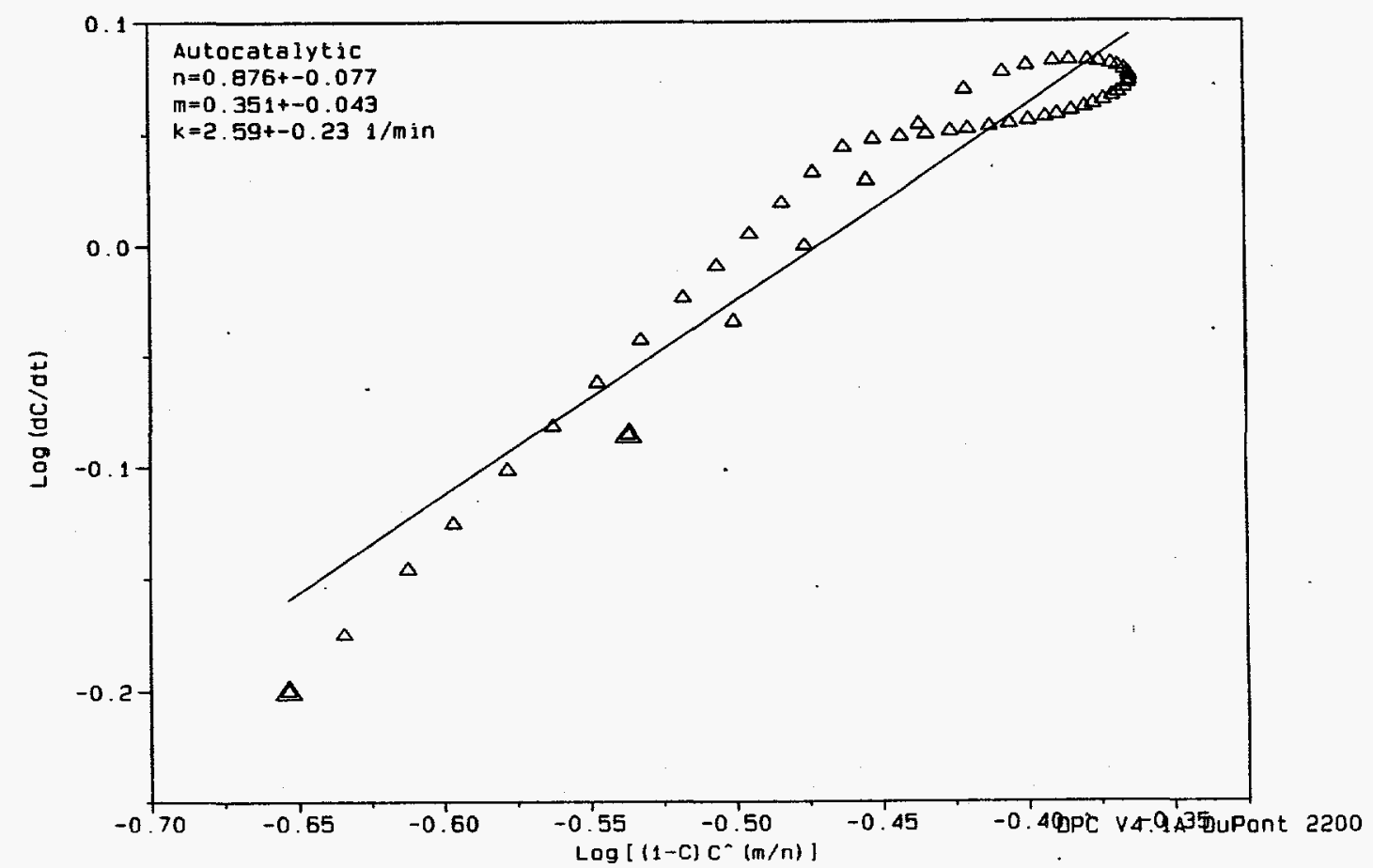

Figure D-12. Closeness of Fit Curve for $40 \mu \mathrm{L}$ Sample of HA84F Conformal Coating 
DIFFERENTIAL PHOTO CALORIMETRY KINETICS REPORT

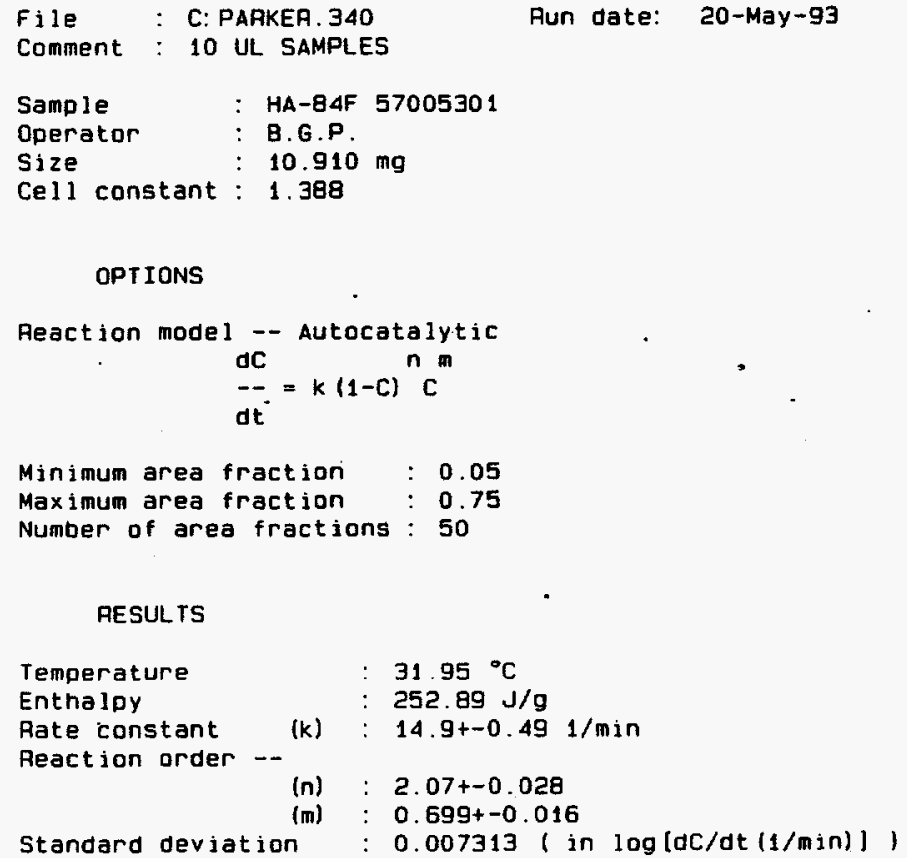

RESULTS

Figure D-13. Kinetics Report for $10 \mu \mathrm{L}$ Sample of HA84F Conformal Coating

Sample: HA-84F 57005301

Size: $\quad 10.91 \mathrm{mg}$

Fi le: C: PARKER. 340

Comment: 10 UL SAMPLES

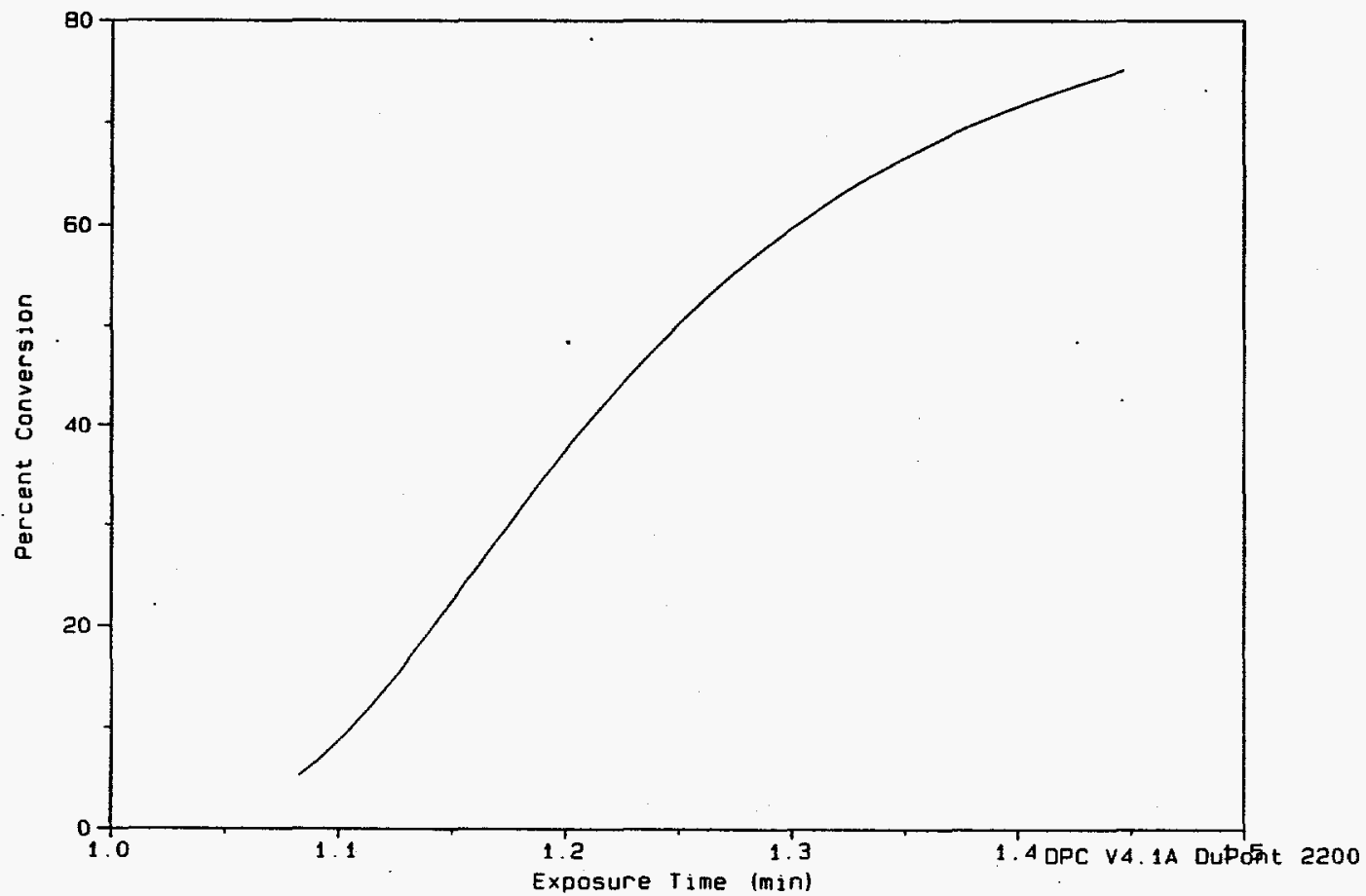

Figure D-14. Cure Rate Versus Exposure Time for $10 \mu \mathrm{L}$ Sample of HA84F Conformal Coating 


\section{APPENDIX E}

Characterization of UV Curing Equipment 


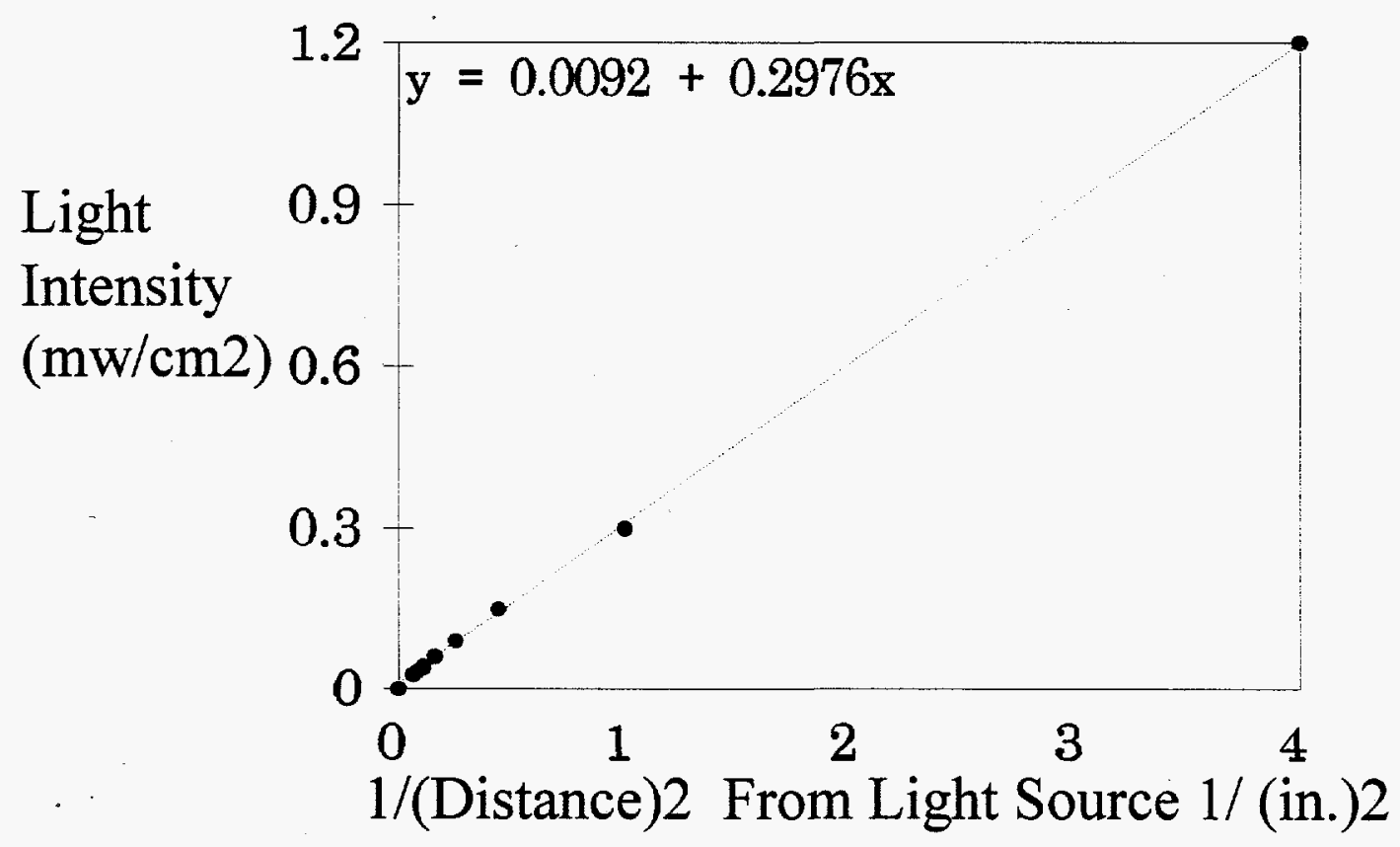

Figure E-1. Light Intensity Versus 1/(Distance) ${ }^{2}$ for Teklite Handgun

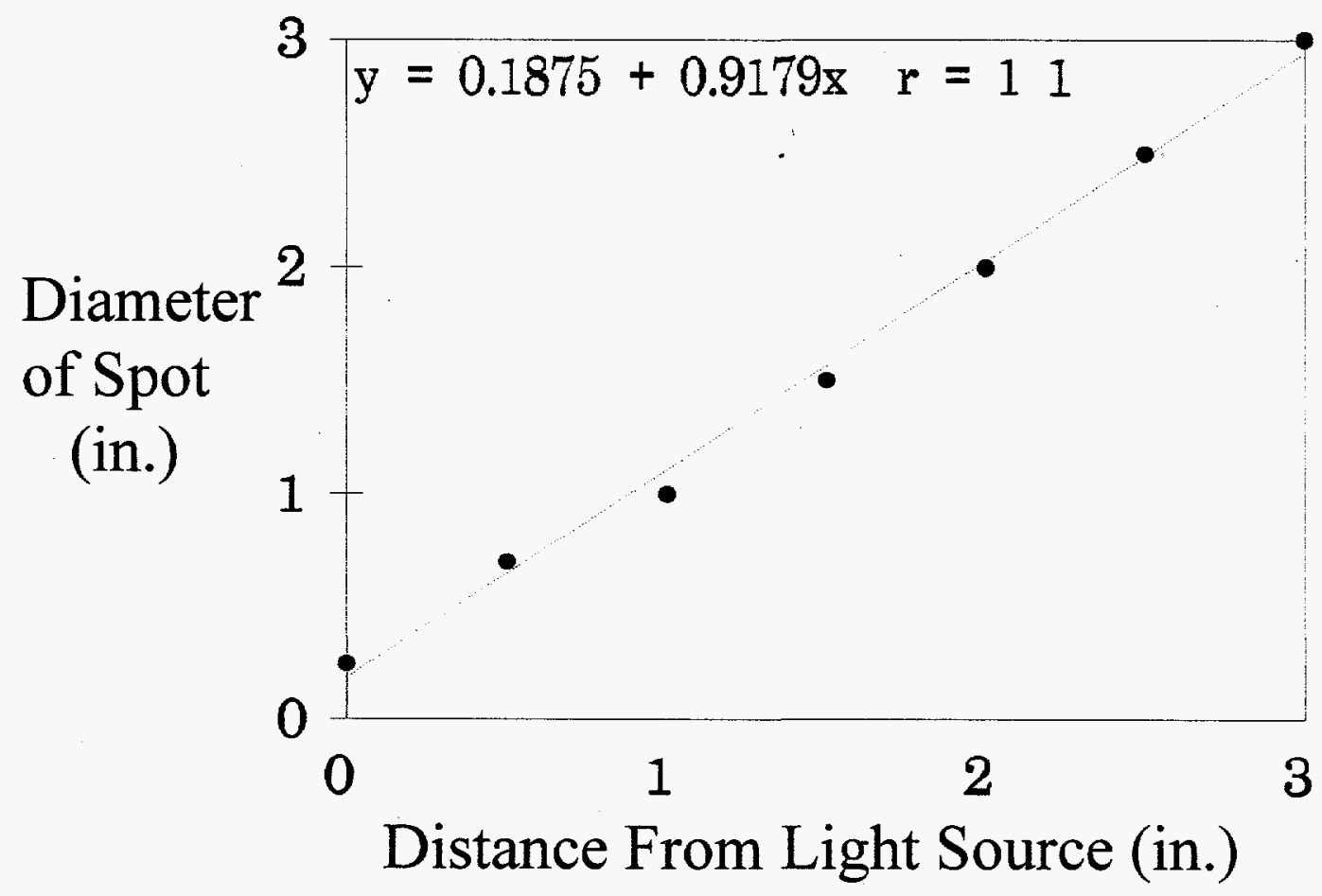

Figure E-2. Spot Diameter Versus Distance From Tecklite Handgun 


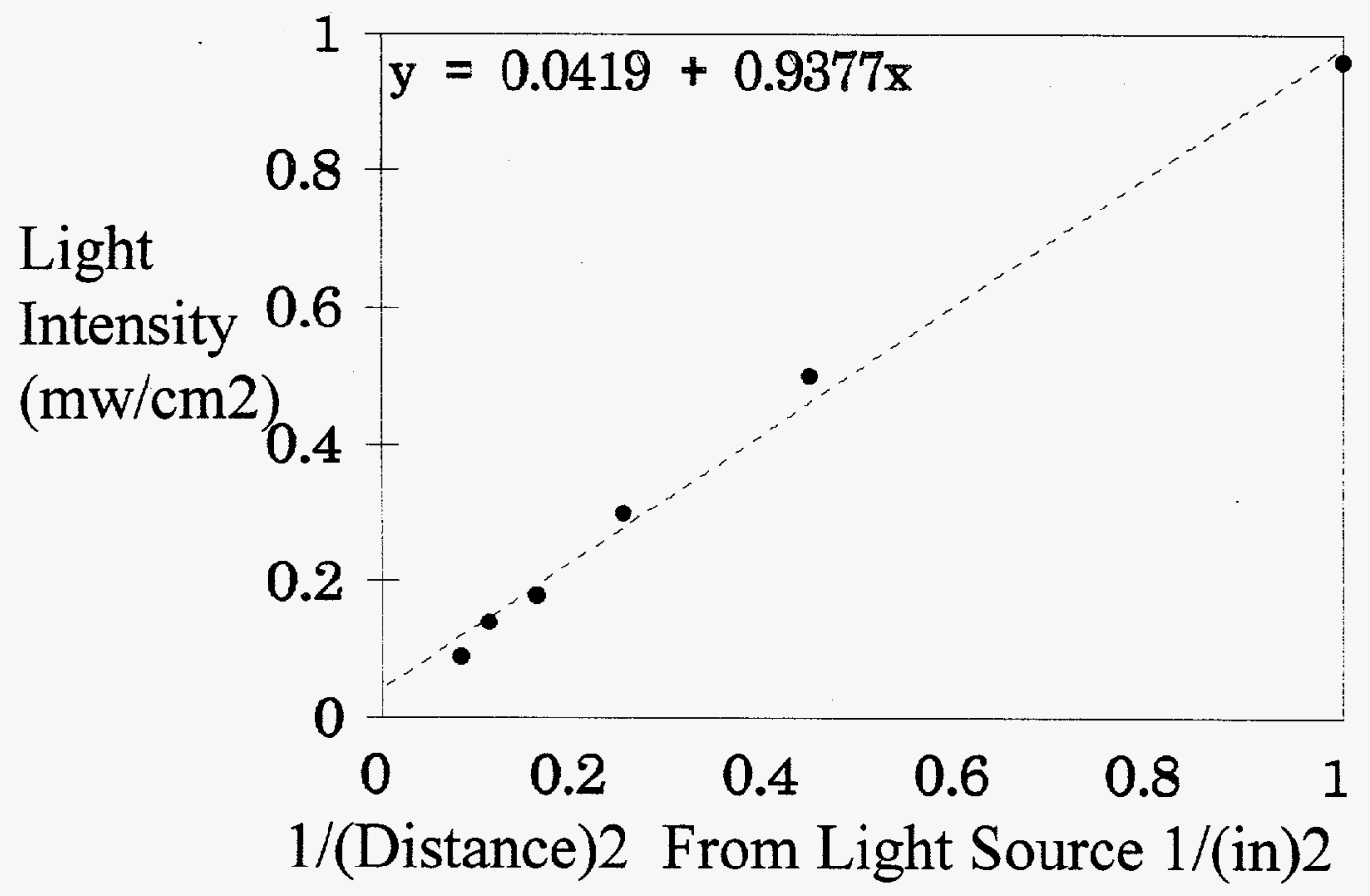

Figure E-3. Light Intensity Versus $1 /$ (Distance) $^{2}$ for Teklite ECLM 400

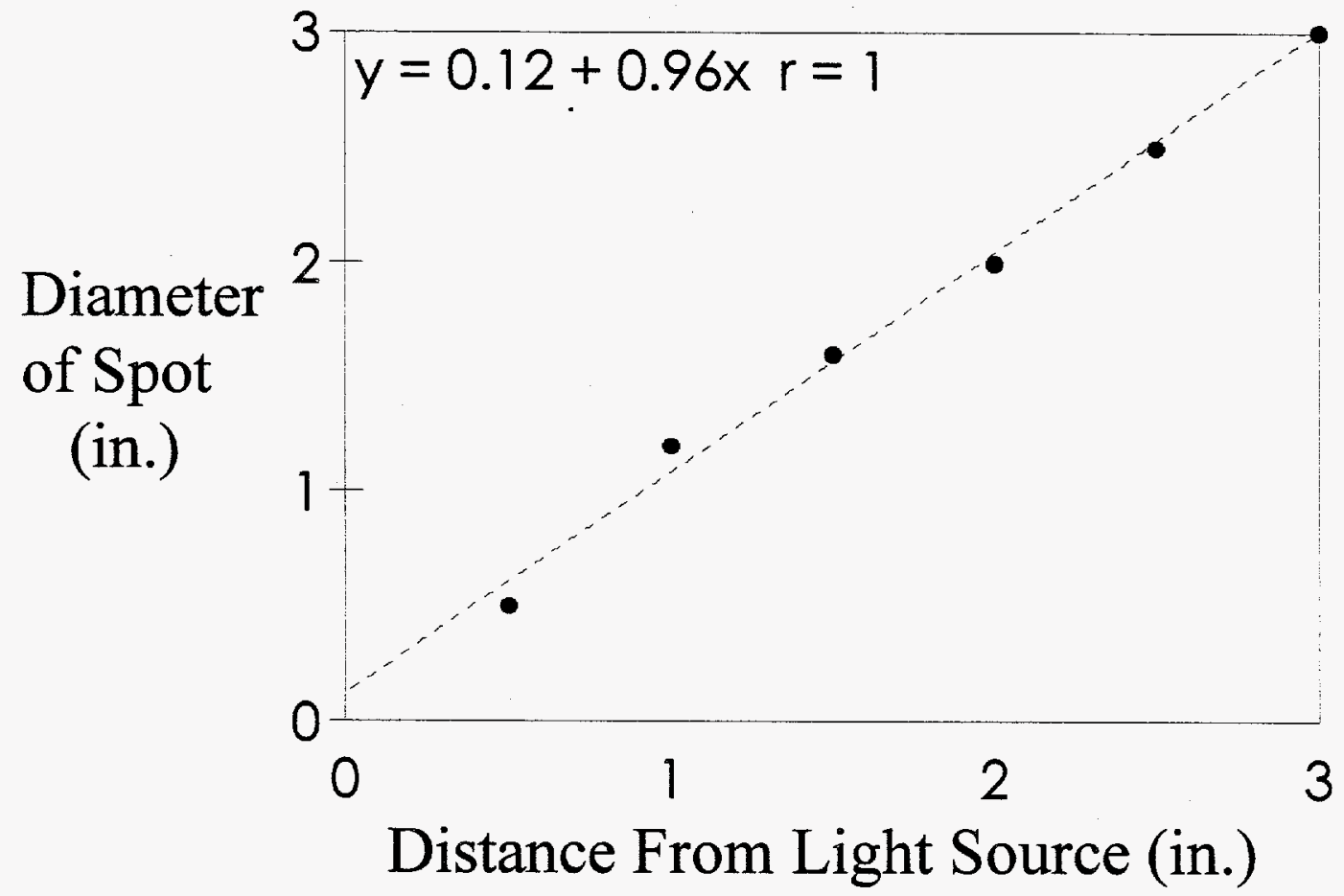

Figure E-4. Spot Diameter Versus Distance From Tecklite ECLM 400 


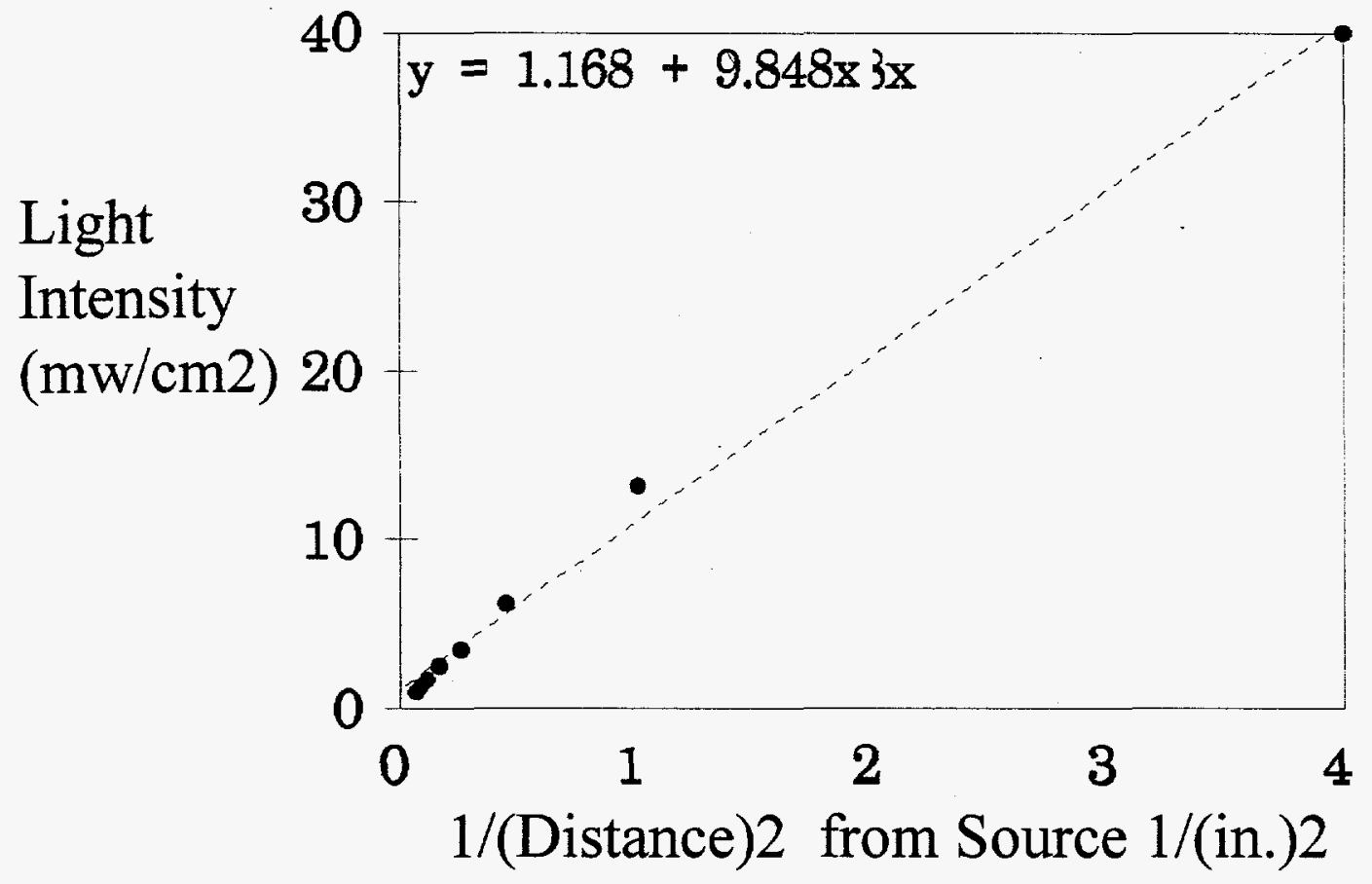

Figure E-5. Light Intensity Versus $1 /$ (Distance) $^{2}$ for EFOUS Ultracure 100 UV Light Source

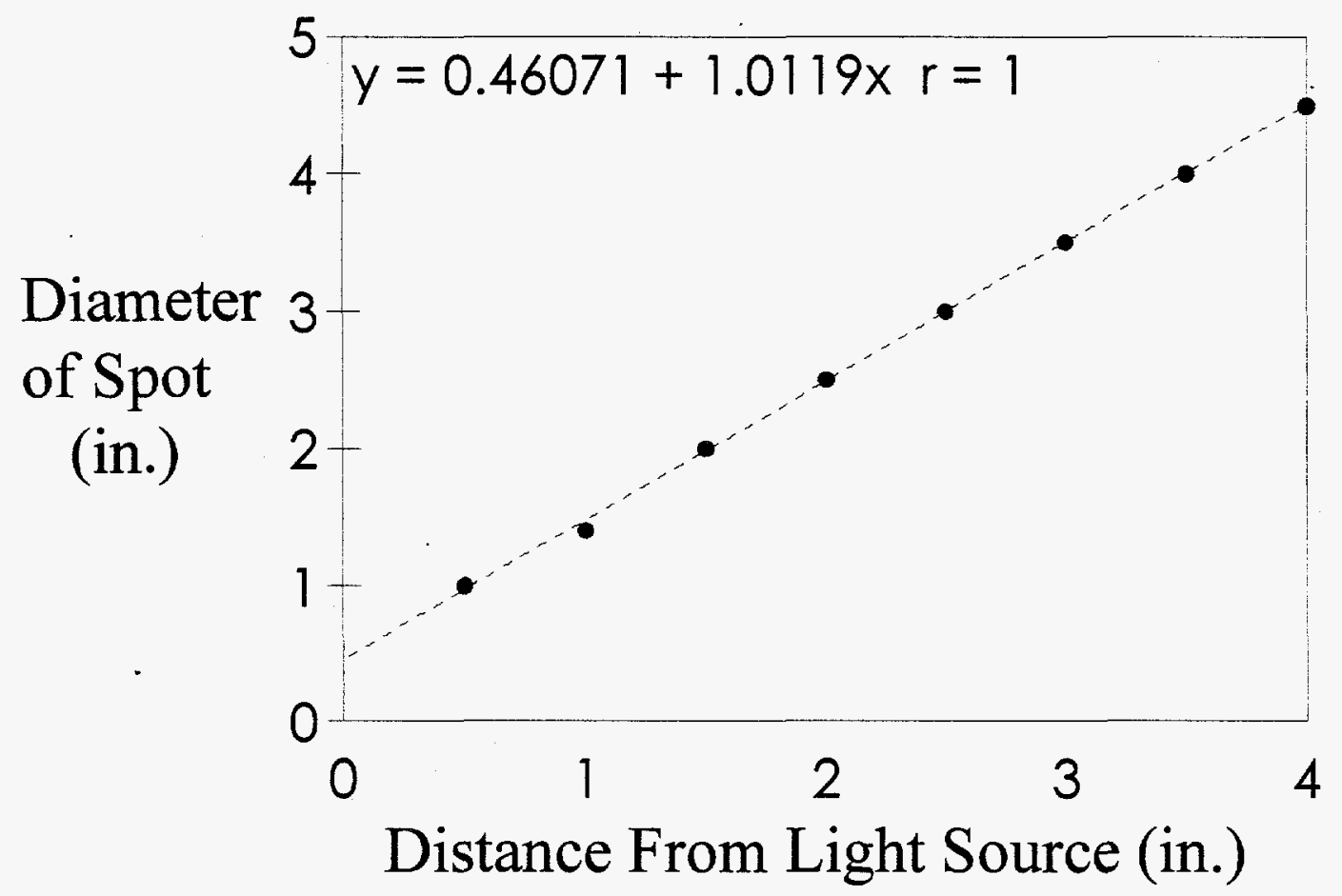

Figure E-6. Spot Diameter Versus Distance From EFOUS Ultracure 100 UV Light Source 


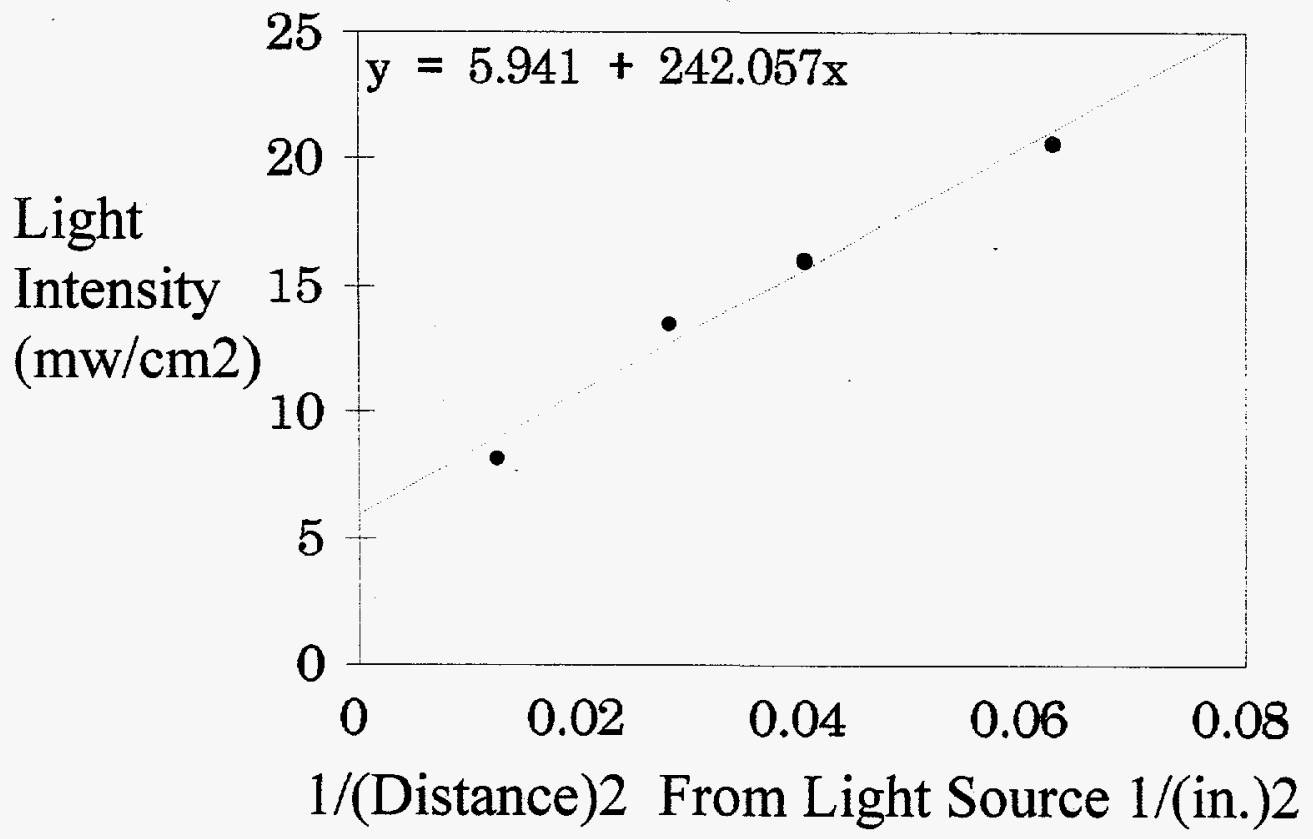

Figure E-7. Light Intensity Versus 1/(Distance) $)^{2}$ for Dymax UV Light Source

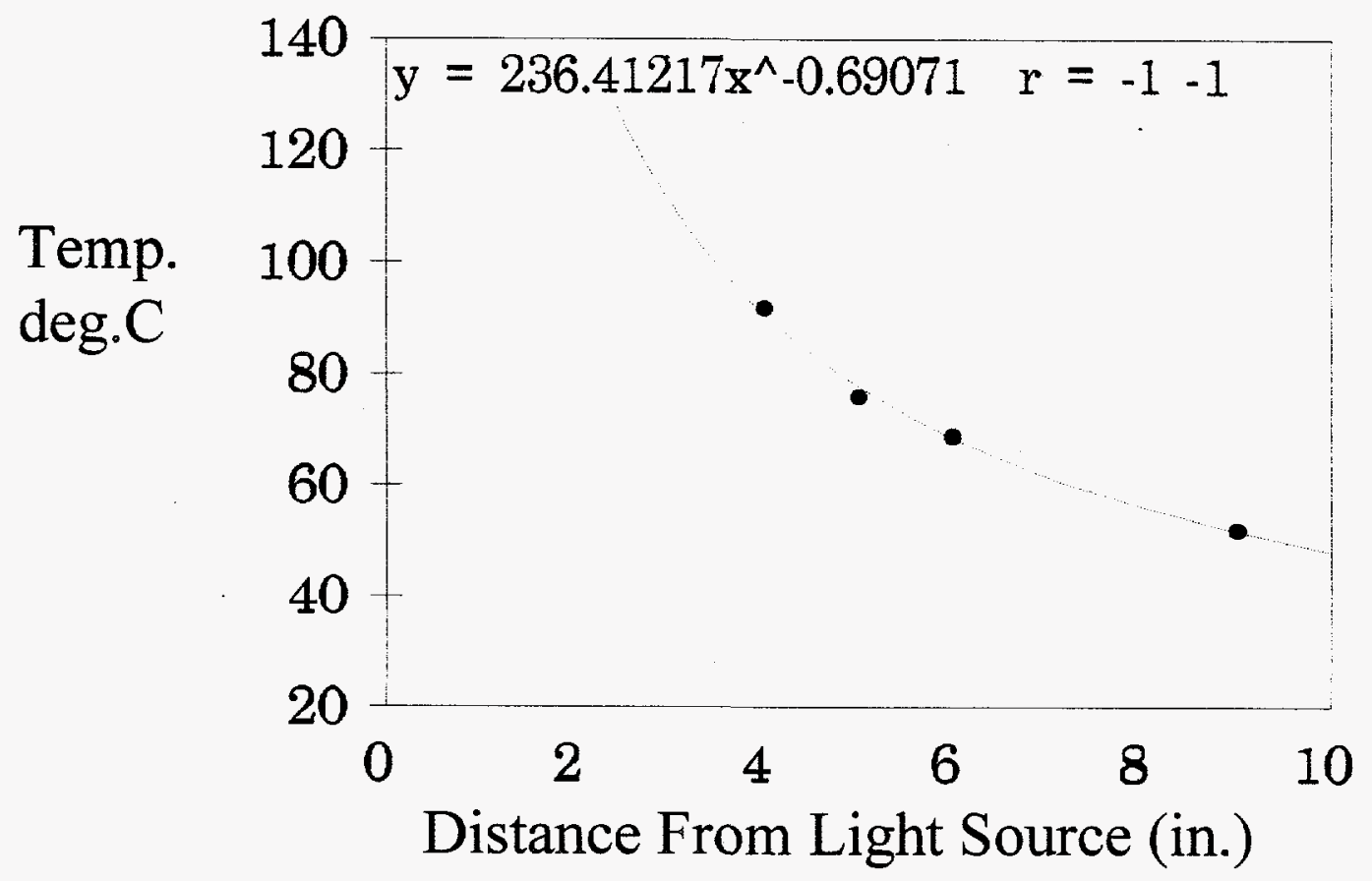

Figure E-8. Temperature Versus Distance From Dymax UV Light Source 


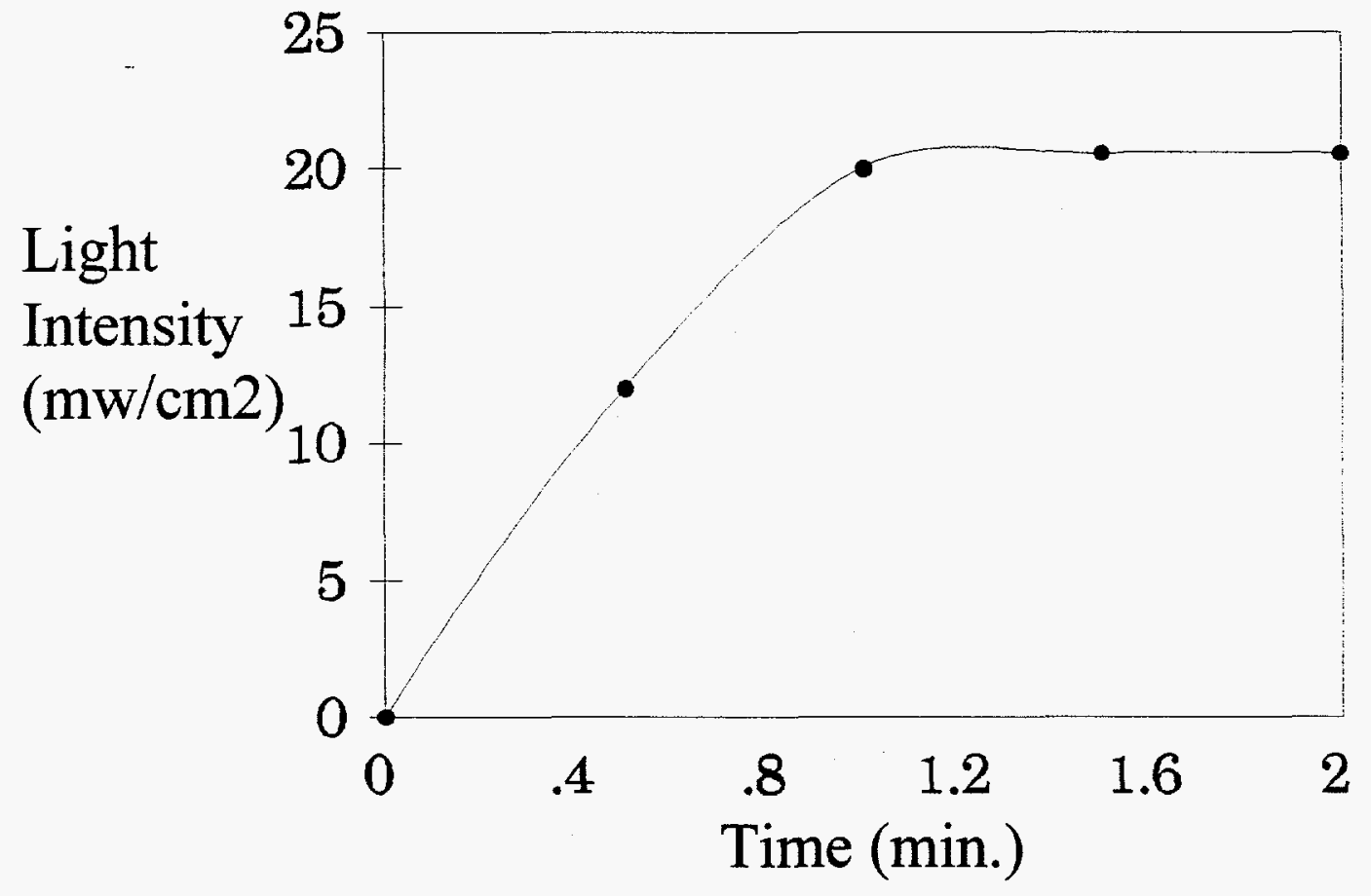

Figure E-9. Light Intensity Versus Time for Dymax UV Light Source at 4 Inches

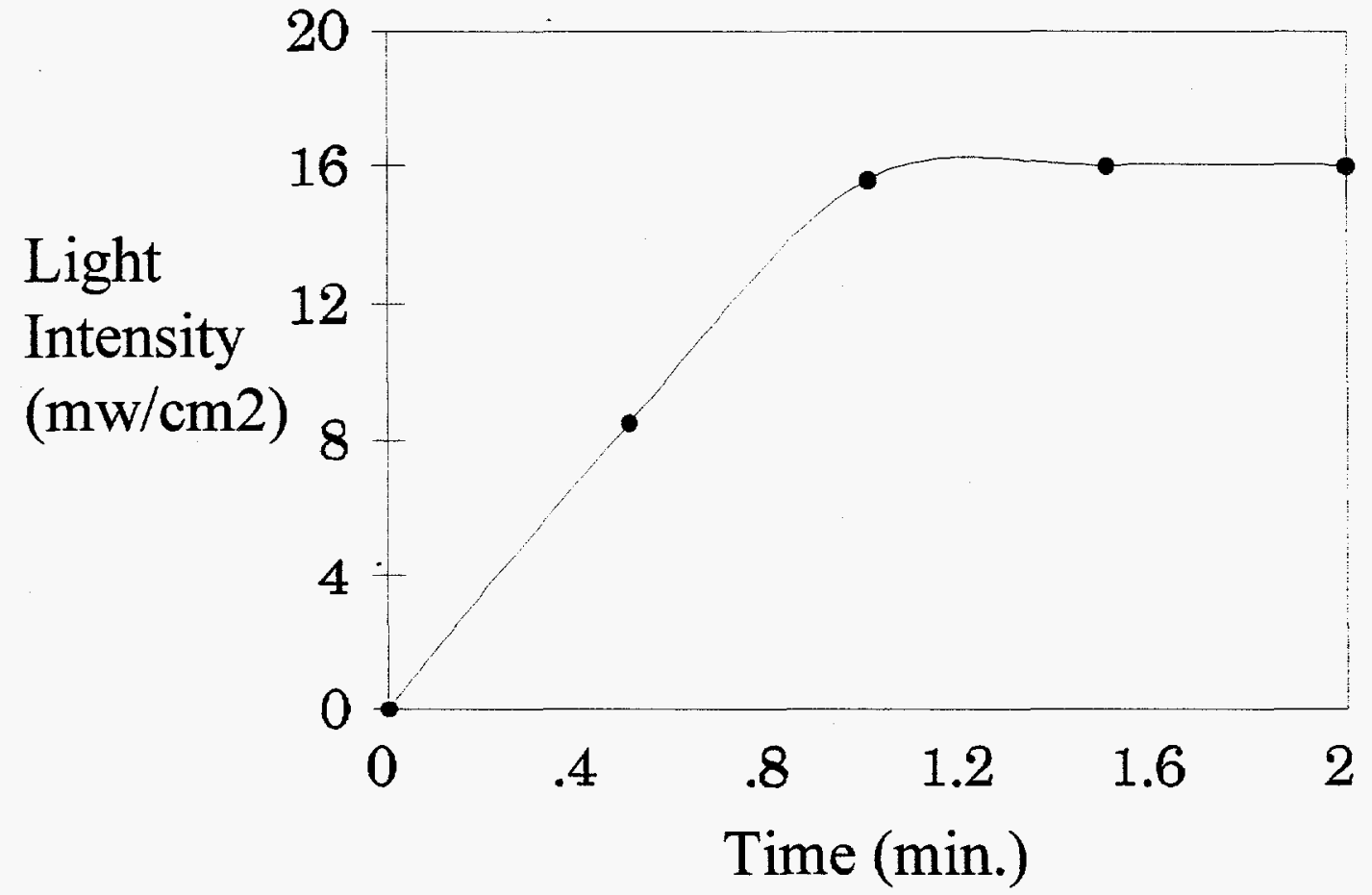

Figure E-10. Light Intensity Versus Time for Dymax UV Light Source at 5 Inches 


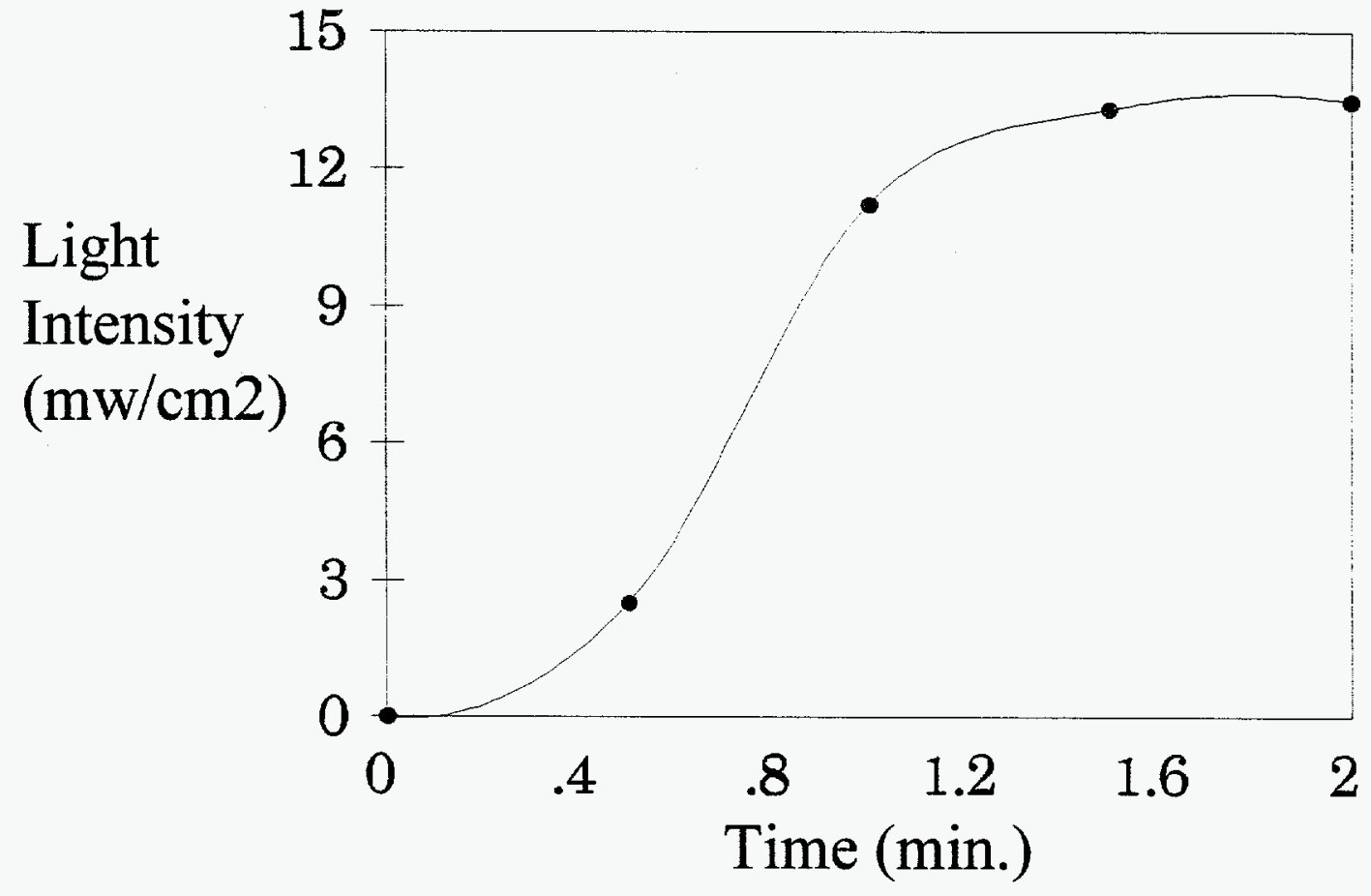

Figure E-11. Light Intensity Versus Time for Dymax UV Light Source at 6 Inches

Light

$$
10
$$

Intensity $(\mathrm{mw} / \mathrm{cm} 2)$

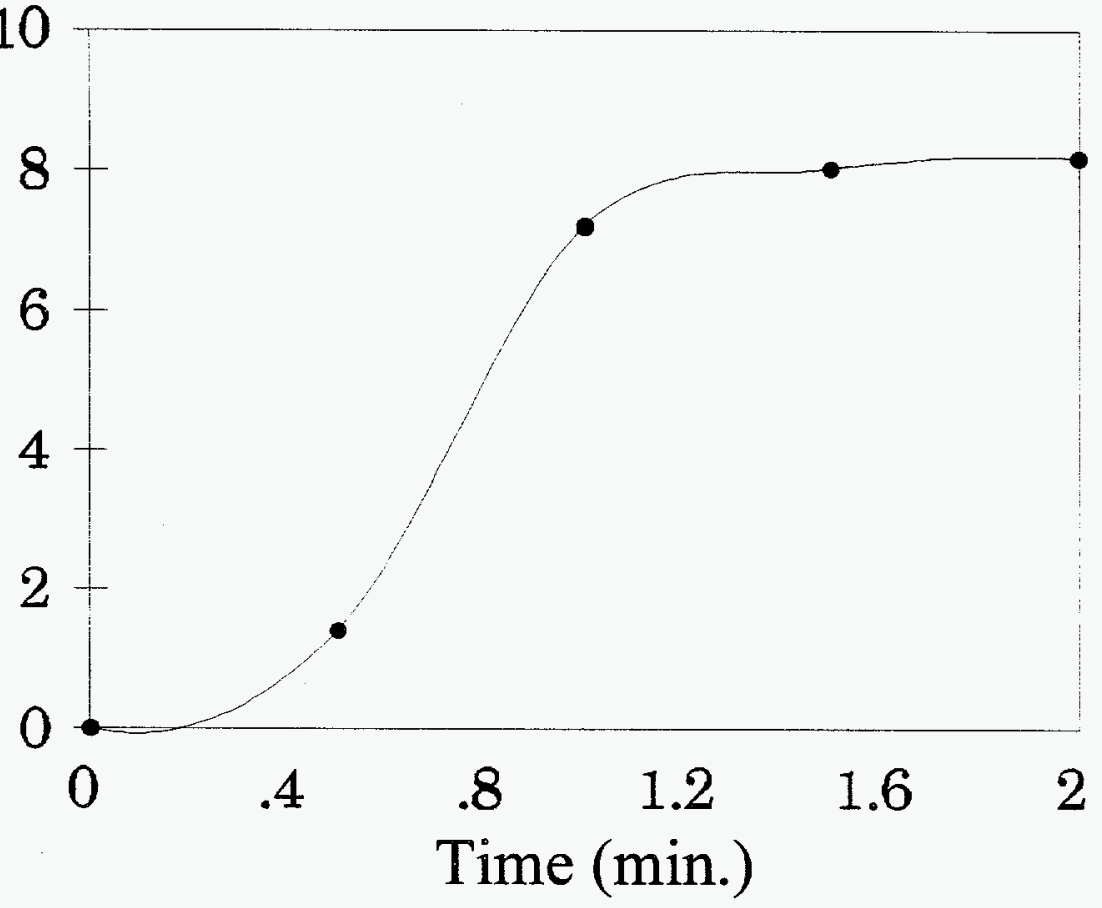

Figure E-12. Light Intensity Versus Time for Dymax UV Light Source at 9 Inches 


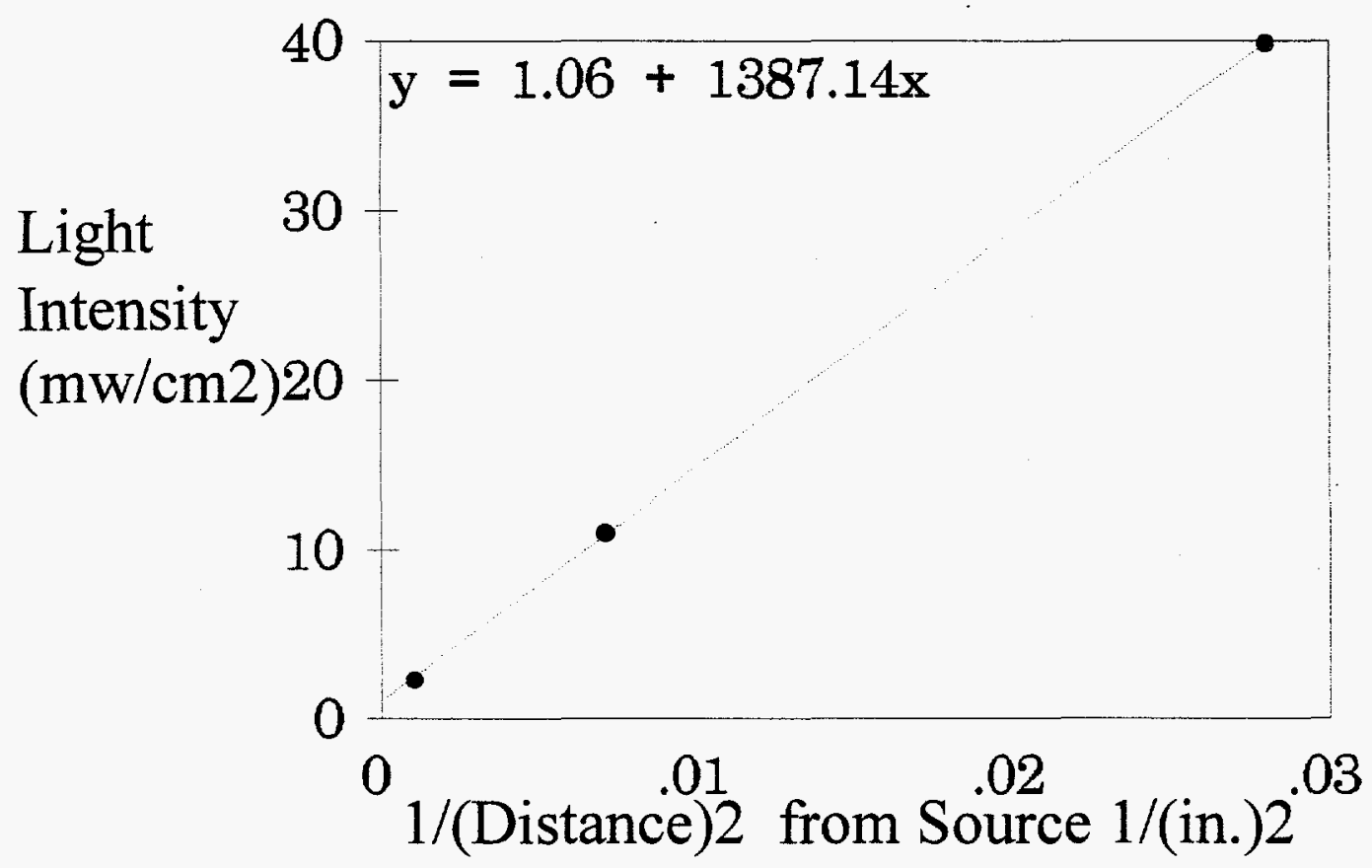

Figure E-13. Light Intensity Versus $1 /$ (Distance) $^{2}$ for Fusion Systems UV Light Source 


\section{APPENDIX F}

Solvent Swell Testing 


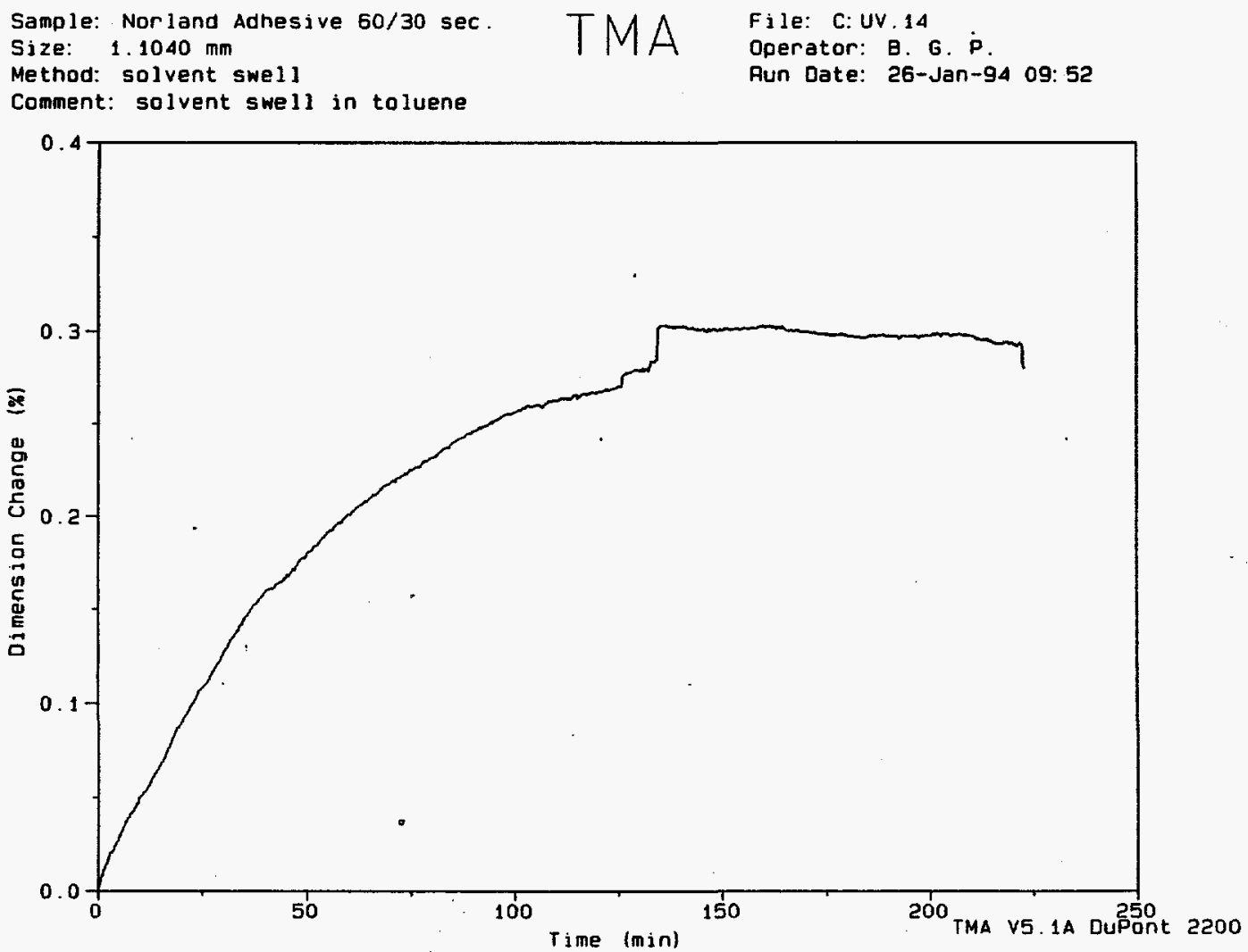

Figure F-1. Solvent Swell Test for Norland 60 in Toluene (30 sec. UV Cure)

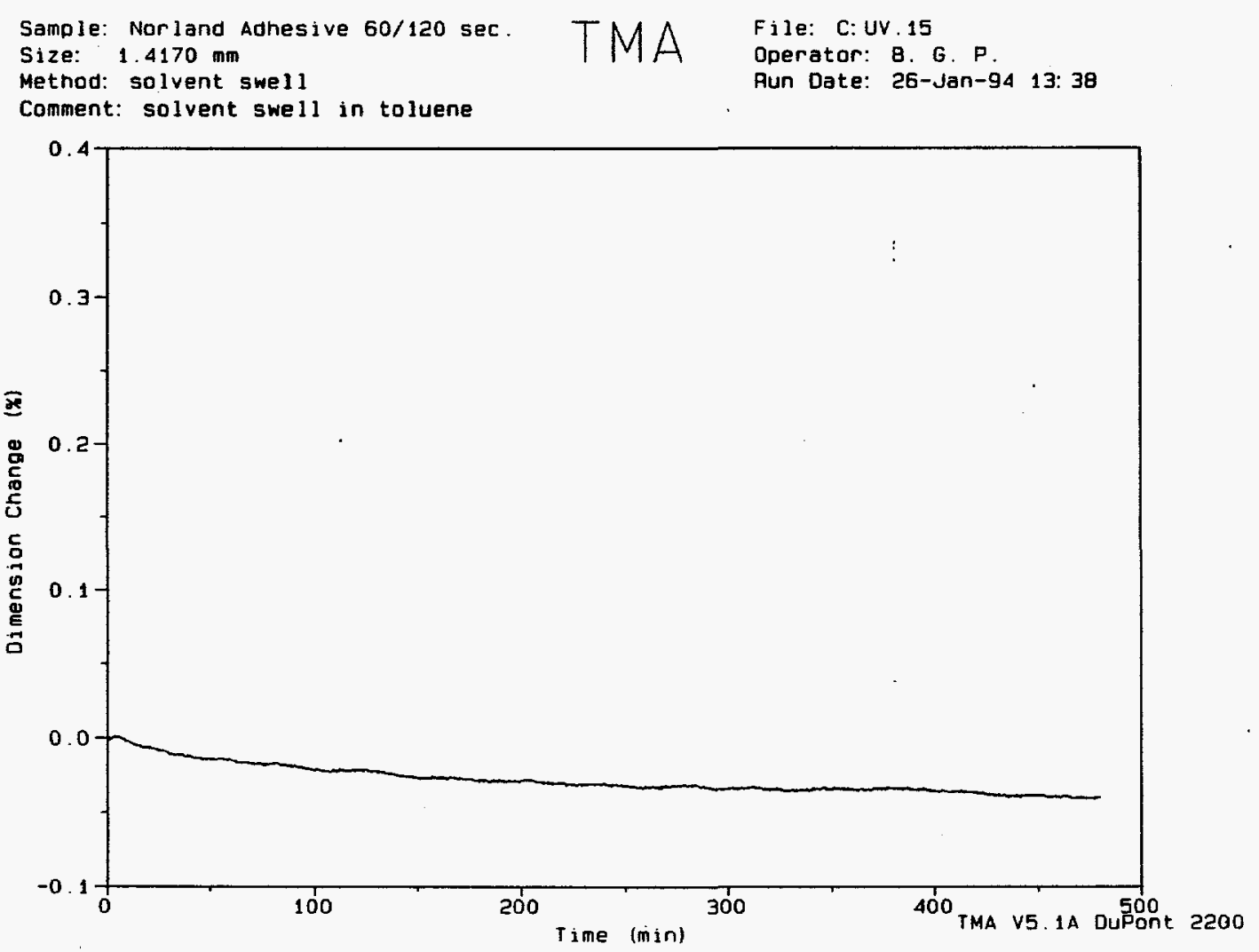

Figure F-2. Solvent Swell Test for Norland 60 in Toluene (120 sec. UV Cure) 


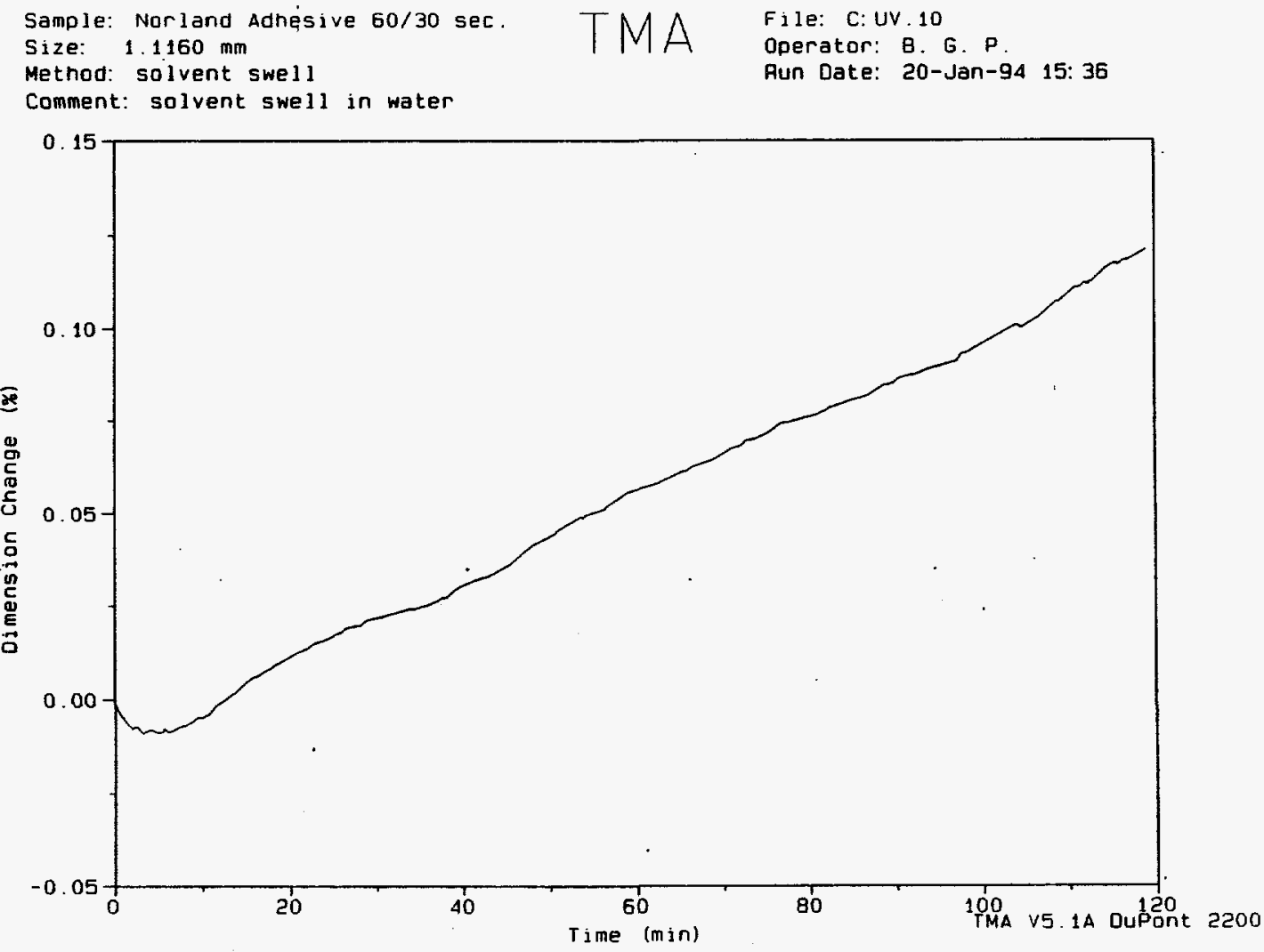

Figure F-3. Solvent Swell Test for Norland 60 in Water (30 sec. UV Cure)

Sample: Norland Adhesive 60/30 sec. Size: $1.2580 \mathrm{~mm}$

TMA

File: C: UV. 07

Method: solvent swell

Doerator: B. G. P

Comment: solvent swell in IPA

Ruri Date: 19-Jan-94 14: 16

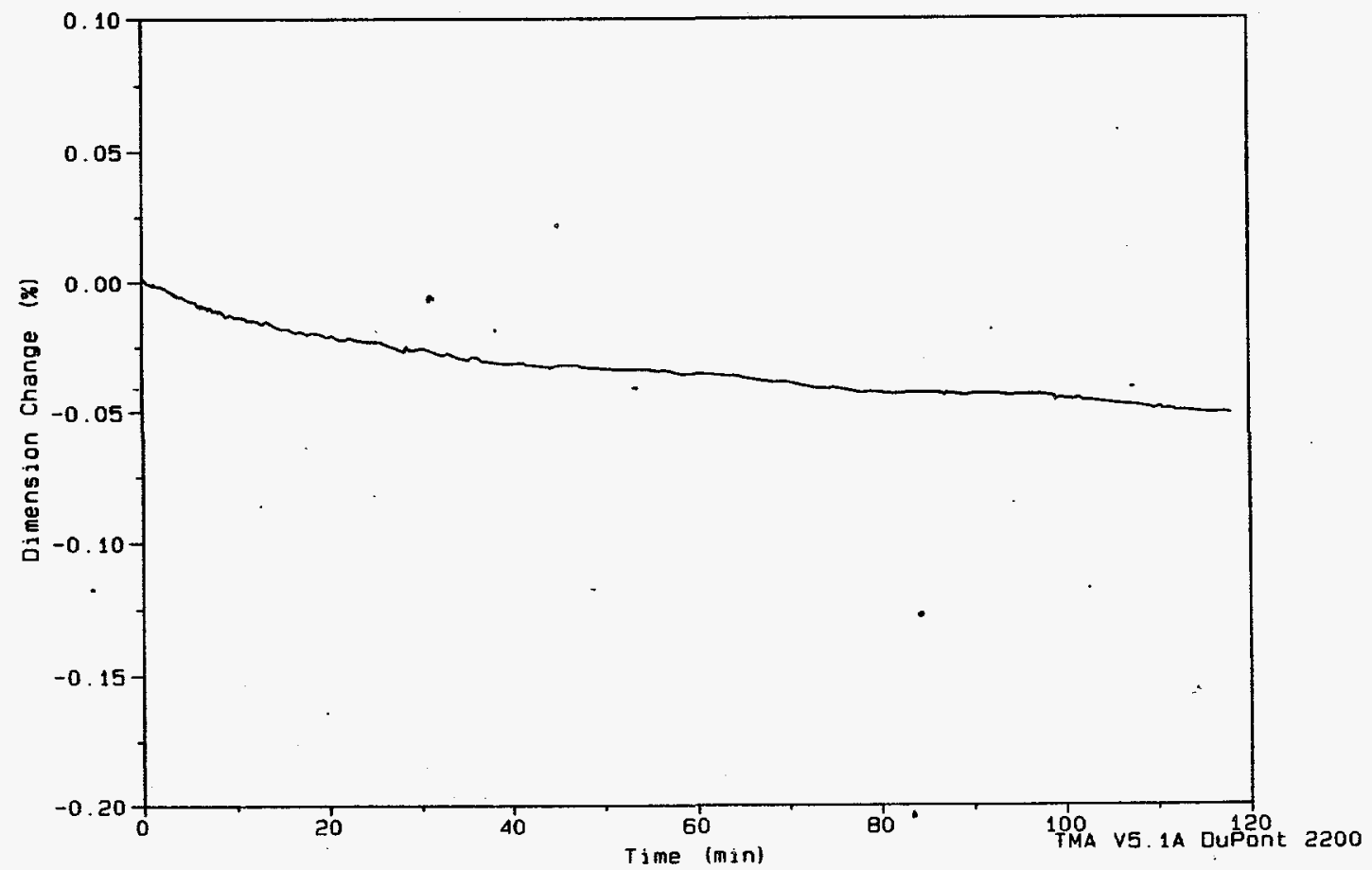

Figure F-4. Solvent Swell Test for Norland 60 in IPA (30 sec. UV Cure) 
Semple: Norland Adhesive 60/30 sec.

Size: $\quad 1.2110 \mathrm{~mm}$

Method: solvent swell

TMA

File: C: UV. 13

Comment: solvent swell in methylene chloride

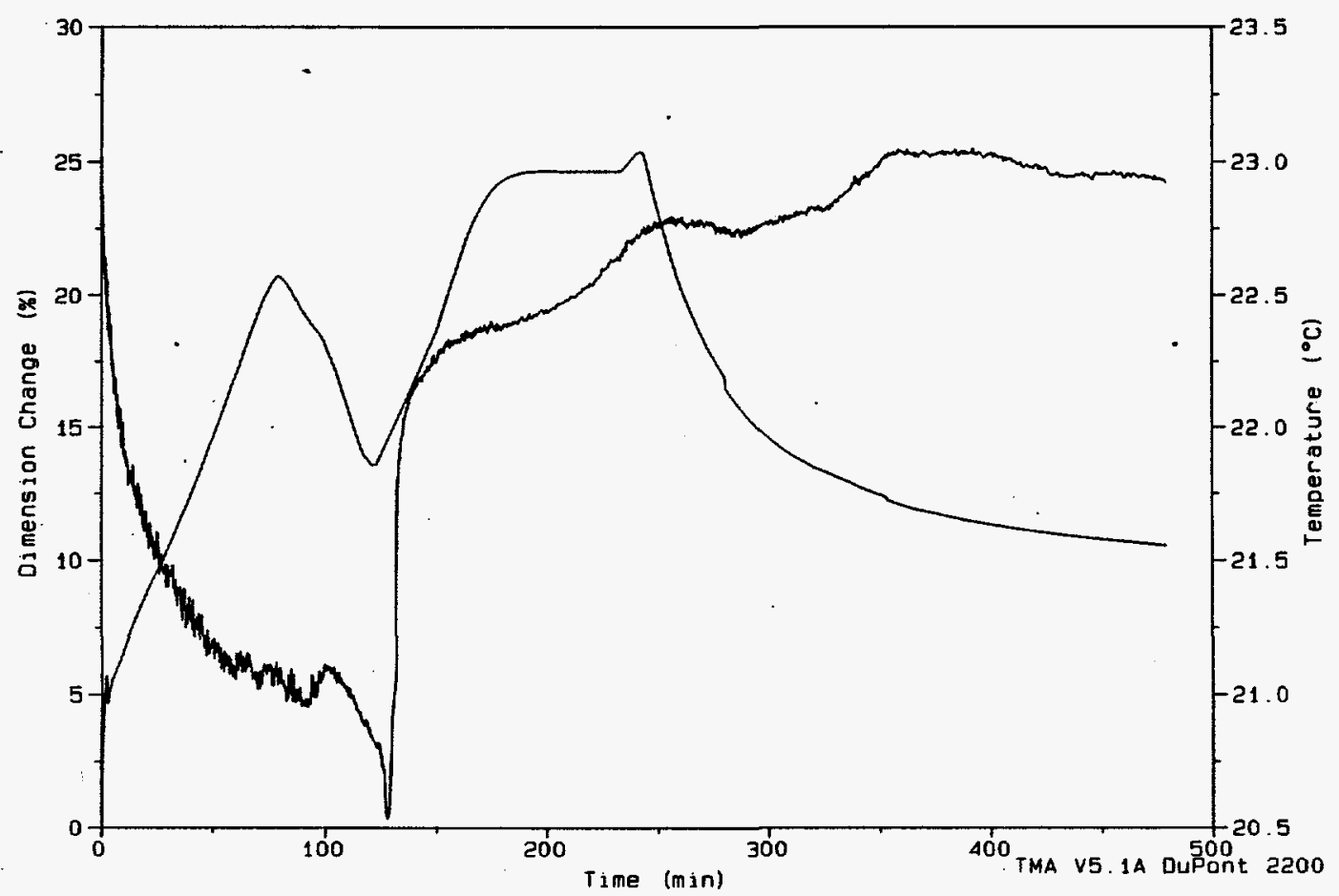

Figure F-5. Solvent Swell Test for Norland 60 in Methylene Chloride (30 sec. UV Cure)

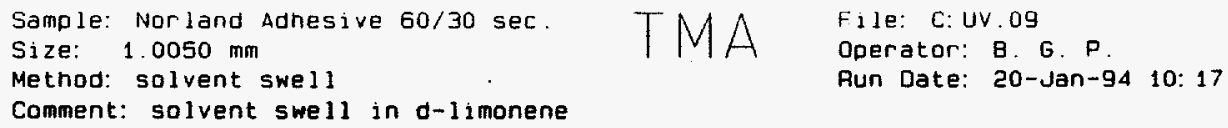

Comment: solvent swell in d-limonene

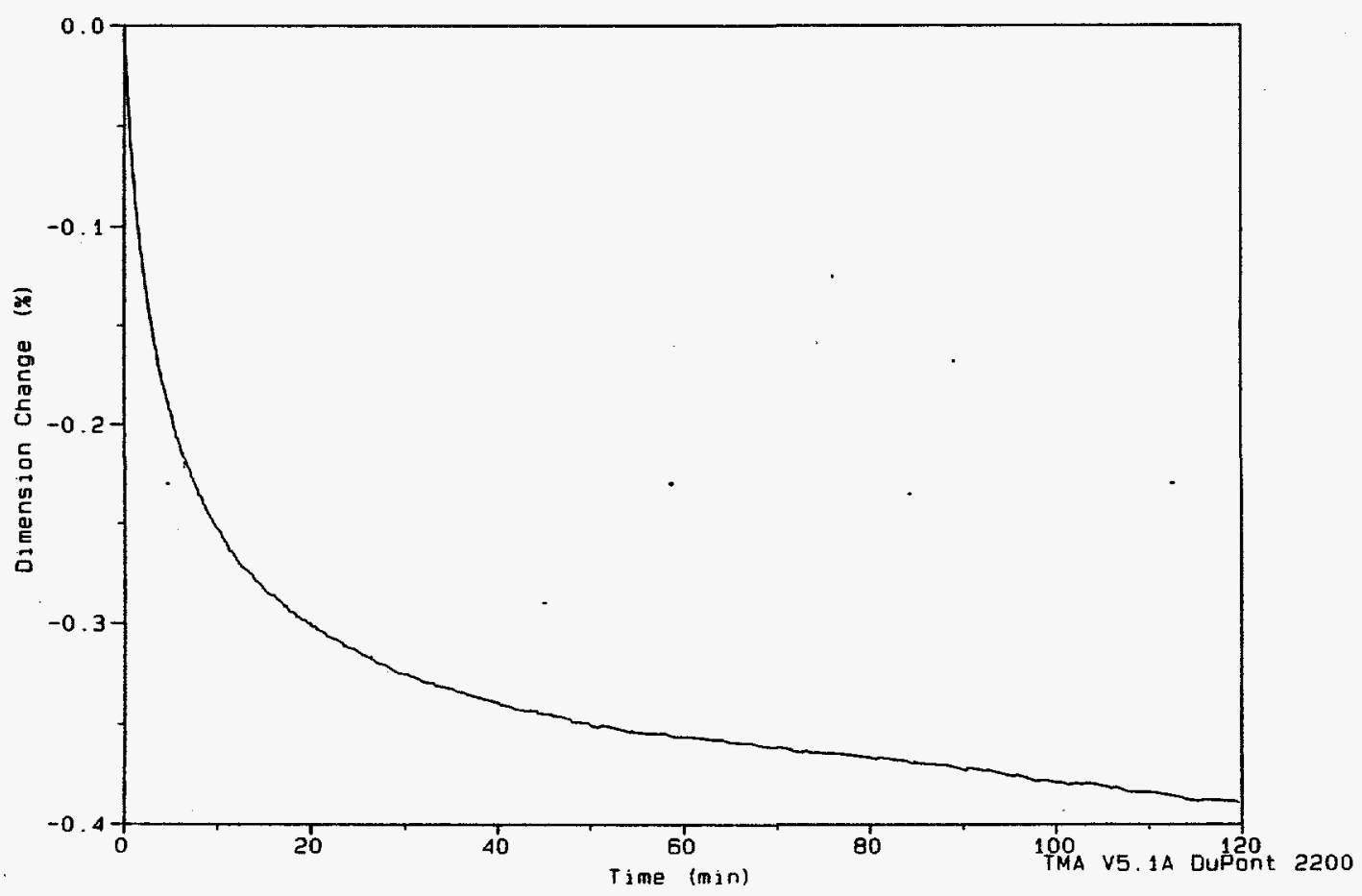

Figure F-6. Solvent Swell Test for Norland 60 in d-Limonene (30 sec. UV Cure) 
Sample: Nor land Adhesive 60

Size: $1.2800 \mathrm{~mm}$

TMA

File: C: UV. 04

Method: solvent swell

Operator: B. G. P

Comment: solvent swell in d-limonene

Pun Date: 18-Jan-94 10: 43

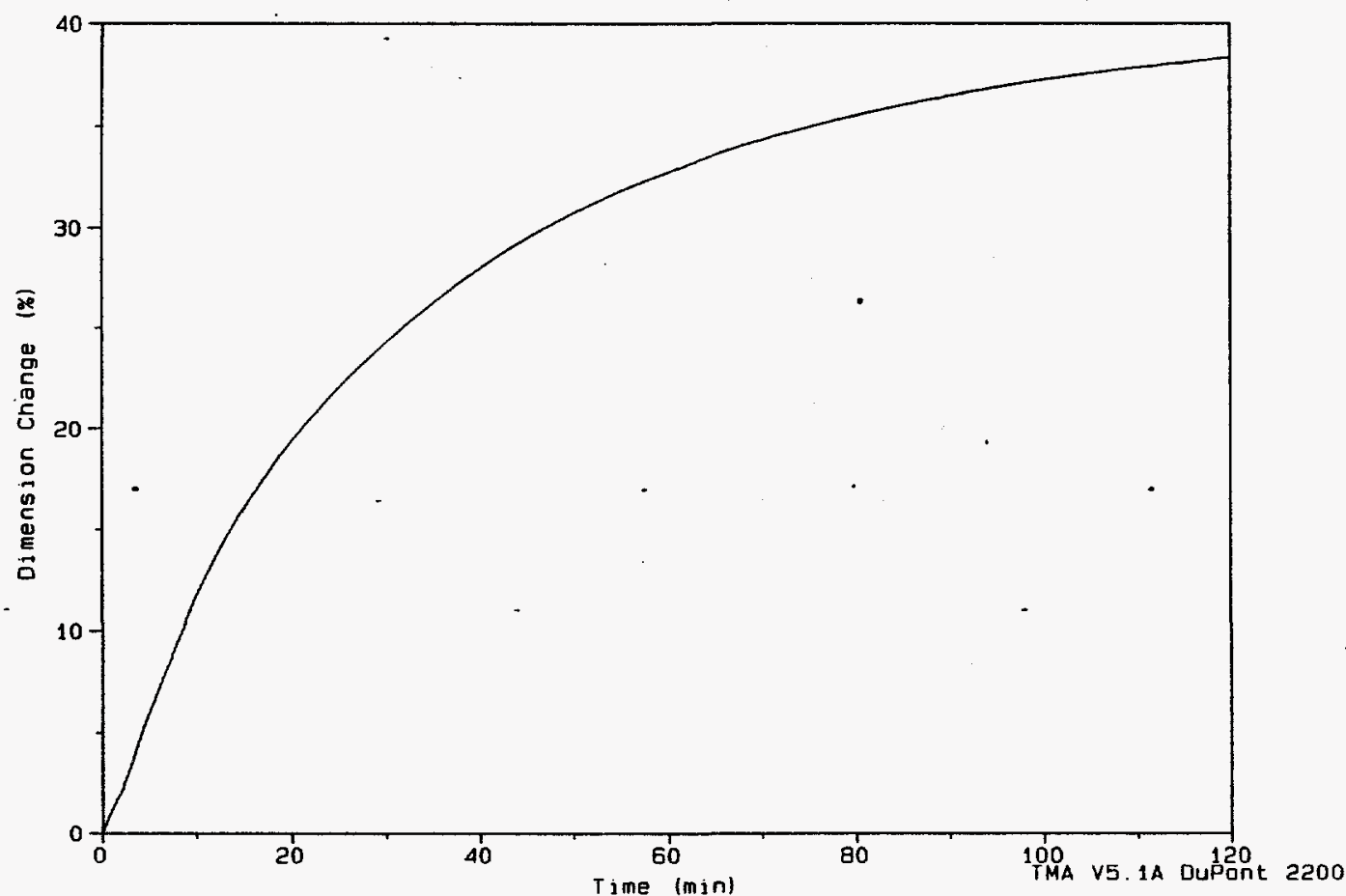

Figure F-7. Solvent Swell Test for Norland 60 in d-Limonene (120 sec. UV Cure)

Sample: Norland Adhesive 60

Size: $0.9740 \mathrm{~mm}$

Method: solvent swell

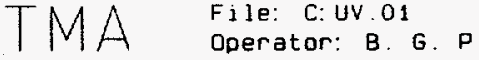

Comment: solvent swell in acetone

Run Date: 17 -Jan-94 10: 24

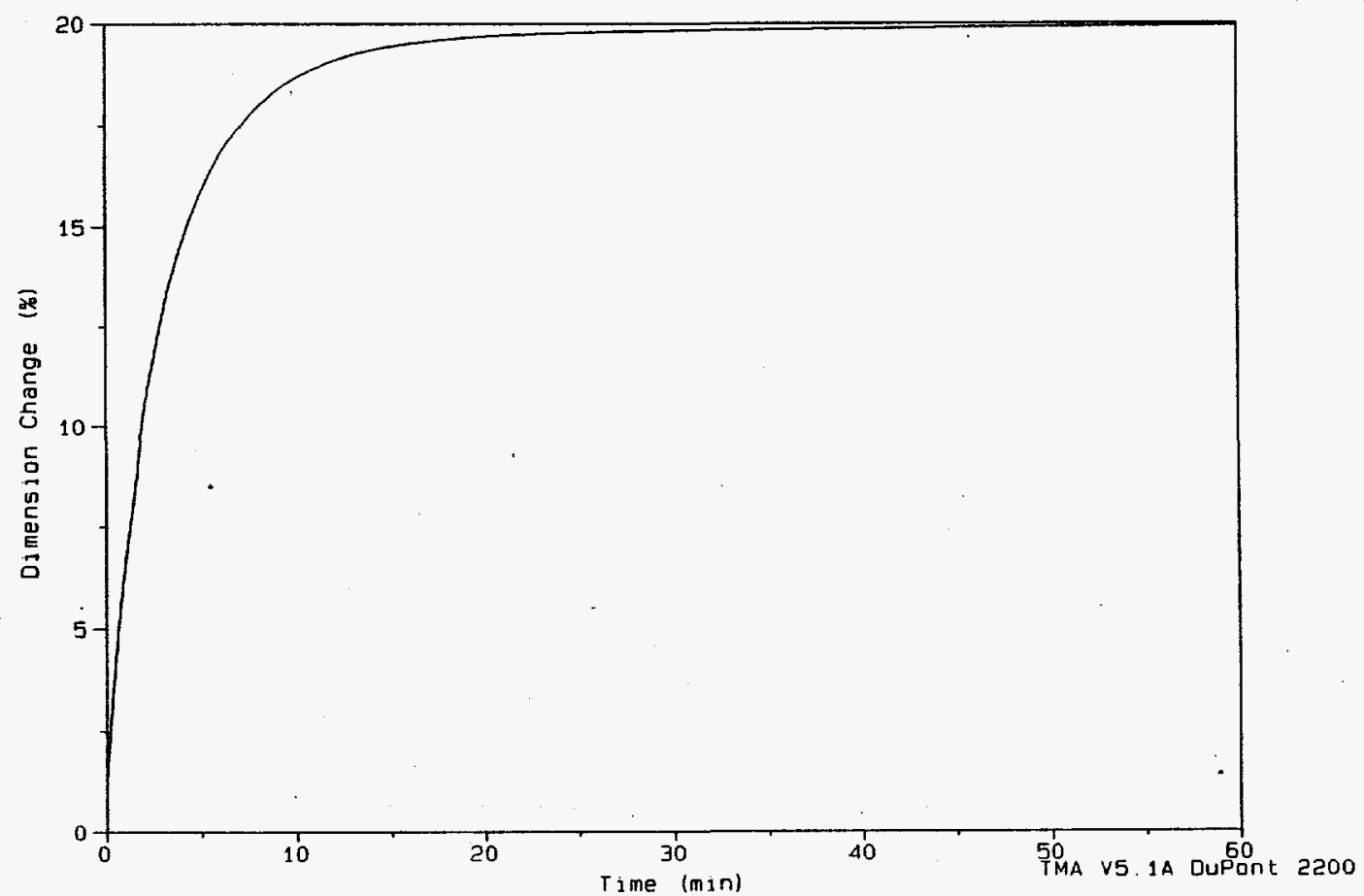

Figure F-8. Solvent Swell Test for Norland 60 in Acetone (120 sec. UV Cure) 
Sample: Norland Aahesive 60

Size: $\quad 0.9740 \mathrm{~mm}$

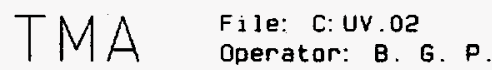

Method: solvent swell

Pun Date: 17-Jan-94 13: 44

Comment: solvent swell in IPA

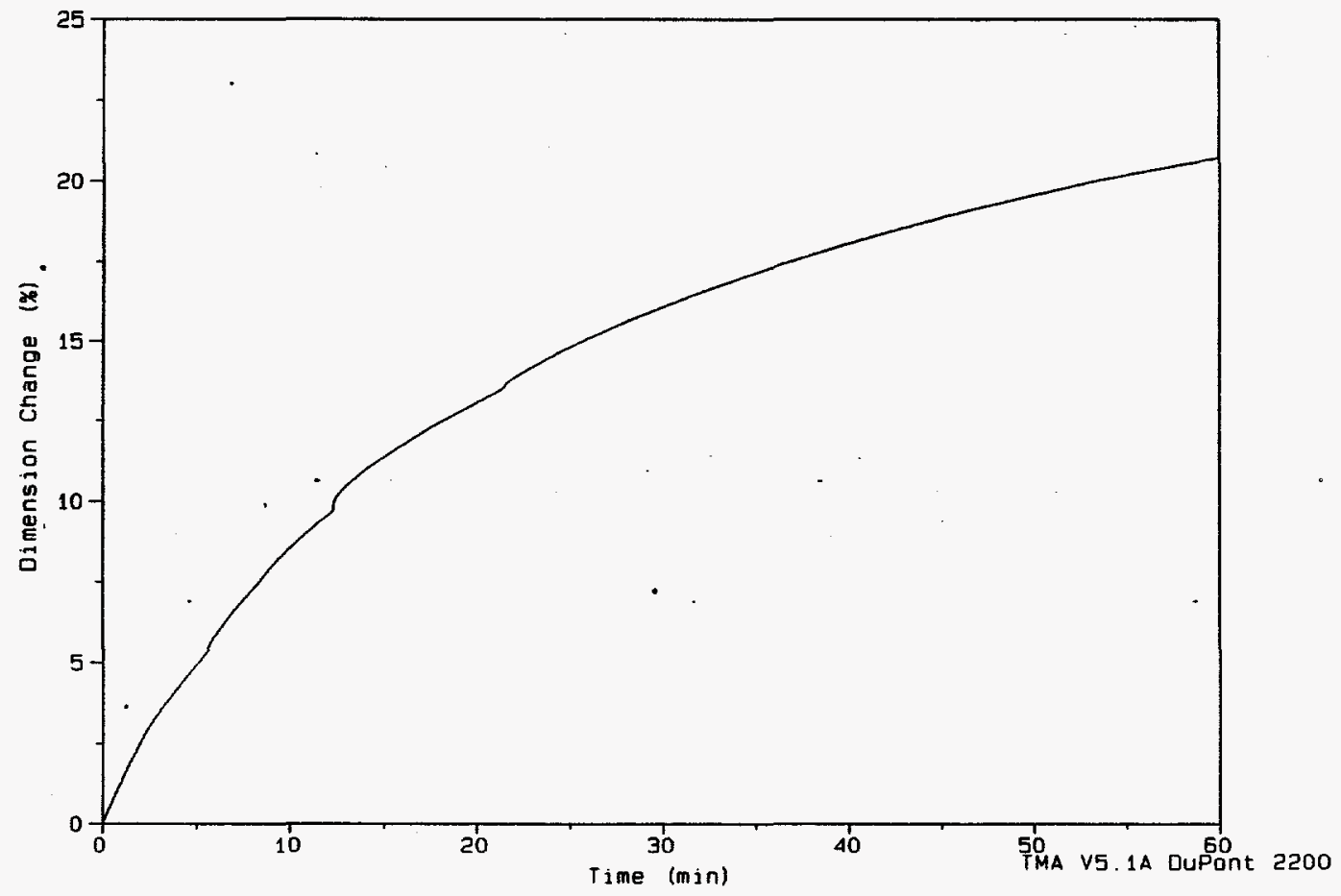

Figure F-9. Solvent Swell Test for Norland 60 in IPA (120 sec. UV Cure)
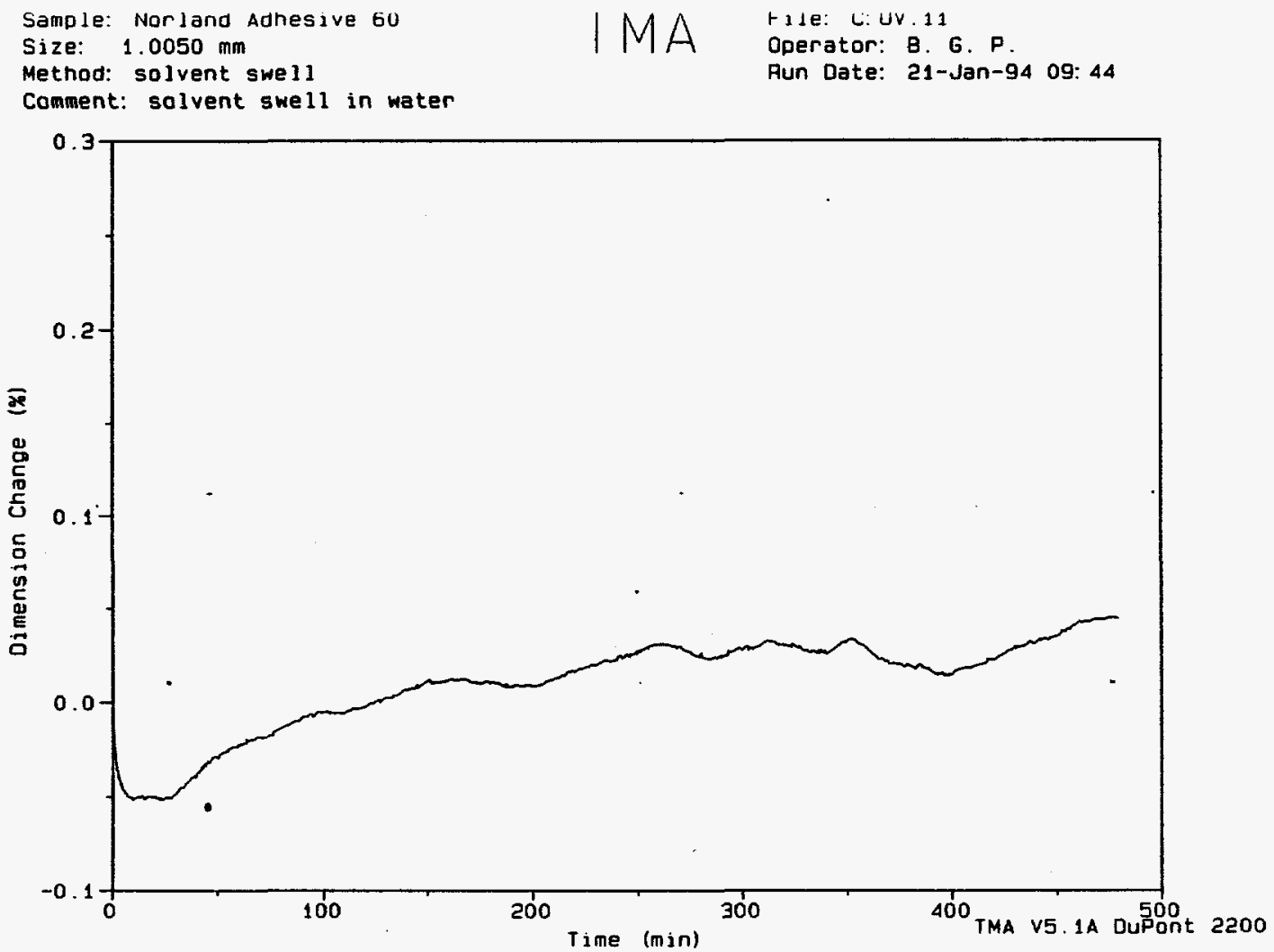

Figure F-10. Solvent Swell Test for Norland 60 in Water (120 sec. UV Cure) 